\title{
Cardiac reinforcement and assistance by electrically stimulated skeletal muscle
}

Citation for published version (APA):

Lorusso, R. (1998). Cardiac reinforcement and assistance by electrically stimulated skeletal muscle. [Doctoral Thesis, Maastricht University]. Datawyse / Universitaire Pers Maastricht. https://doi.org/10.26481/dis.19980703rl

Document status and date:

Published: 01/01/1998

DOI:

10.26481/dis.19980703rl

Document Version:

Publisher's PDF, also known as Version of record

\section{Please check the document version of this publication:}

- A submitted manuscript is the version of the article upon submission and before peer-review. There can be important differences between the submitted version and the official published version of record.

People interested in the research are advised to contact the author for the final version of the publication, or visit the DOI to the publisher's website.

- The final author version and the galley proof are versions of the publication after peer review.

- The final published version features the final layout of the paper including the volume, issue and page numbers.

Link to publication

\footnotetext{
General rights rights.

- You may freely distribute the URL identifying the publication in the public portal. please follow below link for the End User Agreement:

www.umlib.nl/taverne-license

Take down policy

If you believe that this document breaches copyright please contact us at:

repository@maastrichtuniversity.nl

providing details and we will investigate your claim.
}

Copyright and moral rights for the publications made accessible in the public portal are retained by the authors and/or other copyright owners and it is a condition of accessing publications that users recognise and abide by the legal requirements associated with these

- Users may download and print one copy of any publication from the public portal for the purpose of private study or research.

- You may not further distribute the material or use it for any profit-making activity or commercial gain

If the publication is distributed under the terms of Article $25 \mathrm{fa}$ of the Dutch Copyright Act, indicated by the "Taverne" license above, 
Cardiac Reinforcement and Assistance by Electrically Stimulated Skeletal Muscle 
(6) 1998 Roberto Lorusso, Brescia, Italy

ISBN 9052782377

Vormgeving en druk: Datawyse / Unversitaire Pers Maastricht 


\title{
Cardiac Reinforcement and Assistance by Electrically Stimulated Skeletal Muscle
}

\author{
PROEFSCHRIFT \\ ter verkrijging van de graad van doctor \\ aan de Universiteit Maastricht, \\ op gezag van de Rector Magnificus, \\ Prof. dr.A.C. Nieuwenhuizen Kruseman, \\ volgens het besluit van het College van Decanen \\ in het openbaar te verdedigen \\ op vrijdag 3 juli 1998 om 12.00 uur
}

door

Roberto Lorusso

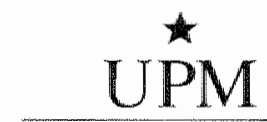

UNIWERSITAIRE PERS MAASTRICHII 


\section{Promotor}

Praf dr. H.I. Wellens

Coupromotar

Dr. ir. F.H. wan der veen

\section{Beoondelingsommisste}

Prof dr. M.J.A.P. Daemen (voorzitter)

Prof. dr. T. Mesana (Marseille, FR)

Prol. dr. RS. Reneman

Prof dr. S. Salmons (University of Liverpool, UK)

Prof. dr. M.A.J. Struijker Boudier

Financial support by the Foundation "Hartsurienden RESCAR" and the Dutch Heart Foundation for publication of this thes is gratelully acknowledged. Additional financial support of Medtronic Inc. Bakken Research Center Mastricht has been appreciated. 
L'osservazione della natura e delle cose è l'anima della scienza, la spinta per l'apprendimento è la consapevolezza della limitatezza della conoscenza umana

The observation of nature and of life events is the soul of science, the drive of the learning process is the awareness of the limitation of human knowledge

Lemardo da Whei

Wat je niet kent, herken je niet

What you do not know, you do not recognize

Hen J Wellens

To Chiara, Barbara and Francesca, drives for a continuous search to expand my knowledge and for the identification of some small "secrets" of science 


\section{Acknowledgements}

"Quelli che s"innamoran di pratica sanza scienzia son come "l nocchier ch'entra in navilio sanza timone o bussola, che mai ha certezza dove si vada"

"Who is fond of pure practise without science is like the skipper who enters the harbour without any steering compass or rudder, and has never certainty where he is going to"

\section{Leonardo da Vinci}

Since the beginning of mankind, scientific investigation of expressions of normal or abnormal behawior of nature, either human related or not, varied a great deal. It is well known that social and religious attitudes influenced the human approach to medical disorders and to the interpretations of disease manifestations along the past centuries. Nonetheless, during the Renaissance, a great impulse to anatomical analysis of normal and diseased bodies led to the preliminaries for a better understanding and major breakthroughs in medicine. Leonardo certainly represented one of the "motors" of this cultural revolution, and a genious for the multidisciplinary approach he used to address his extraordinary evaluation of natural phenomena, and the superb art to represent it. His personal way to approach the misteries of the nature, either environmental or human, showed us how meticolous and critical he was in the process of knowledge, and how the way to progress in science is hard and not always successful.

My "scientific journey" in the field of heart failure, and, more specifically, in the surgical options to treat it, has witnessed the same experiences many scientists had in the past. Along my studies in the experimental and clinical settings in the field of cardiomyoplasty many controversies characterized such a procedure, and, above all, much skepticism. As a matter of fact, neither the defenders nor the accusers were using objective means to debate and discuss it. I consider myself extremely fortunate to have met a person who repeated in practice what was already clear to Leonardo in 1492 when he used to tell his pupils. 
"Fuggi i precetri di quelli speculatori che le loro ragioni won sono confermate dalla isperienza"

"Escape the beliefs of those speculators whose reasons are not substantiated by the experience".

Prof. Wellens represented for me the same teaching. His objective, honest, critical, and scientific approach even to surgicall treatments has been a remarkable example how the scientific feeling and attitude did not change much from Leonardo's times, and should prompt every our initiative towards the search for a "less limited knowledge". I am extremely grateful and indebted to him for what he did, acting as a "scientific philanthrope", and teaching me to refrain from claiming to have the "real truth, but, instead, to critically and carefully revise every "certainty".

Furthermore, I would like to express my endless gratitude to Prof. Wellens since he helped me to appreciate how important and crucial is the tight cooperation between a cardiologist and a cardiac surgeon, since, besides every common place, lack of incomplete knowledge is the solely enemy to fight against. His scientific opened mind made all this work possible.

When I started my experience at the Maastricht Cardiovascular Research Centre, I had the feeling as if I was undertaking a journey in the search for the truth in the scientific and relatively unexplored world of heart failure and its forms of treatment. Along my journey in this field I had the privilege to meet my "angel" and guide, Frederik H. van der Veen, like Virgilio was for the Italian Poet Dante Alighieri in the fatiguing, but extraordinary journey through the Hell, Purgatory, and Heaven in the "Divine Commedy". He attempted, sometimes unsuccessfully, to guide my immature impetus towards experimental work, and to drive me towards the search for deeper and more objective knowledge on the topic. He was above all a great friend, to whom I most probably did not express enough my esteem, but I believe that this thesis may represent a tribute to his work, to his friendship, and to his motivation too. I could not proceed in my acknowledgments without spending a few words about the uncomparable

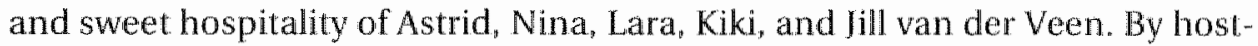
ing and keeping me busy during all my visits to Maastricht I did really miss less my family!!!!

Along my "phylosophical" travel "I had the great chance to meet many distinguished people who represented a real input to my perseverance, and continuous stimulus for my "cultural thirsty". It is no doubt that without the help of Theo van der Nagel and Jo Habets, my dream would have not seen the light. Caroline Lucas gave me many opportunities to understand more quickly the weak points of cardiomyoplasty procedure, to look for new aspects, and to 
achieve an objective point of view on the technique. Olaf Penn should be thanked for teaching me the technical fundamentals of the surgery and allowing me to develop and study new aspects.

Prof. Salmons and Prof. Carraro have been extremely helpful to my scientific growth, by especially showing me, once again, how little science a cardiac surgeon often has in his initial intentions, but how important his contribution may be if properly motivated and scientifically guided.

Jan Schreuder represented a remarkable input to my scientific curiosity, and I should thank him for his constant search for new scientific insights of our loved, but unfortunately so often sicked heart. I thank you Jan, and your undestroyable Volvo which took you, your expertise, and your technical equipment around Europe, allowing us to understand a little bit more on our work.

Special appreciation should be devoted to Francois Chaussande and Chester Struble who represented first of all friends, and then precious collaborators in the experimental and clinical settings. Hans Kaulbach and Gill Bolotin have to be congratulated for their help in my studies, which are going to be further developed by their brilliant minds and attitudes, and for their friendship, with a secret hope for a common future in our professional life. If someone originally got the idea to abate Country borders for an united Europe, I truly believe he thought of us!!

I had the great chance to meet many people in Maastricht, and everyone was extremely important to me for their friendship, kindness, and availability to help me in any difficulty, and, at last but not least, to make me feel at home even $1000 \mathrm{kms}$ away. It is with no doubts that Jos Maessen, Marion, Jos Widdershoven, Monique, Birgit, Marc Vos, Jet, Ruud and all the other people and Fellows I had the chance to meet in Maastricht deserve my thanks and my greatest appreciation.

A special thank has to be addressed to Prof. Alfieri, who could afford all my experimental and clinical efforts to make my idea come true. His unquestionable wisdom controlled my enthusiam and guided my struggles, which, Il can assure, were many, along the way.

I would like to reserve a special thank to Prof. Carpentier and Prof. Chachques, who showed me how human creativeness and genious have no limits, and how, more than often, progress must pay a tribute to skepticism whatever field of human life is involved in.

My family, however, deserves my deepest appreciation for the continuous support and patience for the time stolen. My parents who have been supporting and helping me from the "backstage", never claiming even a small thank, but just rewarded by my perseverance. Thank you Chiara, for the overwhelming burden you weared, and, I am sure, after your endless patience listening to my discussions and debates with collegues, you could defend this thesis with as much expertise as I have (or more ???!). 
Finally, I would like to express a few words about the patients we are taking care of. Patients and their health are our ultimate goal, an easy, but often for gotten concept. Therefore, if the following work could contribute, even partially, to alleviate their suffer, I think that this thesis would reach its main and, I would say, unique purpose. 


\section{Abbreviations and Acronyms}

CHF : Chronic Heart Failure

ACE : Angiotensin Converting Enzyme

$\mathrm{CABG}$ : Coronary Artery Bypass Grafting

CAD : Coronary Artery Disease

NYHA : New York Heart Association

LDM : Latissimus Dorsi Muscle

FDA : Food and Drug Administration

LV : Left Ventricle

RV : Right Ventricle

PVR : Pulmonary Vascular Resistance

SVR : Systemic Vascular Resistance

PAP : Pulmonary Arterial Pressure

$\mathrm{CO}:$ : Cardiac Output

EF : Ejection Fraction

CI : Cardiac Index

SV : Stroke Volume

SW : Stroke Work

EDP : Left Ventricular End-Diastolic Pressure

EDD : Left Ventricular End-Diastolic Diameter

ESD : End-systolic diameter

EDV : End-diastolic Volume

ESV : End-systolic Volume

ICU : Intensive Care Unit

PER : Peak Ejection Rate

IABP : Intra-aortic Balloon Pump

AICD : Automatic Implantable Cardioverter Defibrillator

MRI : Magnetic Resonance Imaging

CT : Computed Tomography

ECC : Extra-corporeal circulation 


\title{
Table of Contents
}

\author{
CHAPTER 1
}

Introduction

1. Cardiomyoplasty: Historical Overview

1.1 Chronic heart failure: limitations of standard treatment and the need for alternative options

1.2 Use of skeletal muscle to treat cardiac or vessel diseases

1.3 Electrostimulation of skeletal muscle: the concept of "muscle plasticity"

1.4 The experimental basis of Cardiomyoplasty: development of a permanent, biomechanical cardiac support 19

2. Application and Evaluation of the Cardiomyoplasty Procedure 20

2.1 Patient selection 20

2.2 Surgical techniques and peri-operative care 23

2.3 Management of muscle conditioning and cardiac/wrapped $\begin{array}{ll}\text { muscle interaction } & 28\end{array}$

2.4 Clinical experiences, hemodynamic results, and postoperative complications $\quad 30$

2.5 Skeletal muscle structural changes following cardiomyoplasty 37

2.6 Mechanisms of action 40

3. Current limitations of cardiomyoplasty and aim of the thesis 43

\section{CHAPTER 2}

"Observations during early muscle stimulation following dynamic cardiomyoplasty"

\section{CHAPTER 3}

"Hemodynamic effects in acute cardiomyoplasty of different wrapped muscle activation times as measured by pressure/volume relations"

\section{CHAPTER 4}

"Preoperative physical training effects on latissimus dorsi muscle in patients undergoing dynamic cardiomyoplasty: a preliminary report" 
CHAPTER 5

"Cardiomyoplasty as isolated procedure to treat refractory heart failure"

CHAPTER 6

Progress in cardiomyoplasty techniques and management of clinical problems

6.1. "Right latissimus dorsi cardiomyoplasty in diaphragm eventration and cardiac malposition"

6.2 "Pericardial "suspenders" to enhance right latissimus dorsi cardiomyoplasty"

6.3 "Bacterial infection of cardiomyostimulator abdominal pocket following cardiomyoplasty procedure: an original approach to preserve synchronous muscle stimulation"

6.4 "Management of pacing system-related complications in patients submitted to dynamic cardiomyoplasty"

6.5 "Preserved muscle structure with modified stimulation protocol following cardiomyoplasty procedure"

6.6. "Cardiomyoplasty and implantable cardioverter defibrillator: efficacy and safety of concomitant device implantation"

\section{CHAPTER 7}

Conclusions

Summary

Samenvatting

Riassunto

Publications

Curriculum Vitae 
Chapter

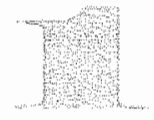

\section{Introduction}

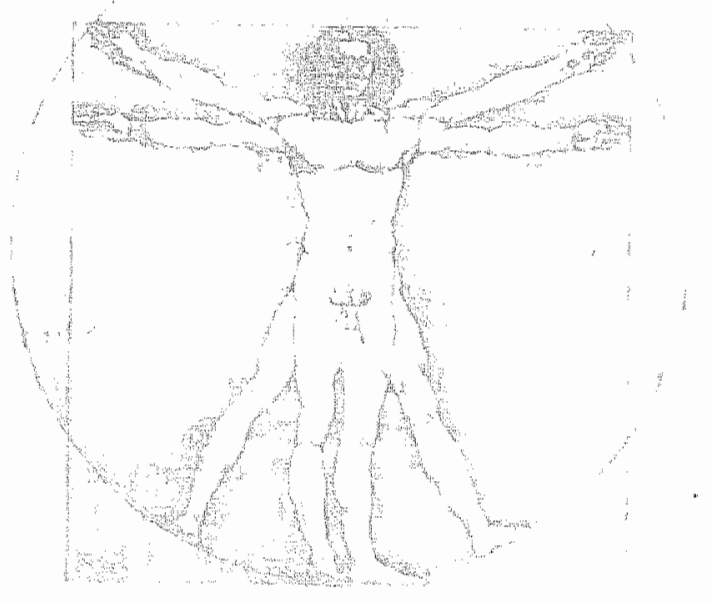




\section{Cardiomyoplasty: Historical Overview}

\subsection{Chronic Heart Failure: limitations of the current treatment and need for alternatue options}

The prevalence of CHF is constantly increasing $(1,2)$. It affects more patients, and has resulted in an increasing number of hospital admissions in recent years (3). These developments will not only lead to growing activities in the diagnosis and therapy of CHF, but will also absorb a substantial portion of our financial resources (4). Therefore, treatment of CHF represents a major problem and challenge in health care worldwide.

In recent years there has been substantial advances in the treatment of $\mathrm{CHF}$ (5), with significant improvement in short and long-term patient survival (6-9). More recently, re-hospitalization rate and quality of life are new targets besides traditional endpoints like mortality (10). The introduction of ACE-inhibitors in CHF treatment has been a major breakthrough in patient management $(7,8)$, and recent trials with $\beta$-blockers appear to provide additional benefits $(11,12)$. Nevertheless, when CHF is present the prognosis remains poor (13-16). The introduction of cardiac transplantation in the late sixties was an important step in the treatment of severe CHF. Cyclosporine triple-drug therapy and better patient selection have steadily improved the results of heart transplantation (17), making this intervention the gold standard treatment for end-stage depressed cardiac function. Unfortunately, organ shortage progressively limits the access to such therapy, leading to more restrictive criteria for its application, inevitably resulting in a larger waiting list, and search for potential alternatives (18-22). Recent predictions on organ availability foresee the implementation of transplantation only in urgent candidates in the near future (23). Additionally, the mortality on the waiting list is substantial $(24.25)$. The outcome of patients presented for cardiac transplant, but considered to have contraindications, is poorly known. Only a few reports are available, describing a 1 -year survival ranging from $13 \%$ to $25 \%$ in this subgroup of patients $(26,27)$. Therefore, be sides renewed interest in traditional procedures, namely, CABG and valve repair (28-31), or the introduction of the innovative technique of partial left ventriculectomy introduced by Batista (32), the search continues for potential surgical options for the treatment of CHF patients, with particular interest in mechanical cardiocirculatory support systems. Temporary support devices have become more suitable for permanent implantation, prompting the investigators to currently use some mechanical systems not only as a bridge for car. diac transplant, but as a final therapy $(33-35)$. Costs, complications (infection, thromboembolism, psychological problems), and still not optimal technology. are hampering wider application of such tools in the therapeutic scenario of CHF. 
It is unquestionable and unfortunate that the patient with medically refractory CHF not suitable for heart transplantation experiences a high morbidity and mortality with the physician having no therapeutic modalities to ameliorate at least his quality of life. Not surprisingly therefore, attempts have been made to apply autologous forms of permanent cardiocirculatory support. This is an attractive concept because of the availability of the assist system, the lack of need for postoperative immunosuppression, and the lack of blood contact with foreign material. In the following pages the experimental and clinical findings on the use of the patient's own skeletal muscle for cardiocirculatory support will be reviewed, specifically addressing the cardiomyoplasty technique. Indications, results, limitations, and the interpretation of mechanisms of action will be discussed.

\subsection{Use of Skeletal Muscles to treat cardiac or vessel disease}

Intrathoracic muscle transposition was first described in 1911 by Abrashanoff to close a bronchopleural fistula (36). Subsequently, De Jesus and Leriche described the first applications of skeletal muscle to treat cardiac injury or aneu* rysm $(37,38)$. Beck and O'Slaughnessy introduced the concept of transposing muscle onto the heart to treat refractory angina hoping to create collateral circulation between the muscle vessels and the epicardial coronary arteries $(39,40)$. Petrovsky showed reinforcement of cardiac aneurysm repair by mobilized diaphragmatic muscle in a series of 100 clinical cases $(41,42)$. Appiani, Christ, and Sola, independently showed by using the pectoralis major, the LDM, and the sternohyoid and sternocleidomastoid muscles, respectively, the formation of new vessels at the muscular/cardiac interface (43-45). In addition, Sola showed the transplanted muscle fibres remained viable up to 435 days (45). Pairolero presented a series of 31 patients treated with intrathoracic transposition of extrathoracic skeletal muscle to treat refractory infection (46). Four patients had muscle flap transposal because of infected aneurysm of the heart or great vessels to reinforce suture lines. The use of vascularized muscle mobilization to repair aortic wall defects was described by Horneffer (47), and a pseudointima formation at the muscle flap site starting 24 hours postoperatively could be detected, with no aneurysm formation at the site of the muscle flap at 12 weeks. Papp reported the use of mobilized intercostal muscles to reconstruct induced cardiac defects again confirming no late aneurysmatic complication at the site of repair (48). Transposal of pectoralis and rectus abdominis muscles for potential correction of heart defects was also described $(49,50)$. These laboratory studies were mainly addressing the possibility of using skele. tal muscle flaps to correct congenital defects. The idea of using free musculat autografts to treat cardiac diseases was introduced by Weinstein (51). The possibility of preserving denervated and transposed skeletal muscles was shown by 
Shepard and Mustard in 1968 (52). They documented maintained muscle structure and contractile properties in denervated pedicled grafts used to enlarge the RV, following electrical stimulation. Thompson in 1978 showed the feasibility of transposing free grafts of pronator teres muscles from the leg onto the myocardium, followed by partial phrenic nerve implantation in the muscle (53). At 6 months from transplantation muscle preservation could be demonstrated, with only slight atrophy. This fascinating concept has been reproposed recently $(54,55)$. Experimental studies are required, however, to document the feasibility of such a procedure.

\subsection{Electrostimulation of skeletal muscle: the concept of "muscle plasticity"}

Muscle fatigue always represented an insurmountable problem in designing any form of continuous skeletal muscle cardiocirculatory support in laboratory investigations. In 1966 Buller and Eccles described the structural adaptation of peripheral skeletal muscle after cross-innervation (56). Indeed, fast-twitch fatigue-prone muscles became slower and fatigue resistant, whereas slowcontracting, fatigue resistant muscles converted to fast-twitch fatigue-prone fibres after switching the respective innervation. Subsequently, the outstanding research of Salmons and collegues on the activity patterns involved in neural stimulation of different type of muscles, led to the assumption that electrical stimulation might generate the same adaptive changes observed after crossinnervation. He showed that the skeletal muscle was capable of functional and structural changes by applying continuous electrical stimulation $(57,58)$. Modification in muscle biochemistry (increase of aerobic metabolism), structure (increase of number of mytochondria, increase in capillary density), and fibre type (from mixed type 2 and type 1 fibre population, to full conversion in type 1 fibres) represented the fundamentals of the discovery of the "plasticity properties" of skeletal muscle. Thereafter, many studies have addressed this topic (59-61), confirming the marked muscular changes induced by the new functional demand, which ultimately lead to a fatigue-resistant oxidative motor unit, suitable to deliver sustained power and potentially applicable to the cardiocirculatory system. Another major advance was the demonstration of a myocardial-like contraction pattern, namely a prolonged tetanic contraction by specific pacing techniques, which is in contrast to the fast contraction (twitch) normally occurring when stimulating the skeletal fibres. Dewar and associates were the first to show the possibility of using a pulse-train delivering device, ensuring the temporal summation of single twitch-induced contractions, thereby obtaining a durable and cardiac-like contraction (62). Therefore, the single witch induced by a single impulse was substituted by a pulse-train burst with a square-wave form leading to a more effective and sustained skeletal muscle contraction. 
The muscle transformation process and the achievement of forceful contraction attracted new interest in the feasibility of biomechanical cardiac assistance. Chachques showed the use of a progressive stimulation protocol in a chronic goat model to induce fibre conversion in a properly mobilized and wrapped LDM, able to chronically sustain the cardiocirculatory system (63). This study confirmed the capability of progressive electrical stimulation to induce muscular transformation, and the beneficial action of the wrapped LDM contraction in terms of hemodynamic response. However, Salmons and Jarvis subsequently demonstrated loss of muscle mass, an eight-fold reduction in power output, and a five-fold decrease in the shortening velocity during chronic electrostimulation (64). It appeared that the necessity of constructing a permanent and electrically activated biological support was obtained at a great price: a fatigue-resistant muscle assist device with a less efficient skeletal muscle engine. The target of mixed muscle fibres, that is, maintaining a higher percentage of type II fast-twitch anaerobic fibres to preserve most of the original native muscle power, is, at present, a topic of investigation, and recent findings of the effects of modified electrical stimulation protocols, which will be discussed later, appear to confirm these hypotheses in terms of percentage of muscle fibres and related power.

\subsection{The experimental basis of Cardiomyoplasty: development of a permanent biomechanical cardiac support}

After the attempts to enhance myocardial revascularization by transposed skeletal muscles $(39,40)$, another target in the use of muscles flaps was to reinforce, substitute or enlarge hypoplastic portions of the native heart using autologous, contractile, and potentially growing tissue. Kantrowitz is credited for the first attempt to perform cardiocirculatory support by using electrostimulated skeletal muscle $(65,66)$. He wrapped the mobilized diaphragm around the ventricles and paced the phrenic nerve during cardiac systole. Notably, he could elicit muscle contraction, but not generate hemodynamic improvement. Nakamura and Glenn in 1964 applied the same concept to replace part of the myocardium in an attempt to treat hypoplastic hearts by providing systolic support through paced diaphragmatic muscle (67). This study showed some positive effects on atrial and aortic pressures in animals followed for up to 9 months, and the importance of nerve preservation as a critical factor for effective muscle contraction was underlined. The use of the diaphragm muscle was described also by Phillips to replace part of the myocardium, but, like Kantrowitz, he was unable to show hemodynamic improvements during muscular electrostimulation (68). Interestingly, he evidenced the importance of skeletal muscle graft orientation as a critical factor to obtain optimal muscle contraction, as was subsequently outlined by Dewar, Drinkwater, and Kao $(62,69,70)$. 
In 1973, Kusaba reproposed the attempt to improve cardiac performance by electrically stimulating a mobilized diaphragm muscle, and calculated that the paced muscle was able to generate $57 \%$ of the LV force (71). Furthermore, in that study muscle viability could be documented up to 4 months of stimulation. Macoviak, Mannion, and Acker, all working at Dr. Larry Stephenson's laboratory, further investigated the effects of continuous electrostimulation on skeletal muscles, and showed the potential of transposed skeletal muscle to provide mechanical energy for neoventricles connected to the circulation in a counterpulsation mode (72-75). In 1984 Dewar and collaborators at the McGill University in Montreal developed the aforementioned prototype hybrid stimulator capable of delivering several electrical impulses in a short time span, leading to the activation of the paced skeletal muscle in a tetanic-like contraction pattern which could simulate myocardial contraction (62). Dewar subsequently reported the feasibility of full-thickness excision of the $L V$ to be replaced by vascularized LDM flap. He underlined the necessity to reproduce appropriate neoendothelium, by the implementation of a pericardial patch, to avoid any thrombo-embolic complication (76).

The use of the LDM was introduced in 1966 by Termet (77) who mobilized the muscle flap onto the heart. The muscle grafts were sutured to the myocardium, and, after 8 months, five out of seven transposed flaps were still viable, and he could demonstrate efficient muscular hemodynamic effects during induced ventricular fibrillation and concomitant muscle stimulation. Because of the ease of mobilization, the muscle surface, and the neurovascular pedicle characteristics, he hypothetized LDM as the ideal muscle for cardiocirculatory support. The elegibility of LDM as an ideal muscle for cardiac assist was subsequently outlined by other investigators (78-81). Indeed, the vicinity to the heart, the wicle muscle surface, the presence of a main neurovascular pedicle, and the relative absence of functional defects after its mobilization, made the LDM the muscle of choice for cardiomyoplasty.

These experimental studies and anatomical investigations, together with the urgent need for alternative options to cardiac transplantation, ultimately led to the first application of skeletal muscle for cardiocirculatory support in a human case in 1985 in Paris (82).

\section{Application and Evaluation of the Cardiomyoplasty Procedure}

\subsection{Patient Selection}

Appropriate patient selection represents a key factor for any kind of surgery to be successful. Accordingly, cardiomyoplasty faced the initial uncertainty concerning appropriate indications, and the substantial refinements of inclusion 
criteria during its evolution had marked influence on postoperative results. Because of the urgent need for alternative methods of treating patients in the terminal state of CHF, cardiomyoplasty was viewed when it appeared clinically as a potential surgical option for these patients. Therefore, skeletal muscle flaps were applied to a wide variety of cardiac diseases in the initial clinical experience with a severely depressed $L V$ pump function as the only common feature. Many patients underwent surgery in the terminal stage of CHF. For example, $46 \%$ of the cases from FDA Phase I Study were in Class IV of the New York Heart Association Classification (83-87). The first analysis of preoperative data and postoperative results was provided by Grandjean in 1991 (88). He documented that the profile of the cardiomyoplasty candidate differed considerably. In the FDA Phase I Study, $29 \%$ of the patients received additional cardiac surgery. More importantly, he showed the poor postoperative outcome of patients in NYHA IV versus patients in NYHA III preoperatively. Indeed, patients in functional class IV exhibited higher early and late death ( $33 \%$ and $30 \%$, respectively) compared with patients in NYHA class III (12\% and $7 \%$, respectively). This analysis was subsequently confirmed by reviews of individual and cumulative clinical experiences from different centres $(83,89)$. It is now widely accepted that patients undergoing cardiomyoplasty surgery should have a reasonable cardiac reserve in order to overcome the initial further decrease of function due to the static LDM. Additionally, terminal CHF patients are often characterized by multiorgan dysfunction which jeopardizes the perioperative period, and, therefore, a stable clinical and multiorgan condition is required.

Furnary underlined the importance of preserved RV function and absence of pulmonary hypertension for a good prognosis (90). Indeed among 15 patients operated at the Allegheny Hospital in Pittsburgh, patients who presented with a RVEF less than 40\% had a high operative mortality, and no long-term survivors. Pulmonary hypertension (mean PAP higher than $30 \mathrm{mmHg}$, or PVR more than 3 Woods units) also negatively influenced the cardiomyoplasty outcome, with 3 of 5 patients with pulmonary hypertension surviving the operation, but with no late survivors. However, 11 pts in this study were in NYHA class IV preoperatively, and RV dysfunction with pulmonary hypertension might have represented clues of the terminal stage of congestive heart failure. The importance of RV function and contractile reserve, as assessed by pharmacological test (dobutamine infusion), as crucial predictor of patient outcome in case of severe heart failure has been confirmed recently (91).

Carpentier and collaborators extensively discussed the main inclusion criteria, and claimed that atrial fibrillation, biventricular failure, poor LVEF $(<15 \%)$, and extreme cardiac dilatation (cardiothoracic ratio $>0.60$ ) should be considered as contra-indications for cardiomyoplasty or resulling in unfavorable postoperative outcome (83). Cabrera-Fischer recently showed that cardiomyoplasty exerts beneficial effects even during atrial fibrillation (92). Indeed, by us- 
ing the cardiomyostimulator of the new generation which allows the burst duration to be a defined percentage of the $R-R$ interval, the author showed a significant increase of $L V$ systolic pressure, $C O$, and mean aortic pressure, and a concomitant decrease of SVR, LVEDP, and right atrial pressure. They analysed stimulated beats in an acute goat model of atrial fibrillation and heart failure by acetylcholine and propanolol administration, and observed effective skeletal muscle cardiac support even in atrial fibrillation. Nevertheless, Furnary considered atrial fibrillation a risk factor reviewing his previous findings in combination with the clinical experience from the Broussais Hospital and from Sao Paulo (93). Cox regression model, taking into account demographic, cardiac, and surgical variables in 127 patients, showed that atrial fibrillation, elevated pulmonary capillary wedge pressure, reduced metabolic exercise response (VO2 $<1000 \mathrm{ml} / \mathrm{min}$ ), and perioperative requirement for $\mathbb{L A B P}$, were independent predictors of a poor long-term survival. Further mathematical analysis ensured the appraisal of strictly procedural versus long-term risk factors. Indeed, atrial fibrillation and high pulmonary pressure were predictors of reduced late cardiomyoplasty effectiveness, whereas the use of intraoperative LABP and low peak excercise test represented negative predictors in terms of procedural mortality. The analysis of preoperative patient variables in terms of postoperative predictors has been performed after the Phase II FDA Dynamic Cardiomyoplasty Study (94). Multiple logistic regression analyses on preoperative data showed that only peak VO2 $(<10 \mathrm{ml} / \mathrm{kg} / \mathrm{min})$ and LVEDP ( $>35 \mathrm{mmHg}$ ) were predictors of reduced hospital survival (from $8.5 \%$ to $15 \%$ ), suggesting heart transplantation a more suitable therapy for this subset of patients.

Jegaden showed in a series of 12 patients that no hemodynamic improvement after cardiomyoplasty was observed in patients with higher LVEDD (95). Chiu reported reduced benefit following cardiomyoplasty in patients when incomplete wrapping was performed (96). Bocchi and collaborators showed no correlation between the degree of wrapping and the 1-year clinical outcome and changes in LVEF after cardiomyoplasty in 21 patients (97). The hypothesis that suboptimal ventricular covering may lead to reduced cardiac support in patients with greater $L V$ dimensions has been postulated (83). Nevertheless, the LV is wrapped in all instances, and therefore, according to the Laplace's law, reduction of myocardial wall stress can still be expected (96).

The potential impact of the etiology of the cardiomyopathy in terms of pelioperative outcome was recently outlined by Mesana (98). In his series of 14 patients, those having ischemic cardiomyopathy developed perioperative heart failure, suggesting that a low coronary reserve may predispose to additional LV dysfunction. Furthermore, he described adjunctive parameters which may be considered risk factors for early and late outcome. The importance of the type of underlying myocardial disease as a negative factor has been underscored by Moreira in the South American cardiomyoplasty experience (92) by comparing 
postoperative survival in patients affected by idiopathic cardiomyopathy ( $86 \%$ and $50 \%$ at 1 and 5 years, respectively) versus patients with Chagas' disease ( $50 \%$ and $9 \%$, respectively). The negative impact of active myocarditis on patient outcome has been shown by other authors $(89,99)$, and it should therefore be considered a contraindication to cardiomyoplasty.

Additional factors, like preserved lung function (vital capacity and forced expiratory volume $>$ than $60 \%$ ), absence of hemodynamically important valve disease, and absence of cachexia, are essential inclusion criteria. The presence of malignant ventricular arrhythmia has always been an exclusion factor, recently, however, the combination of an AICD and a cardiomyoplasty procedure has been suggested.

Interestingly, besides the early clinical series (39) and the experimental evidence $(43-45,100)$ of myocardial revacularization from onlay muscular flaps, cardiomyoplasty has been recently described by Akhmedov as an alternative and effective way of treating ischemic cardiomyopathy. Myocardial revascularization through angiogenesis at the intermuscular interface was proposed in an attempt to relieve anginal symptoms and LV dysfunction.

Patients at a high risk of deterioration or death in a relative short time should be considered for cardiomyoplasty (101). In particular, patients with contraindications for heart transplantation may represent an additional subset of patients suitable for LDM permanent support. Current knowledge and results allow the surgical intervention mainly in patients refractory to optimal medical therapy. Recent findings (102-104) concerning the effects of wrapped LDM on ventricular dimensions might lead to the proposal to apply the technique in selected patients, in an early phase of CHF to prevent irreversible cardiac dilatation, in an attempt to improve myocardial function by having the heart function under more favorable mechanical and energetic conditions.

\subsection{Surgical Techniques and Peri-operative Care}

The surgical technique underwent little changes diring the past years, but some of them represented significant improvements.

Chachques and Carpentier were the first to introduce LDM wrapping in clinical practice, when a cardiomyoplasty was performed in a 48 year-old woman affected by heart failure secondary to biventricular invasion of a malignant tumor (82). The patient received a "substitution technique" which consisted of the resection of the invading tumor and replacement of the resected myocardium by the transposed LDM.

The surgical technique differs according to the basic pathology treated, which muscle is going to be wrapped, and the direction of skeletal muscle fibres in relation to the interventricular septum. Cardiomyoplasty can be performed to reinforce or to substitute the myocardium (105). A combination of the two 
techniques is also possible. The reinforcement technique, that is, the application of a transposed muscle graft onto the ventricle or the atrium, aims to increase muscle mass, and to enhance systolic ejection because of an electrically activated and synchronized skeletal muscle contraction. The substitution technique refers to the resection of portions of damaged myocardium (tumor, aneurysm) and the replacement of contractile tissue with transplanted pedicled muscle flap. In that case, the skeletal muscle may serve to replace the resected part, or may cover completely the two ventricles and substitute the resected myocardium. As shown by experimental studies $(45,76)$ the presence of the native endocardium is crucial to avoid thrombotic material at the bloodcontacting surface. Currently, the reinforcement technique is the most common procedure (106).

The surgical technique implies harvesting of the right or left LDM. The use of different muscles has been proposed (107), but apparently no real alternatives to LDMs are at this time suitable for an effective wrapping procedure.

The use of intramuscular electrodes weaven at the level of the branching point of the main thoracodorsal nerve has been the procedure of choice during cardiomyoplasty surgery (106). Nonetheless, implantation of nerve electrodes has been used by several investigators in experimental studies (1.08-1.11). So far no studies have been performed comparing intramuscular and neural pacing. It is conceivable that nerve stimulation may represent an appealing alternative to intramuscular pacing, but further investigations are required to show benefit.

Nomenclature of different wrapping configurations has recently been proposed and adopted worldwide (112). The posterior cardio-costal left cardiomyoplasty represents the most common technique in clinical practice (113). The original technique consisted of suturing the posterior border of the pedicled LDM along the posterior atrial-ventricular groove by several interrupted stitches (105). Such a procedure required long-lasting and troublesome lifting of the heart, with hemodymamic deterioration and the frequent appearance of ventricular arrhythmias, resulting in the use of ECC. Subsequently, Carpentier introduced the so called "no myocardial touch technique" which consisted of lixing only two points of the posterior LDM margin just at the lateral sides of the atrio/ventricular groove (113). By passing two stitches at the level of the left atrial appandage and at the level of the inferior caval vein, on one hand, and in the LDM at the same distance on the other hand, the LDM can be placed behind the heart with minimal lifting, while pulling at the same time the two sutures, thereby fixing the LDM at the pericardium without any suture on the myocardium.

Muscle tension has been shown to be a critical factor to obtain optimal muscle power (114-116). Using the original muscle stretch would be a logic approach. However, induction of the same muscle tension after the wrapping 
procedure is virtually impossible because of the generated cardiac constriction. Furthermore, muscle fibre adaptation to the new preload seems to occur slowly (117), allowing the wrapping tension to be looser, which has another advantage related to the avoidance of ipsilateral lung compression.

Kao, as outlined by other investigators $(62,68,69)$, demonstrated that fibre orientation of the onlay grafit as opposed to myocardial fibre direction plays a critical role to achieve optimal hemodynamic response (70). By comparing the configuration of the skeletal muscle flap lying parallel to the interventricular septum (clockwise posterior wrap) with the LDM laying perpendicular to the septum (counterclockwise anterior wrap), Kao showed the superiority of the second configuration in terms of hemodynamic effects during assisted beats. No other study addressed this controversial aspect, and further analyses are necessary. Partial modification of the current technique has recently been proposed by El Oakley, who suggested to avoid complete wrapping of the heart in order to abolish the lateral displacement secondary to muscle contraction (118). He proposed to enhance cardiac squeezing by passing the muscle graft behind the heart, and suturing the distal border to the contralateral side of the sternum, with expected compression of the heart against the sternal bone at each muscle contraction, but no evidence has been provided to confirm the validity of such a procedure.

Magovern proposed the use of the right LDM for cardiomyoplasty, hypothesising that the contraction vector obtained with this configuration (contraction from the apex to the base of the heart) is more effective since it resembles cardiac systolic movement (119). Despite preliminary promising results $(120,121)$, the long-term postoperative data appeared to mirror the findings observed with the left cardiomyoplasty, with modest hemodynamic changes at late follow-up (122,123). Furthermore, the surgical technique for right cardiomyoplasty is more demanding, with the common use of ECC (123) due to the occurrence of hypotension during the required cardiac lifting to anchor the anterior muscle edge posteriorly to the pericardium. Thereby, no objective data are currently available to assess the real efficacy of this muscle orientation as compared to the stanclard left cardiomyoplasty. Experimental reports have shown beneficial effects of the right cardiomyoplasty using MRI (124). By using threedimensional reconstruction, this study showed that during the right LDM contraction there is a marked compression of the heart from the apex to the base, and a substantial clockwise rotation around the long axis, which is more pronounced along the anterior portion of the LV wall. On the contrary, almost no effects were observed as far as the short-axis compression was concerned, documenting no actual "squeezing" action during supported beats. Nevertheless, it is still confusing how the currently used animal model might provide meaningful information on different surgical configurations since the animal 
heart lies almost on the midline of the mediastinum, making right or left cardiomyoplasty practically indistinguishable.

Isolated RV cardiomyoplasty has been proposed in the animal laboratory (125-127), and has clinically been performed in one case of primary RV failure (83), but meaningful clinical data and investigations on long-term results are lacking. The use of skeletal muscle contractile contribution has been investigated even to augment the atrial kick in case of Fontan-like procedures. Chachques, Binet, and Lange (128-130) independently described the feasibility of enhancing the systemic venous drainage into the pulmonary artery by wrapping the muscle over the right atrium and symchronizing the LDM activation to the early diastole in animal models. Clinically, only 1 case has been performed (83), and, therefore, further studies are required to confirm these preliminary data.

The concept to use concomitantly the two LDMs was originally proposed by Chachques and coworkers (131). Bilateral cardiomyoplasty has been experimentally investigated in an attempt to augment skeletal muscle contribution to ventricular systole. Stephenson's group first addressed this topic and showed beneficial effect of double LDM wrapping (132). Magovern and Furnary investigated different aspects of bilateral cardiomyoplasty $(133,134)$. Notably, by assessing the different contributions of left, right or combined LDM cardiomyoplasty, they demonstrated that right cardiomyoplasty was more effective than the left in the animal model, whereas bilateral cardiomyoplasty represented the most effective configuration (134). Other studies have been performed on the concomitant use of the right and left LDMs in cardiomyoplasty $(135,136)$, and better hemodynamic effects appear to result from this configuration, which, however, are unlikely to be transferred into clinical practice because of the highly demanding surgery in such hemodymamically unstable patients.

\section{Peri-operarive Care}

Limited information is available regarding perioperative management in patients submitted to cardiomyoplasty surgery.

Cardiomyoplasty patients usually present with depressed cardiac function and high SVR and PVR. Carpentier and Mesana proposed extensive use LABP in order to better support the failing heart during surgery and in the early postoperative period, especially for unstable patients $(83,98)$. Use of dobutamine and sodium nitroprusside is recommended to improve peripheral perfusion and to counteract the high release of endogenous catecholamines. Patient ventilation through a dual-lumen endotracheal tube has been suggested to facilitate the surgical procedure (137), but is not mandatory. After muscle dissection and transposition into the ipsilateral thoracic cavity, it is common to observe a de- 
crease in $\mathrm{PaO}_{2}$ (138) and an increase in mechanical ventilatory resistance. Slight end-expiratory positive pressure ventilation should be implemented to overcome the left lung compression due to the LDM passage in the ipsilateral pleura. Indeed, the LDM may represent approximately $5 \%$ to $10 \%$ of the hemithorax volume, with a subsequent mean reduction of vital capacity of $18 \%$ (137). If blood gasses and lung resistance become unacceptable, manual ventilation is adviced to overcome lung compression and the expected mediastinal displacement by the transposed LDM. During the second surgical step (cardiac wrapping), and the first postoperative hours the most frequent problems are caused by arrhythmias and a low cardiac output (139). Lidocaine infusion for the first postoperative hours, followed by continuous amiodarone infusion to prevent high-risk ventricular arrhythmias, is advised. Another important aspect of the cardiomyoplasty procedure is the danger to induce further impairment of the already malfunctioning heart. Corin and associates demonstrated in a normal animal heart that because of a significant increase of both the time constant of isovolumic pressure decay, and the maximal rate of pressure decay, diastolic function was negatively affected by cardiomyoplasty in the acute car diomyoplasty procedure (140). Bolotin and coworkers showed a significant decrease of $\mathrm{CO}$ and LVEDV soon after the cardiomyoplasty procedure in a chronically dilated heart ( 141 ), with partial recovery after 45 minutes (CO from 8.7 L/Min to $6.7 \mathrm{~L} /$ min immediately after wrapping, and $7.5 \mathrm{~L} / \mathrm{min}$ after $45 \mathrm{~min}$ utes). Opposite findings have been reported by Lazzara and Polidori, who independently investigated the acute effects of static unstimulated wrapping on cardiac function $(142,143)$. Using load-independent methods (conductance catheter and pressure-volume analysis) no impairment of systolic and diastolic functions could be detected. Clinically, Barbier and associates reported the results of transesophageal echocardiographic monitoring during and just after cardiomyoplasty surgery. No impairment of cardiac performance was observed by the application of the static LDM pedicled flap (144). On the contrary, Katircioglu hypothetized the occurrence of RV dysfunction in the immediate postoperative phase by observing a rise of central venous pressure (from 2 to 9 $\mathrm{mmHg}$ ) because of a decrease of RVEDV and increase of RVESV, and suggested careful management in the ICU in order to prevent further deterioration by undue loading (145). Dobutamine infusion is usually maintained even after patient extubation, and then gradually decreased. Venous oxygen saturation is, of course, carefully monitored throughout the stay in the ICU.

Skin necrosis may occur next to the incision of muscle dissection area following surgical harvesting because of impaired blood perfusion, and venous return from the subcutaneous tissue (83), and therefore early patient mobilization and soft pads laying along the posterior thoracic wound should be implemented as soon as possible. 


\subsection{Management of muscle conditioning and heart/wrapped muscle interaction}

Synchronized electrical activation of transposed and wrapped skeletal muscle, and progressive electrically induced muscle transformation, represent the basic concept of cardiomyoplasty cardiac support. Nonetheless, lloss of muscle mass due to reduction of muscle fibre diameter, and substantial decrease of contractile speed, occur after electrical conditioning and represent the major drawback of such a muscle fibre conversion. Salmons and Jarvis calculated the loss off power after electrically-induced transformation to approach $90 \%$ of the original value (64). Furthermore, muscle mobilization requires the severance of peripheral vessels jeopardizing the viability of the distal muscle portions (146148), calling for a cautious use of postoperative muscle activation to prevent ischemia of those territories and subsequent irrewersible damage. The protocol proposed by Carpentier and Chachques (106) was designed to meet these requirements, but no thorough investigation has been performed using other protocols. The two-week recovery period is currently adopted worldwide, followed by a sequential and progressive stimulation in order to achieve a completely transformed and tetanically contracting wrapped muscle graft after 12 weeks. However, it is worth underlining that this protocol was not instituted in the initial clinical series and is not worldwide applied currently. The first clinical experiences were characterized by marked differences in terms of the beginning of electrical activation $(82,87,149)$, and, apparently, no muscle damage was described when less than 15 days of recovery were used. Chekanov recently reported that by using low frequency pacing ( 15 beats per minute) starting 1 hour after surgery, no muscle damage was induced (150). Indeed, the contractile force of the untrained LDM lost only $6 \%$ of the initial value at 15 beats $/ \mathrm{min}$, whereas the loss was $28 \%$ by using 60 beats/min. Additionally, this lowfrequency training was conducted for two weeks, and no muscle fatigue was observed on day 6,11 , and 16, during 42 -minute work-rest fatigue testing. In this study light microscopy did not show any muscle degeneration, whereas an increase in vascularity and more interstitial tissue were detected at day $1 \mathrm{l}$ and 16. It can be hypothetized then that early stimulation is not invariably linked with irreversible muscle damage.

Preoperative conditioning was also used in some experimental $(115,151)$ and clinical (86) series, and, despite evidence of potential benefit on preventing muscle ischemia, was clinically abandoned due to the additional surgical burden applied to the patient. Different modalities of electrical training to minimize the current disadvantages of muscle stimulation and transposal have been reported experimentally. Gealow recently investigated in situ LDM with modified stimulation protocols which consisted in progressive pulse rate or pulse number, in comparison with a standard protocol (152). These altemative 
trainings produced muscles with less fibrosis, and with an increase of stroke work in the early (progressive pulse rate) or late (progressive pulse number) period, providing some basis for potential benefit of stimulation at an earlier stage after cardiomyoplasty.

Stimulation parameters proved to have substantial influence on the cardiomyoplasty outcome as well as on muscle properties. The delay of the activation of LDM contraction during cardiac systole has been a topic of thorough investigation. Lucas demonstrated that the muscle contraction/relaxation cycle may negatively affect the following beat $\{153$ ). Indeed, prolonged and delayed activation time may lead to a still contracted muscle at the initial phase of the following diastolic filling period, with potential interference and impediment on cardiac loading. Therefore, the use of the high contraction rate (i.e., $1: 1$ contraction mode) may induce diastolic impairment, apart from the potential effects on muscle viability which will be discussed later. Pekarsky and associates demonstrated in a combined experimental and clinical study that contraction and relaxation duration markedly decreased after cardiomyoplasty using a rheomyosignal detective apparatus, and that an excessive length of LDM contraction duration was directly responsible for hemodynamic deterioration in one patient (154). They suggested the importance of adaptation of LDM burst duration during the follow-up because of the inevitable prolongation of muscle contraction times. A future device under development in their Institution will modify the stimulation features according to the changes of the recorded (reomyosignal) mechanical data. Gealow confirmed the detrimental effects of prolonged contraction/relaxation time secondary to muscle electrical conditioning, and showed the "protective" action of adaptive LDM duty cycle in relation to the underlying heart rate for an efficient mechanical perfomance (155). Soltero experimentally (double cardiomyoplasty) showed that stimulating the wrapped LDM at every other heart beat produced an equivalent hemodynamic response to a $1: 1$ stimulation ratio (136), suggesting that the latter contraction mode should be abandoned for factors related to muscle preservation, hemodynamic effect, and energy battery sparing. Latissimus dorsi blood flow and related metabolism was shown to be markedly affected by the contraction ratio by van Doom and associates (156). In this laboratory investiga tion, the 1:1 stimulation mode was shown to be detrimental to the LDM as indicated by the high lactate production, whereas at a contraction ratio of $2: 1$ a decrease of thoracodorsal venous lactate was observed. Both stimulation regimen were shown to induce significant hyperemia in the conditioned 1.DMs. The effects of highly demanding contraction ratio regarding muscle structure at long-term was indeed outlined by Kalil-Filho in a study in cardiomyoplasty patients with LDM paced at the 1:1 mode (157). Magnetic resonance imaging indicated extensive fat infiltration in the wrapped LDMs, corroborating the potential danger of such a stimulation protocol. Despite these findings and the 
apparent lack of rationale to stimulate the wrapped LDM every cardiac beat (158), clinical application of a 1:1 stimulation mode still persists.

The importance to select a proper delay between sensed cardiac electrical activity (QRS-complex) and LDM contraction was recently outlined by several investigators and by our laboratory. Grubb showed the clinical impact of incorrect stimulation programming in 2 patients submitted to cardiomyoplasty (159). Helou described the available modes of LDM/heart interaction by different activation modes, namely fixed mode, aortic flow-related mode, and mitral valve closure-related mode (160). It appeared that the second setting induced the best hemodynamic effects by obtaining better tailored cardiac/muscle interaction in terms of hydrodynamic response. Almada was the first investigator to stress the importance of such a detail in LDM stimulation setting (161), and to suggest the use of echocardiography to monitor the hemodynamic changes induced by the different delay times. Levin confirmed the influence of this parameter in the optimization of cardiomyoplasty effect by using a mathematical model (162). Geddes analysed the effect of varying the timing of LDM activation in an animall model (163). He clearly showed the marked variability of stroke volume and hemodynamic response according to synchronization of the LDM to LV contraction. Schreuder showed in 9 patients after cardiomyoplasty a significant influence on hemodynamic response if incorrect stimulation parameters were applied especially regarding the LDM synchronization interval and stimulus strength (164).

Stimulation frequency as well as impulse amplitude are two other critical factors to achieve an optimal effect of LDM contractile contribution. Lucas showed that 30 pulses/sec delivered a near maximal contractile force ( $80 \%$ ), and was significantly less fatiguing (165). Chen confirmed that suboptimal amplitude and frequency settings may lead to reduced benefit on myocardial wall stress reduction ( 166 ).

Because muscle overuse is assumed to be one of the main causes of longtern muscle degeneration, recent experimental studies are applying intermittent electrical stimulation. Iannuzzo showed that intermittent electrical stimulation ( 16 hours on and 8 hours off) induced less damage to the dissected LDM as compared to the continuously conditioned LDM (167). Arpesella and Carraro confirmed that discontinuous electrical stimulation induced a more powerful and better preserved wrapped muscle up to 1 year of pacing (168).

\subsection{Chinical experiences, hemodynamic results, and complications}

Cardiomyoplasty has been used in patients for more than a decade, with substantial changes in patient selection criteria, operative technique, anesthetic and perioperative management, and methodology for postoperative patient assessment. Furthermore, cardiomyoplasty has been applied in an attempt to 
treat sequelae of cardiac tumor removal, to provide additional contractile sup port following aneurysmal correction or to repair congenital diseases, to assist the chronically failing myocardium, or even to alleviate angina. Clinical results, therefore, should be evaluated against the background of the cardiac abnormality presented.

It is unquestionable that a discussion about clinical experiences should start with the Hopital Broussais experience in Paris, which is approaching 12 years of application. Since the very first case performed in 1985 (82), around 100 patients have undergone cardiomyoplasty at this institution. As previously stated, this important clinical series has been characterized by consistent heterogenous features of treated patients, with substantial modifications of all the aspects of the operation over the time. Carpentier and Chachques have repetitively documented their clinical results (170-172). The most recent report on the Broussais experience (173) refers to $84 \mathrm{pts}$, with a mean follow-up of 4.8 years (the longest being almost 11 years). The authors showed an 8 -year survival of $52 \%$, a significant reduction of hospitalization rate due to congestive heart failure, and a stable heart size at long term. Besides significant functional improvement (NYHA Class from 3.2 to 1.8), significant hemodynamic amelioration was observed (radionuclide LVEF from $17 \%$ to $27 \%$, and LVSV from $25 \mathrm{ml}$ to $33 \mathrm{ml} /$ beat $/ \mathrm{m}^{2}$ ). LDM preservation was documented in $82 \%$ of the patients by CT scan. Five patients eventually underwent heart transplantation because of progression of the underlying cardiomyopathy after a mean delay of 29 months. A previous publication (83) on 52 pts gives a more objective analysis of the clinical experience. In that study, severe functional impairment (NYHA Class IV) was present in $45 \%$ of the patients, and $23 \%$ underwent concomitant surgical procedures. Even the cardiomyoplasty procedure varied substantially because it was being used as a reinforcement technique in $75 \%$ of the cases, and as a substitution technique in $25 \%$. Forty-six patients were submitted to posterior wrapping (posterior cardio-costal in 14 patients, and posterior cardiosubcutaneous in 38 patients), 5 patients underwent anterior wrap (counterclockwise), and 1 received atrial wrapping following a Fontan procedure. Furthermore, the surgical technique changed during the most recent years with the application of the "flap-sliding" technique, which enabled less heart manipulation, and reduced the need of ECC, resulting in a favorable postoperative course. Indeed, Carpentier reports a postoperative mortality during the first 2 months of $23 \%$ (12 patients) with an important improvement in the last series (from $54 \%$ to $12.8 \%$ ) attributed to better patient selection (only NYHA Class III), and to improved experience and perioperative management. In this study, the authors reported a 5 -year survival of $70 \%$, but they excluded the hospital mortality which substantially influences overall results. Significant hemodynamic improvements have been reported (LVEF from $24 \%$ to $30 \%$, Cl from 2.4 $\mathrm{L} / \mathrm{min} / \mathrm{m}^{2}$ to $2.9 \mathrm{~L} / \mathrm{min} / \mathrm{m}^{2}$, and LVSV increase of $27 \%$ in 21 patients at 2 -year 
follow-up). Reduced hospitalization rate (from 2.4 per patient per year to 0.4 ) and medical therapy (in $62 \%$ of the patients) were also shown.

Magovern and associates were the second centre to perform clinical cases, and the first centre in the United States (149). Their initial protocol was somewhat unusual since only combined procedures (aneurysmectomy and $C A B G$ ), and the use of a single pulse dual-chamber pacemaker were used (174-176). The clinical experience of the Pittsburgh group showed the same variability of cardiomyoplasty applications, and the potentially misleading interpretation of the clinical data, as the Broussais series. Ten patients in their series received preoperative muscle stimulation ("preconditioning") meant to allow early muscle stimulation by having an already fatigue resistant muscle, and by ensuring muscle blood flow enhancement (86). The cardiomyoplasty technique, based on their outstanding experimental work, ranged from left posterior cardio-costal CMP (10 patients), to left posterior cardio-subcutaneous CMP (7 patients), to left anterior cardio-costal CMP (i patient), and, finally, to the more recent series of right anterior cardio-costal CMP (16 patients). In addition, 10 patients received concomitant procedures (3 aneurysm resection, I mitral valve repair, and $6 \mathrm{CABG}$ ), 18 patients required extracorporeal circulation (with a time ranging from 21 to 216 minutes), with 8 cases in the isolated cardiomyoplasty group. Twelve patients had IABP as perioperative mechanical support. Interestingly, Magovern and collaborators made an attempt to verify any po. tential difference between the patients who had isolated cardiomyoplasty (2) patients) as compared to the patients who underwent combined procedures (10 patients), finding no relation between preoperative data and postoperative outcome (122). Additionally, no changes in survival rate were observed in relation to operative mortality ( $14 \%$ for isolated cardiomyoplasty and $20 \%$ for concomitant surgery). Their most recent experience revealed a substantial improvement in operative mortality $(6 \%)$, but no changes in terms of 1 year survival rate (63\% as compared to $60 \%$ in the previous experience). Arrhythmias were the principal cause of death. This was also found in the analysis of the ten-year Unired States experience (63\% of the late death) (86). Magovern introduced the right cardiomyoplasty procedure based on experimental studies in his laboratory (134), and since 199116 patients have undergone such an operation (123). Despite initial promising results (at 6 weeks LVEF increased from $26 \%$ to $33 \%$ ) no improvement in survival was detected at 12 and 24 months. Significant reduction of LVEDV was shown at 6 months (from $300 \mathrm{ml}$ to $250 \mathrm{ml}$ ), and marked improvement of functional capacity (NYHA Class from 3 to 2.0 at 24 months) was also observed. However, no significant change was recorded in terms of long-term survival $(75 \%, 68 \%$, and $50 \%$ at 6,12 , and 24 months, respectively), or in cause of death (almost $80 \%$ due to sudden death) as compared to the left cardiomyoplasty group. 
Jegaden and collegues also contributed to the clinical cardiomyoplasty series with isolated (4 cases) and combined ( 8 cases) procedures in the treatment of congestive heart failure (95). Their results showed no perioperative mortality in a very selected group of patients (NVHA III). Survival at 1 and 2 years was excellent ( $83 \%$ and $73 \%$, respectively), with concomitant reduction of medical therapy and an improved subjective condition. Significant hemodynamic amelioration was shown in LVEF and in LVEDP at 2 years (from $25 \%$ to $40 \%$, and from $20 \mathrm{mmHg}$ to $1 \mathrm{ImmHg}$, respectively). They noted a descrepancy between angiographic and radionuclide findings in terms of LVEF. The isotopic investigation gave lower values than the catheterization procedure. The lifting of the heart due to LDM contraction might be responsible for an underestimation of this LV function parameter, as previously suggested by Acker and collegues (1.24). One patient was successfully transplanted after cardiomyoplasty because of refractory worsening of the underlying cardiomyopathy (177). Additionally they observed failure after cardiomyoplasty in all the patients with preoperative atrial fibrillation (2 patients), as was also suggested by Chachques and by Furnary $(83,93)$.

The series from Paris, Lyon, and Pittsburgh are characterized by the use of associated procedures, whereas the use of cardiomyoplasty as an isolated approach may provide more meaningful results, especially in terms of mechanisms of action and actual benefits. Unliortunately, isolated cardiomyoplasty was performed and reported in only a few centers. Lange recently described the Heidelberg experience, and they performed isolated cardiomyoplasty in highly selected patients with contraindications for heart transplant (178). Due to the limited patient population ( 8 patients) no definitive conclusions can be drawn. Additionally, selected candidates showed absence of severe impairment in cardiac function or geometry (all patients had LVEF $>20 \%$, LVEDD ranged from 64 $\mathrm{mm}$ to $76 \mathrm{~mm}$, and were in sinus rhythm). Their situation may represent the ideal conditions for a successful outcome. Indeed, the significant increase of LVEF at 1 and 2 years (from $21 \%$ to $38 \%$, and to $37 \%$, respectively) may be related to the early phase of cardiac impairment of such patients who seem to be benefiting the most from biological cardiac support.

Another significant contribution to the analysis of the effects of isolated cardiomyoplasty came from the group of Sao Paulo, Brasil. The first clinical report by Moreira and coworkers appeared in 1990, presenting the data obtained in 11 patients, with a mean follow-up of 11 months (84). All patients had contraindications for heart transplant, and the etiology of underlying cardiomyopathy was idiopathic disease in 9, and Chagas disease in 2. The mean age was lower ( 43.5 years) than in the European or North American experience (55 years). In accordance with the other initial clinical series. NYHA Class IV was present in 4 patients, but no operative death and no use of ECC were reported, despite the surgical technique which uses separated stitches on the posterior 
myocardium to fix the superior border of the mobilized LDM, requiring longlasting heart lifting.

An intriguing report by the San Paulo group has been published in " 91 concerning the prospective analysis of 2 nonrandomized groups of patients affected by congestive heart failure and no candidates for heart transplantation (179). The medically treated group (17 patients) consisted of patients who refused the cardiomyoplasty procedure and who were followed for 2 years. These results were compared with the surgical group (15 patients). Survival was significantly better in the cardiomyoplasty subset $187 \%, 79 \%$, and $66 \%$, at 6 months, 1 year, and 2 years, versus $59 \%, 41 \%$, and $27 \%$ in the medically treated patients). The Brasilian experience depicts a less favorable outcome of cardiomyoplasty patients at long-term (180). Analysis of the results in 31 patients with isolated cardiomyoplasty for idiopathic cardiomyopathy reveals a 5 yearsurvival of $43 \%$, with 7 late deaths due to heart failure and 4 related to sudden death. Nineteen patients of this series had undergone LDM stimulation at a 1:1 mode which could have been responsible for progressive muscle deterioration and reduced muscle support at late follow-up (181). Detailed assessement of hemodynamic parameters concerning diastolic or systolic LV function was done by the Sao Paulo group (182-186). Jatene described a significant increase of LV segmental wall shortening (from $11 \%$ to $16 \%$ ) and SV (from $23 \mathrm{ml}$ to $34 \mathrm{ml}$ ) in 13 patients after cardiomyoplasty. A more pronounced increase of EF was observed in patients with smaller LVEDD $(<75 \mathrm{~mm})$. Bocchi studied the hemodynamic changes at rest and during exercise in 3 patients, comparing pre versus postoperative data, and found that $\mathrm{CO}$ and VO2 were substantially increased after surgery, with a 3.2 fold increase of SV during exercise. Furthermore, they specifically evaluated quality of life in cardiomyoplasty patients (187), demonstrating a substantial decrease in limitation of physical activity, with improvement in sleep pattern, social activity, and perceptions and expectations about the treatment. The analysis of the acute effects of muscle support were addressed by Bellotti who compared cardiomyostimulator on versus off in 8 patients, and beneficial changes were observed during assisted beats in diastolic as well as systolic function.

Multicenter trials attempted to provide more meaningful data by combining outcome from several centers, despite substantial heterogeneity in patient features at the different institutions. The first multicenter report was described by Grandjean in 1991, the Phase I FDA trial (88), and consisted of 78 patients operated in 11 centers throughout the world. Interestingly, the patient population mirrored the selection criteria characterizing the early experience of cardiomyoplasty. Indeed, NYHA Class IV was present in $46^{\%}$ of the cases, isolated cardiomyoplasty was performed in $71 \%$ of the patients, and $48 \%$ received $1: 1$ mode LDM stimulation. Despite the common finding of substantial subjective improvement (NYHA Class improved in $85 \%$ of the patients, from 3.5 to 2.1 ) sur- 
vival rate showed rather poor results $(78 \%$ and $60 \%$ survival at 1 month and 1 year, respectively). An important finding was the striking difference in mortality rate in relation to preoperative functional condition. Patients in NYHA Class III had a 1 year survival of $81 \%$ whereas patients in NYHA Class $\mathrm{V}$ had a survival of $37 \%$. Arrhythmic death was responsible for $40 \%$ of the total postoperative mortality. These data greatly affected subsequent patient selection, with the exclu. sion of end-stage heart failure patients, but it did not resulted in treatment changes in regard to the prevention of sudden death. Recently, Furnary and coauthors presented the Phase II Multicenter Study obtained in 5 US, 2 Canadian, and 1 Brasilian center (188). Sixty-eight patients were enrolled in the study and despite better defined selection criteria (NVIIA Class III, LVEF $<40 \%$ ) the cardiomyoplasty approach varied a great deal, being right cardiomyoplasty performed in 13 patients (Pittsburgh group) and left cardiomyoplasty in 55 patients. Each center taking part in the study was furthermore asked to enroll a nonrandomized group of medically treated patients as a reference group. There was no significant differerence in survival at 12 months between the two groups.

Moreira presented the South American experience with 112 patients operated on in 12 differerent institutions (89). The mean follow-up was 22.1 months. Seventeen patients received a standard dual-chamber pacemaker for muscle stimulation and were excluded for late follow-up evaluation. The patient survival was $78.4 \%, 59.7 \%$, and $41.7 \%$ at 1 year, 2 years, and 5 years, respectively. Sudden death accounted for $40 \%$ of the late deaths. Detailed analysis of patient features and survival confirmed that Chagas disease and NYHA Class IV were negative predictors for long-term outcome.

Additional series have been described worldwide $(87,96,98,186,189-192)$, and several features can be commented upon. Chiu addressed the controversial and yet unsolved question of the outcome of complete versus uncomplete ventricular coverture (96). He observed reduced benefit in 2 patients who received $60 \%$ and $70 \%$ wrapping of the ventricular surface as compared with 2 patients who underwent a full wrap. This concern has been raised by many other investigators $(83,97)$ but definitive proof is lacking, when correct this potentially has substantial impact on patient selection (refusal of extreme cardiomegaly). Therefore, careful revision of previous data, and prospective analysis will be mandatory to elucidate this technical aspect. Other interesting observations have been presented by the Russian groups. Chekanov reported data from 25 patients treated at the Bakulev Institute in Moscow (186), and showed consistent postoperative changes when comparing cardiomyostimulator on versus off $(\mathrm{Cl}$ and stroke index increased from $3.9 \mathrm{~L} / \mathrm{min} / \mathrm{square}$ meter to 5.1 $\mathrm{L} / \mathrm{min} / \mathrm{m} 2$, and from $38.5 \mathrm{ml} / \mathrm{square}$ meter to $51 \mathrm{ml} / \mathrm{square}$ meter, respectively), and reported better hemodynamic response with low synchronization ratio (1:4 or 1:6). Akhmedov described the outcome of 35 patients (87) operated 
upon in Tomsk. Thirty patients were affected by ischemic cardiomyopathy. In this series no consistent hemodynamic changes could be detected (mean LVEF increase of $12 \%$ ), but evidence of myocardial revascularization from the wrapped LDM could be demonstrated.

\section{Complications}

Because of the relative limited number of patients in individual experiences, postoperative complications have rarely been described in detail. Furnary showed that $19 \%$ of patients of the Phase II Study experienced one or more major, nonfatal complications (93).

Bacterial infection has been documented in a few centers, and failure of treatment has been reported with inevitable electrical equipment explantation, and subsequent patient deterioration in a few cases $(83,87)$. Additional and anedoctal reports of postoperative morbidity after cardiomyoplasty have been published $(98,194)$, but agreement or guidelines concerning appropriate therapeutic measures are lacking.

Infection of the pacing-system related structures represents one of the most freightful complications (195-198). In cardiomyoplasty, the incidence of bacterial contamination is highly variable, ranging from $0 \%$ to $15 \%$, and treatment varies from conservative approaches to explantation of the pacing material. Surgical debridement and long-term antibiotic therapy has been used, but in some instances with no success.

Heart failure progression together with sudden death remain the main events at long term. Heart transplantation has been shown to be feasible (177) after cardiomyoplasty, and may represent the ultimate option in patients with refractory clinical deterioration.

Malfunctioning or rupture of the stimulation devices are extremely rare. Lead fiacture has been reported only in one case (87). Additional problems related to the electrical system, apart from physiological depletion of battery life. have rarely been encountered. Spontaneous reversal of cardiomyostimulator to asynchronuous LDM stimulation due to casual contact with external magnetic field has been recently reported (199).

Arthythmias are a common event after cardiomyoplasty. The incidence of sudden death varies a grear deal, ranging from $0 \%$ (84) to $80 \%$ (123). Radermecker showed, using an electrophysiological analysis in a chronic goat model, that cardiomyoplasty per sè did not have a pro-arrhythmic effect, and that LDM performance and stimulation was always optimal even during stressfull electrophysiological tests (200). Bocchi attempted to elucidate the influence of cardiomyoplasty on the incidence of sudden death or arrhythmia (201), but no specific parameter could be detected also when analysing pre- and postoperative arrhythmic episodes. Sudden death remains, however, the main long-term problem of cardiomyoplasty patients, but still no consensus exists whether to 
give a concomitant pharmacological antiarrhythmic support or io install an implantable defibrillator. The presence of ventricular rhythm disturbances is very common in CHF patients, and even ventricular arrhythmias considered to be non-malignant seem to represent predictors for the occurrence of sudden death (202). The use of an automatic implantable cardioverter-defibrillator in patients waiting for cardiac transplantation has been shown to be beneficial and life saving (203-205). Therefore, belief is growing that implantation of an AICD together with a cardiomyoplasty procedure may be advisable. Francischelli showed in a laboratory study the feasibility of having the two systems simultaneously operating (206), and Guiraudon recently reported 2 clinical cases of combined procedures (207). Some concern was raised on the potential detrimental effect of LDM contractions on coronary blood flow. Controversial findings have been published. Soltero and associates showed that acute cardiomyoplasty with different anatomical configurations (single anterior, single posterior, or double) induced significant reduction in coronary blood flow during assisted beats (from $11 \%$ to $23 \%$ of reduction of LAD flow according to the selected cardiomyoplasty technique) (208). On the contrary, Tsukube detected an increase in systolic and diastolic coronary blood flow measured at the main stem of the coronary artery which be related to better ventricular function and, therefore, to an increased forward flow and higher mean aortic pressure (209). Kawaguchi did not observed any change in coronary blood flow during an artificially-reproduced cardiomyoplasty dynamic cardiac compression (210).

\subsection{Skeletal muscle structural changes following cardiomyoplasty}

Skeletal muscle changes after cardiomyoplasty cannot be detached from the changes in muscular condition which occur in CHF patients. Recent reports have shown marked alterations in peripheral muscle structure (211.213). Variable degrees of muscle fibre atrophy, reduced volume density and cytochrome oxidase activity of myocyte mithocondria, reduced capillary density, and smaller type IIb fibres, have been common findings in muscle histology following long-lasting cardiac dysfunction. Muscular structural abnormalities have been claimed to be responsible for reduced exercise capacity (214). Furthermore, muscle maladaptive changes have been shown to markedly reduce muscle mechanical power in CHF patients $(215,216)$. It is evident that those findings are unfavorable when skeletal muscle integrity is a necessary requirement for a biomechanical cardiac support system. The effects of electrostimulation in such a situation may therefore be unpredictable. Long-term skeletal muscle response to chronic electrostimulation has been the topic of thorough investigation only in the recent years. The concept of muscle plasticity implies a "positive" phenotype adaptation of the stimulated muscle to match the new functional demands. It is clear now that muscle damage may also be the conse- 
quence of mobilization and long-term pacing. Pette first described the potential damaging effect of continuous electrostimulation (59), and this concern was underlined by Anderson and associates (109). On the contrary, Chachques showed the effects of long-lasting electrostimulation ( 9 months) in wrapped LDM flaps with no evidence of muscle degeneration (106). Lucas presented the hemodynamic and histologic results in goats submitted to chronic cardiomyoplasty (217). Marked degeneration of muscle fibres was encountered, with extensive lypomathosis, increase in connective tissue content, and fiber atrophy. These results directly correlated with the hemodynamic results, showing significant improvement of cardiac performance in healthy or acute failing hearts when the LDM had a preserved structure. The strict correlation between muscle histology and mechanical response in cardiomyoplasty was subsequently confirmed by Kratz (218). The lack of clinical autopsy reports led to controversial and anedoctal findings. Rossi and Odim independently reported necroscopic analysis of wrapped LDM 4 and 4.5 months following cardiomyoplasty, respectively (99,219). No major abnormalities in the stimulated LDM were found. Histologic studies have been shown by Jegaden in one case 9 months after surgery (177), and Carraro recently described the histological structure in a patient who died 8.5 years following cardiomyoplasty (220). Even in these reports no gross deterioration of the chronically paced muscle graft could be demonstrated. Mesana described two cases of autopsy after cardiomyoplasty (98), and found that one LDM structure was normal, whereas the second muscle showed fibrotic degeneration. Kalil-Filho indirectly showed profound changes in muscular signals by MRI imaging at long-term, suggesting fat replacement of the transposed L.DM (157). It is worth underlying, however, that in these patient a highly demanding stimulation mode (every cardiac beat) was programmed. Bocchi reported the autopsy evaluation in 5 patients after cardiomyoplasty (97), and all presented with some degree of alteration in the mobilized LDM. Interestingly, in 2 patients who developed a CK serum peak level $>1400 \mathrm{IU}$, extensive area of perymisial fibrosis and severe atrophy of muscle fibres were observed, suggesting the surgical harvesting as the responsible factor of subsequent muscle damage. The causes of LDM degeneration are multifactorial. It is, therefore, evident that muscular degeneration may occur after cardiomyoplasty, but represents an individual response which may be related to procedural (surgery and stimulation protocol) or to patient-related factors (vascularization feature, preoperative muscle condition, intrinsic muscle adaptation capabilities]. Indeed, muscle mobilization alone may be responsible for substantial muscle derangement (115). Muscle dissection inevitably damages the distal vasculature of the muscle leading to an ischemic insult of the related areas $(146,148)$. Moreover, the stimulation protocol may induce additional damage due to the overdemanding function of the paced muscle (221). 
El Oakley elegantly demonstrated that the loss of resting tension was the worst damaging factor, with increasing damage when electrical stimulation and peripheral vessel ligation were associated (222). Iannuzzo and Anderson confirmed the muscular abnormalities induced by surgical harvesting of the LDM $(223,224)$. Nonetheless, these studies had been conducted without transposing the LDM in the cardiomyoplasty configuration, which may represent an additional insult to muscle structure.

Many attempts have been made to overcome the postoperative muscle derangement. Mechanical and pharmacological support have been proposed. The administration of "trophic" substances has been a topic of investigation in recent years. Anabolic hormones, growth factor, heparin infusion, or Badrenoceptor agonist (clenbutarol), have been claimed to have a protective effect on the LDM (225-231). Besides positive influence on muscular structure, these iatrogenic means proved to ameliorate muscle performance. Heat shock protein release did not prove to protect the LDM pedicle against the ischemic insult caused by peripheral vessel ligation during mobilization (232). There is no doubt that these investigations are of importance.

Goldspink and collaborators showed that muscle stretch represents an ana bolic factor which promotes muscle growth, especially in combination with electrical stimulation (116). Nevertheless, the restoration of the muscle resting length appears to be associated with potential negative effects on cardiac per formance (tamponade or constriction), and may be not essential for optimal muscle contraction due to the conformational adaptation to the new preload after surgery as described by Gealow (117). Chachques reported the use of muscle surface expansor associated with electrical stimulation to increase muscle length and to favor intramuscular vascularization before muscle transposal (233). This method has been applied in 2 patients with good results, and might represent an additional tool in an attempt to optimize LDM wrapping surface and give some protection to the inevitable ischemic insult.

Refinements of LDM stimulation protocols have been addressed by many investigators, and some evidence of their importance for muscle structure preservation has recently been shown. Discontinuous daily stimulation has gained renewed interest. lannuzzo demonstrated the lack of muscle damage in LDM submitted to rest period during the day (168). Arpesella and collaborators have shown that 10 hours/day of stimulation lead to partial fibre transformation (large amount of MHC2A fast fibre) which relates to higher power output (almost twice as much as in the continuously stimulated muscle) and with minimal negative changes in the LDM structure (only $10 \%$ of muscle fibre atrophy). This high muscle power seems to be constantly maintained from 2 months till 1 year (169). 


\subsection{On mechanisms of action}

The understanding of cardiomyoplasty mechanisms of action is extremely complex, certainly related to the biological nature of the assist system, and to the variable and geometrical interaction between two contractile organs.

The initial concept of cardiomyoplasty was to transfer skeletal muscle power to the ventricles, and so, to increase stroke volume. Indeed, systolic augmentation provided by LDM contractions was the sole target of the first experimental and clinical investigators $(84,106,175)$, and, therefore, no additional mechanism was described or looked for. Despite very promising experimental results showing impressive and consistent improvement in traditional hemodynamic parameters (106), the clinical application did not respond to the expectations, showing moderate, and in some istances, inconclusive objective evidence of hemodynamic improvement $(87,109,234)$. These findings are in contrast with the functional capacity of the patients which is frequently improved. These observations resulted in debates and critical attitudes $(109,235,236)$, forcing the investigators to a better appraisal of skeletal muscle capability for circulatory assistance. More sophisticated tools to estimate cardiac performance, and search for additional effects of permanent skeletal muscle support have been introduced in the laboratory and clinical settings.

Lee and associates described the effects of acute cardiomyoplasty (untrained LDM) on a chronically failing animal heart (by rapid ventricular pacing) (237). This study showed a mean decrease of LV wall stress of $13 \%$ during LDM pacing with a direct effect on the related myocardial oxygen consumption. The beneficial influence of LDM contraction on myocardial energetic expenditure has been confirmed by Kawaguchi in isolated and dynamically compressed hearts $(210,238)$. Chen, by applying a balloon at the intermuscular level, was able to evidence a significant decrease of transmyocardial pressure during LDM contractions, but no changes of traditionall hemodynamic values in this acute study could be demonstrated (239). Studies of chronic cardiomyoplasty using trained LDM have been reported by Cho and Nakajima $(240,241)$. The first investigator, used pressure-volume analysis (with the conductance catheter) to show that CO, LVEF, and SW were not different during assisted beats, whereas a significant increase of elastance (slope of the end-systolic pressurevolume relation) and a decrease of LVEDV were present. The model of chronic cardiomyopathy by coronary ligation was used by Nakajima in combination with a wrapping procedure and progressive LDM training protocol. Stroke volume and $\mathrm{CO}$ remained unchanged during assisted beats, whereas Emax (index of cardiac contractility) increased from 2.66 to $4.59 \mathrm{mmHg} / \mathrm{ml}$. The pressurevolume area, which strongly correlates with myocardial oxygen consumption, decreased significantly from $3776 \mathrm{mmHg} . \mathrm{ml}$ to $1932 \mathrm{mmHg}$.ml, suggesting that the probable mechanism of cardiomyoplasty was more an active constrain and 
prevention of further LV dilatation than a direct systolic contribution. However, it is worth mentioning that a significant increase in CO in one animal (from 1.52 $\mathrm{L} / \mathrm{min}$ to $3.01 \mathrm{~L} / \mathrm{min}$ with pacemaker on and $1.67 \mathrm{~L} / \mathrm{min}$ at pacemaker off) during LDM contraction was observed in this study, which might be attributed to systolic contribution of the wrapped muscle graft.

Whereas it is difficult to characterize the effects of cardiomyoplasty on cardiac pump function with conventional load-dependent hemodynamic parameters, the slope of LV end-systolic pressure-volume relation (Emax) positively reflects acute changes in contractile state, independently from ventricular loading conditions $(242,243)$. In addition, LV pressure/volume area have been shown to correlate linearly with myocardial oxygen consumption at any given contractile state, and is, therefore, considered as a measure of total mechanical energy generated by ventricular contraction.

The demonstration of a direct systolic contribution to cardiac performance by the wrapped LDM contraction has been a topic of extensive investigation. Objective proof of significant systolic augmentation induced by the LDM synchronized contraction have been shown clearly in some reports, provoked either by a "squeezing" or a "pulling" effect. Schreuder showed that at the clinical stimulation settings a significant improvement was obtained only in LVPER (165). Nevertheless, by increasing the stimulus strength (1.5 to $3 \mathrm{Vs}$ higher) an immediate and significant increase in systolic aortic pressure and LVSV were detected. Effects of discontinuation of LDM stimulation on systolic and diastolic LV performance have been investigated at rest $(244,245)$ and during exercise (245), but no significant changes in hemodynamics were observed in these studies. Unfortunately, no attempts were made to assess whether optimal stimulation settings were selected by changing the synchronization delay or the impulse amplitude. Nevertheless, Hagège observed that in a subset of patients LVEF, $C I$, and peak positive $\mathrm{dP} / \mathrm{dt}$ decreased while wedge pressure increased when the stimulator was switched off (244). These rather heterogeneous results have been interpreted by the authors as lack of objective evidence that effective and beneficial dynamic compression of the LV occurred. On the contrary, Tasmedir analysed 10 patients who underwent discontinuation of LDM stimulation for 1 week (193), and showed higher LVEF (from 33\% to $36 \%$ at rest, and from $33 \%$ to $40 \%$ during exercise) and lower LVESVI with the cardiomyostimulator on, suggesting a direct systolic contribution of the LDM.

These contradictory findings can be explained by the marked heterogenity of the patients treated and by the variable wrapped muscle performance. Another possible explanation may be that traditional parameters are not sufficiently sensitive to assess more subtle changes induced by wrapped muscles. Furthermore, the lack of direct significant improvement does not imply that nothing has changed. Potential effects on parameters like the aforementioned myocardial wall stress and oxygen consumption, may contribute to the dis- 
crepancy between clinical and hemodynamic changes following cardiomyoplasty. Remodeling of the dilated ventricle and prevention of further cardiac enlargement have been the topics of recent clinical and experimental investigations. Capouya, showed that unstimulated wrapped LDM impeded ventricular dilatation in a rapid pacing-induced cardiac failure model (102). Kass and associates demonstrated significant reduction of ventricular chamber dilatation, improvement of hemodynamic variables in 3 patients at 6 and 12 months after cardiomyoplasty (246). No significant changes were, however, detected by comparing assisted versus unassisted beats, postulating that cardiomyoplasty benefit was not derived from an active systolic assist, but merely from an external constrain. However, it should be underlined that the active contribution is not necessarely linked with significant pressure data. Kaulbach studied a chronic overloading cardiac dilatation model in goats, and demonstrated that the passive, unstimulated wrapped LDM was capable of interrupting the dilation process, whereas J.DM stimulation was necessary to invert and, thereby, to reduce ventricular volumes to baseline data (103). Chekanov reported one clinical case which showed attenuated ventricular enlargement (LVEDV decreased from $170 \mathrm{~cm}^{3}$ to $140 \mathrm{~cm}^{3}$ soon after cardiomyoplasty surgery achieving $111 \mathrm{~cm}^{3}$ during electrical stimulation), confirming the effect of passive and electrically activated LD action (247).

Recently Schreuder showed significant and progressive reduction of ventricular dilatation and significant hemodynamic improvements comparing pre versus 6 and 12 month-data after cardiomyoplasty in 6 patients (104).

Finally, a less investigated issue is the occurrence of neoangiogenesis at the intermuscular level, with neorevascularization from the wrapped LDM vessels to myocardial tissue. This concept was previously experimentally investigated and clinically studied by Beck, Appiani, and Sola. Mannion measured the extent and actual impact of this revascularization in an animal model of coronary artery disease, and showed that skeletal muscle-derived collateral blood flow, as measured by colored microspheres, nourished ischemic myocardium especially in the epicardial portions (100). Akhmedov confirmed neoangiogenesis by angiography of the thoracodorsal artery. Indirectly, neoangiogenesis was confirmed by radioisotope injection in the thoracodorsal artery and concomitant sampling at the coronary sinus level. True vascular connections were evident between the wrapped LDM and the myocardium, and the arterial flow was directed from the muscle to the heart (two flow peaks at 12 and 22 seconds in the coronary sinus of the wrapped hearts versus only one peak at 22 seconds of the control hearts)(87). Therefore, an attractive concept might be to use cardiomyoplasty for myocardial revascularization in patients with ungraftable coronaries and concomitant ischemic cardiomyopathy. 


\section{Current limitations of cardiomyoplasty and aim of the thesis}

Despite the fact that several advances have been made, cardiomyoplasty remains an investigational procedure, and many controversial issues and drawbacks still need to be solved. An underestimated factor for postoperative outcome is the condition of the skeletal muscle involved. Despite being the actual source of power for effective cardiac assistance, little attention has been devoted to optimize muscular condition pre and postoperatively. Chronic heart failure-related changes, surgical procedure, and muscular adaptations by electrical stimulation constitute a threat to cardiomyoplasty results.

The current stimulation protocol has been claimed to generate a fatigueresistant muscle flap, but also to induce postoperative muscular degeneration. Furthermore, cardiomyoplasty patients often suffer additional cardiac deterioration in the early postoperative phase due to the unstimulated LDM. Accordingly, preoperative LDM stimulation would be desirable, which might to some extent prevent negative changes induced by the two-week muscle immobilization, and provide a minor but significant hemodynamic assist. Chapter 2 addresses the feasibility of an early stimulation protocoll, and histologic and hemodynamic findings are evaluated.

An additional limitation of cardiomyoplasty relates to the preoperative muscle condition. The well-known negative impact of CHF to skeletal muscle structure and function ultimately affects the condition of the "engine" of cardiomyoplasty. In that light, attempts to improve preoperative muscle properties in candidates to cardiomyoplasty may represent a contribution to optimize LDM performance and to favor muscle preservation or to limit subsequent muscle derangement. Effects of preoperative physical training in terms of mechanical and structural properties are presented in chapter 3 .

Optimizing muscle/heart interaction represents an additional critical factor for correct and appropriate muscle assistance. Detailed hemodynamic analysis may help in undertanding the actual impact of LDM contraction at different times of the cardiac systole. Chapter 4 shows the hemodynamic responses of different synchronization times as measured by pressure-volume analysis in an animal model.

Based on laboratory findings and on previous clinical experiences, a longterm clinical evaluation of very selected CHF patients is presented in chapter 5. Results from isolated cardiomyoplasty procedures are presented and discussed in order to elucidate the effects of the surgical technique intrinsically.

The use of right cardiomyoplasty to treat unusual clinical case, and the use of a modified technique are presented in chapters 6.1 and 6.2. The management of complications involving the electrical system may be extremely difficult, and scarcely reported in the literature. A case presentation and procedural techniques are discussed in chapters 6.3 and 6.4 . A major shortcoming in car- 
diomyoplasty is represented by potential long-term degeneration of muscle tissue. The use of a modified stimulation protocol may provide a simple and effective mean to limit or to prevent muscle maladaptive changes. Histological findings are discussed in chapter 6.5. Sudden death accounts for a substantial number of late deaths after cardiomyoplasty and any method to decrease its incidence would result in a significant improvement in patient outcome. Feasibility and effectiveness of the combined AICD and cardiomyoplasty procedure are finally presented in chapter 6.6 . 


\section{References}

1. Deedwania P. Prevalence and prognosis of heart failure. Cardiol Clin 1994:12:1.8

2. Ho KKL, Pinsky J, Kannel WB. Levy D. The epidemiology of heart faiture: the framingham Study. I Am Coll Cardiol 1993:22(SupplementA):6A-13A

3. Reitsma JB, Mosterd A, de Craen AJM, Koster RW, wan Capelle FL, Grobbee DE, Thyssen IGP. Increase in hospital admission rates for heart failure in The Netherlands, 1980-1993. Heart $1996 ; 76: 388-92$

4. Garg $R$, Packer M, Pitt B, Yusuf S. Heart falure in the 1990s: evolution of a major public health problem in cardiovascular medicine.) Am Coll Cardiol 1993,22(Suppl A):3A-5A

5. Amstrong PW, Moe GW. Medical adwances in the treatment of congestive heart failure. Circtlation 1994;88:2941-52

6. Stevenson WG, Stevenson LW, Middlekauff HR, Fonarow GC, Hamilton MA. Woo MA, Saxon LA. Natterson PD, Steimle A, Walden IA, Tillisch JH. Improving survival for paticnts with advanced heart failure: a study of 737 consecutive patients. J Am Coll Cardiol 1995;26:1417.23

7. SOLVD Investigators. Effects of enalapril on survival in patients with reduced lefi ventricular ejection fraction and congestive heart failure. N Engl I Med 1991;325:293-302

8. Consensus Trial Study Group. Effects of enalapril on mortality in severe congestive heart fail ure: results of the Cooperative North Scandinavian Enalapril Survival Study (CONSENSUSH. N Engl I Med 1987;316:1429-35

9. Massie BM, Conway M. Survival of patients with congestive heart failure: past, present, and future prospects. Circulation 1987;75(Suppl IV):IV11-IV19

10. Guyatt GH. Measurement of health-related quality of life in heart failune. I Am Coll Cardiol 1993;22(Suppl A):185A-191A

11. Olsen SL, Gilbert EM, Renlund DG, Taylor DO, Yanowitz FD, Bristow MR. Carvedilol improwes left ventricular function and symptoms in chronic heart failure: a double-blind randomized study. IAm Coll Cardiol 1995;25:1225-31

12. Packer M, Bristow MR, Cohn JN, Colucci WS, Fowler MB, Gilbert EM, Shusterman NH. The effect of carvedilol on morbidity and mortality in patients with chronic heart failure. $\mathbb{N}$ Engl I Med 1996;334:1349-55

13. Franciosa JA, Milen M Ziesche S, Cohn JN. Survival in men with severe chronic left ventricular failure due to either cononary heart disease or idiopathic dilated cardiomyopathy. Am I Cardiol 1983;51:831-6

14. Saxon LA. Stevenson GW, Middlekauff HR, Fonatow G, Woo M. Moser D. Stevenson LW. Predicting death from progressive heart failure secondary to ischemic or idiopathic dilated cardiomyopathy. Am J Cardiol 1993;72:62-5

15. Cohn JN, Rector TS. Prognosis of congestive heart failure and predictors of mortality. Am I Cardiol 1988:62:25A-30A

16. Stevenson LW. Fowler MB, Schroeder IS, Stevenson CW, Dracup KA, Fond V. Poor survitwal of patients with idiopathic cardiomyopathy considered too well for transplantation. Am I Med $1987 ; 83: 871-6$

17. Sarris GE, Moore KA, Schroeder IS, Hunt SA, Fower MB, Valendine HB, Vagelos MH. Billingham ME, Oyer PE, Stinson EB, Reitz BA, Shumway NE. Cardiac transplantation: the Stanford experience in the cyclosporine era. I Thorac Cardiovase Surg 1994:108:240-52

18. Lanza RP, Cooper DKC. Boyd ST, Barnard CNComparison of patients with ischemic, myopathic, and thematic heart diseases as cardiac transplant recipients. Am Hearl I $1984 ; 107: 8-12$

19. Stevenson WG, Stevenson LW, Middlekauff HR, Saxon LA. Sudden death prevention in parients with advanced ventricular dysfuncion. Circulation $1993 ; 882953-61$ 
20. Mancini DM, Eisem H. Kussmaul W, Mull R. Edmunds LH Ir. Wilson JR. Value of peak exercise orygen consumption for optmal timing of cardiac transplantation in ambulatory patients with heart laibure. Circulation 1991:83:778-86

21. Stevenson LW. Sietsena K, Tillisch JH, Lem V, Walden J, Kobashigawa JA, Moriguch I. Exercise capacity for survivors of cardiac transplantation or sustained medical therapy for stable heart failure. Circulation 1990,81:78-85

22. Keogh AM, Freund J, Baron DW, Hicke JB. Timing of cardiac transplantation in idiopathic dilated candiomyopathy. Am J Cardiol 1988:61:418-22

23. Stevenson L.W. Waner SL, Steimle AE, Fonarow GC, Hamilon MA, Moriguchi JD, Kobashiga wald, Tillisch IH, Drinkwater DC, Laks H. The impending crisis awaiting cardiac transplantation: modelling a solution based on selecrion. Circulation 1994;89:450-7

24. McManus RP, OHair DP. Beitzinger MM, Schweiger J, Siegel R, Breen T, Olinger GN. Patients who die awating heart transplantation. I Hedrt Lung Transplant 1993, 12:159-72

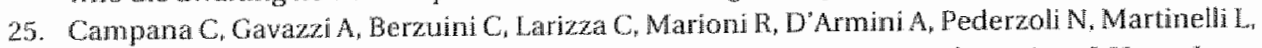
Vigano $M$. Predictors of prognosis in patiends awaiting heart transplantation. J Heart Lung Transplant: 1993; 12:756-65.

26. Stewenson I.W. Fowler MB, Schroeder JS, Dracup KA, Clark SH. Fond V. Patients denied cardiac transplantation for non-medical criteria: a control group. I Am Coll Cardiol 1986;7(Suppl A): 9 A

27. Lindelow $\mathrm{B}$, Andersson $\mathrm{B}$, Watagtein $\mathrm{F}$, Bergh $\mathrm{CH}$. Prognosis of altenative therapies for heart failure patients not accepted for heart transplantation. I Heart Lung Transplant 1994; 13 (part 2) $: 560$

28. Alfieri O, Lorusso R, Sandrelli L, Maisano E. Surgical revascularization for depressed left ventricular function. Ann Card Surg 1996:8:87-92

29. Dreyfus GD, Duboc D, Blasco A, Vigoni D, Dubois C, Brodaty D, de Lentdecker P, Bachet J, Gotudo: B, Guilmet D. Myocardial wability assessment in ischemic cardiomyopathy: benafirs of coronary revascularization. Ann Thorac Surg 1994;57;1402-8

30. Elefteriades $\mathbb{A}$, Tolis $\mathrm{G}$, Levi E, Mills $L K$, Zaret BL. Coronary artary bypass grafting in severe teft wentricular dysfunction: excellent survival with improwed ejection fraction and functional state. J Am Coll Cardiol 1993:22:1411-17

31. Bolling SF, Deet M. Brunsting LA, Bach DS. Early outcome of mitral valve reconstruction in patients with end stage cardionyopathy. I Thorac Cardiovase 5urg 1995;109:676-83

32. Batista IRV, Sanos JLV, Takeshita N, Bocchino I, Lima PN, Cunha MA. Paral left ventriculectomy to improve left ventricular function in end-stage hear disease. J Card Surg 1996:11:96-7

33. MoCarthy MP "lames KB, Savage RM, Vargo R. Kendall $K$, Harasaki H, Hobbs RE, Pashkow 1 . and the Implantable LVAD Sudy Group. Implantable left ventricular assist device: approaching an alternative for end-stage heart failute. Circulation 1994:90(Suppl II), (1/83- [186

34. Frater 10. The development of an implantable, portable electrically powered left wentricular assist dewice. Sem Thorac Cardowase Surg 1994:6:181-7

35. Lewn HR, Chen JM, Oz MC. Catanese KA, Krum H, Goldsmith RL, Packer M, Mose EA. Potential of lef ventricular assist devico as outpatien therapy while awaing tansplantation. Ann Thorac 5 terg $1994 ; 58: 1515-20$

36. Abrashmot: Pastische Methode der Schiessung won Fistelgangen, welche von inneren Organen kommen. Zentralbl Chir 1911;38:186-7

37. De Jesus IR. Breve concideraciones sobre un case de herida penetrante del corazon. Bol Asoc Med (Peurto Ricol 1931:23:380-2

38. Leriche R. Fontaine R. Essai experimental de tratement de certains, infarctus du myocande et de l'aneurisme du coeur pan une greffe de muscle strie. Bull Soc Nat Chir 1933:59:229-32

39. Beck CS. The development of new blood supply to the heart by operation. Ann Surg $1935 ; 102: 8017.7$ 
40. O'Slaughnessy L. An experimental method of providing a collaterat circulation to ithe heart: $\mathrm{Br}$ Y Surg 1936;23:665-9

41. Petrovsky $B V$. The use of diaphragm grafts for plastic operations in thoracic surgery. I Thorac Cardiovase Surg 1961:41:348-55

42. Petrovsky BV. Surgical treatment of cardiac anuerysms. I Cardiovasc Surg (Torino 1966:2:87. 91

43. Appiani E, Almada H, Garlando C, Milei J. Bastaroli I. Potential myocardial revascilarization and mechanical effects of pectoral muscle ransplant. Am Plast Surg 1983:10:252-63.

44. Christ JE, Spira M. Application of the latissimus dorsi muscle to the heart. Ann Plast Surg $1982 ; 8: 118-21$

45. Sola OM. Dillard DH. Ivey TD. Haneda K, thoh T, Thomas R. Autotransplantation of skeletal muscle in to the myocardium. Circulation 1985:71:341-83

46. Pairolero PC, Arnold PG, Piehler IM. Intrathoracic transposition of extrathoracic skeletal muscle. Thorac Cardiovasc Surg. 1983;86;809-17

47. Horneffer PJ, French JH, Hutchins GM, Gardner TJ. The use of muscle flaps in the repair of aortic defiects. I Thorac Cardiovasc Surg 1985;90:361-66

48. Papp C. Parker P, Boeheim C, McCraw JB. Experimental use of intercostal muscle laps for repair of induced cardiac defects. I Torac Cardiovase Surg 1985;90:261-4

49. Bitto T, Mannion ID. Hammond R, Macoviack JA, Rashlkind Wy, Edmunds LHIr, Stephenson LW. Pectoralis and rectus abdominis muscles for potental correction of congenital heart defects. Second World Congress on Pediamic Cardiology. 1985, Procedings, pp $609-12$

50. Gaimes WE, Goldberg NH, Mergner WJ, Tommalso CL, Moulton AL, McLaughlin IS. Recon* struction of the right ventricular outflow tract with a wascularized free flap of striated musclie. Surg Forum 1985;71:341-8

51. Weinstein $M$, Shafiroff BG. Grafts of free muscle transplants upon the myocardium. Science $1946^{\prime \prime} 104(2705): 410-12$

52. Shepard MP, Tamaki H, Mustard WT. Experimental study of the paced denerwated diaphragmatic pedicle graft. Brit I Surg $1968 ; 55: 91-105$

53. Thompson N. Preliminary report on experimental free autografts of skeletal muscle to the myocardium. Scand I Plast Reconstr Surg 1978:12:189-93

54. Morita K, Koyanagi K, Sakamoto Y, Horikoshi S, Matsui M, Arai T. Full-thickness dynamic cardiomyoplasty of the left ventricle with free revascularized latissimus dorsi myografts. I Thorac Cardliovasc Surg 1992;104:1125-34

55. Tapia M, Chachques IC, Tolan M., Pellerin M, Fontaliraw F, Chaussande F, Crthndjean P, Car pentier A. Progressive latissimus dorsi muscle denervalion for fee-llap dynamic candiomyoplasty. I Card Surg 1996;11:256-63

56. Buller AJ, Eccles JC Eccles RM. Interaction between motoneurones and muscles in respect of the characteristic speed of their response. I Physiol Lond 1960:150:417-39

57. Salmons $\$$, Vroba $G$. The influence of activity on some contractile characteristics of mammalian fastand slow muscles. I Physiol t.ond 1969:210:429-39

58. Salmons $\$$. Sreter FA. Significance of mpulse activily in the transformation of sketcal muscle type. Nature $1976 ; 263 ; 30-4$

59. Pette D, Smith ME, Stadde HW, Vrbova C. Elects of long-term electical stimulation on some contractile and metabolic characteristics of fast rabbil muscle Pflugers Archiw 1973:338:257. 72

60. Macoviack JA, Stephenson LW, Armenti F, Kelly AM, Alavi A, Mackler T, Cox J, Palatianos G. Edmunds LH. Electrical conditioning of in situ skeletal muscle for replacement of myocalldium. J Surg Res 1982,32:429-39

61. Mannion JD, Bitto T. Hammond RL, Rubistein NA, Stephenson LW. Histochem calland faligue characteristics of conditioned canine latissimus dorsi muscle. Circ Res 1996\%91:534-4A 
62. Dewar ML, Drinkwater DC, Witwich C, Chiu RC-1. Synchronously stimulated skeletal muscle graft for myocandial repair. I Thorac Cardiovasc Surg 1984;87:325-31

63. Chachques JC, Mitz V. Hero M, Ahran P. Gallix P. Fontarian F, Vilain P. Experimental cardio. plasty using the latissimus dorsi muscle llap. / Cardiovasc Surg 1985;26:457-62

64. Salmons $S$ Jarwis J. Cardiomyoplasty: a look at the fundamentals. In: A Carpentier, JC Chachques, P Grandjean (eds). Cardiomyoplasty. Futura Publishing Inc., Mount Kisko, NY, 1991, pp 3-17

65. Kantrowiz A, Mckinnon W. The experimental use of the diaphragm as an auxilliary myocardium. Surg For 1959;9:266-3

66. Kartrowitz $A$. Functioning autogenous muscle used experimentally as an auxilliary ventricle. Trans Am Soc Artif Organs 1960;6:305-10.

67. Nakamura $K_{\text {ulenn }}$ WL. Grafts of diaphragm as a functioning substitute for the myocardium. J Surg Res 1964; 4 :435-9

68. Phillips WL, Pallin S, Crastnopol P. Diaphragm transplantation. Angiol 1969;20:635-40

69. Drinkwater DC Ir, Ghiu RC-J, Modry DL, Wit tnich C. Cardiac assist and myocardial repair with synchronously stumulated skeletal muscle. Surg Forum 1980;31:271 4

70. Kao RL, Christlieb T, Magovern GI, Park SB, Magovern GJ Ir. The importance of skeletal muscle fiber orientation for dynamic cardiomyoplasty. Ann Thorac Surg 1990;99:134 -9.

71. Kusaba E, Schraut W, Sawatani S, Javon D. Freed P. Kantrowitz A. A diaphragmatic graft for atugmenting left ventricular function: a feasibility study. Trans Am Soc Artif Organs $1973 ; 19: 251-7$

72. Macoviak JA, Silephenson LW, Kelly AM, LikofT M, ReichekN. Edmunds LH Jr. Partial replacement of the right wentricle with a synchonously contracting diaphragmatic skeletal muscle autograft. Proceedings: Third Meeting, Intern Soc Artif Inter Organs 5(Suppl):550-55, 1981.

73. Macoviak JA, Stephenson LW, Spiehman S, Greenspan A, Likoff M, St John Sutton M, Reichek N, Rashkind W, Edmunds yr LH. Replacement of ventricular myocardium with diaphragmatic skeletal muscle. Sllort-term studies. J Thorac Cardiovasc Surg 1981;81:519-27

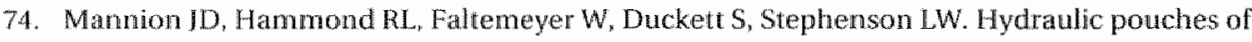
canine latissimus clorsi: potential for: left ventricular assistance. J Thorac Cardiovase Surg $1986 ; 91: 534-44$

75. Acker MA, Hammond RL, Mannion JD, Salmons S. Stephenson LW. An autologous biologic pump motor. J Thorac Cardiovasic Surg 1986:92:733-46

76. Dewar M. Walsh G, Abraham A, DeSimon J, Foot E. Stewart DVMJ, Fraser R, Chiu RC-J. Left ventricular full-thickness cardiomyoplasty with pericardial neoendocardium: experimental development of a surgical procedure. Ann Thorac Surg 1987;44:618-24

77. Termet H, Chalencon IL, Estour E, Gaillard P, Fave JP. Transplantation sur le myocarde d'un muscle strie par excite par pacemaker. Ann Chir Torac Cardio 1966:5:568-71

78. Jobin GR, Schusterman M, Peterson GH, Nichols G, Bland KI. The intramuscular neurovascu. Lar amatomy of the latissimus dorsi muscle: the basis for splitting the flap. Plast Reconstr Surg $1981: 67: 637-41$

79. Perier P. Acar C, Chachques JC, Sola OM, Kakulas BA, Thomas R, Radermecker MA, Fourny I, Fissette J, Limet R. Anatomy of the laissimus dorsi muscle: description, segmental anatomy and finction, intramuscular vascularization. From: A Carpentier, JC Chachques, Prandjean (eds). Cardiomyoplasty. Futura Publishing Inc. Mount Kisko, NY, 1991, pp 63-76.

80. Sola OM, Haines LC, Kakulas BA, Ivey T, Dillard DH, Thomas R, Shoji Y, Fujimura Y, Dahm L. Comparative anatony and histochemistry of human and canine latissimus dorsi muscle. I Hearl Lung Transplant 1990;9:151-9

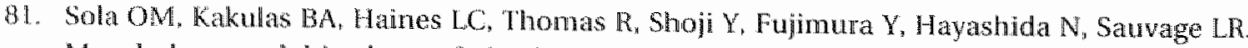
Morphology and histology of the latissimus dorsi muscle. Sem Thorac Cardiovasc Srg $1991: 3124-7$ 
82. Carpentier A, Chachques JC. Myocardial substitution with a simulated skeletal muscle: first successful clinical case. Lancer 1985;1:1267

83. Carpentier A. Chachques IC, Acar C, Relland I Mihaileanu S, Bensasson D, Kieffer JP. Guibourt P, Tournay D, Roussin I, Grandjean PA. Dynamic cardionyoplasty at seven years. I Tho. rac Cardiovase Surg 1993;106:42-53

84. Moreira LFP, Stolf NAG, Bocchi EA, Pereira-Barretto AC, Meneghetti JC, Giorgi MCP, Moraes AV, Leite J, da Luz PL, Jatene AD. Latissimus dorsi cardiomyoplasty in the treatment of patients with dilated cardiomyopathy. Circulation 1990:82 (Suppl 1VI, 1V257-1V263

85. Dumcius $A_{*}$ Salcius K, Giedraitis S, Sirvinskas E. Kibisa R, Skucas J. Myoventriculoplasty with the use of programmed, physiologically controlled electroneurostimulation. IThorac Catdiovasc Surg 1989;97:636 7

B6. Magovern GI Sr, Simpson KA. Clinical cardionyoplasty: review of the ten-year United Stalesi experience. Ann Thorac Surg 1996;61:413-9

87. Akhmedov SD, Krivoschekov EV, Pekarskaya MV, Krylov AL, Vesnina ZN, Chemov VI, Chernyavskiy AM, Vechersky YY, Kampov RS, Nechaev EA, et al. Clinicall results of dymamic cardiomyoplasty. I Card Surg 1995;10:573-9

88. Grandjear PA, Austin L, Chan S, Terpstra B, Bourgeois I. Dynamic cardiomyoplasty: clinical results. J Card Surg 1991;6(Suppl):80-8

89. Moreira LFP. Stolif NAG, Braile DM. Jatene AD. Dynamic Cardiomyoplasty in South America. Amn Thorac Surg 1996;61:408-12

90. Furnary AP, Magovern JA, Christlieb IY, Orie IE, Simpson KA, Magovern GJ Clinical cardiomyoplasty: preoperative factors associated with outcome. Ann Jhorac Surg 1992:54:1 139-43

91. Gorcsan J III, Murali S, Counihan PJ, Mandarino WA, Kormos RL. Right ventricular pertormance and contractile response in patients with severe heart failure. Circulation 1996;94:3190-7

92. Cabrera Fischer EI, Chachques JC, Garcia A, de forteza E, Haab F, Cron C, Campentier A. Effects of cardiomyoplasty on left ventricular diastolic function. Bas Appl Myol 1991:1:253-8

93. Furnary AP, Swanson IS, Grunkmeier $G$, Starr A. Lessons learned before and after cardiomyoplasty: risk sensitive patient selection and post procedure quality of life. I Gard Surg $1996 ; 11: 200-6$.

94. The Phase II Dynamic Cardiomyoplasty Study Group. Factors associated with acute hospital mortality fallowing a latissimus dorsi cardiomyoplasty. Am Coll Cardiol 1994;(Suppl A) A438

95. Jegader O, Delahaye F, Finet G, van der Veen FH, Montagna P, Eker A, Ossete J, Rrossi R, Saint Pierre A, Michaeloff PH. Late hemodynamic results after cardiomyoplasty in congest lve hearl Railure. Ann Thorac Surg 1994;57:1151-7

96. Chiu RC- 0 Odim JNK, Burgess IH. Responses 10 dynamic cardiomyoplasty for idiopathic dilated cardiomyopathy. Am I Cardiol 1993;72:475-9

97. Bocchi EA, Belloti G, Moreira LFP, Gutierrez PS, Stolf NAG, Jatene AD, Pileggi I. Prognostic indicators of one-year outcome after cardiomyoplasty for idiopathic dilated cardiomyopa thy. Am I Cardiol 1994;73:604-8

98. Mesana TG, Bauer S, Caus T, Pomane C, Mouly A, Monties IR. Circulatory assist lechicues after cardiomyoplasty: deteminants for clinical outcome and later consequences. ASAOI 1995;41:M469-M472

99. Rossi MA, Braile DM, Souza DRS, Santos JLV, Thevenard AS, Pinio GH. Suzigan S, Grecco 0. Dynamic cardiomyoplasty in chronic Chagas' theart disease: chinicopathological data. Ann Thorac Surg 1991;51:649-51

100. Mannion JD. Magno MG, Buckman PD. DiMeo F, Greene R, Bowers M, McHugh M, Menduke H. Acute electrical stimulation increases extramyocardial collateral blood flow alter a a candiomyoplasty. Ann Thorac Surg 1993;56:135 l-8

101. Moreira LF. Bocchi EA, Stolf NAG. Pilleggi F, Jatene AD. Current expectations in dynamic cardiomyoplasty. Ann Thotac Surg 1993;55:299-303 
102. Capouya ER, Gerebr RS, Drinkwater DC, Pearl MM, Sack IE, Aharon AS, Barthel SW, Kaczer EM. Chang $P A$, Laks $H$ (1993) Cirdling effect of nonstimulated cardiomyoplasty on left ventricular function. Ann Thorac Surg $56: 867-71$

103. Kaulbach HO, van der Weten FH, schreuder II, Habets JW, Lorusso R, wan der Nagel T, Wellens HIJ (1995) Compensated high output in goats: a new experimental approach to study the mechanisms of accion of dynamic cardiomyoplasty. Europ Heart I $16($ Suppl A):214

104. IJ Schreuder, FH van der Veen, ET van der Welde, G Finet, F Delahaye, O Jegaden, R Lorusso. Hy) Wellens. Left wentrciular pressure/volume relationships pre and post cardiomyoplasty in heart failure patients. Eur I Card Pac Elect 1996,6(Suppl 5):153.

105. Chachques $1 \mathrm{C}$, Grandjean $\mathrm{PA}$, Carpentier A. Latissimus dorsi dynamic cardiomyoplasty. Ann Thorac surg 1989;47:600-4

106. Chachques JC, Grandjean PA, Schwartz K, Mihaileanu S, Fardeau M, Swynghedauw B, Fon-

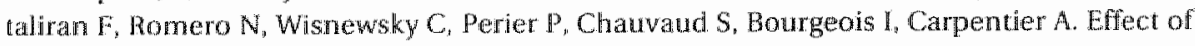
latissimus dorsi dynamic cardiomyoplasty on ventricular function. Circulation 1988;(Suppl III) $78: 11203-111216$

107. Winmberg DS, Ebels $\mathrm{T}$, Robinson PH. Innervated rectus abdomimis myofascial flap for dynamic cardiomyoplasty. Ann Thonac Surg 1994,58:1131-4

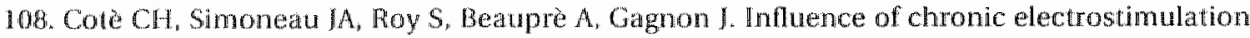
on contractile properties and fibre type composition of the sheep latissimus dorsi muscle. World Symposium on Cardiomyoplasty. Biomechanical Assist and Artificial Heart. Paris 1993 , Proceedings, p 190

109. Anderson WA, Andersen JS, Acker MA, Hammond RL, Chin AJ, Douglas PS, Khallafalla AS, Salmons S, Stephenson LW. Skeletal muscle grafts applied to the heart. A word of caution. Circu-

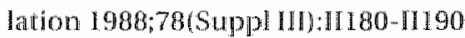

110. Frey $M$, Gruber H. Happak W, Thoma H. Experimental cardiomyoplasty with nerve stimulation. From Carpentien A, Chachques IC, Grandjean PA (eds). Cardionnyoplasty. 1991, Futura Publishing Inc. Mount Kisko, NY, pp 183-1.90

111. Letsou GV, Hogan JF, Lee P, Kum JH, Ariyan S, Dewar ML, Baldwin JC, Elefteriades JA. Comparison of 180 -degree and 360-degree skeletal muscle nerwe cuff electrodes. Ann Thorac Surg 1992;54:925-31

112. AP Fumary, IY Christleb, IA Magovern, RL Kao, Gl Magovern. Nomenclature for latissimus dorsi cardiomyoplasty. Sem Gardio-Thorac Surg $1991: 3: 132-5$

113. A Carpentier, JC Chachques. Cardionyoplasty: surgical technque. In: A Carpentier, JC Chachques, PGrandjean (eds). Cardiomyoplasty. Furura Publishing Inc., Mount Kisko, NY, 1991, pp $105-122$

1.4. Sola OM. Kakulas BA, Dillard DH, wey TD, Thomas $R$, Martin AW. The stretch factor in muscle transformation: gross and cytoarchitectural changes. In, Chui RC-J, Bourgeois I (eds): Trans" formed muscle for cardiac assist and repair. futura Publishing Company, Inc. Mount Kisko, NY. 1990, pp $63-34$

115. MA Rademecker, Sluse PE, Focant B, Reznik M. Foumy J, Limet R. Influence of tension reduction and peripheral dissection on histologic, bochemical and bioenergetic profles, and kineties of skeletal muscle fast-to-slow tansformation. I Card Surg 1991,6 Suppl:195-203

116. DF Gioldspink, I Easion, SK Winterburn, PE Williams, GE Goldspink. The role of passive strerch and repetitive electrical stimulation in preventing skeletal muscle atrophy while reprogramming gene exptession to improve fatigue resistance / Card Surg 1991:66 Suppl):218-24

117. Gealow KK, Solien EL, Bianco RW. Chiu RC-1. Shumway S1. Conformational adaptation of muscle: implications in cardiomyoplasty and skeletal muscle ventricles. Ann Thorac Surg $1993-56: 520-6$

118. El Okley, Jarvis I. Altenative technique for cardiomyoplasty. Ann Thorac Surg 1994;58:279-80. 
119. Magovern JA, Fumary AP, Christlieb R, Kao RL, Magovern GI. Right latissimus dorsi cardio. myoplasty for lefv ventricular failure. Ann Thorac Surg 1992,53:1120-2

120. Magovern JA, Park SE, Cmolik BL. Trumble DR. Christieb IY, Magovern GI Sr. Early effects of right latissimus dorsi cardiomyoplasty on left ventricular function. Circulation 1993;88(Suppl II]:1298-11303.

121. Park SE, Cmolik BL, Lazzara RR, Trumble DR, Magovern IA. Right latissimus dorsi cardiomyo. plasty augments left ventricular systolic perfomance. Ann Thorac Surg 1993:56:1290-5

122. Magovern IA, Magovern GI S., Maher TD, Benckart DH, Park SB, Christieb IX, Magovem GJ Jr. Operation for congestive heart failure: transplantation, coronary artery bypass, and cardiomyoplasty. Ann Thorac Surg 1993;56:418-25

123. Magovern JA, Hunter TJ, Cardone JC, Christleb HY. Long-tem results of right latissimus dorsi cardiomyoplasty. J Card Surg 1996:1 1:264-70

124. Cho PW, Levin HR, Moore CC Tsitlik JE, McVeigh ER, Gardner T, Acker MA. New method for mechanistic studies of cardiomyoplasty: three-dimensional Mfal reconstructions. Ann Thorac Surg 1994:57:1605-11

125. Soberman MS, Wornom IL, Justicz AG, Coleman Jl. Austin GE, Alazraki NP, Sink ID. Latissimus dorsi dymamic cardionyoplasty of the right wentricle. I Thorac Cardiovase Surg $1990 ; 99: 817-27$

126. Milher RWT. Guvendik L, Hynd CH, Pepper JR. Right ventricular dynamic cardionyoplasty: an experimental model. Eur I Cardiothorac Surg 1991;5:311 1-4

127. Guäraudon GM, Morell T, Boughner DR, McLellan DG, Shama AD, Kostuk WI, Guiraudon C. Right ventricular free wall dynamic cardiomyoplasty on a canine chronic right ventricular tailure model: primary report. In, Chui RC-I, Bourgeois I: Transformed musclo for cardiac assist and repair. Futura Publishing Company, Inc, Mount Kisko, NY, 1990, pp 209.218

128. Chachques $\| C$, Grandjean PA, Seuraf A, Latremouille $C$, Jebara VA, ponzio 0 , Mihaincanu $S$, Chauvaud S, Bourgeois I, Carpentier A. Atrial cardiomyoplasty after Fontan-type procedures. Circulation 1990;82(Suppl TV); IV183-IV189

129. Loulmet D, Comtoils $\mathrm{A}_{4}$ Hollmann $\mathrm{C}_{*}$ Beaudet RL Application of cardiomyoplasty to the fon. tan operation: hemodynamic observations. In, Chui RC-1, Bourgeois $\Downarrow$ : Transformed muscle for cardiac assist and repair. Futura Publishing Company, Inc., Mount Kisko, NY, 1990, pp $247-251$

130. Lange P. Sack FU, Saggau W, Cvijanovic C, Nair A, Voss B, Fresquer C, Heinen M, Hagl S. Appli cation of skeletal muscle force to the right arium in at model of atrio-pulmonary connection. Wortd Symposium on Cardiomyoplasty, Biomechancal Assist and Artificial Heart, Pans 1993, Proceedings, $\mathrm{p} 9$

131. Chachques JC, Grandjean PA, Bourgeois IM. Carpentier A. Arial or ventricular assistance using the cardionyoplasty procedure. In: Chiu RC-1, Buorgeois TM, eds. Transformed muscle lor cardiac assist and repair. Mount Kisco, NY: Futura, 1990, pp $161-178$

132. Ninami H, Pochettino $A$. Ruggiero $R$, Koroteyev $A$, Lu H, Hohenhaus E Spanta AD, Hammond RL. Stephenson LW. Ganine latissimus dorsi candio double myoplasty: acule feasibility study. I Card Surg 1991:6:124-31

133. Magovern M, Fumary AP, Christlieb IY, Kao RL, Magowem Gl. Bilateral latissimus dorst cardiomyoplasty. Bnn Thorac Surg 1991;52:1259-65

134. Fumary AP, Magovern $1 A_{*}$ Christheb IY, Trumble DR, Magovern G). Component analysis of bilateral anterior cardionyoplasty. Ann Thorac Sung 1993,55:72-77

135. Soltero ER, Michael LH, Glaeser DH, Hartey CH, Earle NR, Lawrie GM. New configuration of double cardiomyoplasty based on the length-tension properties of the latissimus dors muscle. Thorac Cardiovasc Surg 1993; 106:842-9 
136. Soltero ER, Gleser DH, Michael LH, Hartey CI, Farle NR, LIZ, Lawre GM. Hemodynamic effects of different pacing ratios in chronic dynamic double cardiomyoplasty. Anm Thorac Surg $1996 ; 62: 1390-7$

137. Auler JOC Moreira LlFp de Carvalho MJ! Stolf NAG, do Amaral RVG, Jatene AD. Anesthetic management of patients undergoing cardionyoplasty. Anesthesiology 1992;77:379-81

136. Blanc P. Girard C, Vedrinne C, Mikaelof P, Estanove $\$$. Latissimus dorsi cardiomyoplasty: perioperative management and postoperative ewolution. Chest 1993; 103:214-20

139. Bensesson $D_{\text {. Kieffer }}$ P. Preoperative management and anesthesia. In, Carpentier $\mathrm{A}$. Chach-

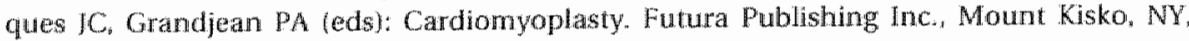
1991, pp 99-103.

\$40. Corin WJ, George DT, Sink JD, Santamore WP. Dynamic cardiomyoplasty acutely impairs left ventricular diastolic function. I Thorac Cardiovase Surg 1992;104:1662 "71

14 1 . Bolotin $G$, van der Veen FH, Schreuder Jj, Lorusso R, Kaulbach $H_{*}$ Uetzsky $G$. Acute remporary decrease of end-diastolic wolume and cardiac output following cardiomyoplasty. Isr \ Med Scilence $1996: 32: 911$

142. Lazzara RR, Park SE, Cmolik BL, Trumble DR, Magovern IA. Static left latissimus dorsi cardiomyoplasty: effect on left wetricular function. J Heart Lung Transplant 1993;12:1024-80

143. Polidon DJ, Lankford EB, Plappert T. Ferrari VA, St John Sutton M, Kass DA, Acker MA. Acute systolic and diastolic indices of lefe ventricular function after cardiomyoplasty in a chronic model of heart failure. ASA1O I 1995:41:M484-M489

144. Barbier P, Gerometa PS, Tamborini G, Biglioli P, Sisillo E, Guazzi MD. Acute effects of dynamic cardiomyoplasty on ventricular geometry and left ventricular filling detected by transe sophageal doppler echocardiography. Am / Cardiol 1996;77:783-7

145. Katircioglu SF, Kucukaksu DS, Vural K Tsademir O, Bayazit K. Effects of dynamic cardiomyoplasty on right ventricular function. I Card Surg 1995:10:580-2

1.46. Mannion JD, Velchik M, Hammond RL, Alavi A, Mackler T, Duckert $S$, Staum M, Hurwitz $S$, Brown W, Stephenson LW. Effects of collaterall blood vessel ligation and electrical conditioning on blood flow in dog latissimus dorsi muscle. I Surg Res 1989;47:332-40

147. Mannion JD, Acker MA. Hammond RL.., Alava A, Stephenson LW. Transmural blood flow of multilayered latissimus dorsi pouches during circulatory assistance. Trans Am Soc Artif Intern Organs $1986^{-15} 15: 14$

148. Palmer AS, Spies SM. Miller Al. Greene R, Balino A. Nuclear scanning with technetium-99mSestamibi to evaluate ischemia in muscle haps for cardiomyoplasty. ASAO I 1995:41:M508M511

149. Magovern GI, Park SH, Magoven Gl]r, Benckart DH, Tullis G, Rozar E, Kao R, Christlieb I Latissimus dorsi as a functioning synchonously paced muscle component in the repair of a lot ventricular aneurysm. (letter) Ann Thorac Surg 1986;41:116

150. Chekinov VS. Thekanov GV, Rieder MA, Smith LM, Jacobs GB "McConchie S, Christensen CW, Schmidt DH. Is it possible to perform immediate cardiac assist using untrained latissimus donsi muscle in a work-rest regimen?. ASAIO / 1995,41:M489-M494

151. Chagas ACP, Moreira LFP, da Luz PL, Camarano GP, Leimer A, Stolf NAG, Jatene AD. Stimulated preconditioned skeletal muscle cardiomyoplasty: an effective means of cardiac assist. Circulation 1989;80(Suppl IIT):111202-111208

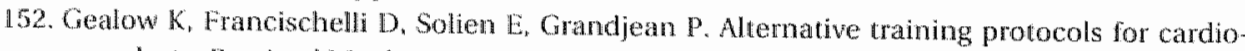
myoplasty. Bas Appl Myol 1997;7:31-8

153. Lucas CMHB, van der Veen FH, Cheriex EC, wan Ommen V, Penn OCKM, Wellens HII. The importance of muscle relaxation in dynamic cardiomyoplasty. PACE 1993:114:230-42

154. Pekarsky VV, Akhmedov SD, Dubrovsky 1A, Baturin AV, Krivoschekov EV, Rizhikh AN, Pekarskay MV. Optimal electrical stimulation for latissimus dorsi muscle after candiompoplasty. I Card Surg 1993:8:172-6 
155. Gealow KK, Solien EE, Bianco RW, Shumway SI. Importance of adaptive stimulation of the latissimus dorsi muscle in cardiomyoplasty. ASAIO 1994:40:M253-M259.

156. wan Doom CAM, Bhabra MS, Hopkinson DN, Barman D, Cranley J, Hooper TL Luassimus dorsi muscle blood flow during synchronized contraction: implications for cardionyoplasty. Ann thorac Surg 1996; $61: 603-9$

157. Kall-Filho R, Bocchi E, Weiss RG, Rosemberg L, Bacal F, Moreira LFP, Stolf NAG, Magallats AAC, Bellotti $G$, Jatene $A$, Pileggi $F$. Magnetic resonance imaging evaluation of chronic changes in latissimus dorsi cardiomyoplasty. Circulation 1994:90:Suppl II):I1102-11106

158. Chekanov $\mathrm{V}$. After cardiomyoplasty there is no need to stimulate the muscle with every heart contraction. (letter) Amn Thorac Surg 1993;56:424-5

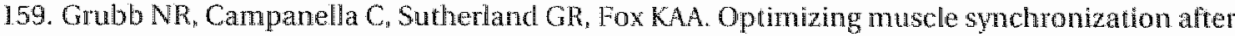
dymamic cardiomyoplasty: two educational cases. Eur J Cardio-Thorac Surg 1995:9:45-9

160. Helou J, Misawa Y. Stewart JA, Colson M, Chilu RC-1. Optimizing "delay period" for burst stimulation in dynamic cardionyoplasty. Ann Thorac Surg 1995;59:74.7

161. Amada $H$, Molteni L, Ferreira $R$, Ortega D, Cianciulli 1 , Llanos $\$$, Prezioso H. The value of the echo-doppler in cardiomyoplasty procedures. I Card Surg 1991;6(Suppl): $113-8$

162. Molteni $L$, Almada HE, Ferreira RF, Ortega D. Assessment of the optimal time interval between QRS and single-pulse stimulation in dynamic cardiomyoplasty. In Chiu RC-1, Bourgeois I (eds): Transformed muscle for cardiac assist or repair. Futura Publishing Company, Inc., Mount Kisko, NY, 1990, pp 189-196

163. Levin HR, Tsitik JE, Halperin HR. Optimization of the timing of skeletal to cardiac muscle contraction during dynamic cardiomyoplasty: analysis using a mathematical model. I Card Surg 1991;6(Suppl):236-44

164. Geddes LA, Janas W, Bourland JD, Cook J. Hinds M. The importance of timing muscle contraction in dymamic cardiomyoplasty. PACE 1993:5:2255-65

165. Schreuder JJ, van der Veen FH, van der Velde ET, Delahaye F, Affieri O Jegaden O, Lorusso R, Jansen IRC, van Ommen V. Finet G, Wellens HJl (1995) Beat-to-beat analysis of left ventricular pressure-volume relation and stroke volume by concluctance catheter and aortic modellow in cardiomyoplasty patients . Circulation 91:2010-2017

166. Lucas CMHB, van der Veen FH, Grandjean PA, Penn OCKM, Wellens HJ. What is the ideal pulse frequency for skeletal muscle stimulation after cardiomyoplasty?. PACE 1991;14:778-82

167. Chen FY, deGuzman BI, Aklog L, Laulz DB, Amhad RM, Laurence RG, Couper GS, Cohn LH, McMahon TA. Decreased myocardial oxygen consumption indices in dynamic cardiomyoplasty. Circulation 1996:94(Suppl II:11239-11244

168. Iannuzzo CD, fannuzzo SE, Anderson WA. Cardionyoplasty: translomation ol the assisting muscle using intermittent versus continuous stimulation. / Caird Surg 1996;1:1293-303

169. Arpesella $G$. Mikus PM, Giannoni A, Lombardi P. Pierangeli A, Zampieri S, Camaro U. Daily activity-rest regimen of latissimus dorsi stimulation for cardiomyoplasty. Bas Appl Myol $1997 ; 7: 45-54$

170. Hagege AA, Desmos M. Baragan I, Guerot C. Chachques JC, Carpentier A. Long-term efficacy of dynamic cardiomyoplasty: climical, ultrasonic and hemodynamic evidence in one case. Eur Heart J 1990; 11:662-5

171. Chachques JC. Acar C, Portoghese M, Bensasson D, Guilbourt P, Grare Ph, Jubara WA, Grandjean PA, Carpentier A. Dynamic cardiomyoplasty at long-term. Eur f Cardio-thorac Surg $1992 ; 6: 642-8$

172. Chachques JC, Acar $C_{4}$ Tapia $M$, Guibown P, Fiemeyer A, Bensasson D, Berrebi A, Grare P. Bechara M, Baron JF, Carpentier A. Resultats à moyen tern de la cardiomyoplasitie. Arch Mal Coeur 1994:87:49-56 
173. Chachques $I C$, Carteaux IP, Berebi $A$, Marino IP. Fabian IN, Carpentier A. Dymamic cardiomyoplasty: clinical follow-up at elewen years. Procedings of the 10th Annual Meeting of the European 14 ssociation for Cardio -Thoracic Surgery. Prague, 1996, Proceedings, p 76

174. Magonern G], Hecker FR, Park SB, Christieb IY, Magovern GJ Ir, Kao RL, Benckart DH, Tullis

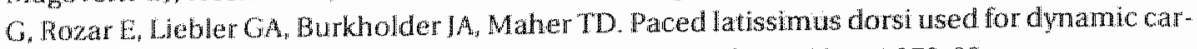
diomyoplasty of left wentricular aneurysms, Ann Thorac Surg 1987:44:379-88

175. Magovern G), Heckler ER, Park SB, Christieb IY, Liebler GA, Burkholder JA, Maher TD. Benckart DH. Magovern GI $\mathrm{r}$, Kao RL. Paced skeletal muscle for dynamic cardiomyoplasty. Ann Thorac Surg 1988:45:614-9

176. Magovern G) Sr. Paced skeletal muscle for dynamic cardiomyoplasty (updated). Ann Thorac Surg 1995;60:11:153 4

177. Jegaden O. Delahaye F, Montagna P, Vedrinne C, Blanc P, Rossi R, Tabib A, Saint-Pierre A, Delathaye JP, Mikadoff PH. Cardiomyoplasty does not preclude heart transplantation. Ann Thorac Surg 1992;53:875-80

178. Lange R, Sack FU, Voss B, De Simone R, Thielmann M, Nair A, Brachmann J, Haussmann $R$, Heischer $\mathrm{F}$. Hagl $\mathrm{S}$. Treatment of dillated cardiomyopathy with dynamic cardiomyoplasty: the Heidelberg experience. Ann Thorac Surg 1995;60:1219-25

179. Moreira LFP, Seferian P Ja, Bocchi EA, Pego-Fernandes PM, Stolf NAG, Pereira-Barretto AC, Jatene AD. Survival improvement with dynamic cardiomyoplasty in patients with dilated cardiomyopathy. Circulation 1991;84 (Suppl III):III296-111302

180. Moreira LFP, Stolf NAG, Bocchi EA, Bacal F. Pego-Fernandes PM, Abensur H, Meneghett IC, Jatene $\mathrm{AD}$. Clinical and left ventricular function outcomes up to five years after dynamic cardiomyoplasty. I Thorac Cardiovase Surg 1995:109,353-63

181. Moreira LFP, Bocchi EA, Stolf NAG, Bellotti G, Jatene AD. Dynamic cardiomyoplasty in the treatment of diated cardiomyopady: current results and perspectives. J Card Surg $1996: 11: 207-16$.

182. Jatene AD, Moreira LFP. Stolf NAG, Bocchi EA, Seferian P Jr, Fernandes PMP, Abensur H. Left ventricular function changes after cardiomyoplasty in patients with dilated cardiomyopathy. I Thorac Candiovasc Surg 1991;102:132-9

183. Bocchi EA, Moreira LFP, Bellotti $G_{1}$ Barreto ACP, Azull LGS, Stolf NAG, Jatene AD, Pileggi F. Hemodynamic study during upright isotonic exercise before and six months after dynamic cardiomyoplasty for idiopathic dilated cardiomyopathy or Chagas" disease. Am I Cardiol $1991 ; 67: 213-4$

184. Bocchi EA, Moreina LFP, de Moraes AV, Belloti G, Gama M, Stoll NAG, Jatene AD. Pileggi F. Effects of dymamic cardiomyoplasty on regional wall motion, ejection fraction, and geometry of left ventricle. Circulation 1992:86(Stippl II):-1/231-11235

185. Belloti $G$. Moraes A Bocchi E. Arie S. Medeiros C. Moreira LFP, Jatene AD. Pileggi F. Late effects of cardiomyoplasty on left ventricular mechanics and diastolic filling. Circulation 1993:86(Suppl II]:11304-11308

186. Hochi EA, Veiga Guimarnes G, Moreira LFP, Bacal F, Villela de Moraes A, Barreto ACP, Wajn-

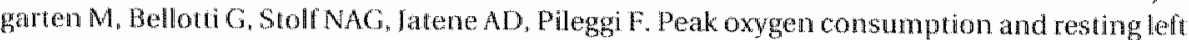
ventricular ejection fraction changes after cardionyoplasty at 6month follow-up. Circulation 1995,92(Suppl II):11216-11222

187. Borgheti-Maio SA, Romano BW, Bocchi EA, Moreira LFP, Barreto ACP, Stolf NAG, Belloti GV, Pileggi fatene AD. Quallity of life after cardiomyoplasty. I Heart Lung Transplant $1994: 13271-5$

198. Fumary AP. Jessup M. Moreira LFP. Multicenter trial of dynamic cardiomyoplasity for chronic heart tailure. I Am Coll Cardiol $1996 ; 28 ; 1175-80$ 
189. Dumcius AS, Sirvinskas EK, Skucas ], Salcius KM, Krakowsky A. Giedraitis S1, Chekanov VS. A method of extended myoventriculoplasty with programmable cardiosynchronized elec. troneurostimulation: description and initial clinical results. Cor Vasa 1989;31:394-401

190. Molteni L, Almada H, Ferretra R. Synchronously stimulated skeletal muscle graft for left wentricular assistance. ) Thorac Cardiovasc Surg 1989;97:439-46

191. Molteni L, Almada HE, de Palma C, Ferreira RF. Dynamic cardiomyoplasty: clinical experience. In, Chui RC-J, Bourgeois I. Transformed muscle for cardiac assist and repair. Futura Publishing Inc., Mount Kisko, NY, 1990, pp 197-198

192. Chekanov V. Dynamic cardiomyoplasty at 5 1/2 years: Russian clinical experience. (letter ] Thorac Cardiovasc Surg 1995; 109:189-90

193. Tasdemir O, Vura KM, Kucukaksu SD, Tarcan OK, Ozdemir M, Kutuk E, Bayazit K. Comparative study on cardiomyoplasty patients with the cardiomyostimulator on versus off. Ann "Thorac $\$$ urg 1996;62:1708-13

194. Robinson RIS, Cecere R, Chiu RC-J. Binocular blindness following dynamic cardiomyoplasty. J Card Surg 1996;11:75-8

195. Gupta S, Prevel CD, Shaheen K, Wilkens E, Smith DI, Kirsh MM, Boling SF, Rees RS. Wound complications and treatment of the infected implantable cardioverter defibrillator generator. J Card Surg 1993;8:671 $* 7$

196. Rao $G$, Ford WB, Zikria EA, et al: Incidence and prevention of infection in patients witly permanent cardiac pacemakers. Int Surg 1974;59:599m-605

197. Hurst LN, Evans HB, Windle B, et al: The salvage of the infected cardiac pacemaken pocket using a closed irrigation system. PACE 1986;9:785-792

198. Vogt PR, Sagdic K, Lachat $M_{*}$ Candinas $R$, von Segesser LK, Turina MI. Surgical management of infected permanent transvenous pacemaker systems: ten year experience. I Card Surg 1996;11:180-6.

199. Peteiro I, Struble C, Vazquez N, Castro-Beiras A. Spontaneous reversal of a cardiomyostimulator to asynchronous mode. PACE 1996;19:367-9

200. Radermecker MA, Waleffe A, Gobin E, Grandjean P, Fourny I, Kulbertus H, Limet R. Rlhyhmic and electrophysiological study after dynamic cardiomyoplasty. PACE 1995; 18:965-72

201. Bocch EA, Moreira LFP, de Moraes AV, Bacal F, Sosa E, Stolf NAG, Bellotti G, Jatene AD, Plleggi F. Arrhythmia and sudden death after dynamic cardiomyoplasty. Circulation 1994:90[Suppl II):11107-11111

202. Francischelli D, Peterson D, Stein PM, Gealow K, Struble C, Grandjean P. Combined cardiomyoplasty and antitachyarnythmia systems. PACE 1995;18:800.

203. Guiraudon GM, Chow L., Lefebvre C, Yee R, Klein GI, Kostuk WJ, Dobkowsky V. Combined latissimus dorsi cardiomyoplasty and jewel PCD implantation. A leasibility non-thoracotomy study in two patients. Eur I Card Pac Elect 1996;6(Suppl 5):151

204. Doval HC, Nul DR, Grancelli HO, Varin SD, Soifer S, Corrado G, Dubner S, Scapin O, Perrone SV. Nonsustained ventricular tachycardia in severe heart failure: independent maver of increased mortality due to sudden death. Circulation 1996;94:3198-203

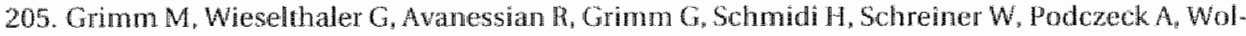
ner $\mathrm{E}$, Laufer $\mathrm{G}$. The impact of implantable cardioverter-defibrillators on mortality among pa* tients on the waiting list for hearu transplantation. I Thorac Cardiovasc Surg 1995:1 10:532-9.

206. Saxon LA, Wiener I, DeLurgio DB, Natterson PD, Laks H, Drinkwater DC, Stevenson WG. Im* pllantable defibrillators for high-risk patients with heart failure who are awaiting cardiac transplantation. Am Heart \1995:130:501-6.

207. DEFIBRLAT Study Group. Actuarial risk of sudden death while awaitimg cardiac transplantation in patients with atherosclerotic heart disease. Am J Cardiol 1991;68:545-6.

208. Soltero ER, Glaeser DH, Michael LH, Hartley CJ, Earle NR, Lawrie GM. Acute impaiment of coronary blood flow by dynamic cardiomyoplasty. Ann Thorac Surg 1994:58:121 -7 
209. Tsukube $T$, Okada M, Mukai T, Kashem MA, Ota T. Effect of dynamic cardiomyoplasty on phasic coronary arterial flow velocity in canine hearts. J Thorac Cardiovasc Surg 1994:108:609-15

210. Kawaguchi $O$, Goto $Y$, Futaki $S$, Ohgoshi Y. Yaku $H$, Suga $H$. The effects of dynamic cardiac compression on ventricular mechanics and energetics. I Thorac Cardiovasc Surg $1994 ; 107: 850-9$

211. Sullivan MJ, Green H1, Cobb FR. Skeletal muscle biochemistry and histology in ambulatory patients with long-term heart fallure. Circulation 1989;81:51:8-27

212. Drester $H$, Riede U, Munzel $T$, Konig $H$, Funke $E_{y}$ Just H. Alterations of skeletal muscle in chronic heart fallure. Circulation 1992;85:1751-9

213. Lampert $\mathrm{E}$, Mettauer $B$, Hoppeler $\mathrm{H}$, Charloux A, Charpentier A, Lonsdarfer J. Structure of skeletal muscle in heart transplant recipients. I Am Coll Cardiol 1996;28:980-4

214. Sullivan MJ, Knight D, Higginbotham MB, Cobb FR. Relation between central and peripheral hemodynamics during exercise in patien ts with chronic heart fallure: muscle blood flow is reduced with maintainance of arterial perfusion pressure. Circulation 1989;80:769-81

215. Braith RW, Limacher MC, Legget SH, Pollock ML. Sleletal muscle strength in heart transplant recipients. J Heart Lung Transplant 1993;12:1018-23

216. Volterrani $M$, Clark AL, Ludman PF, Swan JW, Adamopoulos S, Piepoli M, Cotas AJS. Predictors of exercise capacity in chronic heart failure. Eur Heart I 1994;15:801-9

217. Lucas CMHB, van der Veen FH, Cheriex EC, Lorusso R, Havenith $M$, Penn OCKM, Wellens HyJ. Long-term follow-up 12 to 35 weeks) after dynamic cardionyoplasty. I An Coll Cardiol. $1993: 22: 758-67$

218. Kratz IM, Johnson WS. Mukherjee R, Hu J, Crawford FA, Spinale FG. The relation between latissimus dorsi skeletal muscle structure and contractile function after cardiomyoplasty. I Thorac Cardiovasc Surg 1994:107:868-78

219. Odim JNK, Burgess JH, Williams BH, Blundell PE, Rabinovitch MA, Stewart JA, Lough JO, Chiu RC-J. Pathophysiology of dynamic cardiomyoplasty: a clinico-pathological case study. I Cand Surg 1990;4:336-46

220. U Carraro, JC Chachques, M Desnos, A Hagege, F Fontarilan, A Carpentier. Eight-year human dynamic cardiomyoplasty: preserved structure of myofibres and vessels of the latissimus dorsi. Bas Appl Myol 1996;6:333-6

221. Lexell J, Jarvis JC, Downham DY, Salmons. Stimulation-induced muscle damage Bas Appl Myol 1994:4:59-66

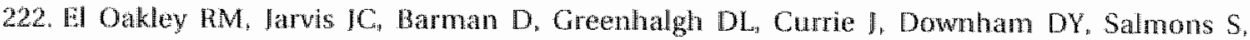
Hooper $\mathrm{T} L$. Factors thecting the integrity of larissimus dorsi muscle grafts: implications for cardiac asstatace from skeletal muscle. I Heart Lung Transplant 1995; 14:359-65

223. Lannuzzo CD, Jannuzzo SE, Carson N, Feild M, Locke M, Gu J. Anderson WA Ktabunde RE. Cardionyoplasty: degeneration of the assisting skeletal muscle. I Appl Physiol 1996;80:120513

224. Anderson WA, lannuzzo CD. Klabunde RE. Cardiomyoplasty: studies on goat latissimus dorsi blood flow and muscle damage following surgical dissection and chronic electrical stimula. tion. I Card Surg 1996;11:237-46

225. Fritzsche D, Krakor R, Asmussen G, Widera R. Caffier P, Berkei J, Cesla M. Anabolic steroids (metenolone) improve muscle performance and hernodynamic characteristics in cardiomyo plasty. Ann Thorac Surg 1995;59:961-70

226. Chekanov V. Anabolic hormones in cardiomyoplasty. (letter) Ann Thorac Surg 1995;60:1461-2 227. VS Chekanow, GV Tchekanov, MA Rieder, EL Silverstein, Q Cheng, LM Smith, GL Zander, GB lacobs, S McConchie, CW Christensen, DH Schmidt. Force enhancement of skeletal muscle used for dynamic cardiomyoplasty and as a skeletal muscle ventricle. ASAIO J 1995;41:M499M507 
228. Mannion JD, Blood V. Bailey W, Bauer TL, Magno MG. DiMeo F, Epple A, Spinale FG. The ef fect of basic fibroblast growth factor on the blood flow and morphologic features of a latissimus dorsi cardiomyoplasty. I Thorac Cardiovasc Sutg 1996;11:19-28

229. Bailey WF, Magno $\mathrm{MG}_{\|}$Bater TL, Mannion JD. Heparin and basic fibroblast growth factor are associated with preservation of latissimus cardiomyoplasties in goats: a retrospective study I Card Surg $1996 \% 11: 247 \cdot 55$

230. Petrou $M$ "Wynne DG, Boheler KR, Yacoub MH. Clenbuterol induces hypertrophy of the latissimus dorsi muscle and heart in the rat with molecular and phenotypic changes. Circulation 1.995:92(Suppl II):483-89

231. Hohenhaus E, Pocchettino A, Hammond RL, et al. The effect of treatment with anabolic steroid (nandrolone decanonate) on physiological and morphological characteristics of unconditioned and conditioned canine latissimus dorsi muscle. Bas Appl Myol 1992:2:1 15-25

232. Iannuzzo CD, lannuzzo $\$ \mathrm{E}$, Feild M, Locke M. Cardiomyoplasty: preserwation of the latissimus dorsi muscle. J Card Surg 1995;10:104-10

233. Chachques IC, Tapia M, Radermercker $M$, Pellerin M, Fuzeller JF, Tolan MJ, Renard X, Mitz V, Carpentier AF. Association of latissimus dorsi muscle expansion with electrostimulation be. fore cardiomyoplasty. Ann thorac Surg 1996;61:138 42

234. F Delahaye, O Jegaden, $P$ Montagna, P Desseigne, P Blanc, $C$ vedrinne, $P$ Touboul, $A$ SaintPierre, M Perinetii, R Rossi, R Iti, P Mikaelof. Latissimus dorsi cardiomyoplasty hn severe congestive heart failure: the Lyon experience / Card Surg 1991;6(Suppl):106-12

235. El Oakley RME, Jarvis IC. Candiomyoplasty. A critical leview of experimental and clinical results. Circulation $1994 ; 90 ; 2085-90$

236. Silverman NA. Clinical and left ventricular function outcome up to five years after dynamic cardiomyoplasty. (letter) J Thorac Cardiovasc Surg 1995;109:397*403

237. Lee FK, Dignan R, Parmar JM, Dyke CM, Benton G, Yeh TIr. Abd-Elfattah AS, Wechsler AS. EF. fects of dynamic cardiomyoplasty on left ventricular performance and myocardial mechanics in dilated cardiomyopathy. I Thorac Cardiovasc Surg 1991;102:124-31

238. Kawaguchi $O$, Goto $Y$, Futaki S, Ohgoshi Y, Yaku $H$, Suga H. Mechanical enhancement and myocardial oxygen saving by synchonized dynamic left ventricular compression. I Thorac Cardiovase Surg 1992;103:573-81.

239. Chen FY, Aklog L, deGuzman BJ, Laurence RG, Couper GS, Appleyard RF, Cohn LH, McMahon TA. New technique measures decreased transmual myocardial pressure in cardiomyoplasty. Ann Thorac Surg 1995;60:1678-82

240. Cho PW, Levin HR, Curtis WE, Tsilik JE, DiNatale JM. Kass DA Gardner TJ "Kunel RW, Acker MA. Pressure-volume analysis of changes in cardiac function in chronic cardiomyoplasty. Ann Thorac Surg 1993;56:38-4:5

241. Nakajima H, Ninami H. Hooper TL, Hammond RL, Nakajima HO, Lu H, Ruggieno, Rhomas

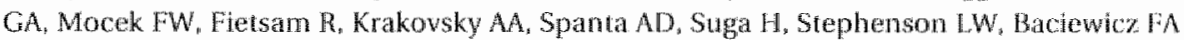
(1994) Cardiomyoplasty probable mechanism of effectiveness using pressure/ wolume relationship. Ann Thorac Surg 57:407-15

242. Suga $\mathrm{H}$, Sagawa $\mathrm{K}$. Instantaneous pressure-volume relationship and their ratio in the excised, supported canine left ventricle. Circ Res 1974;35:117-26

243. Baan J, van der Velde ET, de Bruin HG, Smeenk Gl, Koops J, van Dijk AD, et al. Continuous measurement of left ventricular volume in amimals and humans by conductance catheter. Circulation 1984:70:812-23

244. Jondeau G, Dorent R, Bors V, Dib \C, Dubourg O, Benzidia R, Grandjbakluch $\rrbracket$, Bourdarias IP. J Am Coll Cardiol 1.995:26:129-34

245. Hagege AA, Desnos M, Fernander. F, Besse B, Mirochnik N, Castaldo M, Chachques JC, Carpentien $A$, Guerot $C$. Clinical study of the effects of latissimus dorsi muscle finp stimulation after cardionyoplasty. Circulation 1995;92/Suppl 11)11210-11215 
246. Kass DA, Baughman KL, Pak PH, Cho PW, Levin HR, Gardner TJ. Halperin HR, Tsidik JE, Acker M. (1995) Reverse remodeling from cardiomyoplasty in human heart failure. Cinculation 91.2314 .8

247. Chekanov $V$. Nonstimulated cardiomyoplasty wrap attemuated the degree of left ventricular enlargement (letter). Ann Thorac Surg 1993;56:870 1 


\section{CHAPTER}

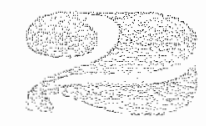

\section{Early latissimus dorsi stimulation after cardiomyoplasty procedure: a preliminary study}

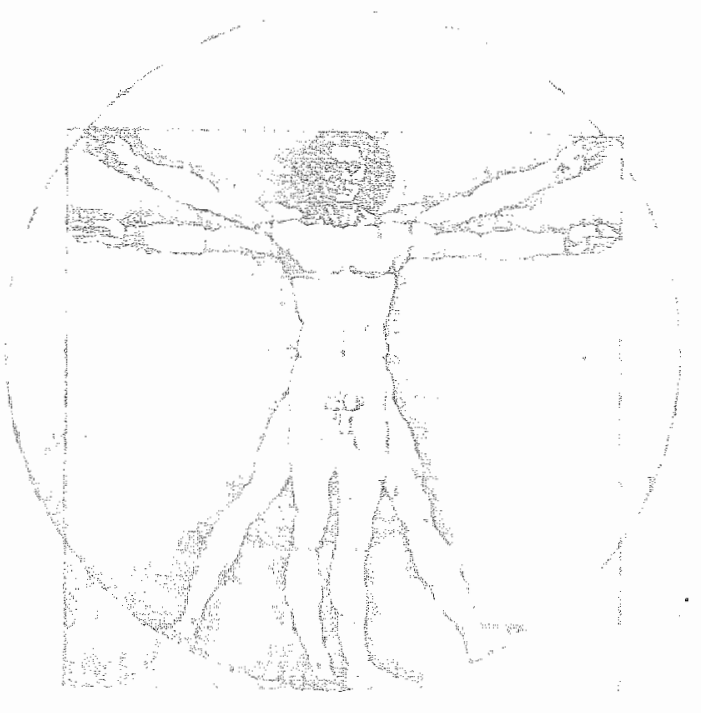

Roberto Lorusso, Caroline Lucas, Frederik van der Veen, Jo Habets, Theo van der Nagel, Michael Havenith, Hein JJ Wellens, OlafC Penn. 


\section{Abstract}

Objectives. Worldwide clinical cardiomyoplasty entails the first 2 weeks after surgery with no wrapped muscle stimulation to allow regeneration of severed distal vessels, and allow intermuscular fixation. Nonetheless, the effects of early Latissimus Dorsi (LD) muscle activation and conditioning following cardiomyoplasty surgery have not been clearly elucidated. This study was designed to observe the histologic changes induced by prudent stimulation protocol started early after surgery.

Methods. A counterclockwise wrapping procedure was performed in eight goats, and LD postoperative electrical training was started one day later (cardiomyostimulator model SP 1005 , Medtronic Inc., Minn).

Stimulation parameters included pacing frequency of 10 pulses/ $/ \mathrm{sec}$, pulse amplitude of $5 \mathrm{Vs}$, and LD/heart contraction ration of $1: 2$. In order to create temporarely proper intermuscular fixation, a fibrin glue (Tissucol, Immuno $A G$, Austria) was applied. LD contribution to cardiac function was assessed two weeks later. Histologic studies were performed on the wrapped muscles to evaluate any sign of muscle damage. Before sacrifice traditional hemodynamic parameters (left ventricular pressure-LVP-, right ventricular pressure-RVP-, aortic systolic pressure-AoP-, and left ventricular $\mathrm{dp} / \mathrm{dt}$ ) were measured to investigate cardiocirculatory support comparing assisted and unassisted beats at conditioning pacing frequency $(10 \mathrm{~Hz})$ and at more forceful LD activation (30 $\mathrm{Hz}$.

Results. On macroscopic evaluation no sign of wrapped muscle damage or displacement was observed. Histologic studies confirmed the absence of muscular degenerative changes. Partial transformation of type II into type I fibres was already present. Hemodynamic measurements, after two weeks, revealed significant ( $p=0.014$ ) LD contribution to cardiac performance (RVP increased from $26 \pm 6$ to $30 \pm 8 \mathrm{mmHg}$ during assisted beats) at pacing frequency of $10 \mathrm{~Hz}$, whereas signilicant increases of $L V d p / d t$, RVP, and AoP were recorded at $30 \mathrm{~Hz}$.

Conclusions. This study clearly shows early postoperative LD conditioning feasibility. For transposed muscle fatigue and ischemia to be prevented, initial pacing parameters and proper $\mathrm{LD} /$ heart contraction ratio may be determinant factors. Fibrin sealant appears to be a valuable surgical tool to enhance intraoperative adhesion formation in order to avoid muscle displacement. 


\section{Introduction}

Because of limited heart transplantation application due to donor shortage, transformed skeletal muscles have been proposed as altemative power source for permanent cardiac support. The use of such biomechanical pumps proved to provide efficient contribution to global ventricular function either experimentally or clinically (1-8). Since the first report of a patient submitted to Latissimus Dorsi (LD) muscle transplant onto the heart in 1985, several investigators subsequently described successful operative as well as long-term results (9-18). Current cardiomyoplasty (CM) technique implies LD recovery period after sur gery. This span has been considered necessary in order to prevent muscle ischemia due to collateral vessel ligation of the distal area of the mobilized $\mathrm{LD}$, and to obtain proper $\mathrm{LD} /$ heart contact through optimal adhesion formation $(3,19,20,21)$. Skeletal muscle atrophy due to immobilization ("disuse atrophy") has been reported $(24,25)$. Furthermore, postoperative hemodynamic deterioration has been described during muscle flap recovery period after cardiomyoplasty $(6,11,15)$. An early activation of $\mathrm{LD}$ might result in beneficial effects either in relation to muscle structural response or to slight hemodynamic support. This study presents preliminary findings regarding the histological changes at short term occurred when early wrapped muscle pacing has been performed after cardiomyoplasty procedure. Also, hemodynamic effects have been investigated to examine mechanical performance of stimulated muscle.

\section{Material and Methods}

Eight adult female goats with a weight range of $40-60 \mathrm{~kg}$ were submitted to the study and cared in conformity to the principles for research use of experimental animals of the American Society of Physiology.

The left LD was exposed through a left lateral thoracic incision. After proper muscle dissection, the proximal portion was carefully examined and the pedicle structures identified. Two intramuscular electrodes (Medtronic model SP 5528, Medtronic Inc, Minn.) where then implanted, with the proximal lead woven at the branching level of the thoracodorsal nerve, and the second lead placed $6-8 \mathrm{~cm}$ distally. Any neural or vascular damage was avoided. Electrode impedance as well as contraction thresholds were measured with a proper device (Medtronic model 3028, Medtronic Inc.). The skeletal muscle transposition into the left thoracic cavity was performed through a window obtained by a partial resection of the second rib. The humeral insertion of the muscle was divided and sutured to the periosteum of the third rib. The pericardial sac was visualized through a left anterolateral thoracotomy at the fifth intercostal space and longitudinally incised to allow optimal cardiac exposure. 
The LD wrapping procedure was performed according to the counterclockwise technique. Before completing the ventricular reinforcement, a fibrin sealant (Tissucol, Immuno AG, Austria) was applied at the intermuscular level (anteriorly and posteriorly) using a spay device (Duploject-Tissomat, Immuno AG, Austria).

A sensing electrode was implanted on the right wentricle and the related threshold assessed by the Medtronic analyser. The cardiomyostimulator was then connected to the leads, and finally positioned in a properly fashioned pocket.

In all animals LD electrical conditioning was started one day after surgery. The stimulation parameters included pacing frequency of $10 \mathrm{pulses} / \mathrm{sec}$, pulse amplitude of 5 Volts, and LD/heart contraction ratio of $2: 1$ or $3: 1$ according to the animal heart rate. After stimulation programming, LD contraction was assessed by ECG recording (Pulse observation) as well as by axilla palpation. During the following two weeks, stimulated muscle flap function was periodically evaluated by palpation to verify muscle contraction.

After fourteen days, accurate muscle dissection was performed to precisely evaluate LD condition after early training submission, and to carefully examine the extent of adhesion degree at the intermuscular level. Fibre typing was also performed in right and left LD muscles to elucidate whether muscle transformation process was ongoing. Attention was paid, moreover, to search for any sign of occurring intramuscular degenerative or inflammatory reactions.

Hemodynamic LD contribution to cardiac performance was assessed at 10 pulses/sec pacing frequency before sacrifice. In order to further stress muscle flap contractile force or to assess muscle contribution to cardiac performance at the clinical settings, stimulation was also performed at 30 pulses/sec for 30 seconds to prevent possible muscle fatigue occurring at unconditioned area. Hemodynamic data were obtained using catheters placed in the right and left ventricles (Millar Instruments, Houston, Texas) positioned through the right jugular vein and right carotid artery, respectively, measuring also left ventricular dP/dt. Aortic blood pressure was recorded through a femoral arterial line.

All hemodynamic data were subjected to statistical analysis with paired ttest. A p value of 0.05 or less was considered significant. The data are given as mean $\pm S D$.

\section{Results}

Eight goats entered into the study. Ventricular fibrillation refractory to any resuscitation manouver occurred in one animal during left ventricular catheter insertion (tip induced arrhythmia). 

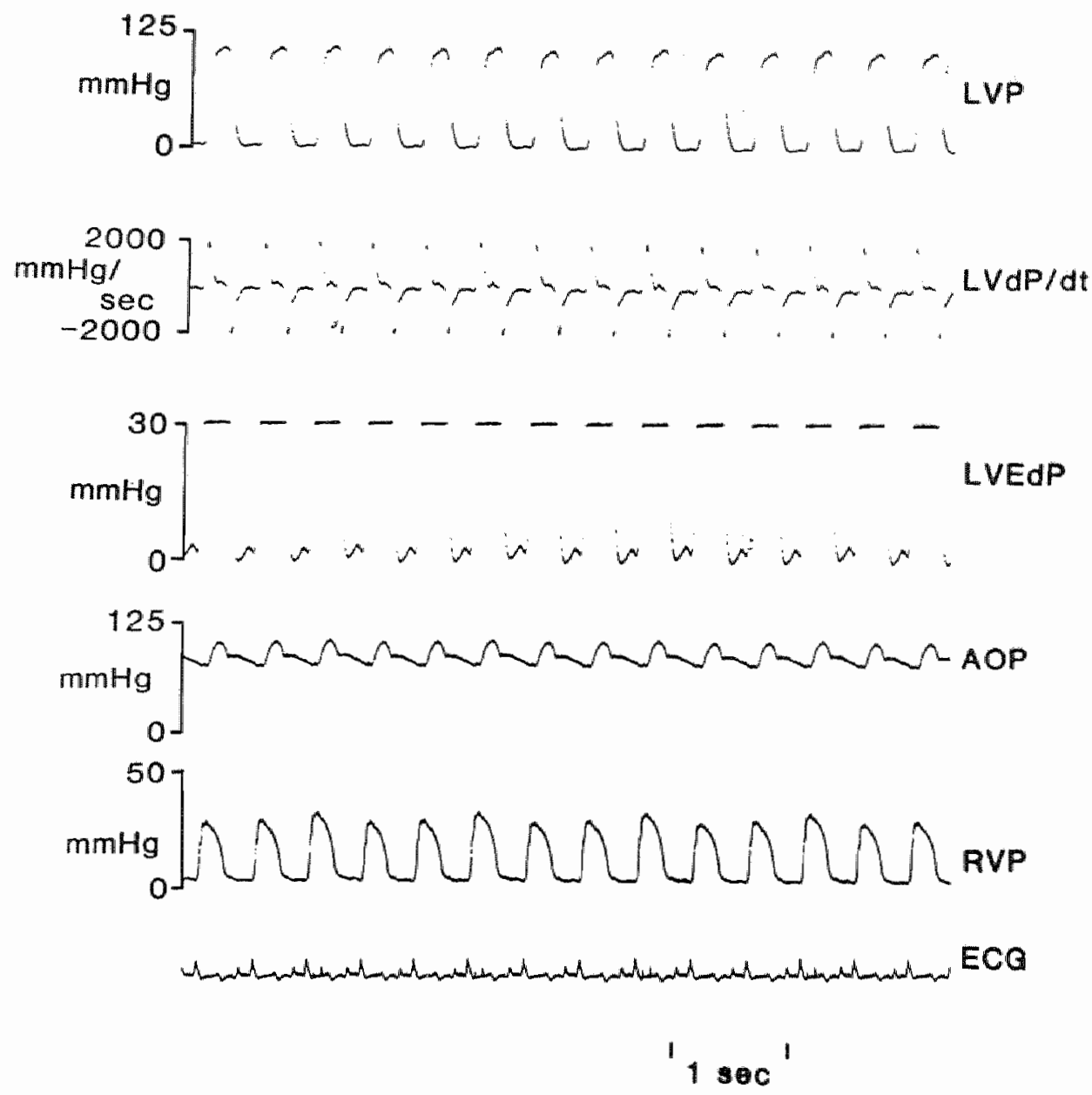

Figure 1. Hemodynamic recording obtained with 10 pulses $/ \mathrm{sec}$ of pacing frequency. $100 \mathrm{msec}$ of in terpulse interval, 5 Vs of pulse amplitude, and $3: 1$ heart/atissimus dorsi muscle contraction ratio. Left ventricular pressure (LVP), left ventricular dP/dt, left ventricular diastolic prescure (LNEDP). aortic blood pressure (AOP), right ventricular pressure (RVP), and electrocardiogram (ECG), are shown. Note maked LD support to righ ventricular function during assisted beats. 
Table 1. Hemodynamic parameters at conditioning (1) and at higher (2) pacing frequency. LVP : left wentricular pressure: RVP : right ventricular pressure: AoP : aortic pressure Values are given as mean $\pm 8 D$. $p$ value 0.05 is considered significant $(*)$

\begin{tabular}{|c|c|c|c|c|}
\hline & LVP & LVdP/dt & RVP & $\mathrm{AOP}$ \\
\hline \multicolumn{5}{|l|}{ 1) 10 pulses/sec: } \\
\hline - non-assisted bears & $110 \pm 18$ & $1.740 \pm 494$ & $26 \div 6$ & $118 \pm 17$ \\
\hline - absisted beats & $112 \pm 17$ & $1.897 \pm 618$ & $30 \pm 8$ & $120 \pm 16$ \\
\hline p value & 0.143 & 0.08 & $0.014^{\circ}$ & 0.111 \\
\hline \multicolumn{5}{|l|}{2030 pulses/sec: } \\
\hline - non-assisted beats & $112+14$ & $1646 \pm 232$ & $26 \pm 8$ & $11.8 \pm 15$ \\
\hline - assilsted beats & $113 \pm 13$ & $1859+325$ & $31 \pm 11$ & $120 \pm 14$ \\
\hline pvalue & 0.656 & $0.018^{*}$ & $0.011^{*}$ & $0.018^{\text {an }}$ \\
\hline
\end{tabular}

Macroscopic as well as histologic evaluations were performed in all 8 animals, whereas 7 goats were submitted to hemodynamic measurements.

Latissimus dorsi contribution to heart performance was objectivated during recording of hemodynamic parameters (figure 1). Right ventricular pressure was markedly influence and increased during assisted beats (table 1). Slight LD support was also noted on LV pressure curve, even if it did not reach statistical significancy, attesting skeletal muscle viability in spite of early postoperative electrical stimulation. Furthermore, the tests performed at higher pacing frequency $(30 \mathrm{~Hz})$ showed more profound effects on cardiac performance, with marked improvement on cardiac contractile index ( $\mathrm{LVdp} / \mathrm{dt}$ ) and aortic pressure (table). It can be argued that these data were obtained with a partially transformed muscle, with expected more power to be expressed because of a higher prevalence of type 2 fibres.

Of note, on autopsy, all the early trained muscles appeared in perfect condition and properly wrapped around the hearts. No muscle necrosis was observed. Histology confirmed no muscular tissue damage or atrophy (no increase of fatty tissue or fibrotic tissue) either at the proximal or distal portion. Adequate LD conditioning was, moreover, demonstrated by fibre typing: partial transformation from type II fatigue-prone fibres to type I fatigue-resistant fibres (from $75 \%$ of type 2 in unconditioned LD to $60 \%$ in stimulated LD muscle) was observed (figure 2).

Cross LD muscle examination at the time of death revealed that optimal intermuscular fusion, and strong as well as uniformly spread adhesions were present (figure 3); no evidence of cardiac constriction was present. 

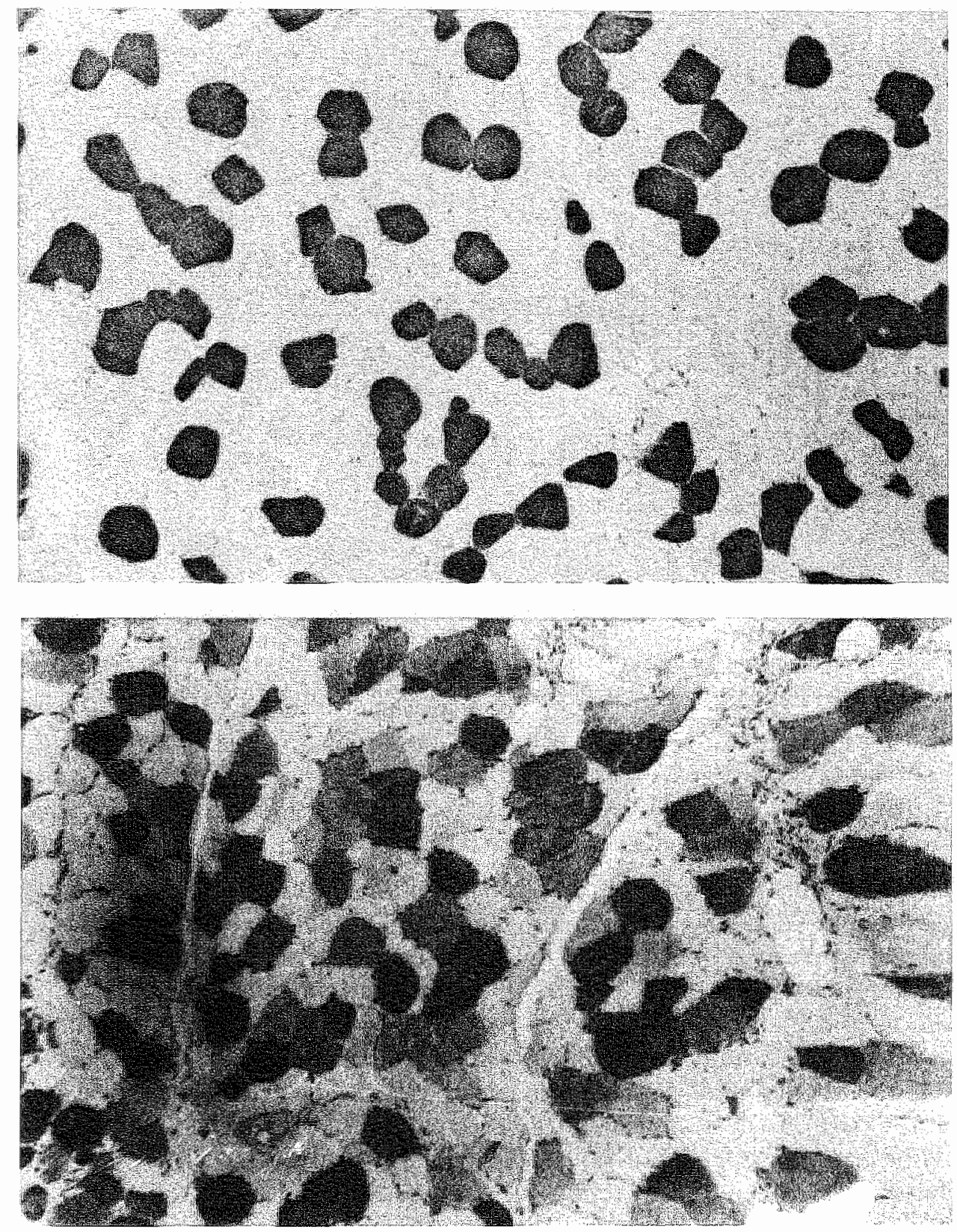

Figure 2. Latissimus dorsi cross-section. A non stimulated right skeletal muscle. B: wo-weck conditioned lleft pedicled nap. The lightly stained fibres are classified as type fl fast-twich fatigue-prone fi bres, whereas darkly stained fibres as type I slow-stwitch fatigue-resistant fibres. Note partial ID. ransfomation afier early electrical stimulation for 2 weeks. 


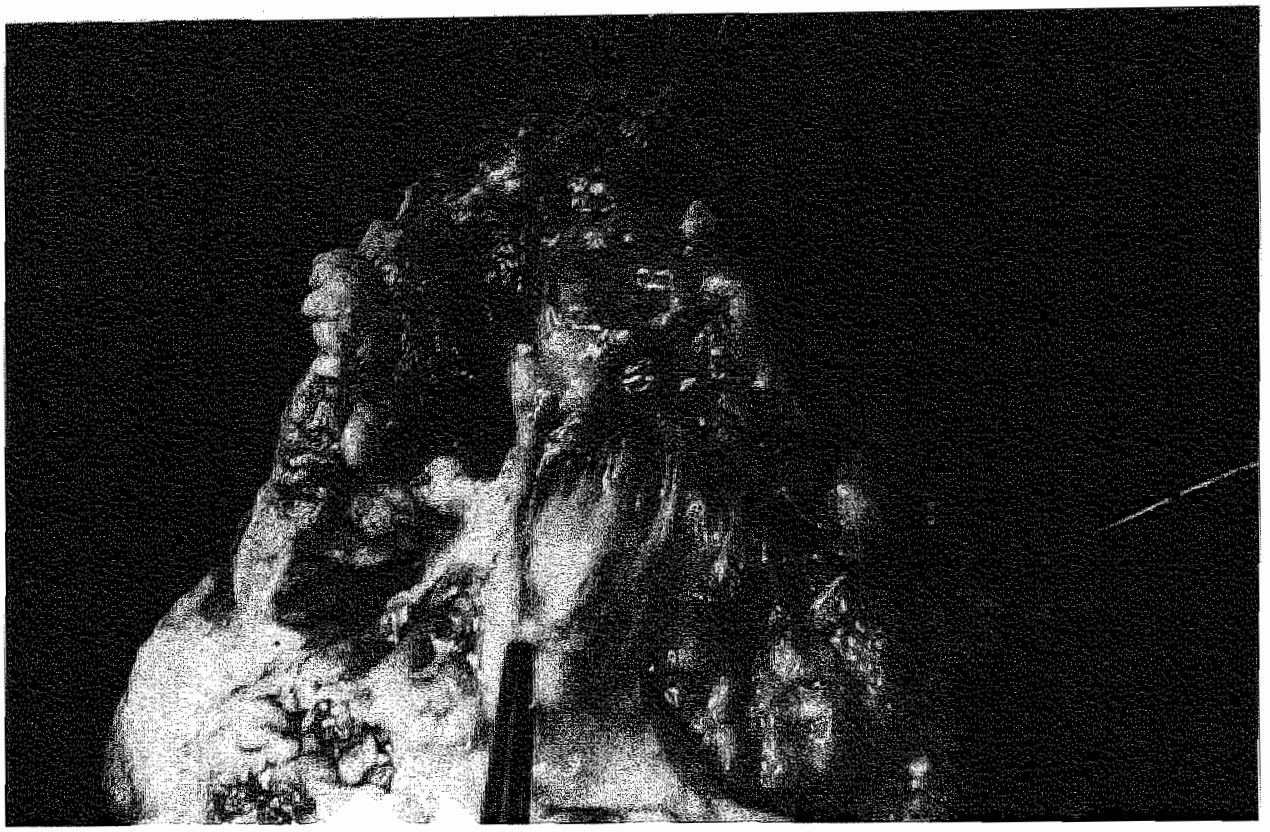

Figure 3. Latissimus dorsi muscle /heart interface. Above: Latissimus dorsi muscle flap. Below: ventricular chambers. Uniform and firm adhesions are evident after early-induced mucle conditioning. No cardiac constriction was observed.

\section{Discussion}

Despite recent advances, cardiac transplantation cannot provide effective treatment to end-stage heart failure because of limited donor pool. Dynamic cardiomyoplasty, which implies unilateral LD muscle mobilization and wrapping around the ventricles, followed by electrical stimulation to allow muscle fibre transformation and cardiac assist, has been proposed as an alternative procedure for chronic heart failure therapy. Several reports described successful experimental cardiac assist during past years leading to the first clinical case in 1985 (1-9). To date, almost one hundred patients have been submitted to dynamic cardiomyoplasty (10-16). Optimal operative results as well as long-term survival have been already reported by some investigators (10-18). Nevertheless, improvement of the surgical technique to augment LD contractile contribution or postoperative patient management refinement have been proposed $(6,21,22)$. The current dynamic cardiomyoplasty procedure requires a LD rest period of two weeks after surgery to allow muscle flap revascularization because of intraoperative collateral vessel severance $(19,20,21,23)$. Concomitantly. this recovery span may give rise to proper adhesion development at the intermuscular site (21). Actually, the preliminary clinical cases did not follow 
such a protocol, and the exact time to start electrical conditioning of the LD was not well established ranging from 5 to 14 dlays after surgery $(9,11$ "15). At present. no muscle damage or pedicled graft dysfunction due to earlier stimulation has been reported. Mannion and associates (19), however, demonstrated negative early LD pacing effects, showing muscle ischemia and fatigue occurrence soon after muscle dissection. These results convincingly led to the current stimulation protocol.

Williams and Goldspink described deleterious effects of skeletal muscle immobilization already after two weeks, leading to muscle atrophy due to serial sarcomere loss, and to intramuscular connective tissue remodeling with subsequent increased muscle stiffness $(24,25)$. Furthermore, episodes of low cardiac output have been reported following cardiomyoplasty surgery likely induced by an inactive wrapped LD muscle which might negatively affect an already failing heart $(11,15)$.

These considerations prompted us to investigate a different protocol regarding an earlier muscle conditioning feasibility. In our laboratory, a low pacing frequency (10 pulses/sec) was chosen and applied 24 hours after the surgical procedure. This short postoperative delay was selected becasue we observed that LD mobilization stress does not require a more prolonged recovery. A fibrin glue was applied during surgery in order to timely create proper LD-heart contact and to avoid LD displacement.

After two weeks of synchronous electrical stimulation, no transposed flap showed any sign of damage or displacement. Strong and effective LD-heart fusion was still maintained despite sustained contractions. No cardiac constriction was observed. All early trained LD muscles were viable at the proximal and distal area. Histologic studies confirmed no intramuscular degenerative reaction nor the occurrence of an inflammatory process. Proper muscle transformation was furthermore demonstrated: partial transformation of type II fast twitch fatigue-prone to type I slow-twitch fatigue-resistant fibres was obtained.

Despite observed right ventricular hemodynamic improvement, the adopted LD pacing protocol did not provide significant left ventricular support. However a minor LD contribution can be hypothesized which may improve rather than deteriorate the ventricular performance.

The present study describes the feasibility of early LD conditioning after cardiomyoplasty procedure. Proper pacing frequency, that is low frequency stimulation, may represent a crucial fator for preventing muscle flap ischemia and subsequent dysfunction. Stimulation-induced increase in muscle blood flow does occur, and the intramuscular hyperemia may compensate distal llow impairement due to collateral vessel ligation. Also, sustained muscle contractions may trigger internal collateral network recruitment.

Finally, the use of fibrin glue during cardionyoplasty surgery should be advocated even when a recovery period of two weeks follows, since LD displace- 
ment may occur during this period because of wrapping suture line weakness (atrio-ventricular fatty tissue). We do believe, moreover, that the technique to apply fibrin glue is crucial since the spray device gives a uniform adhesion layer whereas syringe technique provides only a few less effective anchoring spots.

Accomplishment of the complete conditioning protocol and the long-term effect of early LD stimulation still remain to be investigated. 


\section{References}

1. Dewar ML, Drinkwater DC, Wittnich C, Chiu RC. I. Synchronously stimulated skeletal muscle graft for myocardial repair. I Thorac Cardiovasc Surg 1984;87:325-31

2. Chachques JC, Grandjean PA, Carpentier A. Dynamic cardiomyoplasty: experimental cardiac wall replacement with a stimulated skeletal muscle. In, Chiu RC-I (ed): Biomechanical cardiac assist. Mount Kisko, New York, Futura Publishing Company, Inc, 1986, pp59-84

3. Chachques IC, Grandjean PA, Schwartz K, Mihaileanu S, Fardeau M, Swynghedauw B, Fontarilan F, Romero N, Wisnewsky C, Perier P, Cauvand S, Bourgeois I, Carpentier A: Effect of latissimus dorsi dynamic cardiomyoplasty on ventricular function. Circulation 1988;78(\$uppl III): $111203-\$ 11216$

4. Chachques $\mathrm{JC}_{0}$ Grandjean PA, Bourgeo is IM, Carpentier A: Atrial or ventricular assistance using cardiomyoplasty procedure, in Chiu RC-J, Bourgeois IM (eds): Transformed muscle for cardiac assist and repair. Mount Kisko, New York: Futura Publishing Company, Inc., 1990, pp $161-178$

5. Dewar ML, Walsh G, Abraham RBS, De Simon J, Foot E, Stewart J, Faser R, Chiu RC-J. Left ventricular full-thickness cardiomyoplasty with pericardial neoendocardium: experimental development of a surgical procedure. Anm Thorac Sur 1987;44:61.8-24.

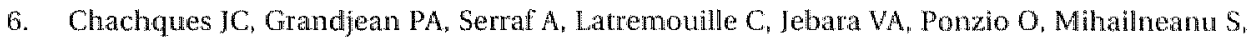
Chauvaud S, Bourgeois I, Carpentier A. Atrial cardiomyoplasty after Fontan-type procedures. Circulation $1990 ; 82$ (Suppl IV):IV183-IV189

7. Molteni L, Almada HE, Ferreira RF, Ortega D. Assessment of the optimal time interval beiween QRS and singte-pulse stimulation in dynamic cardiomyoplasty. In Chiu $\mathbb{R C}-1$, Bourgeois 1 (eds): Transformed muscle for cardiac assist or repair. Futura Publishing Company, Inc., Mount Kisko, NY, 1990, pp $189-196$

8. Soberman MS, Wornom IL, Justicz AG, Coleman Jl, Austin GE, Alazraki NP, Sink ID. Latissimus dorsi dynamic cardiomyoplasty of the right ventricle. I Thorac Cardiovasc Surg $1990 ; 99: 817-27$

9. Carpentier $\mathrm{A}$, Chachques JC. Myocardial substitution with a stimulated skeletal muscle: first successful clinical case. Lancet 1985;1:1267

10. Magovem GJ, Park SB, Magovern GJJn, Benckart DH, Tullis G, Rozar E, Kano R, Christlieb I. Latissimus dorsi as a functioning synchronously paced muscle component in the repair of a left ventricular aneurysm. (letter) Ann Thorac Surg 1986:41:116

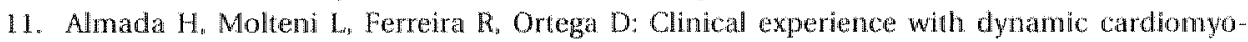
plasty. J Cardiovasc Surg 1990;17:193-197

12. Moreira LF, Stolf NA, Jatene AD. Hemodynamic benefits of cardionyoplasty in clinical and experimental myocardial dysfunction, in Chiu $\mathbb{R C}-1$. Bourgeois $\mathrm{M}$ (eds): Transformed muscle for cardiac assist and repair. Mount Kisko, New York Publishing Company, 1990, pp 179-188

13. Moreira LFP, Stolf NAG, Bocchi EA, Pereira-Barretto AC, Meneghett $\llbracket C$, Giorgi MCP, Moraes AV, Leite II, da Luz PL, Jatene AD. Latissimus dorsi cardiomyoplasty in the treatment of patients with dilated cardiomyopathy. Circulation 1990;82 (Suppl IV); [V257-IV263

14. Magovern G), Heckler FR, Park SB, Christlieb IY, Liebler GA, Burkholder JA, Maher TD, Benckart DH, Magovern GJ J $\mathrm{r}_{\text {, Kao }} \mathbb{R L}$. Paced skeletal muscle for dynamic cardiomyoplasty, Ann Thorac Surg 1988;45:614-9

15. Magovern GJ, Park SB, Kao RL. Christlieb IY, Magovern GJ Ir. Dynamic cardiomyoplasty in patients. I Heart Transplant 1990;9:258 -63

16. Molteni L, Almada HE, de Palma C. Ferreira RF. Dynamic cardiomyoplasty: clinical experience. In, Chui RC-J, Bourgeois I. Transformed muscle for cardiac assist and repair. Fuinara Publishing Inc, Mount Kisko, NY, 1990, pp 197-198 
17. Hagege AA, Desnos M, Baragan J, Gueron C, Chachques JC. Carpenter A. Long-term efficacy of dynamic cardiomyoplasty: clinical, uliasonic and hemodynamic evidence in one case. Eur Heari J $1990 ; 11.662-5$

18. Hagege $A$ A, Desnos M, Chachques $1 C$. Carpentier A, Fernandez F, Fontarian F, Guerot C. Preliminary report follow-up after dynamic cartiomyoplasty. Lancet 1990,335:1122-4t

19. Mannion JD, Velchik M. Hammond R, Navi A, Macker T, Ducket S, Staum M, Hurwite S, Brown W: Stephenson LW: Eftects of collateral wessel ligation and electrical conditioning on blood flow in dog latissimud orsi muscle. I Surg Res 1989,47:332-340

20. Marinion JD, Velchik $M$, Acker MA, Hanmond $R$, Staum M, Alavi $A$. Duckett $S$, Stephenson LW: Transmural blood flow of multi-layered latissimus dorsi skeletal muscle ventricles during circulatory assistance. Trans Am Soc Artif Interm Organs 1986;32:454-460.

21. Anderson WA, Andersen IS, Acker MA, Hammond RL Chin AJ, Douglas PS, Khalafalla AS, Sa. mons S, Stephenson LW. Skeletal muscle grafts applied to the heart. A word of caution. Circulation 1988;78(Suppll III):180-90

22. Kao RL, Chrisilieb IY, Magovern GJ, Park SB, Magovern GJJr. The importance of skeletal muscle fiber orientation for dynamic cardiomyoplas ty. Ann Thorac Surg 1990;99:134-139

23. Isoda $S$, Kando J, Kajinara $H$, Yoshimi $Y$, Matsumoto A: Tissue blood flow measurement of skeletal muscle graf for myocardial repair: experimental study applying a lase flowmeter fabstract) proceedings of the forth world Symposium of transformed skeletal muscle for cardiac assit. 1990

24. Williams PE, Coldspink G: The effect of immobilization on the longitudinal growh of striated muscle libres. I Anat 1973:116:45-55.

25. Williams $P E$, Goldspink $G$ : Connective tissue clmanges in immobilized muscle. I Anat $1984: 138: 343-350$. 
CHAPTER

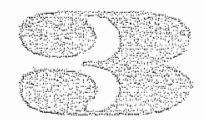

\section{Hemodynamic effects in acute cardiomyoplasty of different wrapped muscle activation times as measured by pressure/volume relations.}

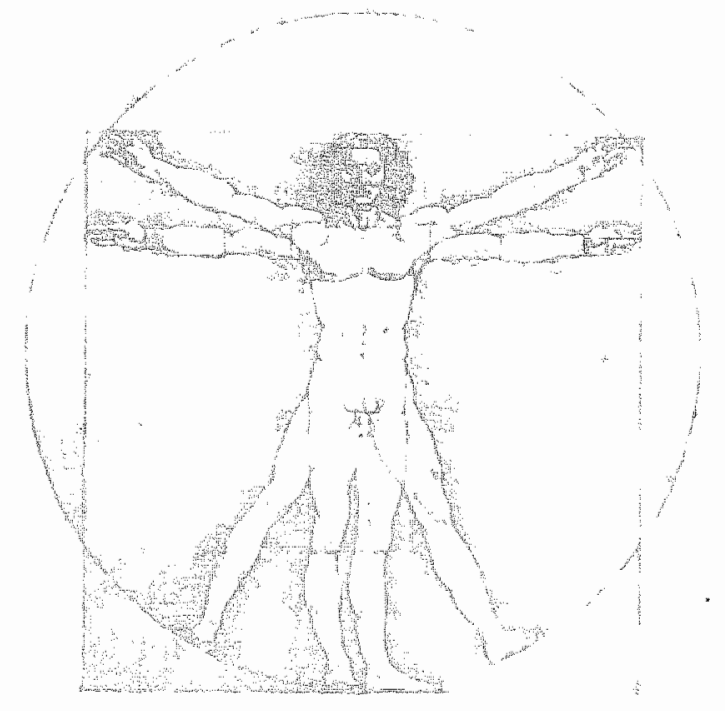

Roberto Lorusso, Frederik van der Veen, Jan J. Schreuder, Gil Bolotin, HG Kaulbach, Robert Frietman. Jo Habets, Theo van der Nagel, Hein J. Wellens.

Presented at Cardiostim 1996, Nice 


\section{Abstract}

Background. Correct timing of mechanical interaction between wrapped latissimus dorsi muscle (LDM) and the heart during cardiac systole has been poorly investigated and remains a controversial issue. We therefore analysed left ventricular pressure-volume relations in acute cardiomyoplasty while changing the synchronization delays.

Methods. Effects of different delays between the sensed cardiac $\mathrm{R}$ wave and wrapped muscle contraction were studied in goats submitted to acute left cardiomyoplasty. Conductance and micromanometer catheters were used to evaluate hemodynamics. Systolic contribution of the wrapped muscle was studied in pre-assisted and assisted beats, whereas diastolic effects were studied in assisted and post-assited beats.

Results. At best settings, cardiomyoplasty resulted in a significant $(\mathrm{p}<0.05)$ increase in left ventricular ejection fraction (from $42.2 \pm 9.2$ to $56.7 \pm 13 \%$ ), in stroke work (from $2769 \pm 1140$ to $4271 \pm 1717 \mathrm{gm} / \mathrm{m} 2$ ), in $\mathrm{LV} \mathrm{dP} / \mathrm{dt}$ (from $1185 \pm 342$ to $1510 \pm 285 \mathrm{mmgHg} / \mathrm{sec}$ ), in end systolic pressure (from $93.5 \pm 22.5$ $\mathrm{mmHg}$ to $97.3 \pm 22.3 \mathrm{mmHg}$ ), and in peak ejection rate (from $282 \pm 64$ to $533 \pm 241$. $\mathrm{ml} / \mathrm{sec}$ ). Stroke volume showed a mean increase of $35 \%$ (from $42.2 \pm 9.9 \mathrm{ml}$ to $56.9 \pm 20.1 \mathrm{ml}$ ) during assisted beats. Diastolic function was not substantially impaired at optimal stimulation delay. Incorrect timing of LD contraction resulted in suboptimal improvement or no change in comparison with unassisted hemodynamics.

Conclusions. Our study documents support of cardiac performance by LDM. Incorrect timing of heart/wrapped muscle interaction led to suboptimal hemodynamic results. Muscle contraction timing is an important factor in cardiomyoplasty outcome. 


\section{Introduction}

Since 1985 (1) cardiomyoplasty has been applied as permanent biomechanical cardiac support in almost 700 patients affected by chronic heart failure refractory to medical therapy. This is achieved by synchronizing the electrically induced Latissimus Dorsi muscle (LDM) contraction to cardiac systole. The delay between the $R$ wave and the stimulation of LDM is generally programmed to elicit the muscle graft contraction at the time of mitral valve closure (2). Additional possibilities of selecting the time interval are represented by a fixed programming mode or a hemodynamically optimized mode (3).

Recently, deterioration of the patient"s clinical status related to inappropriate $\mathrm{LDM}$ /heart coupling has been reported (4).

Study of the effects of incorrect stimulation of wrapped skeletal muscle, and agreement on the best synchronization mode, are still a matter of controversy.

In order to evaluate the impact of differences in timing of skeletal muscle contraction during cardiac systole, acute experiments were performed where wrapped muscle contraction was evoked at varied delays. Systolic as well as diastolic function was studied by analysing pressure-volume relations.

\section{Material and Methods}

Five adult female goats with body weights ranging from 45 to $60 \mathrm{kgs}$ underwent acute cardiomyoplasty. All animals received care in compliance with the "Guide for the Care and Use of Laboratory Animals" (National Academy of Sciences. DHHS publication No. NIH 85-23, revised 1985).

Anesthesia was induced by sodium thiopenthal (Nesdolal $15 \mathrm{mg} / \mathrm{kg}$ body weight) delivered into the left jugular vein. Following endotracheal intubation, mechanical ventilation was started using positive pressure support (Pulmomat), and anesthesia was maintained with Fluothane $[1.5 \%\}$ and oxygen/mitrous oxide mixture $(1: 2)$. The body temperature was controlled by thermal blanket. Extremity ECG leads were continously recorded. Fluid intake (Ringer lactate) was assured through peripheral indwelling catheters. All animals were preoperatively starved for 2 days.

\section{Muscle preparation and transposal}

All animals were placed in the right lateral recumbent position. The left LDM was harvested in all the animals through a lateral thoracic incision.

Following dissection from the surrounding tissues and resection of the distal insertions, the muscle was lifted in order to visualize the proximal neurovascular pedicle. Two intramuscular leads (MyoFlex IML-03U, Telectronics Inc. 
Englewood) were implanted just after the branching point of the thoracodorsal nerve. The anode was positioned proximally, and the catode 3-4 centimeters distally, according to the technique described by Chachques and Carpentier (2).

Proper muscle recruitment was tested by connecting the 2 intramuscular electrodes to an external programmer (MyoProgrammer 7100 , Telectronics Inc., Englewood) and full muscular recruitment threshold was determined.

Muscle translocation was performed by resecting a $4 \mathrm{~cm}$-portion of the 2 nd rib just underneath the neurovascular pedicle. After entering the left pleura, the muscle graft and the intramuscular electrodes were transferred inside the pleural cavity. The humeral tendon was ultimately resected, and secured at the level of the thoracic window by several interrupted sutures. The heart was approached by a Jateral thoracotomy ( 4 th intercostal space), and care was taken to avoid any compression of the proximal part of the muscle during spreading of the intercostal space. The heart was suspended in a pericardial cradle, and a counterclockwise wrapping procedure was performed. The muscle edges were fixed to the myocardium by interrupted stitches while care was taken not to prolong the cardiac lifting time in order to prevent refractory arrhythmia. Cardiac sensing was obtained by implanting an epicardial sensing lead (Myocardial Lead 033-571/572, Telectronics Inc., Englewood). All animals received the cardiomyoplasty procedure without any signifcant complication or longlasting hypotension.

\section{Hemodynamic monitoring}

Right ventricular and pulmonary pressures were measured after insertion of a Swan-Ganz thermodilution catheter via the right internal jugular vein. Left ventricular pressure was recorded by introducing a micromanometer catheter (Sentrom, Roden) positioned in the left ventricle through the left femoral artery. Aortic pressure was measured by means of a fluid-filled catheter transducer located in the contralateral femoral artery.

A dual-field conductance catheter (Sentrom, Roden) was introduced in the left ventricle through the right carotid artery. Appropriate apical position of the catheter was verified by fluoroscopy and by analysing the segmental conductance signals. The volumes were recorded by using the conductance catheter method (Leycom Sigma-5DF condition processor, Cardiodynamics, Leiden) as described by Schreuder et al. (5).

Ejection fraction (EF), Stroke Work (SW), Stroke Volume (SV), positive peak $\mathrm{dP} / \mathrm{dt}$, LV end-systolic pressure (ESP), and Peak Ejection Rate (PER) represented the analysed contractile variables. Negative peak $\mathrm{dP} / \mathrm{dt}$, Diastolic Filling Time (DFT), Peak Filling Rate (PFR), the time constant of LV isovolumic pressure decline (Tau), and left ventricular end-diastolic pressure (EDP) of the beats 
following the assisted ones were used to study the diastolic function and to elucidate any influence of the wrapped muscle contraction. Validation of LV pressure data was obtained by a combined recording of the aortic pressure. Conductance catheter stroke volume was calculated by the sum of the different segments over the conductance catheter along the LV long axis (apex to base).

\section{Stimulation protocol}

After performing the wrapping procedure (counterclockwise cardiocostal wrapping) the muscle graft was stimulated at different delays from the sensed cardiac R wave by connecting intramuscular and sensing leads to a cardiomyostimulator (Myostim 7220, Telectronics Inc, Englewood). The animals were allowed to stabilize for 30 minutes before starting the hemodynamic measurements. An increment of about $25 \mathrm{msec}$ as synchronization delay was used $(25,50,75,100)$ in order to get muscle support at various phases of the cardiac systole. Other stimulation parameters included stimulus pulse width of $125 \mathrm{microsec}$, fixed interpulse interval ( $30 \mathrm{microsec}$ ), burst duration of 185 msec, and burst frequency of $30 \mathrm{~Hz}$ ( 6 pulses per burst). Impulse amplitude was programmed to obtain full muscle recruitment (5 volts).

Hemodynamic data were obtained during cardiac assistance with a heart/ wrapped muscle contraction ratio ranging from 3:1 to 4:1, taking the beat prior to the assisted beat as control. The 2:1 mode was purposely avoided to prevent any potential negative effect of the assisted beat on the following unassisted cardiac contraction.

All measurements were collected during 15 seconds of breathholding (ventilator turned off) to avoid interference with the respiratory-related changes of cardiac loading. At each delay, at least 5 assisted beats were recorded and these values were averaged. A short period of muscle activation was used to avoid the onset of muscle fatigue in the unconditioned muscle fibers.

\section{Sraristics}

Hemodynamic data were computed by a personal computer (Toshiba). All the values are presented as a mean \pm Standard Deviation. Student t test was used to analyse significancy. A p value of less than 0.05 was considered significant.

\section{Results}

One animal did not complete the study because of the occurrence of uncontrollable atrial fibrillation. The data presented apply to the other 5 goats. One animal showed depressed baseline hemodynamics before wrapping (animal 4) 
Table. Systolic variables of the best setting during assisted (A) and pre-assisted beats (NA) are pre. sented. Data are expressed in \% (Ejection fraction: $\mathrm{EF}$ ), ml/gm (Stroke Work: SW), mmHG/min (dP/dD), msec (Peak Bection Rate: PER), and mmHG (End Systolic Pressure : ESP)

\begin{tabular}{|c|c|c|c|c|c|c|c|c|c|c|c|}
\hline \multirow[t]{2}{*}{ Dellay } & & \multicolumn{2}{|l|}{$\mathbb{E F}$} & \multicolumn{2}{|l|}{$5 W$} & \multicolumn{2}{|l|}{$\mathrm{dP} / \mathrm{dt}$} & \multicolumn{2}{|l|}{ PER } & \multicolumn{2}{|l|}{ ESP } \\
\hline & & A & $N A$ & A & NA & $A$ & NA & $A$ & $\mathrm{NA}$ & $A$ & NA \\
\hline Goat 1 & $25 \mathrm{msc}$ & 78 & 42 & 5031 & 2294 & 11567 & 1015 & 808 & 404 & 102 & 96 \\
\hline Goal 2 & $50 \mathrm{msc}$ & $56^{2}$ & 41 & 8367 & 3470 & 1653 & 1570 & 697 & 363 & 99 & 96 \\
\hline Goal 3 & $25 \mathrm{msc}^{\circ}$ & 58 & 54 & 3544 & 2767 & 1445 & 851 & 439 & 308 & 86 & 75 \\
\hline Coat 4 & $25 \mathrm{msc}$ & 35 & 28 & 17887 & 1163 & 1089 & 957 & 346 & 216 & 69 & 57 \\
\hline Goat 5 & $50 \mathrm{msc}$ & 57 & 56 & 4627 & 41.57 & 1568 & 1488 & 263 & 228 & 121 & $11 \%$ \\
\hline
\end{tabular}

most likely due to the anesthesia. In this animal no inotropic drugs were used to normalize blood pressure in order to limit any further interference with cardiac function, and the wrapping procedure did not show additional deterioration as compared to the preoperative condition.

Mean heart rate was $110.2 \pm 8.7$ beats/min (98-120). At best settings, that is, at the delay which ensured the most effective LDM/heart coupling, cardiomyoplasty showed to provide significant $(p<0.05)$ increases in LVEF (from $42.2 \pm 9.2 \%$ to $56.7 \pm 13 \%)$, in SW $\left(2769 \pm 1140 \mathrm{gm} / \mathrm{m} 2\right.$ vs $\left.4271 \pm 1717 \mathrm{gm} / \mathrm{m}^{2}\right)$, in $\mathrm{dP} / \mathrm{dt}(1185 \pm 342 \mathrm{mmHg} / \mathrm{sec}$ vs $1510 \pm 285 \mathrm{mmHg} / \mathrm{sec})$, in ESP $(93.5 \pm 22.5 \mathrm{vs}$ $97.3 \pm 22.3 \mathrm{mmHg}$ ), and in PER ( $282 \pm 64 \mathrm{msec}$ vs $533 \pm 241 \mathrm{msec}$ ) (table).

Stroke volume showed a significant increase at the best setting in each animal (figure 1), but the data did not reach statistical significance as a mean $(42.2 \pm 9.9 \mathrm{ml}$ vs $56.9 \pm 20.1 \mathrm{ml}-\mathrm{p}=0.06)$.

Diastolic function was not impaired at the individual best LDM activation time. Indeed, at each stimulation delay $(25,50,75$, and $100 \mathrm{msec}$, respectively), DFT $(212 \pm 31.4, \quad 392.8 \pm 263.9,220.4 \pm 57.8,227.4 \pm 46.6)$, PFR $(516.6 \pm 230.5$,

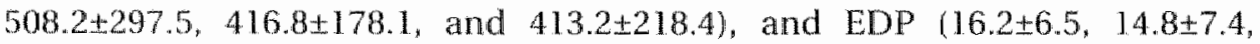
$13.8 \pm 6.5$, and $13.7 \pm 5.21$ values showed no significant changes when comparing assisted versus post-assisted beats. Conversely, Tau data showed negative effect of LDM contraction at only one setting (from $31.4 \pm 4.1 \mathrm{msec}$ to $34.8 \pm 5.3$ msec $-p<0.05-$ ) documenting a prolonged time of pressure decline in the postassisted beats. Negative $\mathrm{dP} / \mathrm{dr}$ showed a positive change at $50 \mathrm{msec}$ (from $1136 \pm 261.8 \mathrm{mmHg} / \mathrm{sec}$ to $1079 \pm 239.2 \mathrm{mmHg} / \mathrm{sec}-\mathrm{p}<0.05$ ) after the supported cardiac contractions, with no substantial changes at the other delays.

Reduced benefits during LDM heart assistance were observed at certain settings suggesting an incorrect LDM/heart coupling, and variable influence of inappropriately timed LDM contraction on not supported heart beats. Indeed, no 

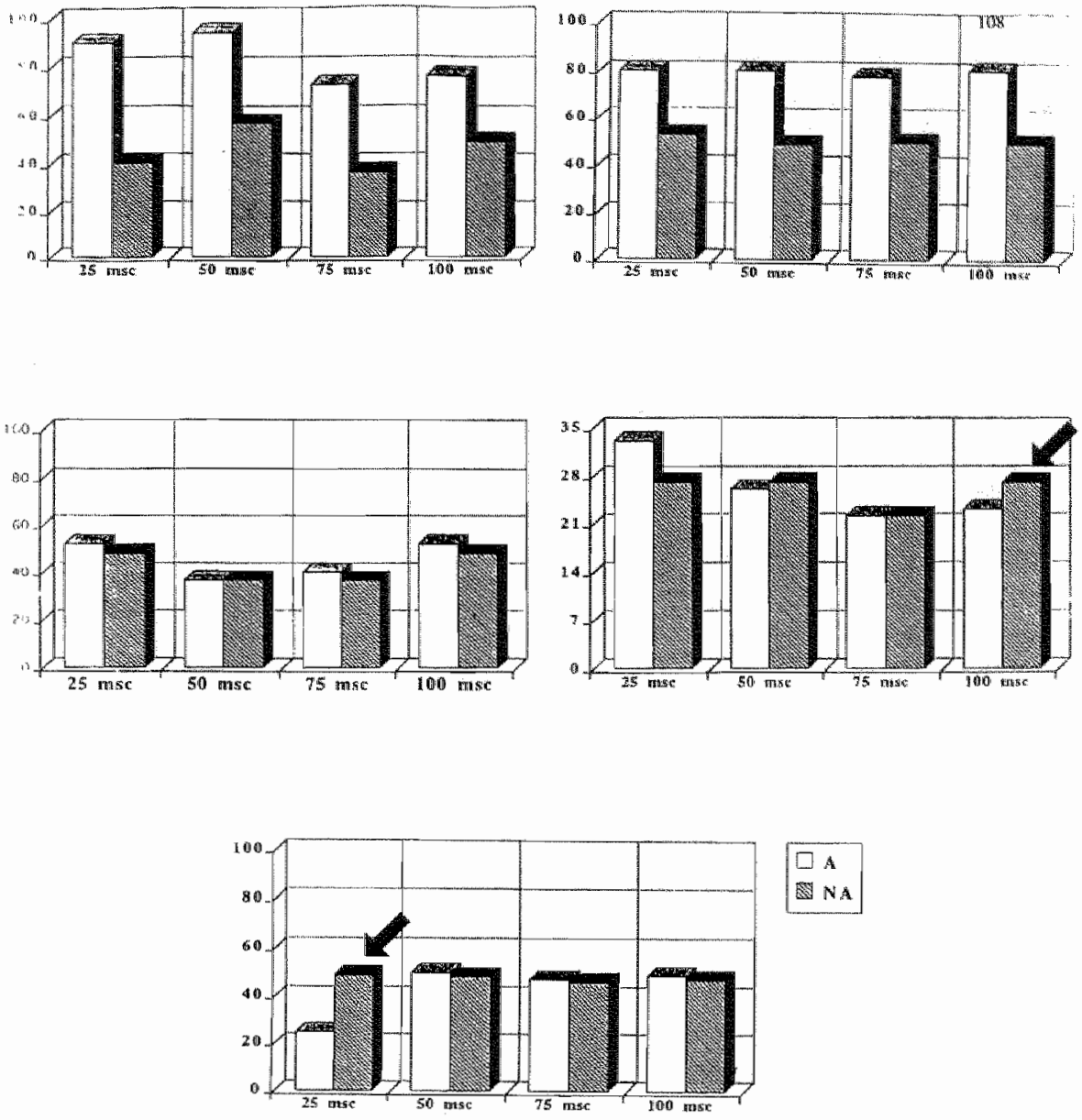

Figure 1. Left ventricular stroke volumes with LDM contraction (A) and without (NA) at dilleren skeletal muscle stimulation delay are presented. In animals 4 and 5 incorrect progranming of LDM activation produced reduced SV during LDM assistance (arrows). "p<0.05

significant changes of not assisted versus assisted beats in ESP (from 87.3125.1 $\mathrm{mmHg}$ to $96.8+32.9 \mathrm{mmHg}$ ), in positive peak dP/dt (from 1414.213.4 $\mathrm{mmHg} / \mathrm{sec}$ to $1456.4+227.7 \mathrm{mmHg} / \mathrm{sec}$ ), in $\mathrm{EF}$ (from $45.6 \pm 11.1 \%$ to $56.8 \pm 20.8 \%$ ), and in PER (from $278.8 \pm 62.3 \mathrm{~m} / \mathrm{sec}$ to $472.8 \pm 291.6 \mathrm{~m} / \mathrm{sec}$ ) were observed. In figure 2 , a range of hemodynamic changes related to different delays of triggered LDM activation are shown. By increasing the time interval between the QRS and the muscle graft contraction, increase of $\mathbb{L V}$ systolic pressure and stroke volume during the assisted beats are achieved, but with a concomitant negative impact (reduced stroke volume) on post-assisted cardiac cycles. 

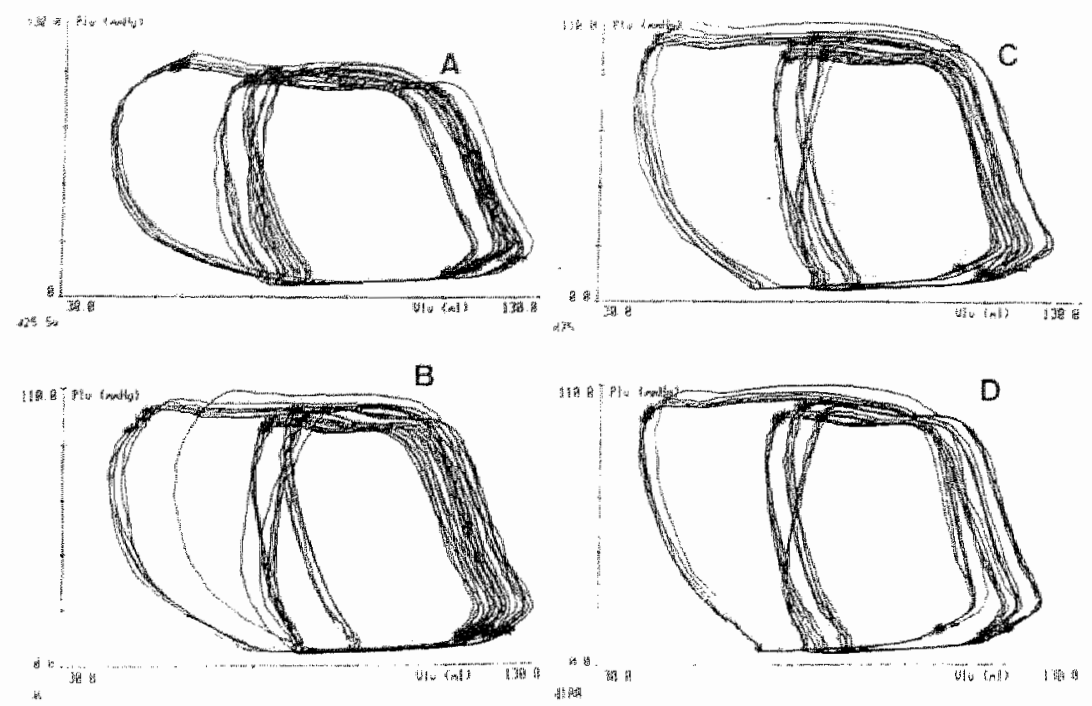

Figure 2. "This figure shows the pressure folume loops with progressively increased stimulation delay from 25 msec-panel A- to 100 msec-panel D) of LDM. By delaying LDM activation an increase of stroke volume associated with an improved left ventricular systolic pressure is documented. Nevertheless, such an augmentation of forward flow at late seltings is associated with a decrease in stroke wolume of the following beas.
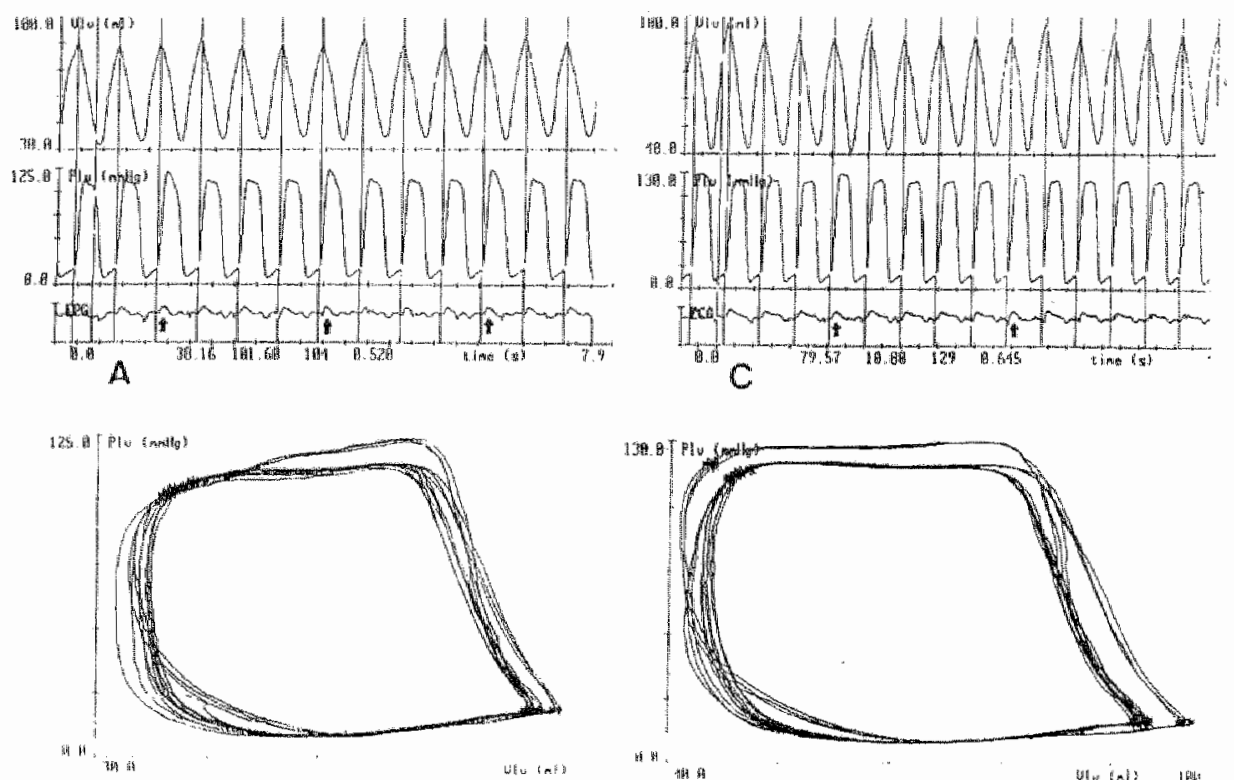

$B$
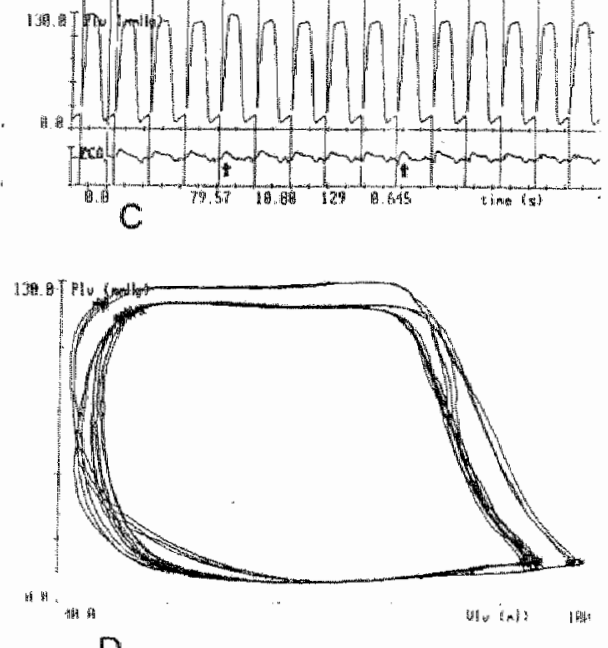

Figure 3. Bffect of adapting the onset of LDM contrachon to optimize cardionyoplasty result is shown in this figure. Pressure/volume tracings $A$ and $C$ and loops $(B$ and $D$ ) of 2 different LDM stimulation delay are presented. In Panels A and B the skeletal muscle burst increased the LV systolic prossure, with virtually no change in stroke volune. By changing the LDM contraction timing (Panels $C$ and $D$, a clea improvement of $S V$ combined with the previous increment of $L V$ pressure is obhamed. 
A
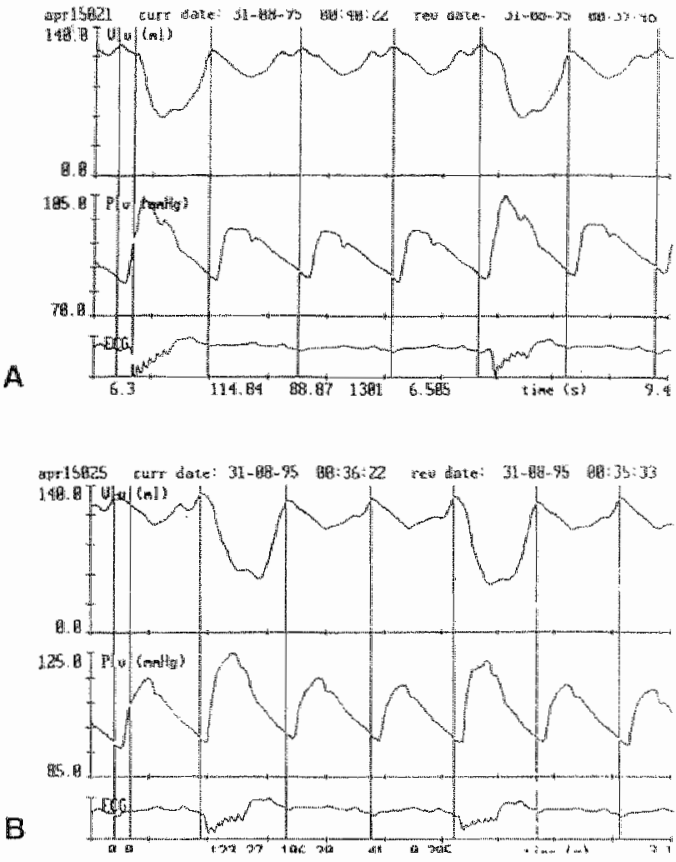

Figure 4. Optimization of stroke volume induced by different stimularion delays. Figure A shows an increase of stroke volume (upper tracing) and aoric pressure during LDM contraction (bursti on ECG). The change of the ime interval beween QRS and muscle graft activation leads to a significant augmentation of stroke volume (Figure Bi).

\section{Discussion}

Long-lasting left ventricular dysfunction due to myocardial disease is characterized by a poor prognosis. Recent progresses in medical therapy have improved survival in these patients, but the long-term prognosis is still disappointing. The limited availability of donor organs obviously limits the application of heart transplantation in those patients (6).

In the last decade a new form of permanent mechanical assistance has been introduced (1). This cardiac support system consists of a transposed skeletal muscle which is firstly electrically transformed and then stimulated to contract in synchronisation with the cardiac systole.

In spite of promising results, current data suggest that cardiomyoplasty cannot represent a real alternative to heart transplantation, but actually is a valuable complementary tool to assist the depressed ventricular function, and to reduce ventricular dilatation at mid or long term (7-11).

However, it is clear that our current knowledge of the mechanisms of action, on actual skeletal muscle potentials, appropriate management, proper patient selection and operative strategies, and the correct use of the stimulation protocol, limit the success of such a biomechanical cardiac assist "device" (12).

One important aspect is the selection of the most effective LDM/heart interaction. 
Incorrect timing of mechanical assist device performance is well known to cause a wide range of adverse effects in cardiac mechanics and hemodynamics. This issue has been poorly investigated in cardiomyoplasty, and only recently investigators are focusing on the crucial role of adapting the LDM contribution to the timing of the cardiac contraction $(3-5)$.

In cardiomyoplasty, the implanted intramuscular electrodes and the sensing leads ensure the native electrical impulse to be sensed and to be synchronized to contraction of the wrapped muscle. Pacing parameters can be adjusted to fullfil the criteria for the progressive conditioning process leading to a fully transformed type l-fiber skeletal muscle, and to ensure effective muscle graft contraction power. Wrapped muscle contraction may be triggered from the sensed QRS complex at a variable time interval by appropriate programming.

The common approach includes activation of the wrapped muscle just after the mitral valve closure in order to avoid a premature muscle graft contraction impeding diastolic filling or inducing mitral regurgitation (2). Additional methods are the use of a fixed delay which is predetermined and does not take into account any synchronization to cardiac valve or hemodynamics. Programming the interval in relation to the hemodynamic response (aortic flow-optimized mode) is a further option in selecting the muscle contraction time.

Molteni showed that by using the evaluation of the flow velocity at the aortic root, the hemodynamic effects of LDM contraction elicited by a single pulse varied according to the onset of contraction, and support was achieved when a time interval ranging from 100 to 150 msec from the sensed $R$ wave (13).

Geddes experimentally reproduced the hemodynamic evaluation at various skeletal muscle stimulation delays (14). He confirmed that such a time interval plays a critical role, and hypothesized that the muscle graft requires a high preloading (the end of the isovolumic phase) to be properly stretched to exert appropriate contractile performance.

The importance of correct burst stimulation onset in cardiomyoplasty outcome has recently been reported by Grubb and coauthors (4), showing clinical deterioration in patients having the timing of muscle graft stimulation wrongly selected. Improvement of the patient condition was observed gradually after restoring an optimal heart/muscle coupling.

Helou and collegues presented the available modes of selecting the timing of the muscle contraction applied in cardiomyoplasty patients (3). They clearly showed that from a hemodynamic standpoint the aortic flow-optimized mode probably represents the best way to ensure maximal efficacy of biomechanical assistance. However, no careful analysis of varying the LDM activation time, comparing assisted versus unassisted beats, was carried out in that study.

Our study analysed the contribution of LDM on global cardiac performance, showing that at certain stimulation delays uneffective $\mathrm{LDM} /$ heart mechanical 
interaction may result. Indeed, increases of external myocardial pressure and therefore, of the LV systolic pressure by the wrapped LDM have been shown not always to result in an increase in SV (figure 3). A slight adjustment of the delay may lead then to a more efficient LDM/heart coupling in LV blood ejection (figure 4).

Pressure/volume loops have previously been shown to represent a useful tool to study the hemodynamic changes in dynamic cardiomyoplasty. Nakajima and collegues studied the hemodynamic response to cardiomyoplasty in a chronic heart failure model (15). They showed that only Emax (endvolume/pressure relationship) increased after wrapping, but no other consistent changes were detected, suggesting that a constraint effect of the wrapped muscle on the dilated ventricle might play an important role. Nevertheless, no evaluation of different LDM stimulation delays was done during the measurements. Notably, in that study 2 animals showed a clear increase in cardiac output (from $1.52 \mathrm{I} / \mathrm{min}$ to $3.01 \mathrm{~L} / \mathrm{min}$, and from $1.68 \mathrm{~L} / \mathrm{min}$ to $3.20 \mathrm{~L} / \mathrm{min}$, respectively) following the wrapping procedure.

Schreuder used pressure/ volume relations to study the effects of LDM contractions on LV dynamics in clinical cardiomyoplasty (5). At a higher voltage burst activation significantly influenced the contractile response of the supported hearts if compared to stimulation at the routine clinical stimulus strength. Additionally, stroke volume decreased during incorrect LDM stimulation in 4 patients.

Although an extensive analysis of diastolic indexes was performed in our protocol, no substantial changes were documented comparing assisted with unassisted beats. This result is in accordance with the observations of Corin et al. (16) who documented a decline in the rate of diastolic pressure decay, a prolongation of the pressure relaxation costant, and an increase in passive chamber stiffness comparing pre versus postcardiomyoplasty diastolic data, suggesting that cardiomyoplasty may acutely induce the functional adaptation seen in hypertrophic hearts. This factor requires further study in severly diseased and dilated hearts.

The search for objective systolic augmentation following cardiomyoplasty often led to controversial findings. The evaluation of cardiomyostimulator-on versus cardiomyostimulator-off hemodynamics has been the subject of extensive clinical observations in recent reports $(17,18)$. Nevertheless, we believe that incomplete investigations have been performed, since a careful analysis of different timing of LDM contraction was not carried out.

The use of pressure/volume curves in our study was designed to evaluate the impact of the LDM contraction on the cardiac cycle. Nonetheless, as previously shown, echocardiography may represent an alternative tool to achieve comparable analysis of properly synchronized pedicled muscle activation. 
Finally, our observations confirm the wide range and heterogeneity of the hemodynamic changes in cardiomyoplasty. Many studies in experimental or clinical settings observed remarkable variability in systolic changes, resulting in no significant or slightly modified changes as an average, but a few cases of significant systolic improvement were observed. Our findings suggest that LDM/heart interaction is responsible for the hemodynamic response, and proper muscle graft contraction timing is necessary to ensure objective improvement. Several factors are likely to influence the actual action of a dynamic cardiomyoplasty, but these factors are still mainly unknown or still difficult to optimize (17). Both Lucas and Pekarsky showed the importance of muscle relaxation time in cardiomyoplasty $(19,20)$. Our study documented that an effective contractile response may be associated with some negative effects on the following beats because of longer LDM contraction/relaxation time than during the native cardiac cycle. Such a mechanical discrepancy may deserve additional attention at long term because of the the structural changes (fibrosis, lypomathosis) of a chronically stimulated skeletal muscle $(21,22)$.

The main limitation of our study may be related to the use of unconditioned. muscle in normal animal hearts. Nonetheless, clinical postoperative studies $(3-5,23)$ confirmed the influence of inappropriate J.DM/heart coupling on hemodynamics in chronically dilated and impaired hearts.

In conclusion, cardiomyoplasty appears to provide useful support to cardiac contractile performance. Our data demonstrate that the current power from the unconditioned muscle is sufficient to significantly improve systolic function, provided that correct synchronization of the LDM and the cardiac contraction is assured. Clinical studies have recently confirmed these findings $(4,5)$, making the analysis of the LDM burst stimulation delay mandatory in each patient. 


\section{References}

1. Carpentier A, Chachques IC. Myocardial substitution with a stimulated skeletal muscle: furst successful clinical case. Lancet 1985;1:1267. Letter.

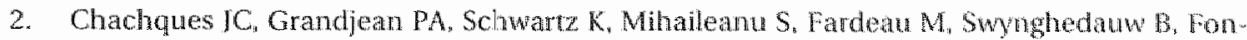
taliran F, Romero N, Wisnewsky C, Perier P, Chanvaud S. Bourgeois I, Carpentier A. Efect of latissimus dorsi dynamic cardionyoplasty on ventricular function. Circulation 1988:(Suppl (II) $78: 203-216$

3. Helou I. Misawa Y, Stewart JA, Colson M, Chiu RCJ. Optinizing "delay period" for burst stimu. lation in dynamic cardiomyoplasty. Arn Thorac Surg 1995:59:74-77.

4. Grubb N.R., Campanella C., Sutherland G.R., Sinclair C. Fox K.A.A. Optimizing muscle syn chronization after dynamic cardiomyoplasty, Lur J Cardiothorac Surg 1995:9:45 49.

5. Schreuder J, van der Veen FH, van den Velde ET. Delahaye F, Alfieri O, Jegaden $O_{n}$ Lorusso $R$, Jansen JRC, van Ommen V. Finet $G$, Wellens HIJ. Beat-to-beall analysis of left ventricular pressure-volume relation and stroke volume by conductance catheter and aortic modelfow in cardiomyoplasty patients. Circulation 1995;91:2010-2017.

6. Costanzo MR, Augustine S, Bourge R, Bristow M,O'Connel JB, Driscoll D, Rose E. Selection and treatment of candidates for heart transplantation. Circulation 1995;92:3593-3612.

7. Lange $\mathrm{R}_{\mathrm{b}}$ Sack FU, Voss B, De Simone R. Thielmann M, Nair A, Brachmann l, Haussmann R. Fleischer $\mathbb{F}$, Hagle $S$. Treatment of dilated cardionyopathy with dynamic candiomyoplasty: the Heidelberg experience. Ann Thorac Surg 1995:60:1219-1225.

8. Lorusso R, Sandrelli L, Volterrani M, Giordano A, Maisano F, van der Ven E, Schreuder , Par. dini A. Afferi O. Cardiomyoplasty as isolated procedure to treat refractory heart falure 9 th Annual Meeting, The European Association for Cardio-Thoracic Surgery, Paris 1995 (Proceed. ings).

9. Moreira LFP, Stolf NAG, Bocchi EA, Bacal F, Pego-Femandes PM. Abensur H, Menegheti JC, Jatene AD. Clinical and left ventricular function outcomes up to five years alter dynamic cardiomyoplasty. I Tharac Cardiovase Surg 1995;109;353-363

10. Jegaden $\mathrm{O}$, Delahaye $\mathbb{F}$, Finet $G$, van der Veen FH, Montagna P, Eker A, Ossete J, Rossi R, Saint Pierre $A_{0}$ Michaeloff PH. Late hemodynamic results after candiomyoplasty in congestive heart failure. Ann Thorac Surg 1994:57:1151-1157

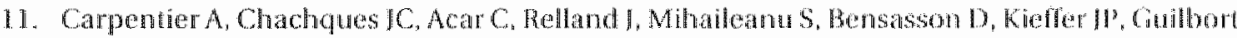
B. Tournay D, Roussin I, Grandjean PA. Dynamic cardiomyoplasty a seven years, I Thotac Candiowasc Surg 1993; 106:42-54.

12. El Oakley $\mathbb{R M}$, larvis JC. Cardionyoplasty: a critical review of experimeniă atud dinical resuls. Circulation $1994,90 \% 2085-2090$.

13. Molteni L, Amada H, Ferreira R, Ortega D. Assessment of the optimal time interval between QRS and single pulse stmulaton in dynarmic cardiomyoplasty. In: Chiu ROA. Bourpeois IM. eds. Transformed muscle for cardiac assist and repair. Mount Kisko, NY. Futura Publishing Co Inc.:1990: $188-196$

14. Geddes 1 , Janas W, Bourland ID, Cook , Hinds M. The importance of timing muscle conutc Hon in dynamic cardiomyoplasty. PACE 1993,5:2255-2265.

15. Nakajima H, Ninami H, Hooper TL, Hammond RL, Nakajima HO, Lu H, Ruggiero R, Thomas GA Mocek FW, Fielsam R, Krakovsky AA, Spanta AD, Suga H. Stephenson LW, Baciewicz l'A Candionyoplasty: probable mechanism of effectiveness using the pressure/ wotume relationship. Ann Thorac Surg 1994:57:407-415.

16. Corin W., George DT, Sink JD, Santamore WP. Dynamic cardiomyoplas ty acutely impars left ventricular diastolic function. I Thorac Cand iovasc Surg $1992 ; 104: 1662-1671$. 
17. Hagège A, Desnos M, Femandez F, Besse B. Mirochnik $N$, Castaldo M, Chachques IC, Carpentier $A$, Guérot $C$. Clinical study of the effects of latissimus dorsi muscle flap stimulation after cardionyoplasty. Circulation 1995;92(suppl 11):210-215.

18. Jondeau $G_{\text {, Dorent }}$ "Bors V, Dib JC. Dubourg $O$, Benzidia $R$, Grandjbakhch I, Bourdarias JP. Dynamic cardionyoplasty effect of discontinuing latissimus dorsi muscle stimulation on left ventricular systolic and diastolic performance and exercise capacity. I Am Coll Cardiol $1995 ; 26: 129-134$.

19. Lucas CMBI, van der Veen HH, Cheriex EC, van Ommen V. Pem OCKM, Wellens HJ. The importance of muscle relaxation in dynamic cardiomyoplasty. PACE Pacing Clin Electrophysiol $1992 ; 15: 1430-1436$

20. Pekarsky V.V., Akhmedow S.D., Dubrovgky IA, Baturin AV, Krivoschekov EV, Rizhikh AN, Pekarskaya MV. Optimal electrical stimulation for latissimus dorsi muscle after cardiomyoplasty. I Card Surg 1993;8:172-176.

21. Lucas CMHB, van der Veen FH, Cheriex EC, Lorusso R, Havenith M, Penn OCKM, Wellens HJ]. Long-term follow-up (12 to 35 weeks) after dynamic cardiomyoplasty. I Am Coll Cardiol $1993 ; 22,758-767$.

22. Kalil-Fiho R, Bocchi E, Weiss RG, Rosemberg L, Bacal F, Moreira LFP, Stolf NAG, Magalhaes $A A C$, Bellott $G$, Jatene $A D$, Pileggi $F$. Magnetic resonance imaging evaluation of chronic changes in latissimus dorsi cardiomyoplasty. Circulation 1994;90(Suppl In):102-106.

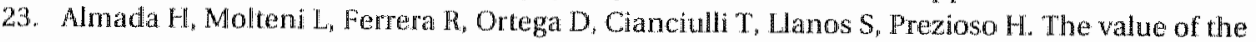
echo-doppler in cardiomyoplasty procedures. J Card Surg 1991;6(Suppl):113-118. 
CHAPTER

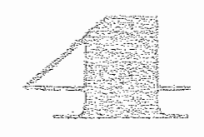

\section{Pre-operative physical training effects on latissimus dorsi muscle in patients undergoing dynamic cardiomyoplasty: a preliminary report}

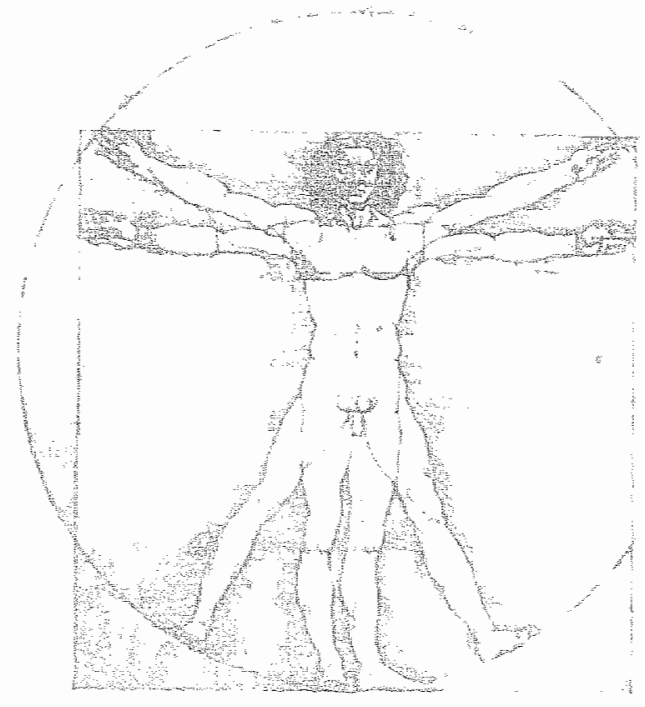

Roberto Lorusso, Valentino Borghetu, Michele De Fabritiis, Roberto Scelsi, Ugo Carraro, Ottavio Alfieri.

Presented at the XIXth World Congress of the International Society of Cardiovascular Surgery 1993, Lisbon Published in: Basic and Applied Myology 1993;3:211-218 


\begin{abstract}
The deleterious effects of long-standing heart failure on skeletal muscle structure have been recently documented. Nevertheless, skeletal muscles have surged in the latest years as potential tools to support a chronically impaired dilated heart. The risk of adopting a suboptimal assist device led us to investigate the changes induced by a physical training on the Latissimus Dorsi (LD) muscle in 3 patients undergoing Dynamic Cardiomyoplasty (DC) procedure.

Methods. All patients were submitted to 1.5-2 month training period before surgery. Muscular biopsies were taken before and after training. Muscle fiber diameter capillary morphometry, fiber/capillary ratio, mitochondrial size and percentage, and fiber typing were assessed in all the specimens. Moreover, computerized exercise equipment allowed comparisons between muscular peak torque (PT), total wotk done (TW), and work for repetition (W) before and after training.

Results. All patients completed the training protocol. Muscle performance clearly and significantly improved after the physical exercises. Peak torque increased from a minimal of $12 \%$ to a maximum of $83 \%$, TW from $82 \%$ to $191 \%$, and $\mathrm{W}$ from $38 \%$ to $100 \%$ according to the variuos exercise velocities. Electron microscopy documented the beneficial effects of such an adopted training: Fib re diameter increased from $42 \pm 6$ to $50 \pm 6 \mu \mathrm{m}(\mathrm{p}<0.001)$ in type 1 , from $40 \pm 7$ to $52 \pm 6 \mu \mathrm{m}$ in type $2 \mathrm{~A}(\mathrm{p}<0.001)$, and from $38 \pm 4$ to $48 \pm 3 \mu \mathrm{m}$ in type $2 \mathrm{~B}$ fibers $(p<0.001)$. Capillary/fiber ratio improved from $1.20 \pm 0.10$ to $2.00 \pm 0.12(p<0.001)$, and mitochondrial size increased from $0.045 \pm 0.018$ to $0.11 \pm 0.05 \mu \mathrm{m}(\mathrm{p}<0.001)$ in type 1 fibers, and from $0.030 \pm 0.019$ to $0.055 \pm 0.037 \mu \mathrm{m}$ ( $\mathrm{p}<0.001)$ in type 2 fibers. Not surprisingly, the myosin heavy chains remained substantially unchanged, since increased trophism of muscle fibers was similar in all the three types of myofibers.

Conchusion. This preliminary report documents the positive influence of physical training on LD structure as well as performance in parients undergoing DC procedure. Further studies are required to observe the effects of preoperative trained LD in terms of DC outcome.
\end{abstract}




\section{Introduction}

Dynamic Cardiomyoplasty (DC) is a surgical technique clinically introduced in 1985 by Carpentier and Chachques (2). Such a procedure was proposed as a new approach in the treatment of refractory heart failure to improve the impaired cardiac contractility by means of a wrapped and synchronously contracting Latissimus Dorsi (LD) muscle. Many investigators have extensively documented the alterations of skeletal muscles in patients with congestive heart failure $(7,9,27)$ and several have shown a wide range of muscular derangements induced by long-standing peripheral hypoperfusion related to chronically impaired left ventricular function $(18,30)$. In order to avoid suboptimal cardiac support to the failing heart following DC we designed a pilot study to thoroughly investigate the effects of a preoperative physical training in an attempt to restore or, at least, improve the performance of the LD muscle. Part of the results were previously reported $(6,24)$.

\section{Material and Methods}

Three male patients were included in this pilot study after informed consent was obtained. Patient age ranged from 51 to 56 years. All patients were affected by end-stage heart failure refractory to conventional pharmacological treatment (digitalis, diuretics, Ace-inhibitors). Hemodynamic parameters included left ventricular ejection fraction varying from $23 \%$ to $27 \%$, left ventricular enddiastolic diameter from $67 \mathrm{~mm}$ to $70 \mathrm{~mm}$, and New York Heart Association Class III. Traditional surgery (coronary bypass) was not considered advisable in case of ischemic etiology due to the absence of viable myocardium in akinetic areas. Heart transplantation was contraindicated in all patients due to severe peripheral vascular disease, diabetes and pulmonary hypertension. Several episodes of acute pulmonary edema occurred in all patients despite maximal medical therapy. Dynamic Cardiomyoplasty selection criteria were fulfilled in all the cases (3).

\section{The training protocol}

The training protocol consisted of repetitive sessions of isokinetic exercises for a 1.5-2 month period by means of a specific equipment (Cybex-Orthotron II, Lumex-Ronkonkoma, N.Y., USA). Such a machine allowed us to exercise a desired group of muscles (arm extensor muscles) leading to circumbscribed training and preventing potantial deleterious cardiovascular effects of a more generalized body training. The patients were recumbent in a supine position during exercise accomplishement. Both body sides were trained (right and left 
LD). All the patients underwent a pre-training evaluation to individually tailor the exercise parameters. The initial pre-training assessment was performed for 3 times and the best parameters were set up for the subsequent repetitions all along the protocol. The exercise consisted of arm extension beginning from an ante-flexion of $90^{\circ}$ which consistently elicit LD contraction as clearly documented by concomitant surface electromyographic monitoring. The patients were submitted to 5 sessions per week, and each session included 10 series of 6 repetitions of the same exercise, with a 2 -minute rest period between each series. Exercise parameters included the peak torque (foot-pounds), and muscle work for repetition (foot-pounds). The tests were performed at different velocities according to the degree scale (low velocity- $60^{\circ} / \mathrm{sec}-$, or $90^{\circ} / \mathrm{sec}$-medium velocity, $120^{\circ} / \mathrm{sec}$, and $180^{\circ} / \mathrm{sec}$-high velocity). The final muscle performance assessment (end-training evaluation) was performed after the training period submitting the patient at 2 tests, recording the best response. At the highest velocity in spite of the work for repetition we recorded the total work done in 15 seconds. The test was performed according to the protocol described by the program HUMAC V 5.01 (Computer Sports Medicine, Inc., Waltham, MA, USA). During exercise accomplishment, heart rate and blood pressure (cuff method) were sistematically controlled (basal, during, at peak, and recovery) to avoid any deleterious effects. Moreover, ECG was costantly monitored to detect any arrhythmia occurrence.

Mechanical data were processed by means of a personal computer (Olivetti 290-30, Ivrea, Italy) which enabled us to visualize in real time the results of the exercise. Pre-training and end-training data were compared to analyse the induced changes in terms of muscular performance.

\section{Histology}

Pre-training muscle biopsies were taken from the right LD in order to avoid any potential damage to the left LD which was utilized for the wrapping procedure at surgery. Other muscle biopsies were taken at the end of the exercise protocol from the right and during surgery from the left LD (post-training samples). Muscle specimens were partially frozen in isopentane cooled in liquid nitrogen at $-170^{\circ}$ for enzyme histochemistry. Other samples were fixed in $10 \%$ neutral formalin for routine staining and other small specimens were fixed in Karnovsky fluid for electron microscopy. Serial transverse cryostat sections were treated for myofiber ATP-ase at $\mathrm{pH} 9.6$ for ATP-ase EDTA reversal at $\mathrm{pH} 4.35 \mathrm{ml}$ and for NADH. According to the staining properties for acid myofiber ATP-ase the muscle fibers were classified into type 1 , type $2 \mathrm{~A}$, and type $2 \mathrm{~B}$ fibers.

Histological evaluation also included the assessment of fiber type diameter. Quantitative analysis of fiber diameter and of mitochondrial parameters was accomplished on micrographs adopting an automatic Interactive Image Analy- 
sis System-IBASI, II (Kontron, Bildanalyse, Munich, Germany). Each micrograph was placed under a TV camera and the related image was shown on a screen. The image was processed according to a program properly devised and selected from the program menu of the IBAS system. Automatically the chosen structures were counted and measured. In our measurements we selected 3 parameters: area, diameter (of area-equivalent circle) and area percentage. The area percentage was automatically assessed as the ratio between the area occupied by the structures and the field where these structures were contained. This field was selected by a determined window inside the fiber. All measurements were calculated in microns (micron square for the area). The estimation of capillaries was performed on paraffin embedded transverse sections stained with Gomori silver impregnation for reticulin and on semithin transverse sections of Karnovsky fixed material. The numerical density of capillaries (CD) was evaluated with the frame in the eyepiece of the microscope at $40 \mathrm{X}$ objective. The $\mathrm{CD}$ per area was calculated as: number of capillaries within the frame/area of the frame. The capillaries/fiber ratio $(\mathrm{C} / \mathrm{F})$ was calculated as: capillary number within the frame/number of fibers within the frame.

We previously described in details the methods of myosin purification and quantitation by densitometry of SDS PAGE of MHC $(5,22,23)$. Histology values were stored on a floppy disk for the statistical analysis by means of the IBAS I system. Histogram were computed either for the area or for the diameter. At the same time, basic statistics data (count number, number of size classes, number of counts in under and/or overflow, minimal, maximal and mean value, and standard deviation) were given.

\section{Results}

All the three patients completed the training protocol and no major complications occurred. For the patient nol the training protocol was not performed according to the HUMAC program, and therefore, we assessed only the peak torque at $60^{\circ}, 90^{\circ}$, and $120^{\circ} / \mathrm{sec}$. In patient no2 the low velocity exercises have been accomplished at $90^{\circ} / \mathrm{sec}$ since the $60^{\circ} / \mathrm{sec}$ velocity induced some derangement of hemodynamic parameters and was considered an excessive workload.

All patients showed improvement of muscle performance. The entity of positive changes from pre-training values encompassed a wide range of results accordingto the different velocities (figure 1). Indeed, PT increased from $43^{\%}$ (pt no 3) to $60 \%$ (pt no 1) at $60 \% / \mathrm{sec}$ exercise, from $15 \%$ (pt no 2) to $68 \%$ (ptno I) at $90 \% / \mathrm{sec}$, from $22 \%$ (pt no2) to $75 \%$ (pt no 3 ) at $120 \% \mathrm{sec}$, and from $12 \%$ (pt no 2) to $83 \%$ (pt no 3) at $180^{\circ} / \mathrm{sec}$. 

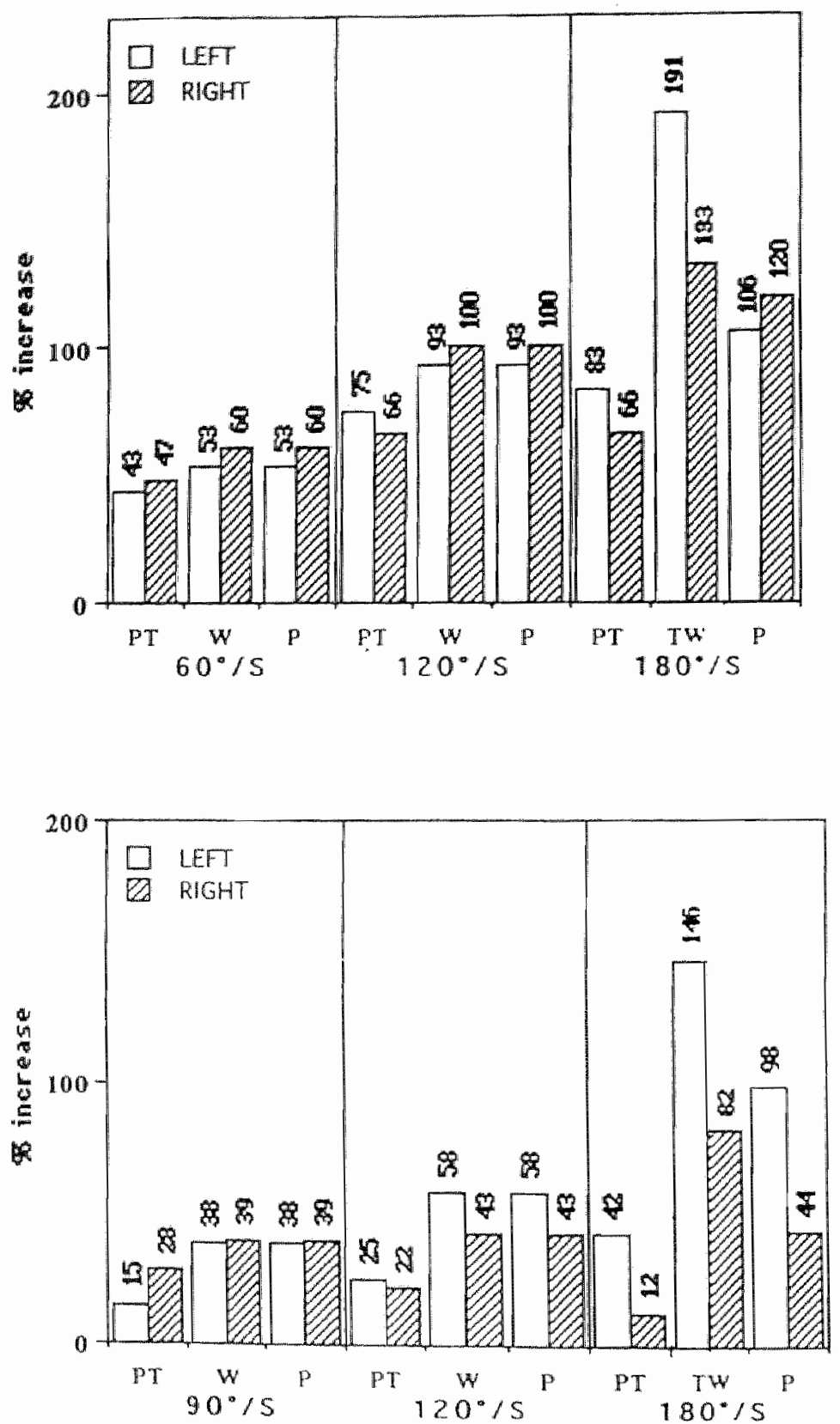

PT: Peak Torque. W: Work for repecition. TW: Total Work (done in $15 \mathrm{sec}$ ) P: Mean Power for repecition

Figure 1. This figure reports the graphics related to muscular performance of patient no 2 upper part) and patient no 3 (lower part) following the raining protocol. The bars relate to the percentage of increase in respect lo pre-training data. Peak torque, work for repetition, power, and total work done are shown. Clear beneficial effects on both muscle groups, right and left, are documented. 
Table 1. Fibre type diameter and composition in LD muscle before and after traming.

\begin{tabular}{|c|c|c|c|c|c|c|}
\hline & \multicolumn{3}{|c|}{ Fibre type diameter (fum) } & \multicolumn{3}{|c|}{ Fibre types $[\%]$} \\
\hline & 1 & $2 A$ & $2 B$ & $\mathbb{1}$ & 24 & $2 B$ \\
\hline Untrained & $42 \pm 6$ & $40 \pm 7$ & $38 \pm 4$ & 44 & 36 & 20 \\
\hline Traned & 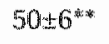 & $52 \pm 6 *$ & $48 \pm 3^{* 4}$ & 40 & $44 * *$ & 16 \\
\hline
\end{tabular}

$* p<0.05 * * 0<0.01$

Table 2. Changes in capillary morphometry in untrained and trained LD muscles. C/F capillary/fibre ratio; $\mathrm{CD}$ : capillary density

\begin{tabular}{lll}
\hline & $C 1 F$ & $C D$ \\
\hline Untrained & $1.20 \pm 0.10$ & $220 \pm 30.8$ \\
Trained & $2.00 \pm 0.12^{\text {*** }}$ & $200 \pm 228$ \\
\hline
\end{tabular}

* $\mathrm{p}<0.01$

Table 3. Mitochondrial size and percentual area in untrained and trained LD muscles.

\begin{tabular}{|c|c|c|c|c|}
\hline & \multicolumn{2}{|c|}{ Size (diameter,fm) } & \multicolumn{2}{|c|}{ Percentual area } \\
\hline & Fibre type 1 & Fibre type 2 & Type 1 & Type 2 \\
\hline Untraned & $0.045 \pm 0.018$ & $0.030 \pm 0.019$ & 19.8 & 8.7 \\
\hline Trained & $0.11 \pm 0.05^{*}$ & $0.055 \pm 0.037^{*}$ & 23.2 & 11.7 \\
\hline
\end{tabular}

*0<0.01

Table 4. SDS PAGE of myosin heavy chains

\begin{tabular}{llll}
\hline & & & \\
\cline { 2 - 3 } MHC lype & $2 A$ & $2 B$ & 1 \\
\hline LD: left $[5]$ & $35(27-40)$ & $26(12-48)$ & $39(24-51)$ \\
LD: right, pre-training $[5]$ & $36(25-49)$ & $24(14-43)$ & $40(22-49)$ \\
LD: right, posturaing $[1]$ & 51 & 19 & 30 \\
\hline
\end{tabular}

Percentual content of myosin heavy chains; Mean with apper and lower figures. Nunuber olcases in square brackets. 

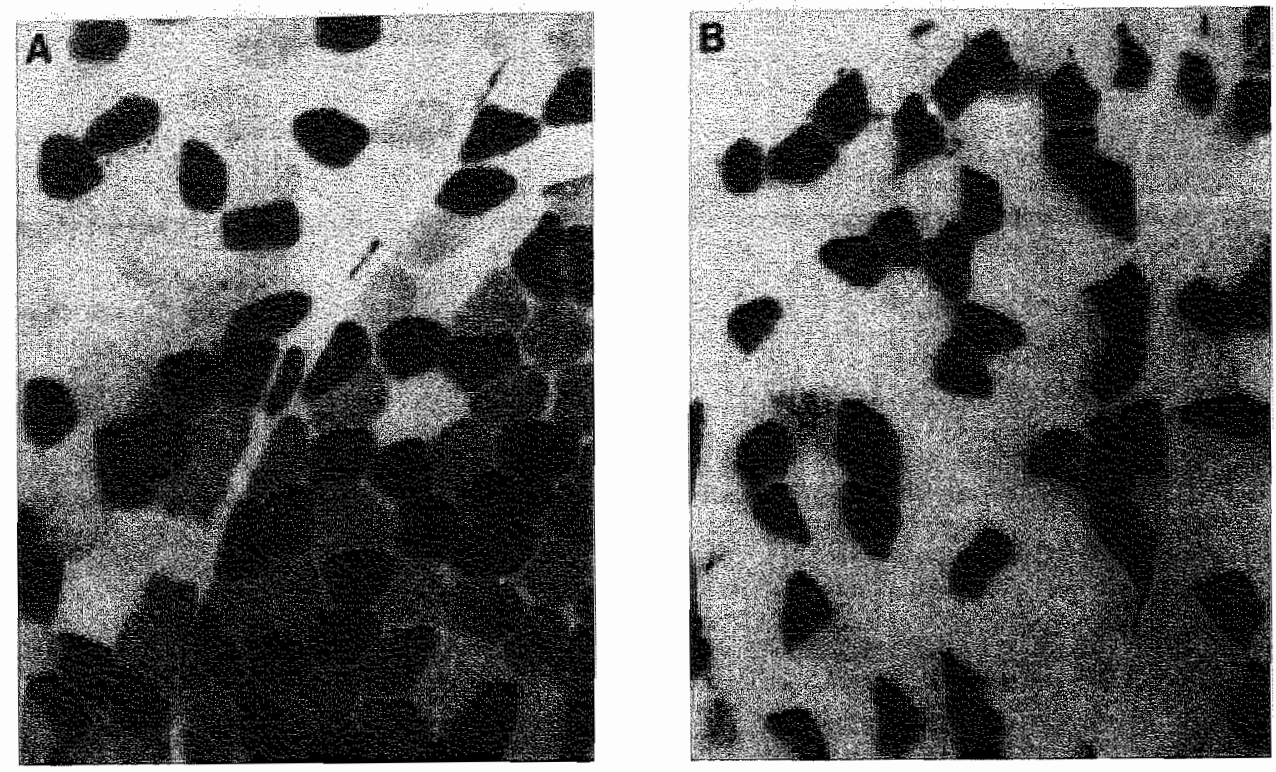

Figure 2. Myofibrillar ATP-ase after incubation at pH 4,6. LD before (A) and after (B) physical training. In pane $B$ there is a predommance of rype 2A fibers. Only scattered type $2 \mathrm{~B}$ fibers (star) are present.

The increases of the work for repetition ranged from $53 \%$ (pt no 3) to $60 \%$ (pt no 2) at $60 \% / \mathrm{sec}$, from $38 \%$ (pt no 2) to 39\% (pt no 3) at $90^{\circ} / \mathrm{sec}$, from $43 \%$ (pt no 2) to $100 \%$ (pt no 3 ) at $120 \%$ sec.

The total work done, obtained only at the velocity of $180^{\circ} / \mathrm{sec}$ in patient no 2 and patient no 3 improved $82 \%$ and $191 \%$, respectively.

Histological findings confirmed a better muscular condition following the training program (figure 2). Indeed, LD type 1, type $2 \mathrm{~A}$, and type $2 \mathrm{~B}$ fiber diameter increased significantly (table 1). Trained muscles were shown to be better perfused since a significant increase of capillary/fiber ratio was documented (table 2). The reported inverse relationship with the capillary density was correlated to the augmented skeletal muscle fiber diameter. A more active and efficient aerobic metabolism was shown by means of documenting an increased NADH activity. The mitochondrial content was positevely changed by exercise program with a marked increased of size and percentage in muscle fibers (table 3).

Since the light exercise affects at the same extent all the myofiber types it is not surprising that the MHC patterns remained unchanged after training: table 4 shows that the variations among trained versus untrained LD is of the same extent or smaller than the changes among right and left muscles of the patients. 


\section{Discussion}

The impairment of cardiac contractility and subsequent reduction of pumped blood flow in CHF leads to a reduction of peripheral perfusion. Chronic hypoperfusion induces some adaptive changes in the peripheral organs, and skeletal muscles have been documented to develope peculiar abnomalities and to represent one of the more affected districts in response to long-lasting cardiac dysfunction $(7,9,27)$. Mancini and coll. documented atrophy occurring in skeletal muscles of patients with chronic heart failuer, even in its mild to moderate states (18). This study furthermore demonstrated the presence of important fatty infiltration among muscle fibers. The authors hypothesized that muscle impairment in CHF might be related to several etiologies, namely malnutrition, inactivity, increased metabolic state secondary to high levels of circulating catecholamines, cortisol, ACTH and tumor necrosis factor. The reduction of exercise capaity of these patients was therefore correlated to the altered skeletal muscle condition, and not solely to the reduced cardiac output. Mancini. moreover demonstrated a derangement of the peculiar metabolic pathways, especially the ones related to phosphocreatine use and resynthesis (7).

An adjunctive and fascinating hypothesis has been indicated by Dunningan and Caforio who suggested that skeletal musle abnormalities might be secondary to cardiac failure, as a part of generalized myopathy, or an underlying genetic disease, or an autoimmune pathology $(1,10)$. Drexler demonstrated that in $\mathrm{CHF}$ patients there is a significant reduction of volume density and surface area of mitochondrial cristae leading to a reduced aerobic activity of skeletal myocyte. Moreover he showed a direct relationship between muscle alteration and exercise capacity arguing that these negative muscular feature might be reversible (9). Wilson and Massie demonstrated a decrease of intracellular $\mathrm{pH}$ values by studying the CHF skeletal muscle adopting a phosphor 31 Magnetic Resonance Image (19,31). Other feature of chronic heart failure-related skeletal muscle derangement consists of an impaired plasma inorganic phosphate utilization.

Patients affected by CHF have been commonly treated so far by conventional pharmacological therapy in concomitance with exercise or exertion avoidance. This conduct is likely to be no longer accepted because of the recent findings on the matter. A slight exercise training has been shown to induce favorable adaptation in the skeletal muscles $(19,29)$. This effect derives from metabolic "improvement" due to greater reliance on fat oxidation and reduced lactate production. The marked negative changes imposed by the muscle deconditioning due to the rest therapy are consistent with a progressive deterioration of the patient clinical status and quality of life. Recent reports have documented a shift from type $\mathbb{I}$ and type $2 \mathrm{~A}$ fibers to type $2 \mathrm{~B}$ fibers with subsequent marked increase of anaerobic metabolism in CHF patients $(25,28)$. All 
these findings clearly underline the imparred condition of skeletal muscles in case of long-lasting cardiac dysfunction.

Nevertheless, skeletal muscle have been recently proposed as potential long-term cardiac assist to treat refractory CHF patients $(2,3)$. Some reports have documented clinical improvement after LD wrapping and synchronous contractions $(4,11,15,20,21)$. Anyhow an heterogeneous range of postoperative results have been published pointing out the lack of predictors in terms of surgical results. All the investigators involved in the cardiomyoplasty project are well aware that still little is known in respect to the skeletal muscle response and adaptation induced by long-term stimulation and by the new functional task. The factors linked to a better postoperative outcome are still unclear. Patient selection, in terms of hemodynamic criteria, has been imputed so far as the main cause of the wide range off surgical results, but other determinants, unfortunately still to be disclosed, are likely to play a major role. Muscle immobilization has been invariably linked to a reduction of oxidative enzymes, muscle mass and capillary density $(12,14)$. Skeletal muscle deconditioning (secondary to reduced exercise activity, frequent hospitalizations, and bedrest) in patients affected by severe left ventricular dysfunction is considered the most likely trigger of myocyte derangement $(8,26,32)$. We can speculate therefore that the abnormalities induced by long-lasting skeletal muscle underpefusion in congestive heart failure and the concomitant phenomenon of muscle deconditioning may be deteriorated by the muscle-related effects of DC procedure (muscle immobilization in the 2 weeks after surgery). Moreover, some evidences have been reported about the damage induced by surgical manipulation (harvesting and transposal) and long-term electrical stimulation at high regimen as adopted in the clinical practice. Lucas and Kali-Filho separately reported degeneration of wrapped skeletal muscle claiming that the actual consequences of such a prolonged stimulation with the current adopted pacing protocol ( $30 \mathrm{~Hz}$ of pacing frequency, and $1: 1$ or $1: 2$ contraction ratio) might negatively influence the muscle viability and performance at long term $(13,16)$. Thereby preoperatively abnormal skeletal muscles are likely adopted during DC surgery and the subsequent postoperative electrical conditioning may act as a further source of muscular damage due to the highly demanding muscle function. Such a combination of negative factors might irreversibly lead to a design of an unproper assist device.

Many studies have shown us the effects of chronic electrostimulation in terms of muscle adaptation, but none focused these changes in CHF skeletal muscles.

These preliminaries prompted us to investigate, in a pilot study, the struccural and functional changes induced by a brief training period merely in LD muscles involved in DC procedure. Our aim was meant as an initial attempt to optimize skeletal muscle condition preoperatively. 
As mentioned before, CHF patients are characterized by well identified muscle abnormalities which should be reversed to provide optimal condition for a long-term cardiac assistance. The preoperative LD muscle training, which was tailored according to the individual features, enabled us to pursue the improvement of the target muscle as well as to prevent potential cardiovascular adverse effects related to strenuous exertion in such patients. Our preoperative data did confirm that these patients were not in terminal phase of heart failure, showing some functional reserve left (NYHA Class III). The programmed physiscal training contributed to improve dramatically the muscular performance. The muscle functional parameters improved significantly in all patients following the tarining program. Histology of trained muscles confirmed the beneficial impact of training on the myocyte structure.

The adopted protocol is absolutely reproducible and feasible. It is conceivable that an improved preoperative muscle condition might favorably influence the muscle response to the new muscular functional demand as required following DC. The preoperatively trained muscles are better vascularized, as documented by electron microscopy. The reduced vascular supply due to surgical harvesting at the distal part of the LD, may be counteracted by such a preoperatively enhanced vascularization or provide more flow in response to the augmented requests, and eventually improve muscle performance.

We strongly believe that current investigation in terms of preoperative muscle histological and functional characteristics following an exercise test will surely add more information and they might provide additional clues for a more precise patient selection.

A thorough knowledge on the correct use of skeletal muscle potentials is still far from the current clinical practice, but ongoing studies are sheding new lights on long-term muscle preservation and function.

The effects of postoperative LD recovery period (no muscle contraction) and subsequent ellectrical stimulation on the preoperative physically-induced muscle changes are still unknown, are careful assessment is required to validate the real clinical impact. 


\section{References}

1. Caforio ALP, Rossi B, Risalu R, Siciliano G, Marcheti A Agnelli C. Crea F, Mariani M, Muratorio A. Type I fiber abnormalices in sketetal muscle of patients with hypertrophic and dilated cardiomyopathy: evidence of subchinical myogenic myopathy. I Am Coll Cardiol $1989 ; 14: 1464-1473$.

2. Carpenter A, Chachques JC. Myocardial substitution with a stimulated skeletal muscle: first successful clinical case. Lancet 1985;1:1267

3. A Carpentier, JC Chachques. Cardionyoplasty: surgical technque. From: A Carpentier, IC Chachques, P Grandjean (eds). Cardiomyoplasty. Futura Publishing Inc., Mount Kisko, NY, $1991,105-122$.

4. Canpentier $A$, Chachques JC, Acar $C$, Relland J, Mihaileanu $S$, Bensasson D, Kieffer JP, Guilbor: P. Toumay D, Roussir 1, Grandjean PA. Dynamic cardiomyoplasty at sewen years. I Thorac Cardiowase Surg 1993;106:42-54.

5. Cararo $U$. Contractile proteins of fatigue resistant muscle Sem Thorac Cardiovase Surg $1991 ; 3: 111-115$.

6." Camaro U. Catani C, Scetsi R, De Fabritis M, Lorusso R, Affieri O. Isomyosin and morphometry of latissimus dorsi muscle physiokinesiologically trained before dymamic candionyoplasty. Congress of Mechanical Circulatory Support, London, U.K. 1993, Proceedings.

7. Drexter H. Skeletal muscl falure in heart failine. Circulation 1992:85:1621-1632.

8. Drexler H, Munzel T, Riede U, Just H. Adaptive changes in the periphery and their therapeutic consenques. Am 1 Cardiol 1991;67:29C-35C.

9. Drexler $H$, Riede U. Munzel T, Kong $H$, Funke $\mathrm{E}$, Just $H$. Alterations of skeletal muscle in chronic hear fallure. Circulation 1992;85:1751-1759.

10. Dunningan A, Staley NA, Smith SA, Pierpont ME, Judd I, Bendit DG, Bensen DW. Cardiac and skeletal muscle abnormalities in cardomyopathy; comparison of patients with ventricular tachycardia or congestive heart failure. I An Coll Cardiol 1987;10:608-618.

11. Furnary AP, Magovern IA, Cgristicb IY, Onie JE, Simpson KA, Magovem GI. Clinical cardiomyoplasty: pte-operative lactors associated with outcome. Ann Thorac Surg 1992;54:11391143

12. Haggmatk T, fansonn E. Eriksson A. Fiber type area and metabolic potential of the thigh musce in mon afua kned surgery and immobitization. J Appl Physiol 1981:2:12-17.

1\%. Kali- Who R, Bochi E, Weiss RG, Rosemberg L, Bacal F, Moreira LFP, Stolf NAG, Magalhaes MC. Belloti G. Jatene A. Pileggi F. MR evaluation of chronic morphological changes in latissimus dorsi cardionyoplasty. Circulation 1993,38(Suppl IV):2889.

14. Krigger DA, The CA, MCMillin-Wood I. Booth FW. Population of rat skellat muscle mirochondria after exercise and immobilization. J Appl Whysial 1980;48;23-28.

15. Lorusso R, Zogno M. La Canna G. Metra M. Sandrelli I. Borghenti V. Maisano F, Alfieri O. Dynamic cardiomyoplasty as an effective therapy for dilated cardiomyopathy .J Card Surg $1993: 8: 177-183$.

16. Lucas $C$, van der Veen H, Cheriex E, Lorusso R. Havenith M, Pen OCKM, Wellens HIJ. Longterm follow-up $(12$ to 35 meeks) after dynamic cardiomyoplasty. I Am Coll Cardiol $1998 ; 22: 758-767$.

17. Mancini DM, Coyle E, Coggan A, Bela J, Fertaro N, Montain S. Wilson IR. Contribution of intrinsic skeletal muscle clanges to $3 \mathrm{H}$ NMR skeletal muscle metabolic abnormalities in palients win chronic heart falure. Circulation 1989:801338-1346.

18. Mancin DM, Walter G, Reichek N, Lenkiski R. McCully KK, Mullen JL, Wilson JR. Contribution of sketal muscle atrophy to exercise intolerance and altered muscle metabolism in heart failure. Circulation 1992;85:1364-1373. 
19. Massie BM, Conway M, Yonge R, Rajagopalan $\mathrm{B}$, Yonge $\mathrm{R}$, Fostick $\mathrm{S}$, Lendigham I. Sleight $\mathrm{P}$, Radda $G$. 31 -P nuclear magnetic resonance evidence of abnormal skeletal muscle metabolsm in patients with congestive heart failure. Am J Cardiol 1987,60:309-315.

20. Minotti IR, Johnson EC. Hudson TL, Zuroske $\mathrm{G}$, Murata G, Fukushima E, Cagle TG, Chik TW, Massie BM, Icenogle MV. Skeletal muscle response to exercise training in congestive heart failure. J Clin Invest 1990:86:751-758.

21. Moreira LFP, Seferian P, Bocchi EA, Femandes PMP, Stoll NAG. Barreto ACP. Jatene AD. Survival improvement with dynamic cardiomyoplasty in patients with dilated candiomyopathy. Circulation 1991;84(suppl III):296-302.

22. Rizzi $\mathrm{C}$, Carraro U. Electroendosmotic preparative gel electrophoresis and peptide mapping of slow and three fast myosin heavy chains. Bas Appl Myol 1991:1:43-53.

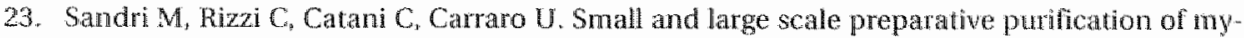
osin light and heavy chains by selective KDS precipitation of myosin subunits: $Y$ eids by SDS PAGE and quantitative orihogonal densitometry. Bas Appl Myol 1992:2:107-114.

24. Scelsi R, Carraro U, Rizzi C, Lorusso R, Afferi O. Utilization of latissimus dorsi muscle in dy. namic cardiomyoplasty. A morphometric and electrophoretic study. 29 th Meeting of the Iralian Neuropathological Association, Verona, Italy, 1993, Proceedings.

25. Shabetai R. Beneficial effects of exercise training in compensated heart failure. Circulation $1988 ; 78: 775-776$.

26. Sulliwan MI, Binkley PF, Unwerfeth DV, et al. Prevention of bedrest-induced physical deconditioning by daily dobutamine infusions: implications for drug-indituced physical conditioning. I Clin Invest 1985:76:1632-1642.

27. Sullivan MJ, Green HI, Cobb FR. Skeletal muscle biochemistry and histology in ambulatory patients with long-term heart fallure. Circulation 1990;81:518-527.

28. Suliwan MJ, Green HJ Cobb FR. Altered skeletal muscle netabolic response to exercise in chronic heart failure. Cinculation 1991;84:1597-1607.

29. Sultivan MI, Higginbotham MB, Cobb FR. Exercise training in patients with severe left ventricular dysfunction: hemodynamic and metabolic effects. Circulation 1988;78:506m-5 15 .

30 . Wasserman $K$. Reduced aerobic enzyme activity in skeletal muscle ol patients with heart failure. Circulation 1991;04:1868-1870.

31. Wilson IR, Funk L. Maris J, Ferrano N, Power-Vanwart I, EletlS, Chance B. Evaluation of energy metabolism in skeletal muscle of patients with heart failure will gated phosphorus-31 nucleat magnetic resonance. Circulation 1985,71:57-62.

32. Wison JR, Mancini DM. Skeletal muscle metabolic dysfunction implication for exercise intolerance in heart failute. Circulation 1993;87 (suppl VIl): $104-109$. 


\section{CHAPTER}

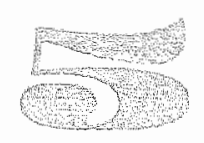

\section{Cardiomyoplasty as isolated procedure to treat refractory heart failure}

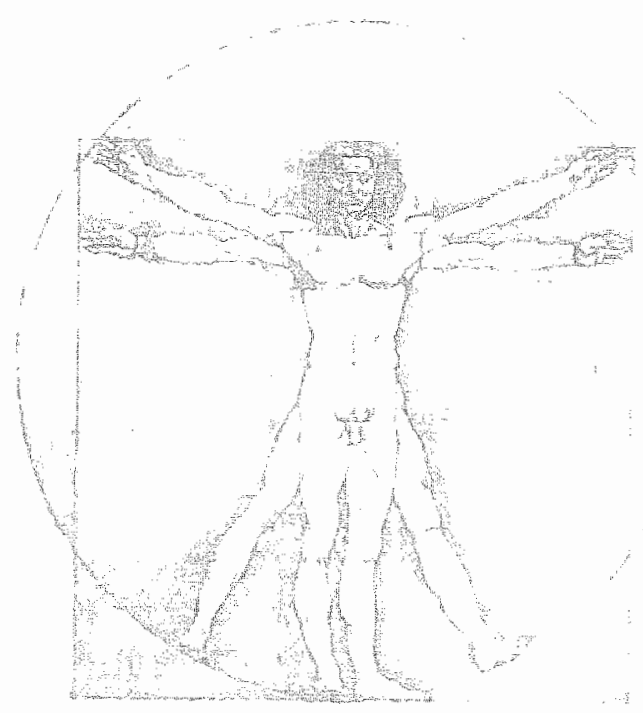

Roberto Lorusso, Elisa Milan, Maurizio Volterrani. Raffaele Giubbini, Frederik H. van der Veen, Jan J. Schreuder. Alberto Picchioni, Ottavio Alfieri.

Presented at the 9th EACTS Congress 1995, Paris - Winner of the Young Investigator's Award 1995 of the European Association for Cardio-Thoracic Surgery

Published in: The European Joumal of Cardio-Thoracic Surgery 1997;1 1:362-372 


\section{Abstract}

Objective. Cardiomyoplasty represents a controversial therapy for chronic heart failure. The aim of this study is to review our experience of such a surgical procedure as an isolated approach to treat refractory left ventricular dysfunction.

Methods. Twenty-two patients were considered candidates for cardiomyoplasty because of chronic heart failure. Mean age was $58.7 \pm 5.3$ (48-71 yrs), 19 patients were male and 3 were female. Eleven cases had an ischemic cardiomyopathy, and 11 an idiopathic cardiomyopathy. Traditional as well as innovative techniques were used to assess hemodynamic function. Preoperative hemodynamic profile included mean left ventricular ejection fraction of $20 \pm 5.8 \%(9-28 \%)$, absence of severe right ventricular failure, and mean left ventricular end-diastolic diameter of $75.5 \pm 7.4 \mathrm{~mm}$ (range from 61 to $92 \mathrm{~mm}$ ). All patients were in New York Heart Association Class III or Intermittent IV despite conventional medical therapy.

Results. There was no intra-operative death. No additional surgery was performed. Left latissimus dorsi (LD) muscle was used in 20 cases, and right LD in 2 patients. Early mortality occurred in 1 patient (low cardiac output syndrome), whereas late moriality in 5 patients ( 3 sudden deaths, 1 lung cancer, 1 heart failure). Mean follow-up is $20.7 \pm 16.7$ months (from 3 to 51.1 months). Actuarial survival at 4 years is $70 \%$. Cardiac index increased at 6 months (from $2.59 \pm 0.5$ $\mathrm{L} / \mathrm{min} / \mathrm{m} 2$ to $3.08 \pm 0.5 \mathrm{~L} / \mathrm{min} / \mathrm{m} 2-\mathrm{p}=0.04$ ), but no other significant changes were observed at long term $(3.03 \pm 0.7 \mathrm{~L} / \mathrm{min} / \mathrm{m} 2,3 \pm 0.7 \mathrm{~L} / \mathrm{min} / \mathrm{m} 2$, and $2.85 \pm 0.7$ $\mathrm{L} / \mathrm{min} / \mathrm{m} 2$, at $1.2,24$, and 36 months, respectively). Ejection fraction improved at 6 and 12 months $(29.1 \pm 1.03 \%-p=0.0017$, and $27.3 \pm 5.62 \%-p=0.0091$, respectively), while no change was documented at 2 and 3 years $(25.6 \pm 2.5$, and $25.1 \% \pm 4.0$, respectively). Left ventricular end-diastolic diameter was markedly reduced at $6(73.2 \pm 8.0 \mathrm{~mm}-\mathrm{p}=0.0176), 12(69.4 \pm 8.5 \mathrm{~mm}-\mathrm{p}=0.002)$, and 24 months $(71.1 \pm 7.0 \mathrm{~mm}-\mathrm{p}=0.011)$, remaining stable $(74.0 \pm 9.1 \mathrm{~mm}-\mathrm{p}=0.47)$ at 36 months, Post-operative pressure/volume loop evaluation showed some improvement of hemodynamic function from skeletal muscle assistance. Acute pulmonary edema episodes, as well as number of hospitalizations, were considerably reduced following cardiomyoplasty.

Conclusions. In our experience, cardiomyoplasty showed to have moderate beneficial influence on left ventricular performance, to significantly reduce cardiac dilatation, and to promote stabilization of the disease course. 


\section{Introduction}

The increasing incidence of chronic heart failure, with the impossibility to control this by means of heart transplantation [25], necessitates the search for surgical alternatives in the treatment of refractory heart failure.

Permanent cardiac assistance has been the target for many scientists and investigators. The attractive concept of using the autologous power of patient's own skeletal muscle to drive a biologic cardiocirculatory assistance prompted many surgeons to become involved in that challenging research to halt progressive cardiomyopathy and to improve cardiac performance.

The need to develop an alternative to heart transplantation, led the first pioneers to perform cardiomyoplasty in terminal patients, with subsequent suboptimal results [8]. Also, the use of cardiomyoplasty together with other surgical procedures may have masked the actual influence of wrapped skeletal muscle on the patient outcome $[3,9,19]$.

This study reports on the application of cardiomyoplasty as an isolated procedure in patients with no other therapeutic options (refractory heart failure and heart transplant contraindicated) in order to precisely evaluate the effects of such a surgical therapy.

Our 4-year experience is presented, with emphasis on originall contributions in terms of patient selection, surgical technique, and post-operative evaluation.

\section{Material and Methods}

Twenty-two patients were accepted for cardiomyoplasty in our institution. All patients were not eligible for heart transplantation because of medical or social reasons (table 1). Ages ranged from 48 to 71 years (mean $58.7 \pm 5.37$ years), 19 patients were male and 3 were female.

All patients were under conventional medical therapy for chronic heart failure (digoxin, ACE-inhibitors, diuretics, and other vasodilators), and in New York Heart Association (NYHA) Class III or Intermittent IV at the time of surgery. No patient was in a terminal stage of congestive heart failure. The preoperative hemodynamic profiles of the patients are shown in table 2.

The etiology of dilated cardiomyopathy consisted of coronary artery disease (CAD) in 11 patients, and idiopathic cardiomyopathy in 11 patients. In CAD patients, the presence of potentially reversible akinetic myocardium (thibernating myocardium) was pre-operatively ruled out with traditional techniques (restredistribution Thallium, stress-test echocardiography). No patients suffered from angina.

One patient had cardiac malposition (displacement to the right), left diaphragm eventration and hypotrophy of the left upper trunk muscles because of 
Table 1. Contrandications to heart transplantation

\begin{tabular}{ll}
\hline Age & 4 \\
Diabetes (nosulin dependent) & 6 \\
Peripheral wascular disease & 4 \\
Pumonary Hypertension & 1 \\
Pumonary disease & 1 \\
Left diaphagm eventration & 1 \\
Chronic Rerial Insufficiency & 2 \\
Social reasons & 3 \\
\hline
\end{tabular}

Table 2. Pre-operative hemodynamic and functional data of patients submitted to cardiomyoplasty procedure.

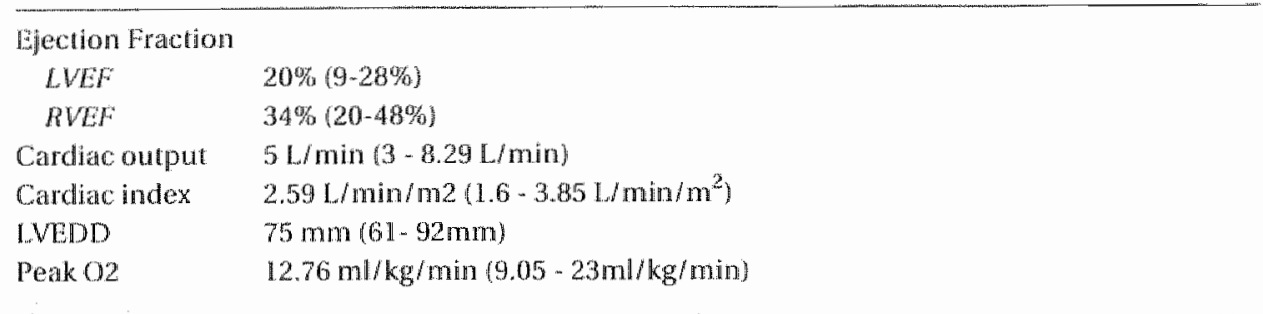

LVEF: Left Ventricular Ejection Fraction, RVEF: Right Ventriculat Ejection Fraction. Al data are presented as mean.

previous trauma. One patient had had a left lung tubercolosis treated by pneumothorax leading to extensive calcification of the left pleura.

\section{Patient selection}

Cardiomyoplasty was considered only when the course of heart failure was characterized by frequent hospitalizations ( $3.3 \pm 1.5$ hospitalizations 1 year before surgery) or episodes of acute left ventricular dysfunction (from 1 to 7 episodes in the year preceding the operation), despite appropriate medical therapy.

Patients affected by CAD received more careful evaluation. The approach of our first 6 ischemic candidates was characterized by a search for any sign of viable myocardium using traditional diagnistic methods. Echocardiographic evaluation during low-dose dobutamine infusion was used to quantitate the contractile response of akinetic segments. The observation of a non significant recovery of myocardial function represented a strict criteria for ineligibility for CABG and an indication for cardiomyoplasty, if the patient fulfilled the other 
inclusion criteria. In the second part of the clinical series, we studied cardiac response at higher dosage of dobutamine (up to $40 \mu \mathrm{g} / \mathrm{kg} / \mathrm{min}$ ) when no significant contractile response was evoked at lower concentration. Such a protocol was designed in order to preoperatively reproduce the quality of cardiocirculatory reaction or the occurrence of adverse effects (arnhythmia, appearance or deterioration of mitral regurgitation, etc.) because of residual ischemia of small myocardial zones.

Atrial fibrillation (4 patients) or a previously implanted pace-maker (1 patient) were not considered absolute contraindications for cardiomyoplasty unless a failure of medical therapy to control ventricular response during exercise testing was documented.

Further inclusion criteria followed the guidelines proposed by Carpentier and Chachques [3], refined by Fumary and coauthors [7].

\section{Hemodynamic assessment}

Efforts were made to better define mechanisms of action of cardiomyoplasty and to objectively assess actual benefits. Left ventricular ejection fraction was calculated by means of echocardiography, left ventriculography, and by MUGA. Cardiac output was measured by the thermodilution technique.

Left ventricular pressure-volume (P/V) relationships were measured by the conductance catheter technique in 5 patients 6 to 12 months after cardiomyoplasty. The effects of Latissimus Dorsi (LD) stimulations on left ventricular $\mathrm{P} / \mathrm{V}$ loops were studied on a beat-to-beat basis at different cardiomyostimulator settings. The conductance catheter technique uses a Leycom Sigma 5 DF signal conditioner-processor (Cardiodynamics, Leiden, The Netherlands) to estimate left ventricular volume. The technique is based on measuring the time varying electrical conductances of five segments of blood in the left ventricle $\llbracket 1]$. Total left ventricular volume is calculated from the sum of the five segmental conductances. A 12-electrode conductance catheter 7 F, Sentrom, Roden, The Netherlands) was inserted into the left ventricle. A double lumen micromanometer transducer catheter $(7.5 \mathrm{~F}$, Sentrom, Roden, The Netherlands) was also inserted into the left ventricle for the measurement of aortic and left ventricular pressures [24].

\section{Pre-operative muscular training}

All patients underwent a pre-operative physical training programme to improve muscle condition.

Controlled training by means of a computerized fitness equipment ( 6 patients), or tailored arm exercise with light weights, was performed. Pre and post-training muscle biopsies (right LD pre- and post-training, left LD post- 
training at the moment of surgery) were taken in a few patients in order to analyse the effects on muscle structure of such a protocol. Mechanical measurements (peak torque, total work done and work for repetition) were performed before and after the training period to detect any change in muscle performance. The details of the physical training monitored by a computerized equipment, and the biopsy procedure are discussed elsewhere [17].

\section{Surgical technique}

A left LD cardio-costal clockwise procedure, according to the "non cardiac suture" and "flap sliding maneuver" described by Carpentier [3], was performed in 20 patients, whereas right LD was performed in 2 patients. Right cardiomyoplasty was performed in these patients because of the impossibility of using the left LD (cardiac malposition with concomitant left diaphragm eventration, and severe left pleural calcification, respectively). In the second case the ventricular wrapping was accomplished according to a modification of the original technique for right cardiomyoplasty described by Magovern [20].

From the first case intraoperative transesophageal echocardiography was performed to monitor the ventricular wrapping. Care was taken to assess the grade of tightness during the wrapping procedure. Any change in the cardiac geometry (especially along the base of the heart), or any sign of constriction (reduction in transmitral and transtricuspidal flow) was looked for. Furthermore, the intraoperative echocardiographic study was used to ensure a correct volume loading of the heart before starting the ventricular covering by the pedicled muscle, in an attempt to perform cardionyoplasty in the actual baseline hemodynamic state.

\section{Latissimus Dorsi Stimulation}

Latissimus Dorsi stimulation was done using a pair of intramuscular electrodes (Medtronic SP 5528 in 13 patients, and Medtronic 4750 in 9 patients, Medtronic Inc, Minneapolis, Mirn.) placed according to the technique described by Chachques 15 . The synchronous activity to the cardiac systole was achieved by implanting a sensing electrode (Medtronic SP 5548 in 13 patients, and Medtronic 4755 in 9 patients, Medtronic Inc. Minneapolis, Minn.). The intramuscular and the sensing electrodes were then connected to a cardiomyostimulator (Medtronic SP 1005 in 13 patients, and Medtronic 4710 in 9 patients, Medtronic Inc, Minneapolis, Minn.) positioned in an abdominal pocket. Progressive electrical stimulation of the skeletal muscle according to the protocol described by Carpentier and Chachques [5] was followed in the first 13 patients (contraction ratio 2:1), whereas a modified stimulation protocol was instituted in the last pa- 
tients (from patient no 14), adopting an increased heart/ muscle contraction ratio (4: I) with the burst duration being a fixed percentage of the $R$ - $R$ interval.

\section{Skeletal muscle contraction timing}

The standard method to select the wrapped muscle contraction timing is represented by the time of mitral valve closure. We used a protocol allowing a more accurate analysis of the hemodynamic response in relation to different delays of muscle activation time from the sensed cardiac QRS [15].

Transthoracic echocardiographic monitoring was performed while progressively increasing the delay (from $4 \mathrm{msec}$ to $125 \mathrm{msec}$ ) between sensed cardiac electrical activity and elicited LD contraction. Hemodynamic parameters (Velocity Time Integral, Stroke Volume, mitral regurgitation, left ventricular EF on a beat-to-beat basis) were measured to observe changes, if any, related to the differences in timing of the LD contraction.

\section{Statistics}

All values are presented as mean \pm Standard Deviation. Statistical analysis was accomplished by using a Student's t test for paired values. A p value of 0.05 or less was considered significant. Kaplan-Meyer analysis of Jong-term survival was performed.

\section{Results}

\section{Pre-operative skeletal muscle training}

The pre-operative training appeared to induce significant changes in structural and contractile properties of skeletal muscles. Indeed, repetitive sessions of isokinetic exercise induced an increase in peak torque (foot-pounds) which varied from $12 \%$ to $83 \%$, while total work and work for repetition improved with a range from $82 \%$ to $191 \%$, and from $38 \%$ to $100 \%$, respectively.

Electron microscopy showed marked improvement in muscle structure after training. Muscle fiber diameter increased from $42 \pm 6$ to $50 \pm 6 \mu \mathrm{m}(\mathrm{p}<0.001)$ in type I, and from $40 \pm 7$ to $52 \pm 6 \mu \mathrm{m}(\mathrm{p}<0.001)$ ) in type ILA. Capillary/fiber ratio increased from $1.20 \pm 0.10$ to $2.00 \pm 0.12(p<0.001)$, whereas mitochondrial size increased from $0.045 \pm 0.018$ to $0.11 \pm 0.05 \mu \mathrm{m}(\mathrm{p}<0.001)$ in type I fibers, and from $0.030 \pm 0.019$ to $0.055 \pm 0.037 \mu \mathrm{m}(\mathrm{p}<0.001)$ in type IJ fibers. 


\section{Peri-operative outcome}

No intra-operative death was observed. Cardiomyoplasty procedure was accomplished without the use of extra-corporeal circulation in all cases. Ventricular coverture by the muscle graft was complete in 20 patients, whereas a pericardial flap was necessary in 2 cases to fill the wrapping gap over the right ventricular outflow tract. Operative time ranged from 4.5 to 7 hours.

Transesophageal echocardiography revealed a tight wrapping in 2 cases (echocardiographic image of compression of the posterior portion of the ventricles, and significant reduction in transmitral flow, respectively) requiring correction of the ventricular coverture to avoid immediate and potential late hemodynamic complications. All the procedures were performed after optimization of ventricular loading since an over- or a reduced ventricular filling before performing the wrapping procedure could lead to a suboptimal heart/skeletal muscle contact.

The mean intubation time was 1.5 days (from I to 14 days). Two patients had supraventricular arrhythmia (atrial fibrillation and sinus tachycardia). Two patients developed transient acute renal insufficiency which was successfully treated.

Early mortality (within 30 days) consisted of 1 patient with ischemic dilated cardiomyopathy who suffered severe hemodynamic deterioration in the first few hours requiring high dosages of inotropic support. Dobutamine infusion induced ischemic damage which further reduced ventricular function and caused deterioration of a pre-operative mild mitral insufficiency. Despite partial resolution of the impaired cardiac contractility by intra-aortic ballon pumping, the patient developed ventricular fibrillation refractory to treatment.

Post-operative creatine phosphokinase remained within acceptable levels (120 to 1800), except in one patient who developed a severe increase (up to 6500 ), with subsequent acute renal failure, which was successfully treated. Nevertheless, the response of the LD muscle to the electrical stimulation in this patient was appropriate during follow-up.

\section{Follow-up}

The complete muscle stimulation protocol was achieved in 20 patients. No failure as far as appropriate muscle contraction was detected.

Follow-up ranged from 3 months to 51.1 months (mean $20.7 \pm 16.7$ months). Actuarial survival is $69.7 \%$ at 48 months after surgery (figure 1 ).

Late mortality resulted in 5 deaths ( 1 death before completing the muscle stimulation protocol). Notably, 4 deaths occurred in patients affected by an ischemic cardiomyopathy. 


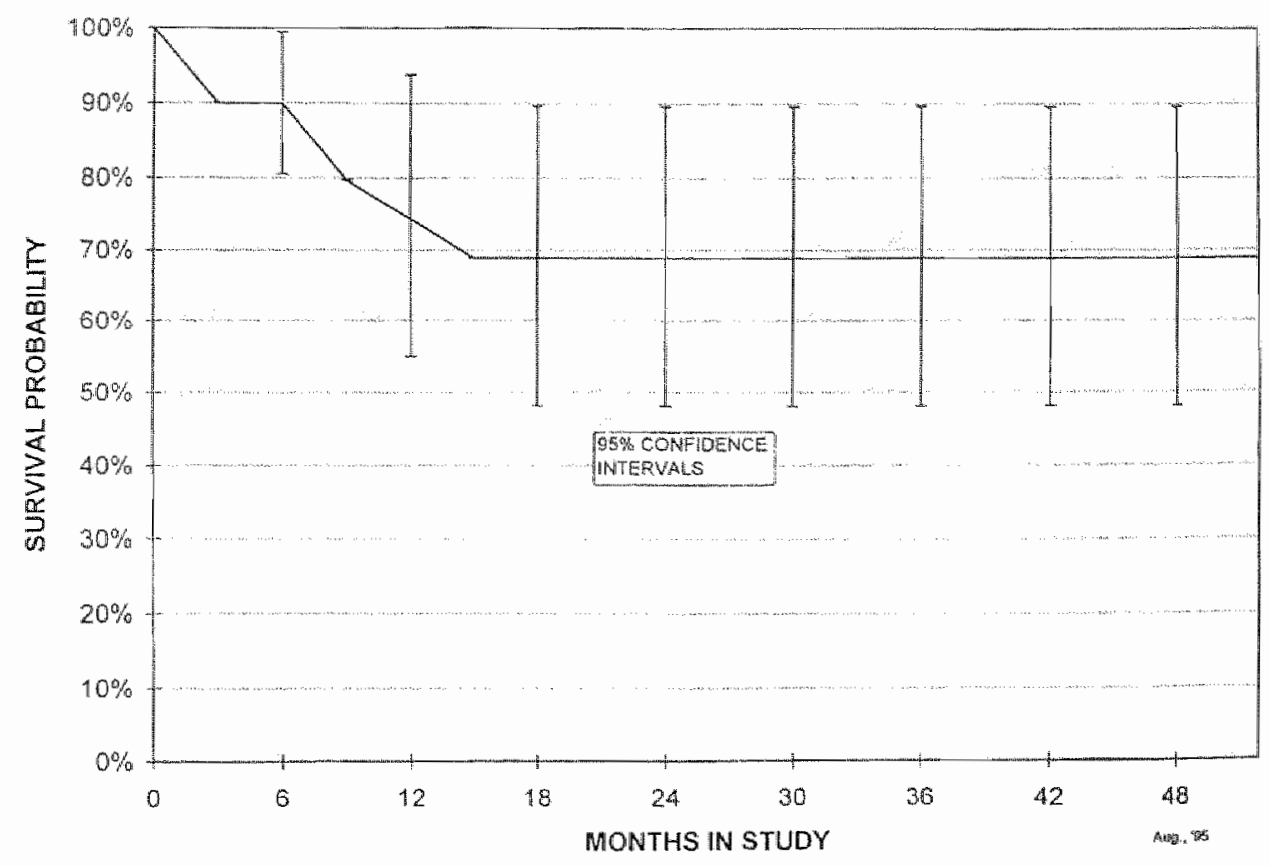

Figure 1. Long-term survival following cardiomyoplasty procedure.

Analysis of pre-operative variables confirmed the presence of minor inducible ischemia, at the level of postero-inferior segments (papillary muscle) in 2 patients who experienced adverse outcome shortly after surgery (15 days and 7 months respectively). Sudden death ( 3 cases) occurred in 2 patients with no sign of viable myocardium, but with the worst quality of coronary vessels (diffuse coronary atherosclerotic disease), and in 1 patient who had a primary cardiomyopathy.

Two patients required the replacement of the cardiomyostimulator because of end of battery life 2 and 3 years after cardiomyoplasty, respectively.

\section{Post-operative complications}

Two patients suffered from infection of the abdominal pocket containing the cardiomyostimulator. An original approach was adopted to preserve the muscle support while treating the infection process in both cases [1.6].

Supraventricular arrhythmia (atrial fibrillation in 2, and sinus tachycardia in 1) occurred in 3 patients. The evaluation of pre and post-operative Holter monitoring did not show significant changes in heart rhythm or rate of the operated patients compared with pre-operative data. 


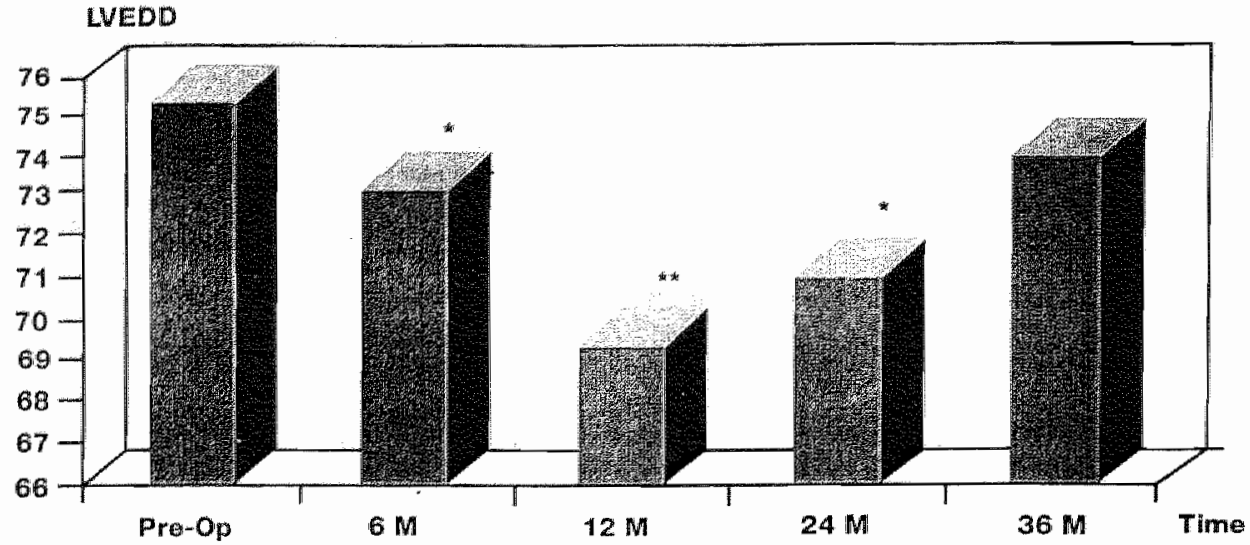

Figure 2. Left ventricular end-diastolic diameter (LVEDD) data before and after cardiomyoplasty. Significant reduction of LVEDD was observed at $6 \quad(73.2 \pm 8.0 \mathrm{~mm}-0.0176), 12$ $(69.4 \pm 8.5 \mathrm{~mm}-\mathrm{p}=0.002)$, and 24 months $(71.1 \pm 7.0 \mathrm{~mm}-\mathrm{p}=0.011)$, respectively, whilst no substantial modification in comparison with preop data was observed at 3 years $(74.0 \pm 9.1 \mathrm{~mm}-\mathrm{p}=\mathrm{N} 5)$.

M: months: * $0<0.05 ;$ * $p<0.01$

\section{Post-operative hemodynamic evaluation}

Conventional hemodynamic assessment showed a significant improvement at short term, whereas a lesser benefit was observed during further follow-up. Cardiac index (by thermodilution technique) increased sustantially at 6 months (from $2.59 \pm 0.5 \mathrm{~L} / \mathrm{min} / \mathrm{m} 2$ to $3.08 \pm 0.5 \mathrm{~L} / \mathrm{min} / \mathrm{m} 2-\mathrm{p}=0.04$ ), but no significant changes were observed at 12 months $(3.03 \pm 0.7 \mathrm{~L} / \mathrm{min} / \mathrm{m} 2), 24$ months $(3 \pm 0.7 \mathrm{~L} / \mathrm{min} / \mathrm{m} 2)$, and 36 months $(2.85 \pm 0.7 \mathrm{~L} / \mathrm{min} / \mathrm{m} 2)$. Left ventricular ejection fraction (LVEF) by angiographic assessment revealed positive improvement at 6 and 12 months $(29.1 \pm 1.0 \%-\mathrm{p}=0.0017$, and $27.3 \pm 5.6 \%-\mathrm{p}=0.0091$, respectively), whereas no substantial augmentation was shown at 24 and 36 months $(25.6 \pm 2.5 \%$, and $25.1 \pm 4.0 \%$, respectively).

Notably, radionuclide assessment of left ventricular function was not comparable with angiographic data (LVEF from $20.0 \pm 5.8 \%$ to $21.5 \pm 8.5 \%-\mathrm{p}=\mathrm{NS}$, to $23.3 \pm 7.5 \%-\mathrm{p}=\mathrm{NS}$, to $19.5 \pm 2.9-\mathrm{p}=\mathrm{NS}$, and to $17.7 \pm 4.5-\mathrm{p}=\mathrm{NS}$, at $6,12,24$, and 36 months respectively), as already observed by Jegaden [9], probably due to heart lifting during skeletal muscle contractions [6].

Two-dimensional echo evaluation documented a positive influence of cardiomyoplasty on left ventricular end-diastolic dimension up to 2 years, while no significant change was observed at 3 years (figure 2). No diastolic deterioration was documented at late follow-up. 
Tablle 3. Hemodynamic assessement after cardiomyoplasty (fom 6 to 12 months) by pressure/wolume analysis comparing assisted $A$ ] versus unassisted (U) beats at best stmulation settings. LWSV: left wentricular stroke volume, percentage of increase during assisted beats: AoP : aortic pressure; LVEDP : left ventricular end-diastolic pressure; LVPER : left ventricular peak ejection rate

\begin{tabular}{|c|c|c|c|c|c|c|c|c|c|}
\hline \multirow[t]{2}{*}{ Patient } & \multirow[t]{2}{*}{$\begin{array}{l}\text { LVSV } \\
\%\end{array}$} & \multicolumn{2}{|c|}{$\begin{array}{l}\text { AoP } \\
\text { mmHg }\end{array}$} & \multicolumn{2}{|c|}{$\begin{array}{l}\text { LVEDP } \\
\text { mmHg }\end{array}$} & \multicolumn{2}{|c|}{$\begin{array}{l}\mathrm{LWPER} \\
\mathrm{m} / \mathrm{sec}\end{array}$} & \multicolumn{2}{|c|}{$\begin{array}{l}\mathrm{LV}-\mathrm{dP} / \mathrm{d} \\
\mathrm{mm} \mathrm{Hg} / \mathrm{sec}\end{array}$} \\
\hline & & A & U & $A$ & U & A & U & $A$ & $U$ \\
\hline S.B. & 29 & 96 & 91 & 15.2 & 1.4 .3 & 176 & 754 & -1156 & -1074 \\
\hline $\mathrm{V} . \mathrm{S}$. & 17 & 115 & 109 & 11.2 & 11.2 & 947 & 642 & -774 & -739 \\
\hline A. L. & 21 & 127 & 118 & 22.5 & 18.3 & 973 & 669 & -998 & -895 \\
\hline
\end{tabular}

\section{Beat-to-beat analysis}

Echocardiographic study showed evidence of support by the wrapped muscle contractions [15] during on/off study at short term (Stroke Volume, Velocity Time Integral, and EF, increased from $53 \pm 4.5$ to $64: \pm 7.2 \mathrm{ml-p}<0.05-$, from $12 \pm 1.6$ $\mathrm{cm} / \mathrm{sec}$ to $15 \pm 2.3 \mathrm{~cm} / \mathrm{sec}-\mathrm{p}<0.05-$, and from $19 \pm 2.1 \%$ to $32 \pm 4.3 \%-\mathrm{p}<0.05$, respectively, during assisted beats at best settings), documenting an active contribution of the wrapped muscle to cardiac performance, and confirming the critical role of the LD contraction timing to optimize postoperative results.

Radionuclide study, by modified gated acquisition, showed a comparable effect on assisted versus unassisted beats.

Hemodynamic data obtained in 3 patients after cardiomyoplasty as measured by pressure/volume analysis are shown in table 3 , whereas the data concerning the other 2 patient including pre- and postoperative measurements and are currently under evaluation. It should be mentioned that these changes were documented at a pulse amplitude 2 to 3 volts higher than the clinically used values [24]. Pressure/volume relations clearly showed the importance of stimulation tuning to optimize skeletal muscle contraction timing and to achieve correct heart/LD coupling |24].

\section{Disease course}

The majority of the patients ( 21 over 22) improved at least 1 NYHA Class, but exercise test (peak oxygen consumption) showed a significant change only at 6 and 12 months, with no substantial increase observed at late follow-up (table 4)

Remarkably, hospitalization rate because of heart failure symptoms (shortness of breath, excessive fatigue, increase in body weight, peripheral edema) was markedly reduced after surgery (from $3.3 \pm 1.5$ to $0.3 \pm 0.7-p=<0.0001$, to 

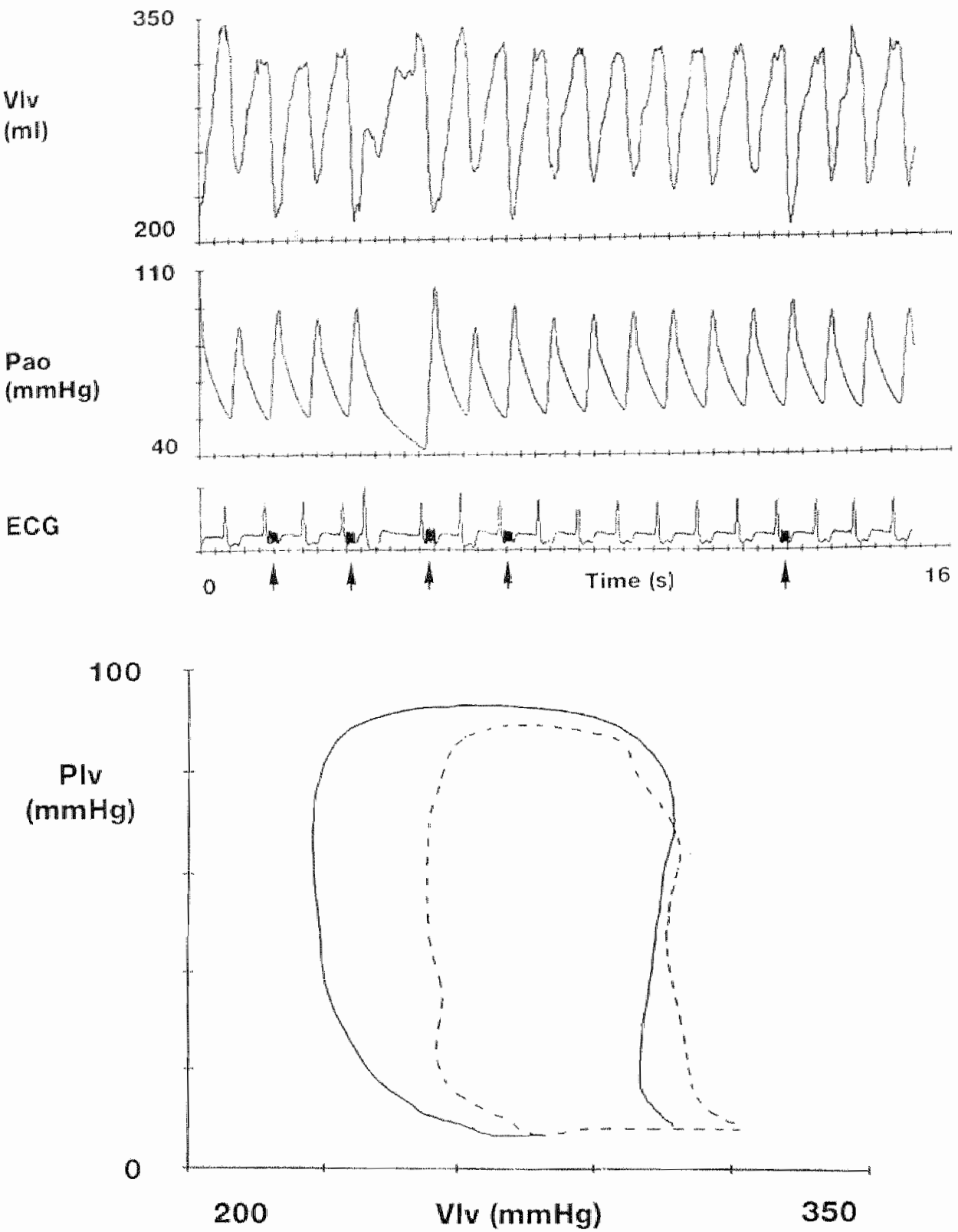

Figure 3 . Left ventricultr volume and pressure tracings, and pressure volume toops are shown. Volune (top figure) and pressure tracings during assisted beats and after stopping the muscle support are shown. The first two assisted (sold line) and unassisted (dotted line) beats of the tracings lave been ploted on a pressure/volume loop configuration (bottom figure). Clear improvements in stroke volume and left ventricular systolic pressure during skeletal muscle contractions (arrows) are documented. VIv: left ventricular wolume; Pao: aortic pressure; Plv: left ventricular pressure. 
Table 4. Functional assessment after cardiomyoplasty. NYHA : New York Heart Association; NP: not performed (severe claudicatio in 3 patients); NS : not significant

\begin{tabular}{|c|c|c|c|c|c|}
\hline & Pre-op & 6 Months & 12 Months & 24 Months & 36 Months \\
\hline NTHAClass & 3 & $\begin{array}{l}1.9 \pm 0.54 \\
p<0.0001\end{array}$ & $\begin{array}{l}1.71 \pm 0.46 \\
p<0.0001\end{array}$ & $\begin{array}{l}2 \\
p<0.0001\end{array}$ & $\begin{array}{l}2 \\
p<0.0001\end{array}$ \\
\hline Peak O2 & $1.2 .76 \pm 3.54$ & $\begin{array}{l}14.50 \pm 4.15 \\
p=0.04\end{array}$ & $\begin{array}{l}16.50 \pm 3.88 \\
p=0.02\end{array}$ & $\begin{array}{l}13.66 \pm 1.5 \\
p=N S\end{array}$ & $\mathbb{N P}$ \\
\hline
\end{tabular}

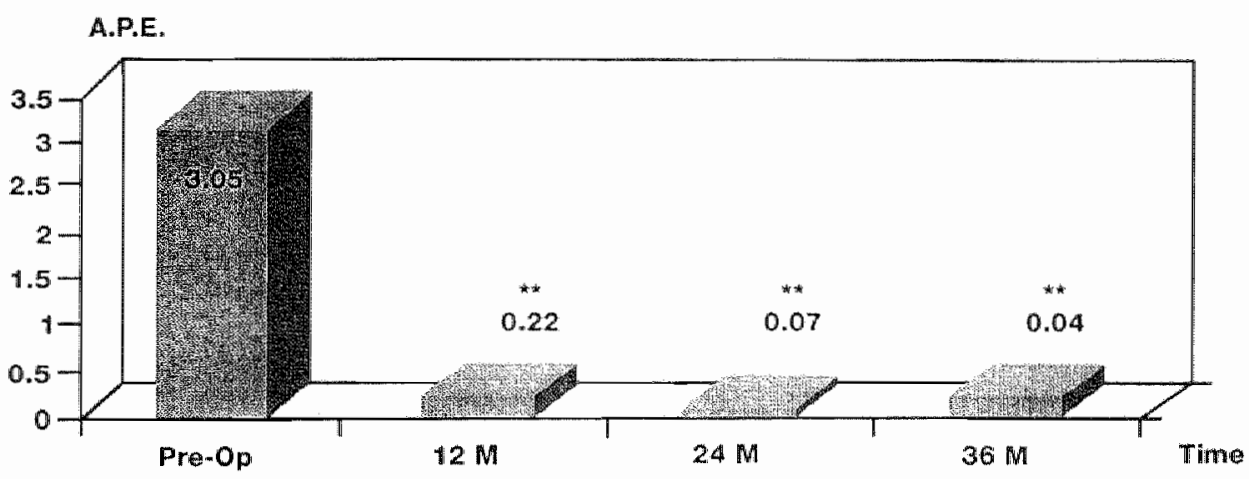

Figure 4 . This diagram shows the number of episodes of acute pulmonary edema before (1 year) and after cardiomyoplasty. APE: Acute pulmonary edema; M: months. * $p<0.05$, * p<0.01

$0.4 \pm 0.5-p=0.0001$, to $0.1 \pm 0.3-p=<0.0001$, and to $0.6 \pm 0.5-p=0.0032$, at $6,12,24$, and 36 months, respectively). Accordingly, the number of episodes of acute pulmonary edema decreased significantly after cardiomyoplasty (figure 4).

One patient was without muscle support for almost 1 month because of a severe infection, and he showed progressive and significant deterioration of clinical condition as well as hemodynamic function (LV EF from $23 \%$ to $12 \%$, and cardiac output from $6.2 \mathrm{~L} / \mathrm{min}$ to $3.4 \mathrm{~L} / \mathrm{min}$ ), with recovery after restoration of LD assistance [16].

Pharmacological therapy was reduced in the majority of the patients in the first 12 to 24 months post-operatively, with a tendency to increase at late follow-up. 
ECG

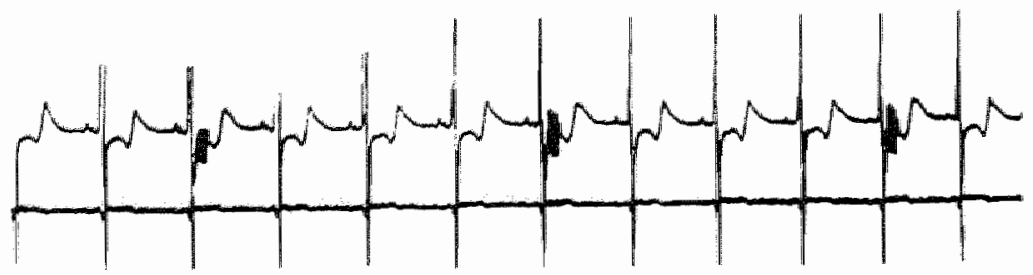

LVP

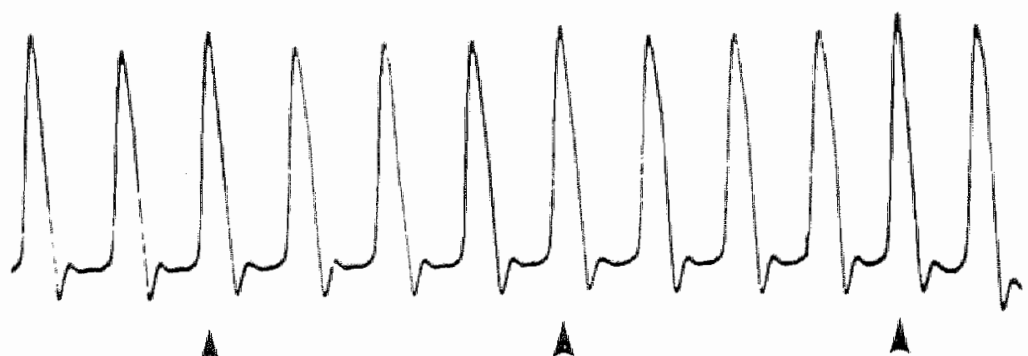

Pigure 5. Aleft ventricular pressure curve of a cardiomyoplasty patient at 6 months after surgery is shown. The latissimus dorsi muscle contractions (arrows) coincide with the bursts on the above ECG. Increase of left wentricular systolic pressure is documented during assisted beats (heart/skeletal muscle contraction ratio 4:1). LVP: left ventricular pressure

\section{Discussion}

The last two decades have faced the extraordinary advances of heart transplantation [23]. Nevertheless, donor shortage, high mortality on the waiting list, and strict selection criteria, have limited access to this therapeutical option to a small number of patients [25], forcing the medical community towards the development of new forms of treatment.

The use of permanent cardiocirculatory assistance represented a potential solution. In this light, cardiomyoplasty, by using the patient's own skeletal muscle to support the dysfunctional heart, appeared an appealing alternative. The pace/maker-induced synchronous contractions, following careful mobilization and wrapping around the ventricles of the selected skeletal muscle, represent the basic principle of this autologous, long-lasting, and safe biomechanical support [5].

Carpentier and Chachques reported the first clinical operation being performed in a young woman affected by an invading tumor of the cardiac ventricles [4|. The first clinical series were characterized by adopting such a 
procedure primarily in NYHA Class IV patients, and often in association with other surgical procedures (CABG, valve surgery, aneurismectomy) [8].

Unlike many other studies, our population is only represented by carefully selected patients (NYHA Class III or Intermittent IV). All patients did not have alternative to heart transplantation, and were not controlled by complete medical therapy (diuretics, ACE-inhibitors, vasodilators, digoxinj inasmuch as progressive deterioration of the clinical and hemodynamic conditions were documented in all of them. In addition no? was needed to solve other problems. This situation provided us with the unique opportunity of evaluating the effects of the operation per sè in a group of patients who can be considered ideal candidates. Previous experiences have well established that patients in a terminal state of chronic heart failure were affected by high perioperative mortallity and suboptimal results at long term [8]. Moreover, the use of associated surgery made interpretation of the postoperative results more difficult.

Another peculiar feature of our series is that includes patients affected by primary and ischemic cardiomyopathy. This is in contrast with Moreira who recently described [21] long-term results in patients affected mainly by idiopathic dilated cardiomyopathy. Report on natural history in congestive heart failure showed that CAD represents a negative predictor for long-term morbidity and mortality [10], which is in accordance with our results after cardiomyoplasty.

In our study we made the effort to enhance the power of the operation by optimizing the preoperative condition of the sellected skeletal muscle, as assessed by mechanical and bioptic studies. This represents an original contribution, but the limited amount of data do not allow us to draw any conclusion whether this factor may provide a positive impact on postopeartive results.

Other aspects of the cardiomyoplasty technique have been modified in our experience. The selection of the LD contraction timing has been a matter of careful evaluation. Echocardiographic and P/V loop studies documented that such a factor is critical for optimal heart/muscle coupling and performance to be achieved $[15,24]$.

Hemodynamic assessment was a further target of our study. Previous reports either failed to objectivate substantial changes or showed moderate improvement in systolic and diastolic left ventricular functions $13,9,19,21]$. Nonetheless, understanding of the mechanisms of action is still limited and matter of debate. The use of sophisticated methods, like P/V relations as measured by conductance catheter, allowed us to better elucidate subtle changes induced by LD support, meanwhile to demonstrate that in a few patients significant contribution of the LD contraction is achieved, leading to substantial changes on a beat-to-beat basis (figures 3 and 5). The important issue, generally underestimated, is that such significant improvement in systolic function is detected in the minority of the treated patients, but does exists. We believe that this finding cannot be ignored, and, on the contrary, should promote fur- 
ther investigations to define which variable (surgery, pre or postop muscle condition, LD contraction timing, stimulation protocol, and so forth) is responsible for few "isolated" success in terms of marked changes of traditional hemodynamic parameter.

Our overall results are quite satisfactory and basically demonstrate that in selected patients the operative risk is low (no intraoperative mortality despite no use of intraaortic ballon pump or extracorporeal circulation). The ischemic etiology is certainly a risk factor for perioperative and late unfavorable events. Patients with ischemic cardiomyopathy should undergo deep evaluation preoperatively, not only to enhance surgical decision making, but also to ensure a better management in the peri and postoperative periods.

By our study the positive impact on clinical status has been demonstrated (reduced hospitalization and number of acute pulmonary edema episodes, improved NYHA Class) in accordance with other experiences.

Patient data, as shown by P/V relation following cardiomyoplasty and by echocardiagraphy, document that complex results are obtained by such a biomechanical cardiac assist. Indeed, despite a moderate and time-limited improvement in left ventricular systolic function, significant reduction of ventricular dilatation was obtained up to 24 months after surgery. This is in accordance with recent clinical and experimental reports $\{2,6,12,13,22]$. The reduced efficacy of cardiomyoplasty at late fol]ow-up, despite no increase of ventricular dimension was still present at more than 3 years if compared with preoperative data, may be related to may factors. Muscle derangement due to subotpimal stimulation protocol or to overdemanding use $[14,18]$, and progression of the underlying disease may account for this situation. Therefore, at this point in time, the current use of wrapped muscle to sustain the failing heart seems to support the hypothesis that the main effect is given by a "girdle" to the dilated ventricles, able firstly to effectively influence cardiac enlargement "and subsequently to stabilize the ventricular dilation.

Finally, late mortality in our study was primarily related, despite extensive use of prophylactic medications, to arrhythmic events, which will hopefully be counteracted by the future generation of electrical devices (cardiomyostimulator associated with implantable defibrillator).

In conclusion, cardiomyoplasty pertains a complementary role in the therapy of chronic heart failure. In selected candidates it provides useful cardiocirculatory assistance by reducing cardiac dilatation and preventing progressive left ventricular dysfunction. Significant improvement in hemodynamic function may be achieved in some patients, but the predominant effect of cardiomyoplasty appears to be exerted on ventricular remodeling. 


\section{References}

1. Baan J, van der Velde ET, De Bruin HG, Smeenk GI, Koops J, Van Dijk AD, Temmerman D, Senden PI, Buis B (1984) Conitnuous measurement of left ventricular volume in animals and humans by conductance catheter. Circulation $70: 812-823$

2. Capouya ER, Gerebr RS, Dinkwater DC, Pearl MM. Sack JB, Aharon AS, Barthel SW, Kaczer EM, Chang PA, Laks H (1993) Girdling effect of nonstimulated cardionyoplasty on left ventricular function. Ann Thorac Surg 56:867-871

3. Carpentier A, Chachques JC. Acar C, Relland J. Mihaileanu S, Bensasson D, Kieffer JP, Guillort P. Toumay D, Roussin 1, Grandjean PA (1993) Dynamic cardiomyoplasty at seven years. IThorac Cardiovasc Surg 106:42-54.

4. Carpentier $\mathrm{A}$, Chachques $\mathbb{\mathrm { C }}(1985) \mathrm{My}$ ocardial substitution with a stimulated skeletal muscle: first successful clinical case. Lancet 1:1267

5. Chachques JC, Grandjean PA, Schwantz K, Mihaileanu S, Fardeau M. Swynghedauw B, Fontaliran F, Romero N, Wisnewsky C. Perier P. Chaukatud $S$, Bourgeois I, Canpentier A (1988) Effect of latussimus dorsi dynamic cardiomyoplasty on ventricular function. Circulation (Suppl III) $78.203-216$

6. Cho PW, Levin HR, Moore CC, Tsitlik JE, McVeigh ER, Gardner TJ, Acker MA (1994) New method for mechanistic study of cardiomyoplasty: thee-dimansional MRI reconstruction. Ann Thorac Surg 57:1605-1611

7. Fumary AP, Magovern IA, Cgristlieb IK, Orie JE, Simpson KA, Magovem Cl (1992) Clinical cardionyoplasty: pre-operative lactors associated with outcome. Ann Thorac Surg 54:1139-1143

8. Grandjean PA, Austin L, Chan S, Terpstra B, Bourgeois I (1991) Dynamic cardiomyoplasty: clinical results. J Card Surg 6(Suppl):80-88

9. Jegaden $O$, Delahaye $F$, Finet $G$, wan der Veen FH, Montagna P, Eker A, Ossete I, Rossi $R$, Sain Pierre A. Michaelolf PH (1994) Late hemodynamic results after cardiomyoplasty in congestive heart failure. Ann Thorac Surg 57:1151-1157

10. Jessup M, Chandler SL, Kay HR (1987) Clinical deteminants of mortality in chronic heart failure secondary to idiopathic dilated or to ischemic cardiomyopathy. Am J Cardiol 59:634-638

11. Kalil-Filho R, Bocchi E, Weiss RG, Rosemberg L, Bacal F, Moreira L.FP, Stolf NAG, Magalhaes $A A C$, Bellotri $G$, latene A, Pileggi $F$ (1994) Magnetic resonance imaging evaluation of chronic changes in latissimus dorsi cardiomyoplasty. Circulation 90/Suppl I1]: $102-106$

12. Kass DA, Batuhman KL, Pak PH, Cho PW. Levin HR, Gardner T), Halperin HR, Tsillik JE, Aker MA. (1995) Reverse remodeling from cardionyoplasty in human hean faibure. Circulation $912314-2318$

13. Kaubach HG, van der Veen FH, Schreuder Il, Habets IW, Lorusso R, van der Nagel T, Wollens HII (1995) Compensated high output in goats: a new experimental approach to study the mechanisms of action of dymamic cardiomyoplasty. Hurop Hear ) I6(Suppl A:214

14. Kratz IM, Johnson WS, Mukherjee R, Hu J, Craw ford FA, Spinale VG (1994) The relation be tween latissimus dorsi skeletal muscle structure and contactile function affer cardiomyoplasty. I Thorac Cardiovase Surg 107:868-878

15. Lorusso R. Sandrelli L, Maisano E: Zogno M, La Canna G Giubbini R, Metra Mi, Visioli O, Alleri O (1992) Echo-doppler assessment to optimize wrapped skeletal muscle actiwation lime lotlowing cardiomyoplasty procedure Europ Heart I $3($ Suppl A):230

16. Lonusso R, Cumis A, Struble C. Sandrelli L. Affer O (1995) Bacterial infection of cardiomyostimulator abdominal pocket following cardiomyoplasty procedture: an original approach to preserve synchronous muscle stimulation. ) Card Surg $10.358-362$ 
17. Lorusso $R$, Borghetti $V$, De Fabritis M, Scelsi $R$, Carraro $U$, Alfien $O$ (1993) Pre operative physical traning effects on latissimus dorsi muscle in patients undergoing dynamic cardiomyoplasty: a preliminary report. Bas Appl Myol 3.211-218

1.8. Lucas $C M H B$, van der Veen FH, Cheriex EC, Lorusso R, Havenith M Penn OCKM, Wellens HID (1993) Long-term follow-up (12 to 35 weeks) after dymamic cardiomyoplasty. I Am Coll Cardiol $22.758-767$

19. Magovern JA, Magovern GJ, Maher TD, Benckart DH, Christieb IY, Magovern G] (1993) Operation for congestive heart fallure: transplantation, coronary artery bypass, and cardiomyo. plasty. Ann Thorac Surg 56:418-425

20. Magovern JA, Fumary AP, Christlieb IY, Kao RL, Magovern GI (1992) Right latissimus dorsi cardiomyoplasty for left ventricular failure. Ann Thorac Surg 53:1120-1122

21. Moreira LFP, Stolf NAG, Bocchi EA, Bacal F, Pego-Fernandes PM, Abensur H, Meneghetti JC, Jatene AD (1995) Clinical and left ventricular function outcomes up to fve years after dynamic cardiomyoplasty. J Thorac Cardiowasc Surg 109;353-363

22. Nakajima H, Ninami H, Hooper TL, Hammond RL, Nakajima HO, Lu H, Ruggiero R, Thomas GA, Mocek FW, Fitetsam R, Krakowsky AA, Spanta AD, Suga H, Stephenson LW, Baciewicz FA. (1994) Cardiomyoplasty: probable mechanism of effectiveness using pressure/volume relationship. Ann Thorac Surg 57:407-415

23. Sarris GE, Moore KA, Schroeder IS, Hunt SA, Fowler MB, Valentine HB, Vagelos RH, Billing. ham ME, Oyer PE, Stinson EB, Reitz BA, Shumway NE (1994) Cardiac transplantation: the Standford experience in the cyclosporine era. T Thorac Cardiowasc Surg 108:240-252

24. Schreuder II, wan der Veen FH, van der Velde FI, Delahaye F, Alfieri O, Jegaden $O$, Lorusso R, Jansen IRC, van Ommen $V$, Finet $G$, Wellens HJJ (1995) Beat-to-beat analysis of left ventricular pressure-wolume relation and stroke volume by conductance catheter and aortic modelfiow in cardiomyoplasty patients. Circulation 91:2010-2017

25. Stephenson LW, Warner SL, Steimle AE, Fonarow GC, Hamilton MA, Morigurhi JD, Kobashigawa JA, Tillisch JH, Drinkwater, Laks: $H$ (1994) The impending crisis of heart transplantation. Circulation 89:450/457 
CHAPTER

C

\section{Progress in Cardiomyoplasty}

Techniques and Management of

Clinical Problems

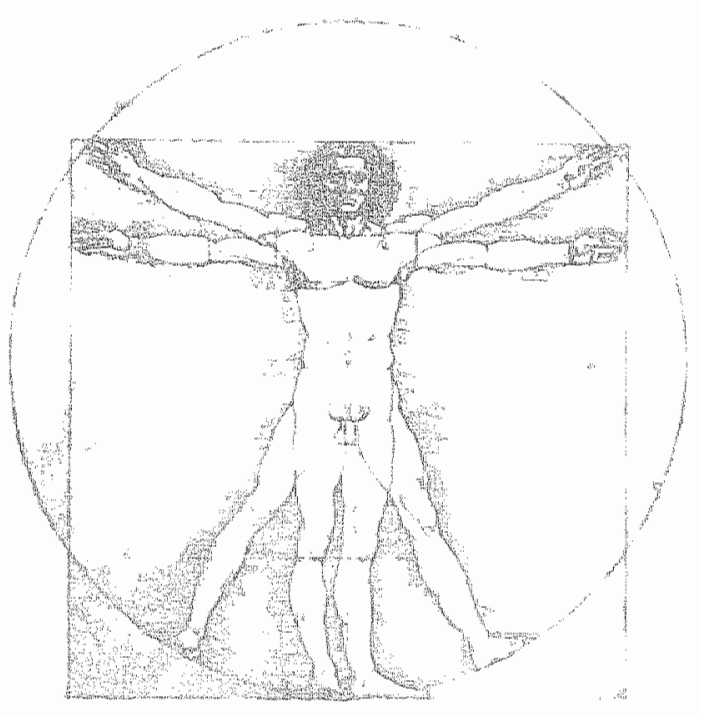


CHAPTER

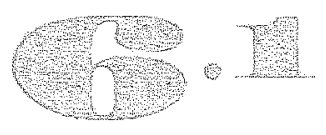

\section{Pericardial "suspenders" to enhance right latissimus dorsi cardiomyoplasty}

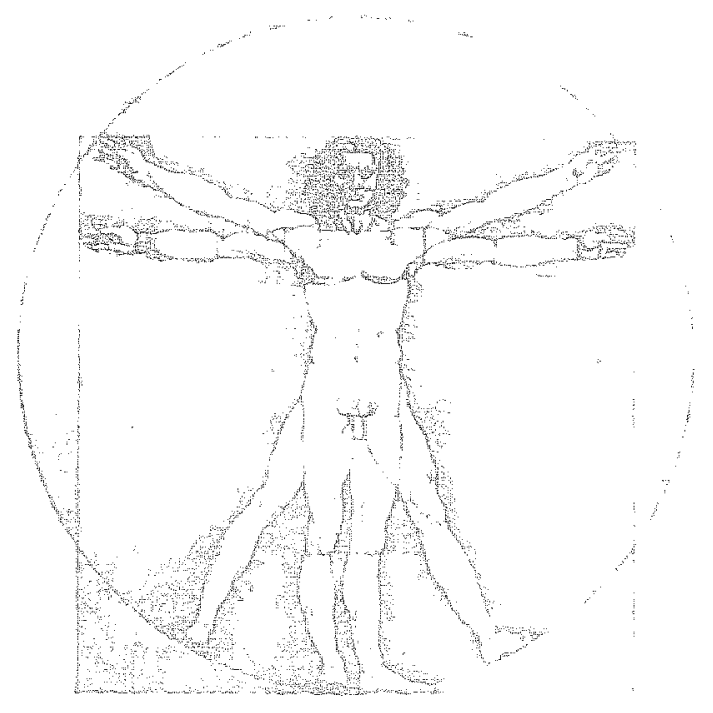

Roberto Lorusso, Ottavio Alfieri. 
Right latissimus dorsi cardiomyoplasty has recently been shown to provide effective support for the chronic failing heart. A simplified technique to perform this procedure is described here. The use of pericardial "suspenders" may avoid dangerous lifting of the heart out of its sac position, and allow a more appropriate adjustment of the applying tension with enhanced surgical management and potential benefits for postoperative outcome.

Cardiomyoplasty is currently under investigation as a therapeutic approach in the treatment of end-stage dilated cardiomyopathy. The majority of cardiomyoplasty procedures are accomplished by mobilizing the left latissimus dorsi (LLD) muscle, which is subsequently wrapped around the cardiac ventricles and synchronously paced during the systolic phase.

We report the case of a patient not suitable for LLD cardiomyoplasty because of previous left lung disease. Right LD (RLD) cardiomyoplasty was therefore the only option. We adopted a modified technique which is described herein.

\section{The case}

A 65-year-old man was referred to our institution because of progressive deterioration of chronic heart failure.

His past medical history revealed previous left lung tubercolosis treated with pneumothorax. Such a treatment led to the calcification of the ipsilateral pleura and to left fibrothorax, making a LLD muscle transposition into the left thorax impossible.

The preoperative left ventricular (LV) end-diastolic diameter was $92 \mathrm{~mm}$. Preoperative pressure-volume analysis of the LV by a conductance catheter showed a cardiac output (CO) of $5.4 \mathrm{~L} / \mathrm{min}$, ejection fraction (EF) of $17 \%$, peak ejection rate (PER) of $643 \mathrm{~cm} / \mathrm{sec}, \mathrm{dP} / \mathrm{dt}$ of $786 \mathrm{mmHg} / \mathrm{sec}$, and a stroke volume (SV) of $75 \mathrm{ml}$.

Because of the unresponsiveness to maximal medical therapy and to patient's age, cardiomyoplasty was proposed.

\section{The technique}

A RLD muscle cardiomyoplasty was deemed the most appropriate, and because of unstable hemodynamics, a modification of the technique was applied.

Following standard mobilization and transposal of the muscle graft into the thorax ( 1 ), the heart was approached by a median sternotomy. 


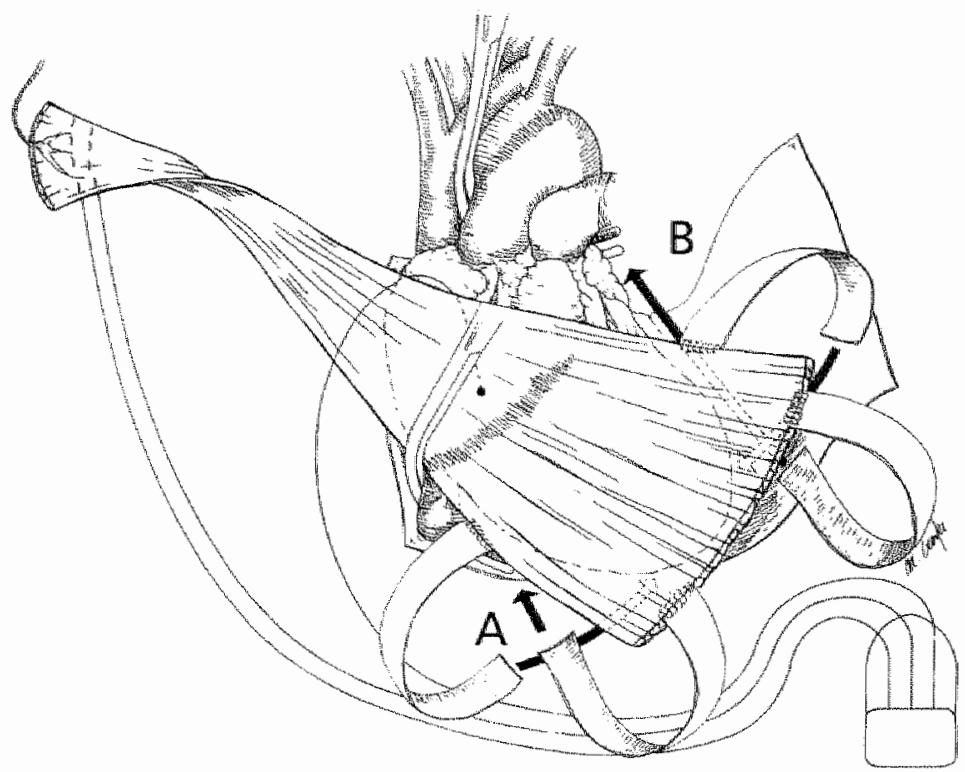

Figure 1. A transposed RLD muscle is shown. Two right angle curved clamps are placed behind the inferior vena cava $(A)$, and through the transwerse simus (B), respectively, to lasten the two anterior pericardial strips.

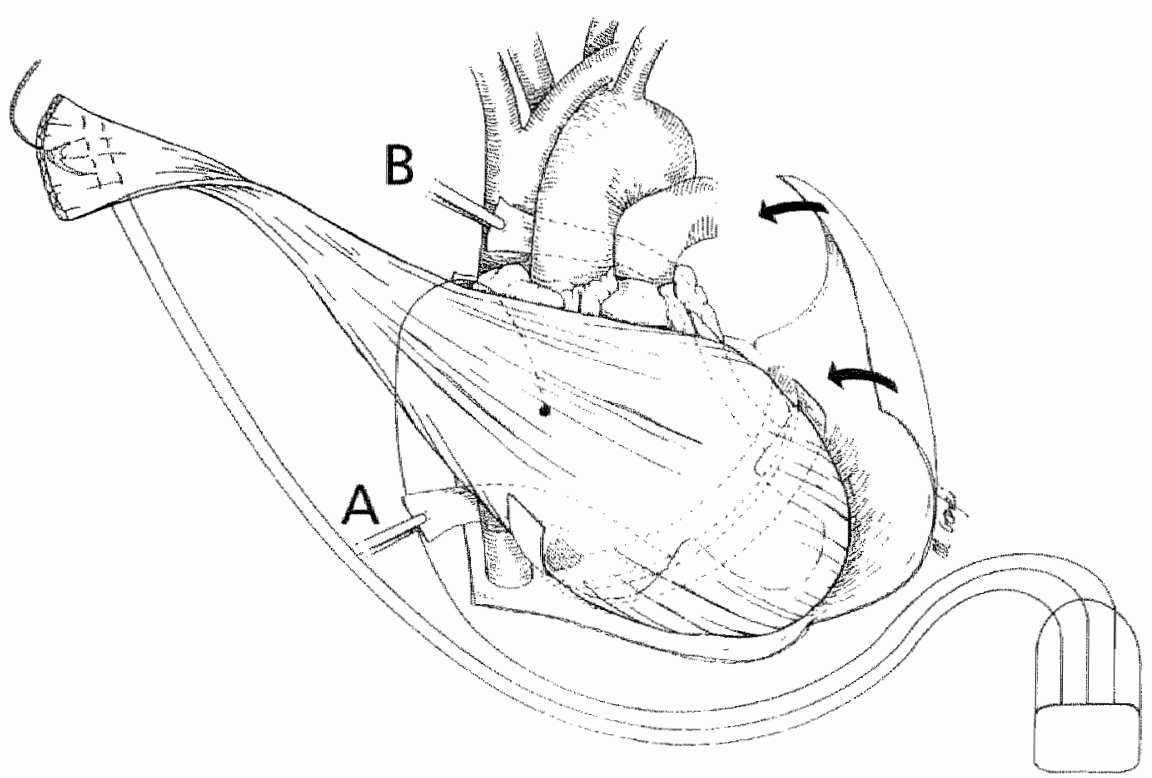

Figure 2. The RLD muscle is placed over the apex while the two clamps pull the anterior pericardial bands ( $A$ and $B$ ) backward, allowing the $L D$ to slip posteriorly toward the A/V groove. The two lateral pericardial strips are then respectively passed to the opposite sides under the ventricles to complete the wrapping procedure. Eventually, the pericardial bands are secured to the native pericatium sac, and the pericardial flap reversed to its original position. 
Four bandles were trimmed using bovine pericardium, since the native one was utilized to fashion a wide flap. Two pericardial bands were sutured to the distal part of the LD muscle graft, and two to the lateral edges. The two distal/anterior bundles were fastened to two right angle curved clamps positioned behind the inferior vena cava, and through the transverse sinus, respectively (figure 1).

A clockwise cardiocostal wrapping was performed. First, the RLD muscle was used to cover the anterior aspect and the apex of the heart. In the meantime, the two clamps pulled the anterior pericardial strips back, allowing the muscle graft to slip posteriorly toward the atrioventricular (AV) groove. Finally, the cardiac covering was completed by passing the two lateral bundles contralaterally. Such a maneuver allowed as much ventricular covering as possible, while still avoiding lifting of the heart.

Adjustment of the wrapping tightness was achieved by pulling backwards under direct transesophageal echocardiographic observation. Echocardiographic monitoring would have detected any effect on the inferior vena cava in ase of compression by the pericardial bundle. No extra-corporeal circulation was required.

The native pericardial flap was finally replaced in the original shape to cover as much mediastinal course of the RLD as possible to reduce the postoperative adhesions between the sternum and the crossing muscle belly (figure 2).

Pressure-volume evaluation was performed 6 months postoperatively, and marked improvement of the $L V$ hemodynamics (CO of $6.06 \mathrm{~L} / \mathrm{min}$, SV of $86 \mathrm{ml}$, EF of $33 \%$, PER of $823 \mathrm{~cm} / \mathrm{sec}$, and $\mathrm{dP} / \mathrm{dt}$ of $902 \mathrm{mmHg} / \mathrm{sec}$ ) was documented.

\section{Comment}

No consensus exists as to whether RLD or LLD muscle is more effective in cardiomyoplasty technique.

Magovern and associates $(2,3)$ described experimentally and clinically the benefits of a right cardiomyoplasty. The basic concept for such an innovation was related to a more pronounced action along the long cardiac axis, which might exert a better effect on cardiac contraction and, therefore, on hemodynamics.

Recently, Cho et al. (4) elegantly showed by means of MRI the effectiveness of the RLD in terms of heart-wrapped muscle mechanics.

RLD wrapping procedure may represent a more challenging surgery in the human setting. "The surgical approach implies the suturing of the distal muscular edges as close as possible to the $\mathrm{A} / \mathrm{V}$ groove, often requiring prolonged and troublesome elevation of the heart. In unstable patients, extracorporeal circulation may be required. Furthermore, displacement of the heart impairs appraisal of wrapping tightness, making the suturing of the distal portion of the 
LD graft on the posterior myocardium or pericardium less precise or even potentially deleterious.

Carpentier and Chachques (5) described a technique which enables minimal handling of the heart during a left cardiomyoplasty procedure. However, no comparable techniques have been reported for the right cardiomyoplasty.

We performed a RLD cardiomyoplasty adopting a technique which reduces the risks of exacerbating already unstable hemodynamics.

Our use of trimmed pericardial "suspenders" allows a safe and more precise ventricular covering. The anterior-posterior wrapping procedure is performed only with the two anterior pericardial bands, which are pulled to place the distal part of the LD as closely as possibe to the A/V groove under transesophageal monitoring. Subsequently, each lateral pericardial strip is passed contralaterlally, allowing covering of the lateral and inferior aspect of the cardiac ventricles. Therefore, only trivial cardiac displacement is needed.

The use of heterologous pericardium was especially designed to leave as much native pericardium as possible in place, thereby allowing the trimming of a wide flap. Such a flap is finally placed in its original position to cover the midline crossing of the RLD, and may reduce the postoperative adhesions between the sternum and the muscular graft, which might limit the contractile action of the wrapped muscle at long-term (6). 


\section{References}

1. Chachques JC, Grandjean PA, Schwartz $K$, et al: Effect of latissimus dorsi dynamic cardiomyoplasty on ventricular function. Circulation 1988; 78 (Suppl III):203-216.

2. Magowern IA, Fumary AP, Chrisulieb IY, et al: Right latissimus dorsi cardiomyoplasty for lef ventricular fallure. Ann Thorac Surg 1993;53:1120-1122.

3. Lazzara RL, Trumble DR, Magovem IA, et al: Clinical and experimental effects on the unstimulated (static) right latissimus dorsi cardiomyoplasty on left ventricular function. Bas Appl Myol 1993;3:281-288.

4. Cho PW, Levin HP, Moore CC, et al: New method for mechanistic studies of cardiomyoplasty: three dimensional MHil reconstructions. Ann Thorac Surg 1994;57:1605-1611.

5. A Carpentier, JC Chachques. Cardiomyoplasty: surgical technque. From: A Carpentier, JC Chachques, P Grandjean (eds). Cardiomyoplasty. Futura Publishing Inc., Mount Kisko "NY, 1991, $\mathbb{1 0 5}-122$.

6. Magovern JA, Magovem GJ, Maher TD, et al: Operation for congestive heart failure: transplantation, cotonary artery bypass, and cardiomyoplasty. Ann Thorac Surg 1993;56:418-425. 
CHAPTER

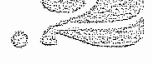

\section{Right latissimus dorsi cardiomyoplasty in diaphragm eventration and cardiac malposition}

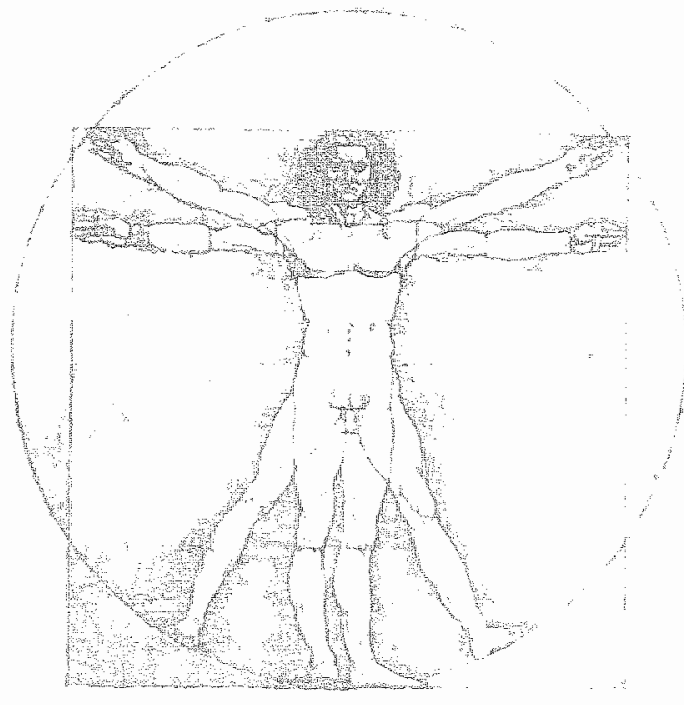

Roberto Lorusso, Giuseppe Coletti, Antonio Dellavalle, Giuseppe Steffenino, M.D., Giovanni Aliprandi, Ottavio Alfieri. 
Cardiomyoplasty recently has been introduced as a surgical therapy for long-lasting cardiac dysfunction in selected patients. We report the case of a patient affected by chronic heart failure, unresponsive to maximal medical therapy, with concomitant posttraumatic injury of the left phrenic nerve, left diaphragm eventration, and cardiac malposition (right displacement). In view of the progressive deterioration of the cardiac function, cardiomyoplasty was recommended, and the right latissimus dorsi muscle was used to perform the wrapping procedure. A 6-month follow-up showed significant functional, as well as hemodynamic improvements in addition to a reduction in medical therapy.

Diaphragm eventration induced by phrenic nerve injury is a rare posttraumatic complication, calling for surgical treatment in symptomatic patients (1). We describe a case in combination with cardiac displacement, clilated cardiomyopathy, and chronic heart failure. Despite maximal pharmacologic support with progressive clinical deterioration, cardiomyoplasty was considered the correct option for our patient, and the right latissimus dorsi (LD) muscle was considered suitable for performing the wrapping procedure (2-4). We report here operative and 6-month follow-up details.

A 58-year-old man with progressive clinical deterioration induced by chronic heart failure secondary to idiopathic dilated cardiomyopathy was referred to us. When young, he had suffered a trauma in his neck and left upper trunk with irreversible lesion of the left phrenic nerve and plexus brachialis, resulting in left diaphragm eventration and functional impairment of the left upper trunk muscles. Later, he suffered mild dyspea, initially referred to his lung dysfunction. A thorough examination revealed cardiac dilatation with depressed left ventricular contractility. Despite a maximal pharmacological regimen, several episodes of acute pulmonary edema developed with severe impairment in functional capacity (New Yor Heart Association Class III, maximal oxygen consumption of $12.5 \mathrm{ml} / \mathrm{kg} / \mathrm{min})$. Chest roentgenography showed left diaphragmatic eventration and severe cardiomegaly with heart malposition (figure 1 ). Cardiac catheterization showed an output of $4.7 \mathrm{~L} / \mathrm{min}$, cardiac index of 2.2 $\mathrm{L} / \mathrm{min}$, moderate pulmonary hypertension, and an ejection fraction of $0,23 \%$ (at ventriculography). The pulmonary function showed a reduction in the vital capacity and forced expiratory ventilation (67\% and $57 \%$, respectively) and important reduction in oxygen diffusion. Electromyography showed a dysfunction of the left upper trunk muscles. The impairment in cardiocirculatory function warranted expeditious management, whereas repair of the diaphragmatic eventration was not considered crucial for clinical recovery. The clinical findings led us to recommend and later perform a right LD cardiomyoplasty. 


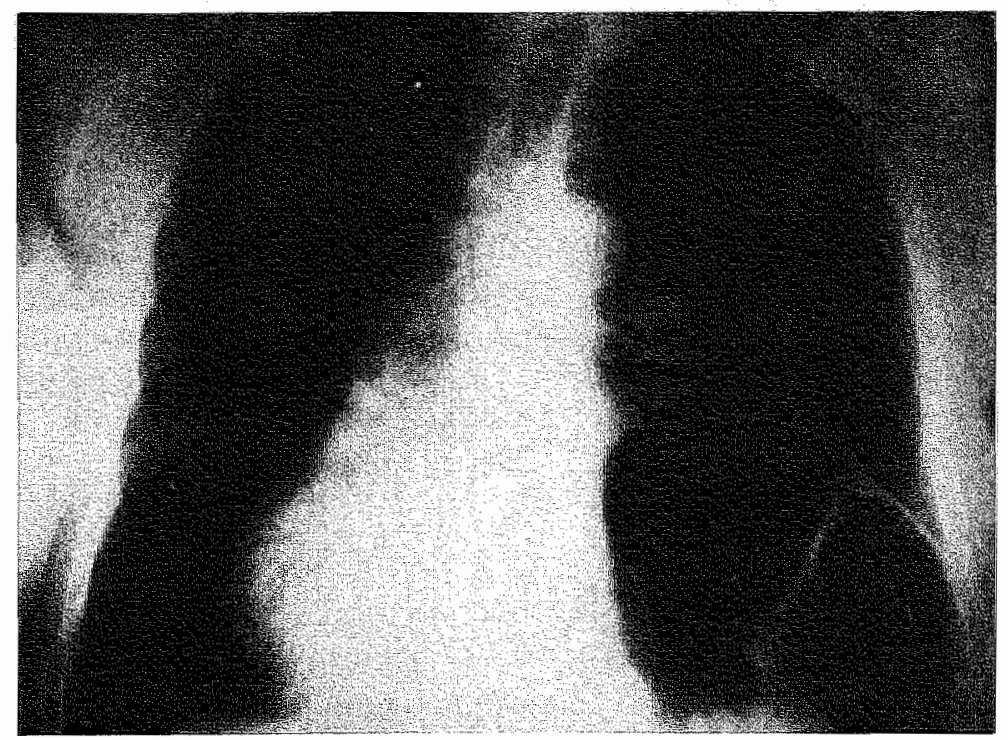

Figure 1. Chest roentgenogram shows left diaphragmatic eventration with ipsilateral lung compression, cardiac enlargement, and dislocation to the right side.

The right $L D$ was harvested, and the implantation of two intramuscular electrodes (Medtronic 5528; Medtronic Inc, Minneapolis, MN) was performed according to the technique described by Chachques and associates (5). The patient was draped in a supine position. Sternotomy was carried out slightly toward the right side of the sternal manubrium to reduce the risk of entering the peritoneum or the left pleura.

A wide left pericardial flap was trimmed. The heart was severely dilated in all the chambers, dislocated to the right, with the anterior descending coronary artery lying along the median line (figure 2 ). After the right mediastinal pleura was entered, the LD muscle and the two intramuscular leads were transposed into the pericardial cradle. The length of the muscle graft allowed a complete anterior clockwise cardiocostal wrapping, requiring no extracorporeal circulation. Appropriate right lung expansion was checked at the end of the wrapping procedure. After the implantation of the cardiac sensing lead, the implanted electrodes were tunneled to a left abdominal pocket and connected to a cardiomyostimulator (Medtronic SP 1005A; Medtronic Inc.). The pericardial flap then was placed over the anterior surface of the mediastinal course of the wrapped LD muscle (figure 3). Throughout the surgical procedure, transesophageal echocardiography monitored the cardiac wrapping and documented possible negative effects on cardiac geometry or dynamics.

The postoperative period was characterized by a prolonged intubation time $(4$ days) due to refractory hypoxia. The patient was discharged after 20 days. 

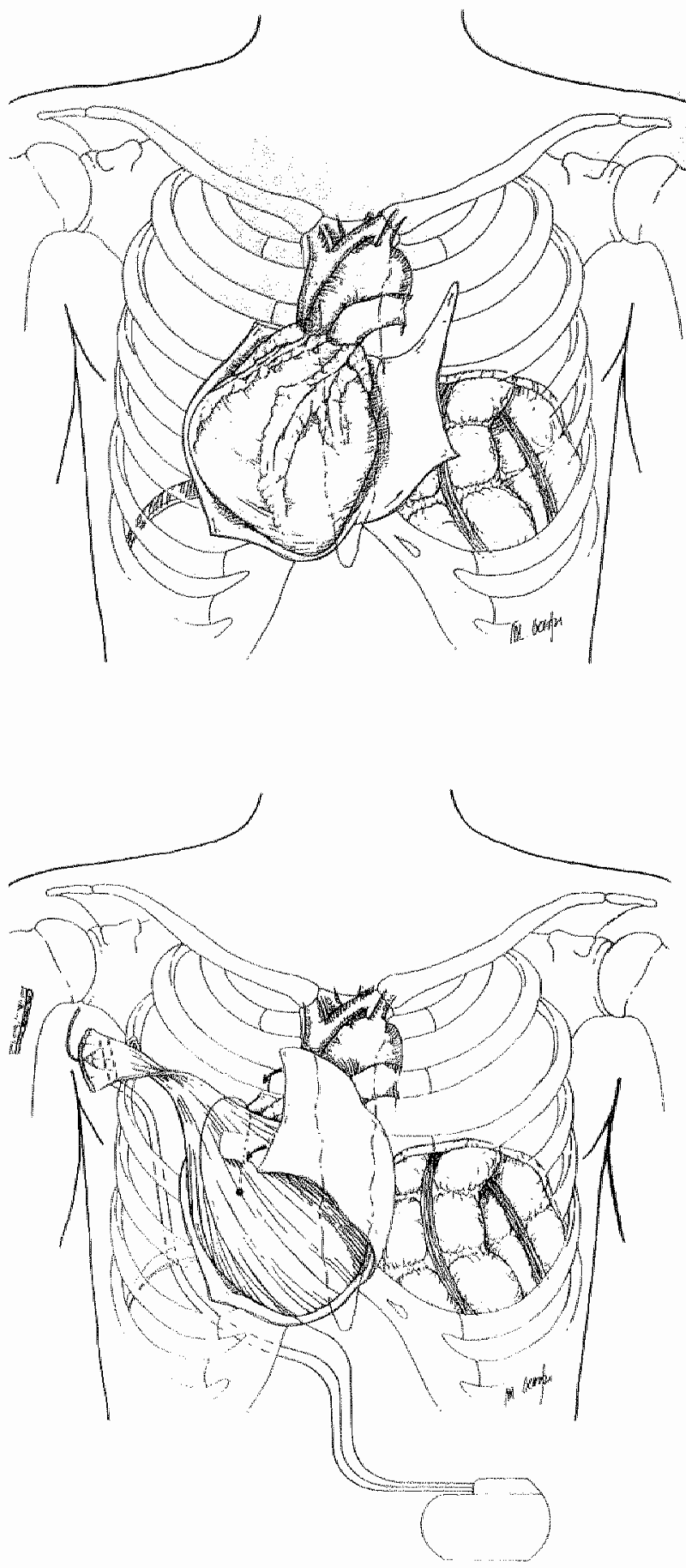

Figure 2. Heart malposition due to the left diaphragm eventration is shown. A wide left pericardial flap is trimmed just after the median stemotomy.
Figure 3. Right latissimus dorsi wrapping is represented: The pericardial flap eventually is re. positioned at the original site to cover the midline crossing portion of the muscle graft to reduce postoperative adhesions. 
Six months after the operation, the patient was submitted to preliminary postoperative evaluation and hemodynamic assessment. His functional capacity improved significantly (New York Heart Association Class I, maximal oxygen consumption of $17.4 \mathrm{ml} / \mathrm{kg} / \mathrm{min}$ ) as did his cardiac parameters (cardiac output from 4.7 to $6.2 \mathrm{~L} / \mathrm{min}$, cardiac index from 2.2 to $3.0 \mathrm{~L} / \mathrm{min} / \mathrm{m} 2$ ). Medical therapy was reduced markedly. Pulmonary function tests revealed no major changes in lung parameters, and significant improvement of the alveolar gas exchange (increase of $23 \%$ ).

\section{Comment}

Injury of the phrenic nerve is an uncommon complication of neck or thoracic trauma. Irreversible lesion of such a nerve usually leads to diaphragm paralysis and eventration, ipsilateral lung compression, and impaired pulmonary function. Surgical treatment for congenital or acquired diaphragmatic eventration has been reported in symptomatic patients (1). Our patient also had concurrent heart displacement, dilated cardiomyopathy, and severely depressed cardiac contractility. Prognosis in the case of medically refractory CHF is poor, and therapeutic altematives limited. Cardiomyoplasty has been proposed to complement surgical therapy (5). Despite controversial results of cardiomyoplasty application, some reports clearly have shown the efficacy of this novel tehnique in improving cardiac contractile dysfunction. Right LD cardiomyoplasty has provided beneficial hemodynamic results in experimental as well as clinical settings probably due to the contractile direction (apex-to-base) of the wrapped skeletal muscle $(4,6,7)$. In our case, the right dislocation of the heart and the concomitant dysfunction of the left LD forced us to use the contralateral muscle for performing the wrapping procedure. Moreover, the use of the left LD might have led to further compression of the already impaired lung.

Magovern and associates (8) showed that the right LD wrapping was more effective in the short term, arguing that degenerative changes of muscle structure, most likely due to overuse, might reduce muscle power in time. We believe that this hypothesis plays a crucial role in cardiomyoplasty outcome, but postoperative adhesions may further hamper the contraction and performance of the wrapped right LD. Therefore, we used a pericardial thap lying over the muscle graft to reduce adhesions between the wrapped LD and the sternum above. In the long run this may favorably affect the performance of the skeletal muscle.

Cardiomyoplasty provided significant circulatory support in this patient, and subjective postoperative improvement was confirmed by hemodynamic evaluation. Further studies are required before recommending the adoption of the right instead of the left LD muscle in cardiomyoplasty. 


\section{References}

1. Graham DR, Kaplan D, Ewans CC, Hind CRK, Donnelly RI. Diaphragmatic plication for unilateral diaphragmatic paralysis: a 10-year experience. Ann THorac Surg 1990;49:248-52.

2. Carpentier $A$, Chachoues JC, Acar $C$, et al. Dynamic cardiomyoplasty at seven years. I Thorac Cardiovase Surg 1993;106:42-54.

3. Moreina LE, Seferian $P_{3}$ Bocchi EA, et al. Survival improvement with dynamic cardionyoplasty in patients with dilated cardiomyopathy. Circulation 1991;84:(Suppl3):296-302.

4. Magovem IA, Park SE, Cmolik BL, Trumble DR, Christieb TY, Magovern GI. Early effects of right latisimus dorsi cardiomyoplasty on left ventricular function. Circulation 1993;88(Suppl 3):298-303.

5. Chachques IC, Grandjean PA, Carpentier A. Latissimus dorsi dynamic cardiomyoplasty. Ann Thorac Surg 1989:47:600-4.

6. Magowern JA, Fumary AP, Christieb [Y, Kao RL, Magovern G]. Right latissimus dorsi cardiomyoplasty for left ventricular failure. Ann Thorac Surg 1992;53:1120-2.

7. Park SE, Cmolik BL, Lazzara RR, Trumble DR, Magovem IA. Right latissimus dorsi cardiomyoplasty augments left ventricular systolic performance. Ann Thorac Surg 1993;56:1290-5.

8. Magovern $/ A$, Magovern GJ Sr, Mager TD, et al. Operation for congestive heart failure: transplantation, cononary artery bypass, and cardiomyoplasty. Anm Thorac Surg 1993;56:418-25 
CHAPTER

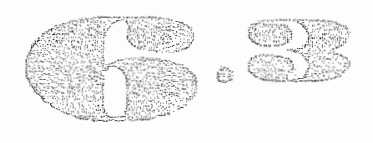

Bacterial infection of cardiomyostimulator abdominal pocket following cardiomyoplasty procedure: an original approach to preserve synchronous muscle stimulation

Roberto Lorusso, Antonio Curnis, Chester Struble, Luca Sandrelli, Ottavio Alfieri. 
Dynamic cardiomyoplasty (DC) represents a new technique in the therapy for refractory heart failure. So far, DC has been applied to more than 500 cases worldwide, but reports on postoperative complications and related management are still lacking. We present the case of a patient suffering from refractory chronic heart failure for which the DC procedure was applied also accompanied by the complication of an infective process at the cardiomyostimulator pocket that began 2 weeks postoperatively. Following trials with several unsuccessful conservative approaches, an original procedure was developed to temporarily retain the implanted stimulation system, while at the same time maintain the synchronous contractions of the wrapped muscle. Finally, reimplantation of the pacing system was achieved with a low-risk procedure, effective cardiac assistance was preserved, and the infection process was arrested 3 years following $D C$.

\section{Introduction}

The basis of the dynamic cardiomyoplasty (DC) pacing system is characterized by wrapping a mobilized latissimus dorsi (LD) muscle around the cardiac ventricles and maintaining of the synchronous contraction of the muscular graft evoked by sensed cardiac activity (1). Therefore, the integrity of the heart-pulse generator-skeletal muscle circuit is essential to establish correct and effective cardio-muscular interaction. Infection processes occurring at the pocket site of pacemakers or implantable defibrillatiors are common and frequent complications. Conservative methods to treat the progressing infection have been described, but, more often, device and electrode explantation are required (2-4). Such management in DC could lead to the definitive loss of long-term circulatory support. We report the case of a patient affected by refractory chronic heart failure who underwent DC that was complicated by the infection of the ab. dominal pocket containing the pulse generator. The patient was submitred to varied approaches in an attempt to preserve the leads originally implanted and maintain the effective cardiac support. Because of unsuccessful results and the necessity of concomitant improvement in hemodynamics, an original procedure was conceived to remove part of the infected foreign materials, to temporarily maintain LD synchronous stimulation, and ultimately to restore heart/muscle interaction by means of a low-risk procedure. 


\section{Case Report}

A 56-year-old man was referred to our institution because of progressive deterioration in chronic heart failure despite full medical therapy (ACE-inhibitors, diuretics, vasodilators, digitalis). The left ventricular cardiac dysfunction was idiopathic in etiology. Hemodynamic parameters included a cardiac output o $4.6 \mathrm{~L} / \mathrm{min}$, cardiac index of $2.2 \mathrm{~L} / \mathrm{min}$ per sqm, left ventricular end-diastolic diameter of $86 \mathrm{~mm}$, and ejection fraction (EF) of $14 \%$ (by scintigraphic assessment-MUGA). He had suffered several episodes of acute pulmonary edema and was in New York Heart Association (NYHA) Class III preoperatively. The patient was originally referred for heart transplantation, but had refused the procedure; therefore DC was considered a valuable therapeutic alternative.

\section{The Technique}

A clockwise wrapping procedure was performed according to the technique described by Chachques and associates (1). The perioperative period was uneventful.

At 2 weeks following surgery, a slight tender redness and swelling were present just above the abdominal pocket. Prompt pocket opening was carried out and overt bacterial infection detected. Thorough wound debridement was accomplished whereas the electrodes were kept intact since apparently they appeared not to be compromised and the bacterial contamination confined to the lower area of the pocket; cultures from the pocket site were found positive for Staphilococcus Aureus.

The leads were then retunneled on a specular pocket (right abdominal wall). and connected to a new stimulator (Medtronic SP 1005, Medtronic Inc., Minneapolis, MN, USA) while specific antibiotic treatment was administered.

When the original pulse generator pocket was recovered, complete LD electrical conditioning could be achieved according to the standard protocol (1), with significant improvement of hemodynamics and functional capacity in the patient.

After 3 months, an infection developed at a location near the new device. Systemic antibiotic regimen, together with local antibiotic and povidoneiodine irrigation, were instituted. Nonetheless, a pocket decubitus developed, and new explantation of the cardiomyostimulator was deemed necessary although the electrodes were again salvaged. In the absence of LD contraction, the patient's clinical course was closely observed. In the following 3 to 4 weeks, the patient's condition clearly deteriorated (NYHA Class IV, EF of $12 \%$, cardiac output of $3.4 \mathrm{~L} / \mathrm{min}$ ) and hospitalization was required for aggressive medical therapy. The electrodes were then exteriorized at the subxyphoid level and con- 


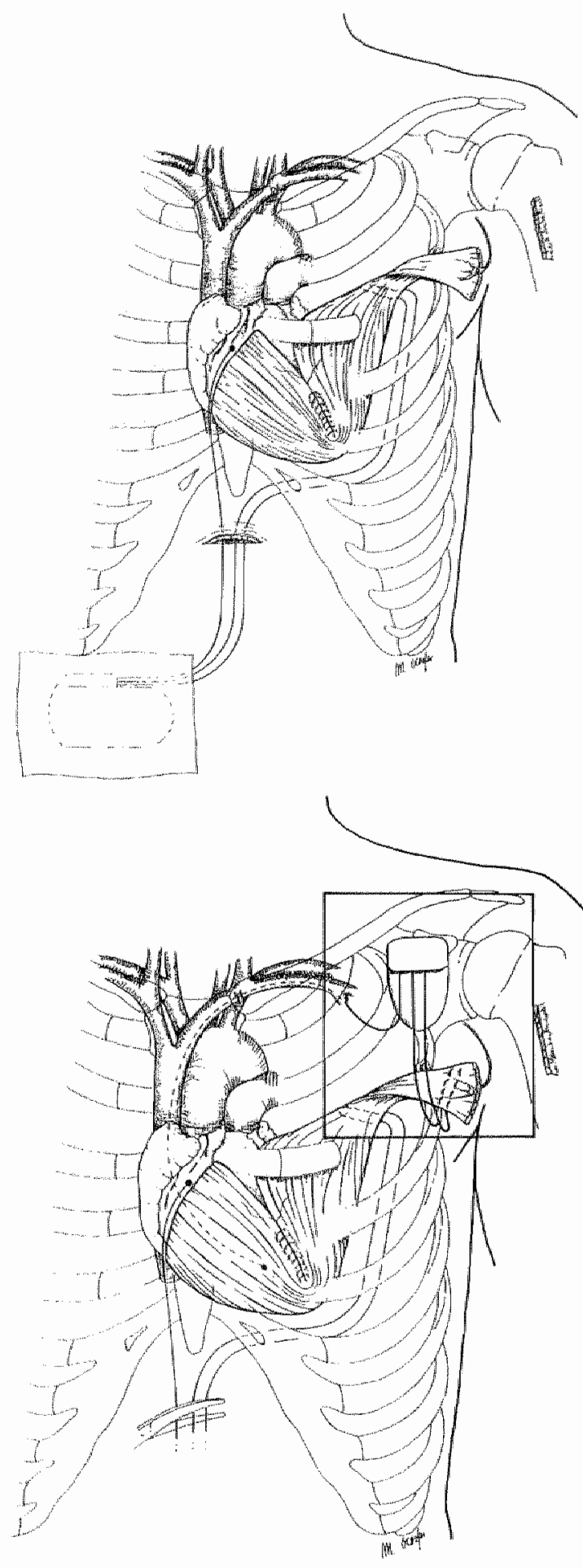

Figure 1. Left Latissimus Dorsi cllockwise cardiomyoplasty is shown. Implanted leads are exteriorized at the subxyphoid level and connected to the cerdiomyostimulator placed above the skin.
Figure 2. The two new intramuscular pacing electrodes are reimplanted proximal to the transplanted muscle graft (thoracic window. The sensing lead is positioned endocatially through the subclavian vein. Finally, all the electrodes are connected to the new stimulator and buried in a subfascial plane below the clavicle (square), whereas the original electrodes are cut at the subxyphoid level. 
nected to the cardiomyostimulator placed above the skin (figure 1). The patient gradually recovered (NYHA Class II) and a reduction in pharmacological sup. port was achievable.

The infection process was checked daily, but it remained localized to the exit site of the electrical drivelines. This steady state allowed us to discharge the patient, who was regularly checked, and to wait for a new low-weight and lowprofile cardiomyostimulator (Medtronic 4710). The new device enabled us to define a new approach and maintain the needed muscular support while excising the implanted leads. The implantation of the new intramuscular leads was accomplished very proxymal to the LD in order to approach a low-risk area cextrathoracic portion) and therefore to reduce a potential spread of the progressing infection.

The proximal muscular portion (muscle tendon) was visualized by a short incision carried out on the most cranial part of the previous lateral thoracic wound. Careful dissection was performed to harvest the tendon of the mobilized LD which was anchored at the thoracic window. The muscular pedicle was detected and skeletonized so as to achieve complete exposure of the neurovascular structures entering the muscle belly and prevent any potential damage. The proximal LD was dissected free from the sorrounding adluesions by pulling gently and progressively the muscular tendon, taking care to avoid opening of the left pleura. Following complete mobilization and exposure of few centimeters of the proximal musle mass, two new intramuscular electrodes (Medtronic 4750) were implanted in the standard way (1). The optimal muscle recruitment and related contraction were assessed by connecting the leads with an external stimulator and programmer. Further, effective LD contraction was checked in real time with fluoroscopy observation. The two electrodes were subsequently tunneled subcutaneously to the already prepared subclavicular pocket. At this site, the subclavian vein was reached and an endocardial sensing lead (Medtronic Capsure, Medtronic Inc., Minneapolis, USA) inserted to reach the right ventricular endocardium. Optimal $R$ wave signal was assessed. Finally, the sensing lead, together with the very recently implanted intramuscular ones, were connected to the new cardiomyostimulator which was buried in a subfascial plane abowe the pectoralis major muscle.

Finally, a deep incision was performed at the subxyphoid level to excise the old electrodes and clear the superficial infected area (figure 2).

The patient recovered quickly, the infection process was arrested, and stimulation of the wrapped muscle and cardiac assistance were preserved. Improved functional capacity and hemodynamics (cardiac output from $4.7 \mathrm{~L} / \mathrm{min}$ preop to $6.2 \mathrm{~L} /$ min postop, cardiac index from $2.2 \mathrm{~L} / \mathrm{mi}$ per $\mathrm{sqm}$ to $3.1 \mathrm{~L} / \mathrm{min}$ per sqm, EF from $14 \%$ to $23 \%$ at MUGA) have still remained constant almost 3 years after surgery with no sign of relapsing infection. 


\section{Comment}

The occurrence of bacterial infection following pacemaker or defibrillator implantation ranges from $0 \%$ to $13 \%$ (5). This troublesome complication may be life-threatening if not properly managed (6). The most accepted approach for alleviating the danger is to completely remove the contaminated device and related leads, and then to follow this by a new implantation (4). Dynamic cardiomyoplasty implies the implementation of a complex electrical system which ensures correct heart/wrapped muscle interaction and long-lasting cardiac support. In terms of postoperative infection following DC, data about complication rate are still lacking. Nevertheless, due to the unstable clinical conditions and to the amount of foreign material used in such a procedure, these patients are at high risk for the development of postoperative infection.

In contrast with pacemaker or automatic implantable defibrillator positioning, DC may be more problematic in terms of management since the leads are linked with two different systems, namely: cardiac sensing and muscle stimulation. Because of the intrathoracic location of the mobilized LD, muscle electrode reimplantation may require troublesome surgery. Furthermore, the structure of the muscle graft is intimately linked with the electrical stimulation which is crucial to maintain the achieved fibre transformation (fatigue resistance), and to preserve its viability.

Our case represents a peculiar situation since we were forced to maintain LD stimulation because of the improved hemodynamics, while at the same time the progressing infection had to be treated. Hurst and associates (3) reported a few cases of successful treatment of pacemaker infection adopting conservative methods. Such management failed in our case even despite specific antibiotic treatment. Furthermore, the patient clearly benefited from the LD muscle assistance since progressive clinical deterioration occurred following the arrest of the muscle graft contraction.

Bocchi and associates (7) described the effects that a 24-hour interruption of LD stimulation can have. Two patients remained without muscle support for 6 days documenting a decrease of the left ventricular EF to preoperative values. To our knowledge, ours is the first case in which muscle support was absent for such a long period (almost I month), showing severe impairment of the patient conditions, and progressive recovery after restoration of the muscle synchronous action.

In left ventricular assistance experience, the presence of exteriorized drivelines is a common feature. Such a situation if often linked to the development of driveline contamination, and exteriorization of the pump to successfully treat the bacterial infection has been reported $(8)$. These preliminaries prompted us to adopt such a strategy, exteriorizing the leads in an attempt to preserve muscle stimulation and to avoid the inevitable loss of chronic assistance in case of 
lead removal. Rigorous dressing changes and skin cleaning allowed the infection to be controlled and confined to the skin exit site. The subsequent approach was adopted to restore synchronous muscular contraction acting far from the infected area. Furthermore, the procedure was of low risk. Such a technique, following appropriate harvesting of the muscular pedicle at the tho racic window, allows proper implantation of new intramuscular electrodes in the standard way (encircling the nerve branches), taking into account that such an approach makes the positioning of a nerve electrode potentially feasible.

In our patient DC provided significant support of the depressed cardiac performance, confirming the importance of sustained biomechanical cardiac assistance.

The preserved muscle contraction and improved hemodynamics, the quick recovery of the patient ( 4 days of hospitalization) and the arrest of the infection process, allow us to conclude that the aforementioned strategy represents a successful approach to solving a life-threatening complication, to shortening the management time, and to effectively preserving the muscle integrity as well as the beneficial effects of long-term synchronous support. 


\section{References}

1. Chachques JC, Grandjean PA, Schwartz K, et al: Effect of latissimus dorsi dynamic cardiomyoplasty on ventricular function. Circulation 1988;78(Suppl HI):IIL203-III216

2. Gupta $\$$, Prevel $C D$, Shaheen $K$, et all: Wound complications and treatment of the infected im. plantable defibrillator generator. J Card Surg 1993;8:671-677

3. Hurst $L N$, Evans HB, Windle B, et al: The salvage of the infected cardiac pacemaker pocket using a closed irrigation system. PACE 1986:9:785-792

4. Mansour KA, Kauten JR, Hatcher CR: Management of the infected pacenaker: explantation, sterilization, and reimplantation. Ann Thorac Surg 1985;40:617-619

5. Rao G, Ford WB, Zikria EA, et al: Incidence and prevention of infection in patients with perma. nent cardiac pacemakers. Int Surg 1974;59:599.

6. Ruiter JH, Degener $\mathrm{JE}$, Van Mechelen $\mathrm{R}$, et al: Late purulent pacemaker pocket infection caused by staphylococcus epidermidis. PACE 1985;8:903-907.

7. Bocchi EA. Moreira LF, Vilela de Moraes A, et al: Effects of dynamic cardiomyoplasty on regional wall motion, ejection fraction, and geometry of left ventricle. Circulation 1992;86; Suppl II): $11231-11235$.

8. Kawa A, Kormos RL, Griffu BP: Management of infections in mechanical circulatory support devices. In Ott RA. Gutfinger DE, Gazzaniga AB (eds): Mechanical Cardiac Assist. Cardiac Surgery: State of the Art Reviews. Hanley and Beifus, Inc., Philadelphia, PA 1993, pp 413-424. 
CHAPTER

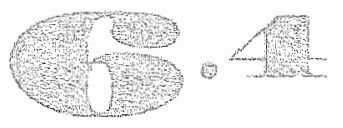

\section{Management of pacing system-related complications following cardiomyoplasty procedure}

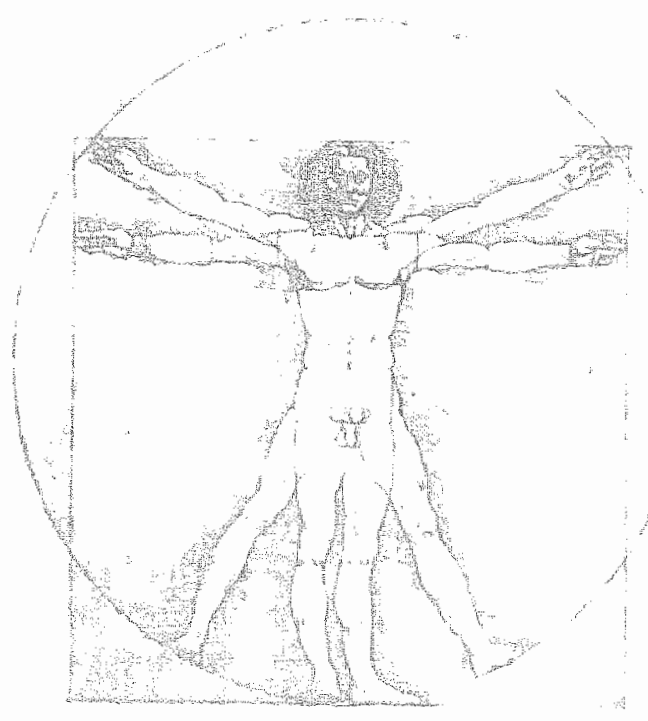

Roberto Lorusso, Chester Struble, Federico Bianchetti, Anna Marchini, Antonio Curnis, Ottavio Alfieri. 
Integrity of the electrical circuit is a necessary requirement for appropriate heart/urapped skeletal muscle interaction to be achieved in cardiomyoplasty. This report describes the management of two different complications after cardiomyoplasty procedure involving the electrical system (infection of the abdominal cardiomyostimulator pocket and intramuscular lead fracture). Minimal approaches have been carried out, which ensured the successful treatment of the infective and of the mechanical insult, and represent useful strategy for solving such uncommon problems.

Complications involving the electrical system which ensures synchronized heart/skeletal muscle interaction in cardiomyoplasty procedure may occur. Bacterial contamination of the electrical equipment represents the most common problem, but damage of any part of the pacing circuit may be an additional event which may require cumbersome management to reinstitute the appropriate connection between cardiac and skeletal muscle activity. These reports present our experience regarding the successful treatment of such uncommon but potential complications after cardiomyoplasty surgery by using minimally invasive procedures.

\section{Case 1}

A 48-year-old ladly was admitted to our Department because of a history of several episodes of acute pulmonary edema despite full pharmacological regimens (vasodilators, ACE-inhibitors, diuretics, digoxin). Idiopathic cardiomyopathy was the underlying disease. Heart transplantation was contraindicated because of insulin-dependent diabetes. Left ventricular (LV) end-diastolic diameter was $68 \mathrm{~mm}$, and LV ejection fraction was $20 \%$ by radionucleide scanning. Her functional capacity was markedly reduced (NYHA Class III). The patient was thus considered a good candidate for cardiomyoplasty procedure, and a left Latissimus Dorsi muscle (LDM) clockwise cardio-costal wrapping technique was performed. Surgical procedure and postoperative course were uneventful. At 3 months from surgery the patient suffered from tenderness at the site of the abdominal pocker containing the cardiomyostimulator. After unsuccessful antibiotic treatment (local and systemic), and based on our previous experience (1), explantation of the device and proximal recision (subxifoid level) of the previously implanted electrodes were carried out to prevent the spread of the infectious process towards the thoracic structures. Concomitantly, the mobilized LDM was approached by a minimally invasive technique. Indeed, the proximal portion of the intrathoracic transposed muscie was reached at the level of the thoracic window where the proximal tendon had been fixed during the prevoius operation. Careful caudal dissection and concomitant gentle pulling 
enabled us to expose an appropriate muscle portion out of the thoracic cavity without entering the ipsilateral pleural space. Two new intramuscular electrodes (Medronic Model 4750, Medtronic Inc) were then implanted at the proximal muscle segment. Subsequently, a new cardiomyostimulator (Medtronic Model 4710 Transform, Medtronic Inc.) was positioned in a subpectoral pocket, ensuring implantation of a new sensing electrode (Medtronic Model Capsure, Medtronic Inc.) through the endocardial route (cephalic vein). Finally, the new implanted intramuscular electrodes were tunnelled to the subclavicular pocket, and connected to the cardiomyostimulator. The entire procedure was performed under local anesthesia with no patient discomfort. No recurrence of the infection occurred in the following postoperative period. At more than 2 years from the original operation, the patient is currently in NYHA Class II, LV end-diastolic diameter is $57 \mathrm{~mm}$, and LV ejection fraction is $34 \%$.

\section{Case 2}

A 63 year-old man underwent left LDM cardiomyoplasty because of refractory chronic heart failure secondary to ischemic cardiomyopathy. Surgery and postoperative recovery were uneventful. At one-year follow-up a right heart catheterization was performed, and modest changes of hemodynamic parameters were observed. However, following hospital discharge, clinical condition of the patient progressively deteriorated, and because of the occurrence of nocturnal paroxysmal dyspnea he was readmitted to our Department. On admission, ECG showed sinus rhythm and synchronized skeletal muscle spikes. Nevertheless, no LDM contraction could be palpated at the patient's axilla. Fluoroscopy showed no electrode movement, even at high electrical pulse amplitude for muscle stimulation. Chest-x ray (figure 1) documented no evidence of lead dislodgement or fracture, but kinking at the level of the proximal electrode was observed. Exploration of the implanted cardiomyostimulator was planned since failure of correct intramuscular electrode/pacing device contact was hypothesized. After pocket opening, no failure of electrode contact with the stimulator was detected, and damage of the thoracodorsal nerve was considered the probable event. After surgical revision, another chest- $x$ ray was performed, and, unexpectedly, fracture of the proximal intramuscular electrode, at the site of the previously recognized kinking (figure 2), was found. Thanks to the close location of the distal intramuscular electrode at the branching point of the main nerve, a change in stimulation mode (from bipolar to unipolar) was performed. The distal electrode, which was originally assigned as the indifferent (anode) electrode, was now switched and re-assigned as the stimulating (cathode) electrode. The lead was then connected to the negative pole of the muscular channel of the cardiomyostimulator (Medtronic Model 4710 Transform, Medtronic 


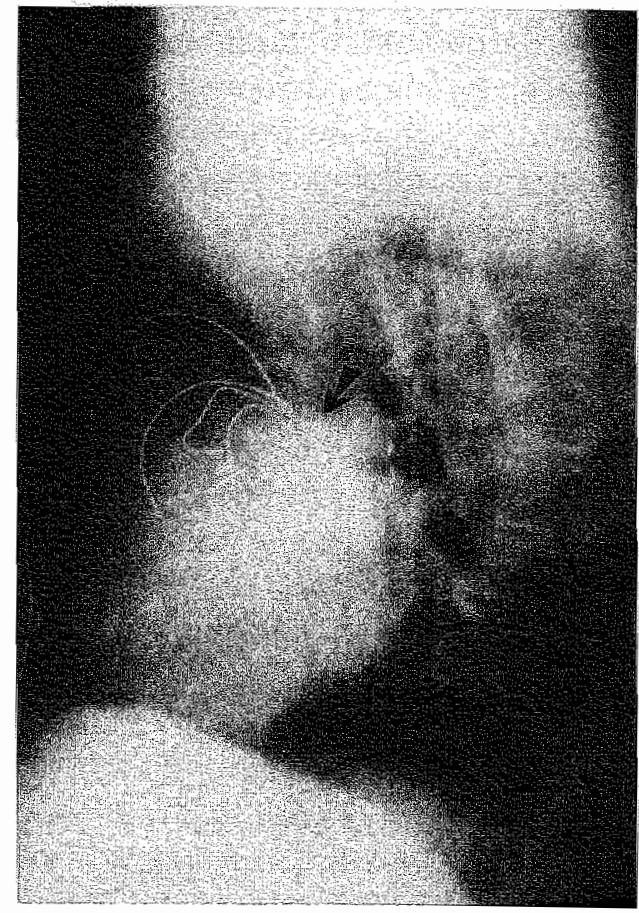

Figure 1. The figure shows kinking (arrow) of the proximal negative electrode.

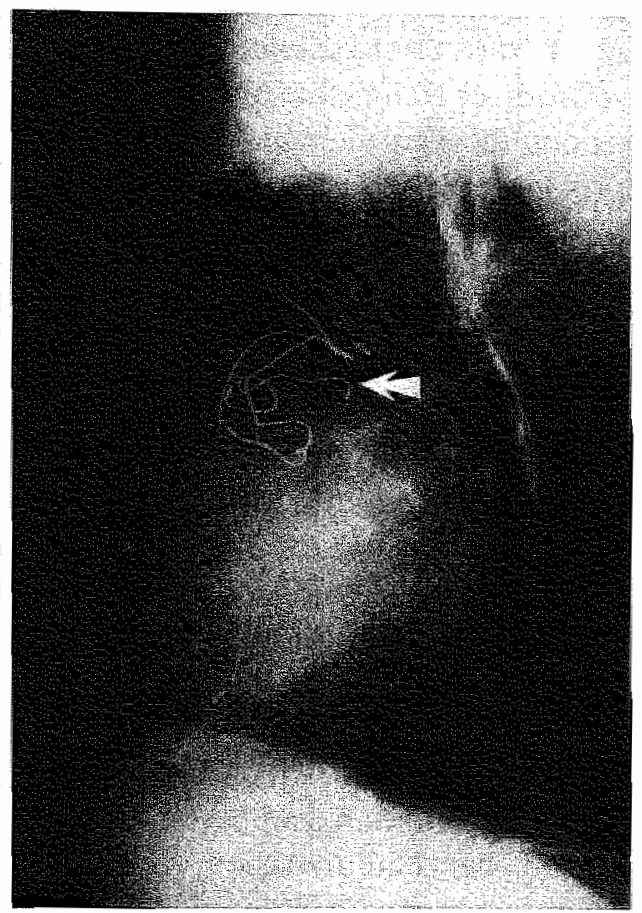

Figure 2. Fracture [arrow) of the previously kinked ellectrode is documented.

Inc.). Such a management allowed to restore full muscle recruitment (contraction of the most peripheral muscle portion at fluoroscopy). The patient gradually recovered, and no additional problems in muscle contraction during follow-up (currently at more than 3 years) were encountered.

\section{Comment}

Complications after cardiomyoplasty related to the electrical system are rare (2). Nevertheless, infective processes involving the electrical devices and electrodes have been described in pacemaker or implantable defibrillator experiences (3-5). Management of such adverse events is difficult, often ultimately leading to explantation of device and electrodes to prevent systemic spread of the bacterial contamination (5). We recently reported a case of bacterial infection involving the cardiomyostimulator pocket where a low-risk procedure was effectively performed to reinstitute synchronized cardiac/LDM function (1). Such an experience prompted us to implement the same technique and to aggressively treat this new case of superimposed infection involving the electrical 
system in a cardiomyoplasty patient. Expeditious removal of the previously implanted device and of all the electrode segments located in close proximity to the cardiomyostimulator is mandatory to prevent any potential spread of the infection. A new cardiomyostimulator and related leads may be repositioned further from the contaminated area. This management allows easy control of the ongoing infection, favoring short hospitalization, and enhancing immediate restoration of LDM contraction.

Failure of the electrical system due to mechanical causes (fracture, displacement, etc.) has not been reported to date within the cardiomyoplasty experience (2), but such complications may be induced by lead kinking, by friction of intramuscular leads against the rib of the thoracic window, or by intraoperative lead damage. Although fluoroscopy represents the gold standard as a diagnostic method, this evaluation may be negative. Kinking of the pacing leads, which may predispose to progressive damage of the insulating electrode sheath or electrode filament, and finally cause to lead fracture, could represent a potential clue for diagnosis. The implantation of intramuscular electrodes as proximal as possible to the branching point of the main LDM nerve, and with a short distance of $30-40 \mathrm{~mm}$ between the proximal and the distal electrodes, may allow switching of the lead polarities in case of failure of one electrode. In this manner, implementation of the unipolar stimulation mode via the distal lead may be realised.

In conclusion, conservative and minimally invasive approaches should be considered whenever a damage or an infection involving the electrical equipment complicates the postoperative course of cardiomyoplasty procedure. 


\section{References}

1. Lorusso $\mathrm{N}$, Curnis A, Struble $\mathrm{C}_{\mathrm{n}}$ et al. Bacterial infection of cardiomyostimulator abdominal pocket following cardiomyoplasty procedure: an original approach to preserve synchronous muscle stimulation. J Card Surg 1995;10:358-362.

2. Grandjean PA, Austin L., Chan S, et al. Dynamic cardiomyoplasty: Clinical follow-up results. I Card Surg; $1991 ; 6$ (suppl) $80-80$.

3. Hammel D, Scheld HH, Block $\mathrm{M}$, et al. Nonthotacotomy defibrillator implantation: a singlecenter experience with 200 patients. Ann Thorac Surg $1994 ; 58: 321-327$.

4. Gupta $\$$, prevel $C D$, Shalheen $\mathbb{K}$, et al.. Wound complications and treatment of the infected implantable cardioverter defibrillator generator. J Card Surg 1993;:8:671-677.

5. Mansour KA, Kauten IR, Hatcher RC. Management of the infected pacemaker: explantation, sterilizaton, and reimplantation. Ann Thorac Surg 1985;40:617.619. 
CHAPTER

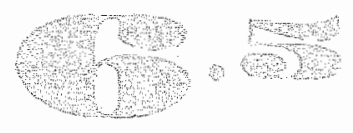

\section{Preserved skeletal muscle structure with modified electrical stimulation protocol in a cardiomyoplasty patient: a clinico-pathological report}

Roberto Lorusso, Ottavio Alfieri. Ugo Carraro, Jan J. Schreuder, Frederik H. Van der Veen, Hein JJ Wellens. 
Experimentaland clinical studies have recently shown variable degree of structural abnormalities in the transposed and chronically stimulated muscle graft after cardiomyoplasty procedure. The postoperative stimulation protocol of wrapped skeletal muscle has been claimed to be a major determinant of late structural derangement. Therefore, a modified stimulation protocol had been used after a cardiomyoplasty procedure in a 63-year-old patient. Improved postoperative hemodynamic data could be detected by pressure/volume analysis. After unexpected sudden death occurred at 15 monihs, autoptic examination showed preserved muscle structure, suggesting that a prudent stimulation protocol may maintain muscle viability and contribute to effective cardiac support.

Skeletal muscle integrity is a fundamental factor for optimal power to be expressed during muscle contraction. Concerns regarding long-term muscular structure have been raised in cardiomyoplasty procedure [1]. The pattern of muscle electrical stimulation has been shown to be responsible for muscle ischemia [2] which may ultimately lead to myocellular death, to lipomathosis, and to fibrotic tissue replacement. Based on these concepts, a modified stimulation protocol has been applied in a patient submitted to cardiomyoplasty procedure. Despite subjective and documented hemodynamic improvements, the patient died because of sudden death at 15 months from surgery. Autoptic findings of conditioned and unconditioned muscles are herein described.

A 63 year-old-gentleman affected by progressive deterioration of chronic heart failure secondary to coronary artery disease, and unresponsive to maximal pharmacological therapy was referred for surgical treatment. The patient was not suitable for myocardial revascularization because of severely depressed left ventricular function and absence of viable myocardium in the akinetic segments. Heart transplantation was contraindicated for complicated diabetes (peripheral vascular disease) and chronic renal insufficiency (previous excision of one kidney because of malignant tumor). Pressure-volume analysis of cardiac performance was performed pre-operatively by using a conductance catherer, as previously reported [3]. Cardiomyoplasty was deemed an appropriate therapeutic option for this patient and performed by using the left Latissimus Dorsi Muscle (LDM) in a clockwise cardio-costal wrapping. No extra-corporeal circulation was required during the wrapping procedure. Following 2 weeks of no muscle pacing to allow muscle graft recovery and to enhance muscular revascularization, the stimulation protocol was started adopting a modilied pattern. The heart/muscle contraction ratio was programmed at 4 to 1 , and the pacing frequency was gradually increased every other week up to $30 \mathrm{~Hz}$. This 
Table 1 . Hemodymamic data as measured by cond wetance catheter preoperatively and 6 months ater cardiomyoplasty procedure.

\begin{tabular}{|c|c|c|c|c|c|c|c|c|c|c|}
\hline & $\begin{array}{l}\text { HR } \\
\text { b/min }\end{array}$ & $\begin{array}{l}\mathrm{co} \\
1 / \mathrm{min}\end{array}$ & $\begin{array}{l}\mathrm{EF} \\
\mathrm{g}\end{array}$ & $\begin{array}{l}\text { EDV } \\
m !\end{array}$ & $\begin{array}{l}\mathrm{ESV} \\
\mathrm{mil}\end{array}$ & $\begin{array}{l}\text { EDP } \\
\text { mnHs }\end{array}$ & $\begin{array}{l}\mathrm{ESP} \\
\mathrm{HmHF}\end{array}$ & $\begin{array}{l}\text { dP/dt } \\
\text { mmHg/sec }\end{array}$ & $\begin{array}{l}\text {-dp/dt } \\
\text { mmig/sec }\end{array}$ & $\begin{array}{l}\text { Tau } \\
\text { msec }\end{array}$ \\
\hline Preop & 99 & 6.66 & 30 & 287 & 195 & 27.4 & 115 & 963 & 817 & 48.6 \\
\hline Postop & 99 & 692 & 50 & 177 & 86 & 25.9 & 102 & 1013 & -676 & 49.7 \\
\hline
\end{tabular}

Table2. Distribution of myosin heavy chain in different regions of Latissimus Dorsi muscles [LDM])

\begin{tabular}{|c|c|c|c|c|}
\hline & \multirow[b]{2}{*}{ Fibre type } & \multicolumn{3}{|c|}{ Myosin heavy chans } \\
\hline & & $2 \mathrm{~B}$ & $2 A$ & 1 \\
\hline & Coratralateral LDM & $62 \%$ & $15 \mathrm{w}_{\mathrm{H}}^{\mathrm{w}}$ & $23 \%$ \\
\hline & $\begin{array}{l}\text { Condinioned LDM } \\
(5 \mathrm{~cm} \text { from the humeral tendon) }\end{array}$ & $19 \%$ & $27 \%$ & $54 \%$ \\
\hline 3 & $\begin{array}{l}\text { Conditioned LDM } \\
\text { (10 cm from the humeral tendon }\end{array}$ & $17 \%$ & $38 \%$ & $45 \%$ \\
\hline 4. & $\begin{array}{l}\text { Conditioned LDM } \\
\text { (15 cm from the humeral tendon) }\end{array}$ & $7 \%$ & $33 \%$ & $60 \%$ \\
\hline
\end{tabular}

protocol allowed to maintain a reduced muscle workload than commonly used in the clinical setting $(1: 1$ or: 2:1). Muscle pulse amplitude was programmed at 4 Volts. At 6 months from cardiomyoplasty the patients was submitted to hemodynamic evaluation by pressure-volume study. Pre and postoperative data are shown in table 1 . Significant hemodynamic changes were documented, and remarkable reduction of cardiac dilatation was observed (figure). Despite maintained clinical improvement, the patient died because of sudden death 15 months after surgery. Post-mortem evaluation was performed. The left LDM appeared well wrapped and grossly viable. Six muscle biopsies were collected from the proximal portion till the peripheral part of the pedicled graft, taking care to include even some portion of the heart/muscle interface. Hive specimens from the contralateral unconditioned LDM were also collected for control morphological analysis and measurements. All biopsies were analyzed for morphology, enzyme-histochemistry, and electron microscopy. Muscle fibre diameter and composition, and intramuscular capillaries were studied. Contralateral unstimulated LDM was composed by fascicles of polygonal muscle fibres (mean diameter $40 \pm 3.0 \mu \mathrm{m}$ ) with focally interposed lobules of fat tissue $(18 \%$ of the total cross sectional area). A moderate variation in muscle fibre size 


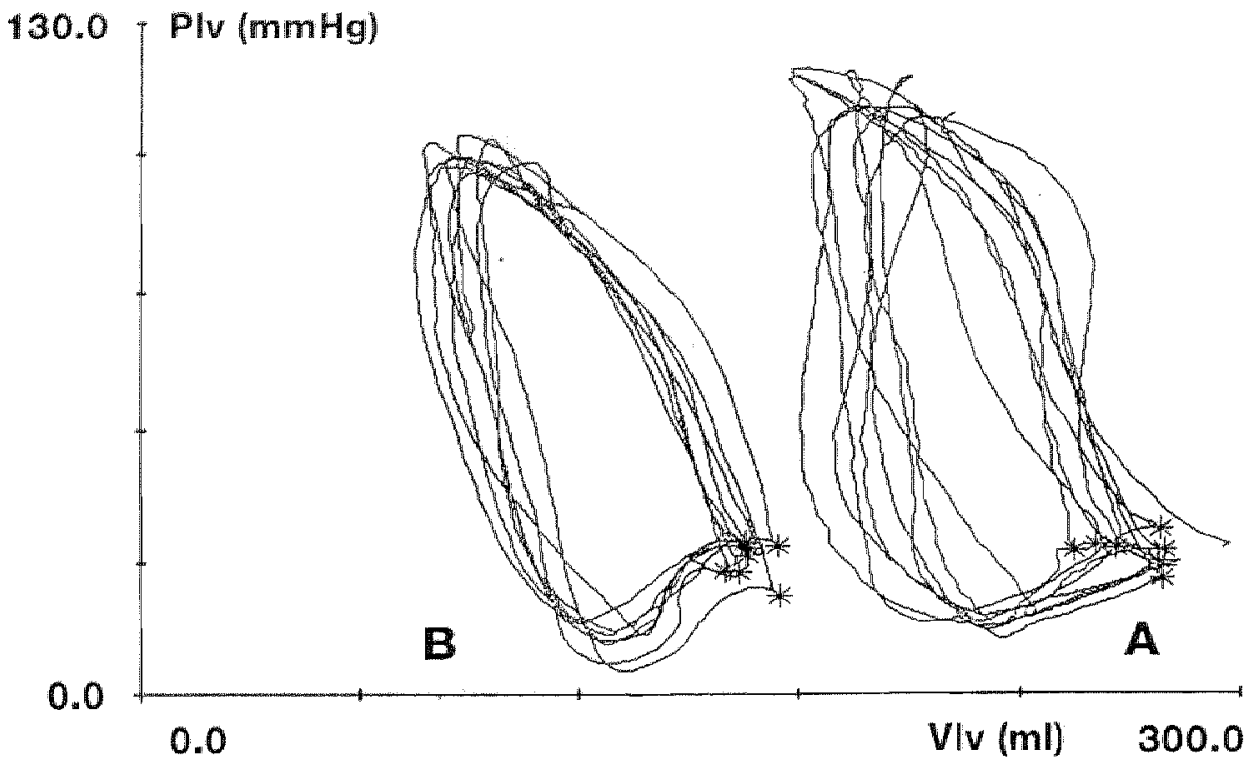

Figure. Pressure / voltume loops of the left ventricle are presented. The right loops (A) correspondend to preoperative cardiac pressures and volumes, whereas left loops ( $B$ ) relate to postoperative data (6* month follow-up). A reduction of ventricular volume is evident (shift to the left). "These loops were obtained with the cardiomyostmulator switched off. Plv: left ventricular pressure; V|v: left verutricular volume.

was observed but no structural alterations were detected. Reactions for myosin-ATPase and densitometric determination of myosin heavy chain showed the expected fast pattern dominated by type $2 \mathrm{~B}$ fibres (table 2). Distribution of intramuscular capillaries was normal and they appeared with restricted lumen. Morphological analysis of wrapped LDM showed homogeneous results in the specimens obtained at different regions except for the muscle portion close to the electrode insertion. In this area only, variation in fibre size (mean fibre diameter $28 \pm 4 \mu \mathrm{m}$ ), scattered degenerative alterations of muscle fibre, moderate reduction in the number of capillaries per fibre, and increase in endomysial connective tissue were observed. In the remaining specimens fascicles composed by polygonal fibres with moderate variation in size were documented (mean fibre diameter $36 \pm 2 \mu \mathrm{m}$ ). Rare atrophic fibres with round profile were observed. Myosin-ATPase and the electrophoretic analysis of myosin heavy chains revealed a partial fibre type transformation (up to $60 \%$ of type 1 fibre), whereas the fast fibres were mainly of type $2 \mathrm{~A}$ (table 2). The percentage of interfascicular fat tissue was $24 \%$ of the total cross sectional 
area. Dilated capillaries were observed in all studied specimens while the number of capillary per fibre was similar to the contralateral muscle.

\section{Comment}

In cardiomyoplasty procedure a skeletal muscle is to be harvested "transposed, wrapped around the ventricles, and synchronously stimulated to provide permanent cardiac support. Patterns of electrical stimulation have been shown to exert profound influence in muscle structural response. Evidences of altered muscle structure (myofibre abnormalities and replacement with fatty and fibrotic tissues) have been described experimentally $[1,4]$ and clinically $[5]$. Mechanical properties of the chronically stimulated muscle are intimately related to the preserved structure (4). The importance of the LDM stimulation mode was recently addressed by van Doorn and collegues (2) who demonstrated that a 1:1 mode was associated with impairment in blood flow of stimulated L.DM, whereas a $2: 1$ mode was able to maintain LDM blood supply/demand balance. Indirect evidences of long-term muscle degeneration in patients submitted to cardiomyoplasty procedure was decribed by Kalil-Fillho and collaborators using MRI evaluation (5). Nonetheless, those findings had been mainly obtained adopting a 1:1 stimulation mode. In our patient, the use of increased ratio between heart and muscle contractions (4:1) was meant to reduce wrapped muscle workload and prevent muscle ischemia, while maintaining an acceptable rate of supported beats. Hemodynamic study in our patient after cardiomyoplasty procedure documented effective LDM cardiac assist and important changes in left ventricular volumes. Nonetheless, despite overall cardiac improvement, high LV end-diastolic pressure persisted and might have provoked a fatal arrhythmia. Clinically, just a few reports described detailed inspection of muscle histology after cardiomyoplasty with controversial findings $[6-8]$, but, to our knowledge, no study showed histological muscle changes at more than 1 year from cardiomyoplasty related with significant hemodynamic changes. In our patient, the modified stimulation pattern was able to induce a partial trans formation (high percentage of type $2 \mathrm{~A}$ fibres) of the transposed muscle which may account for preserved original muscle power. In conclusion, this study showed that a modified stimulation protocol of the wrapped LDM was able to preserve muscle integrity up to more than I year from cardiomyoplasty. Maintained LDM structure was moreover linked to substantial changes in hemodynamics. 


\section{References}

1. Lucas CMHB, van der Veen FH, Cheriex EC, Lorusso R, Havenith M, Penn OCKM, et al. Longtem follow-up (12 to 35 weeks) after dynamic cardiomyoplasty. I Am Coll Candiol $1993 ; 22: 758-767$

2. van Doom CAM, Bhabra MS, Hopkinson DN, Barman D, Cranley J, Hooper TL. Latissimus dorsi muscle blood fow during synchronized contraction: implications for cardiomyoplasty. Ann Thorac Surg 1996;61:603-609.

3. Schreuder IJ, van der Veen FH, van der Velde ET, Delahaye $\mathbb{F}$, Afieri O. Jegaden O, et al. Beatto-beat analysis of left ventricular pressure-volume relation and stroke wolume by conduclance catheter and artic modellow in cardiomyoplasty patients. Circulation 1995:91:20102017.

4. Kratz IM, Johnson WS, Mukherjee $R$, Hu J, Crawford FA, Spinale FG. The relation between ladissimus dorsi skeletal muscle structure and contractile function after cardiomyoplasty. I Thorac Cardiovasc Surg 1994;107-868-878.

5. Kall-Filho R, Bocchi E, Weiss RG, Rosemberg L, Bacal D, Moreira LFP, et al. Magnetic resonance imaging evaluation of chronic changes in latissimus dorsi cardiomyoplasty. Circulation $\llbracket 994 ; 90($ part 2):102-106

6. Odim INK, Burgess JH, Williams BH, Blundell PE, Rabinovich MA, et al. Pathophysiology of dynamic cardiomyoplasty: a clinico pathological case study. f Card Surg 1990:5:336-346.

7. Rossi MA, Braile DM, Souza DRS, Santos JLV. Thevenard RS, Pinto GH, et al, Dynamic cardiomyoplasiy in chronic Chagas's heart disease: clinico-pathological data. Ann Thorac Surg 1991:51:649*651.

8. Canraro U, Chachques JC, Desnos M, Hagège A, Fontarilan F, Carpentier A. Eight year human dynamic candiompoplasty: preserved structure of myotibres and vessels of the latissimus dorsi. Bas Appl Myol 1996;6:333-6. 
CHAPTER

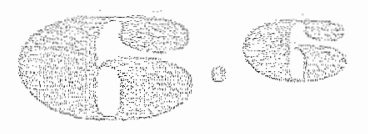

\section{Cardiomyoplasty and implantable cardioverter defibrillator: efficacy and safety of concomitant device implantation}

Sudden death and cardiomyoplasty: ICD rescue?

Roberto Lorusso, M.D., Anna Marchini, M.D., Federico Bianchett, M.D., Antonio Curnis, M.D., Odoardo Visioli, M.D., Mario Zogno, M.D. 
Sudden death represents a common event in the natural history of patients affected by chronic heart failure. Such an outcome has been shown to characterize also the follow-up of cardiomyoplasty procedure. We report two cases of patients submitted to cardiomyoplasty who experienced witnessed episodes of ventricular arrhythmia at wariable times after surgery 12 years, and 2 months, respectively. In the first case, an ICD was implanted subsequent to the arrhythmic episode, whereas the second patient had previously had a combined cardiomyoplasty and ICD implantation procedure. In both cases, ventricular defibrillation did not affect the correct functioning of the implanted cardiomyostimulator.

Our report confirms that ventricular arrhythmia are common in cardiomyoplasty patients. The combined use of skeletal muscle stimulator and implantable defibrillator may therefore be effective in preventing arrhythmia-related sudden death without any concurrent effect on the correct functioning of the wrapped muscleheart circuil, with likely benefit on long-term cardiomyoplasty patient survival.

\section{Introduction}

Long-term patient survival in moderate or severe chronic heart failure is poor, and mortality is often related to sudden death (1). The use of ICD has been successfully introduced into clinical practice, and has substantially reduced arrhythmia-related deaths in dilated cardiomyopathy (2). Amongst the surgical options to treat the chronic failing heart, cardiomyoplasty, which consists of permanent cardiac assistance by a mobilized, wrapped, and synchronously stimulated skeletal muscle, is currently under investigation. Data on mid-term or late survival after cardiomyoplasty indicate that sudden death is a frequent mocle of death $(3,4)$, and ventricular hythm disturbances may play a major role in this respect (5). We report 2 cases in which ventricular arrhythmia were documented following cardiomyoplasty procedure, and successfully terminated. Preventive implantation of ICD proved to be life-saving in one patient. Furthermore, no impairement of the cardiomyostimulator was subsequently detected and attributable to countershock.

\section{Patient 1}

A 64-year-old patient was submitted to right cardiomyoplasty procedure because of medically refractory chronic ischemic heart failure and concomitant disease of the left lung (tubercolosis). His past medical history had revealed two 


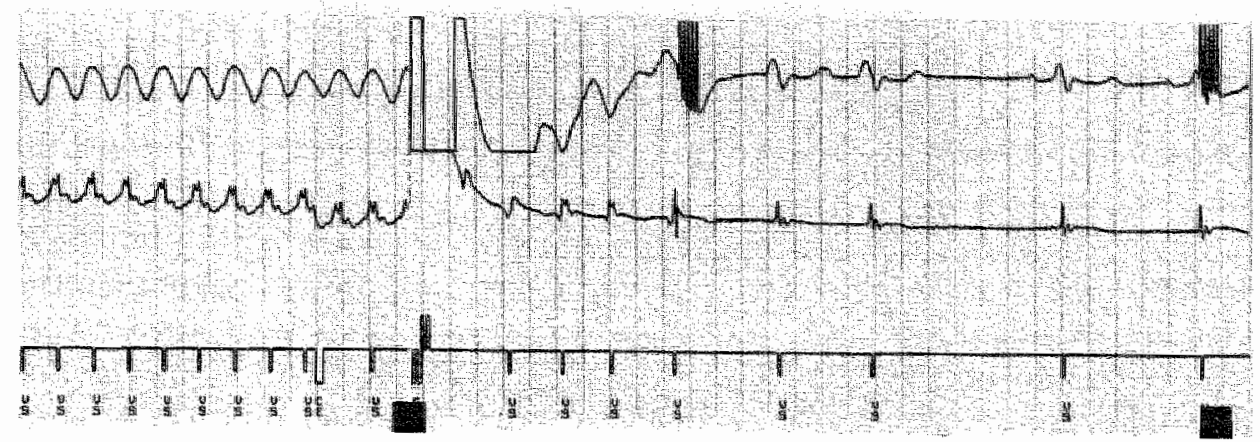

Figure 1. This tracing represents the recording of the ventricular anthymia which occured postoperatively in the patient submitted to combined cardionyoplasty and ICD implantation proce. dure. The ventricular fibrillation has beem recognzed by the lCD and successfully terminated. The cardiomyostimulator thas not been damaged by the countershock, as shown by the restored synchronized skeletal muscle pacing (bursts of spikes) with programned heart/wrapped muscle contraction ratio of 4 to 1 .

episodes of cardiac arrest during an acute myocardial infarction, but no evidence of ventricular arrhythmia thereafter at holter monitoring. Postoperative evaluation of hemodynamic parameters, as assessed by pressure/volume analysis, showed significant improvement compared to preoperative data (6).

At 2 years from the surgical procedure the patient unexpectedly collapsed, and after prompt transferral to the hospital, a ventricular tachycardia ( 160 ventricular rate) was detected and successfully terminated by external countershock. After rhythm normalization, ECG tracings showed correct functioning of the cardiomyostimulator, with synchronized skeletal muscle/ heart contraction ratio (1:4) and palpable muscle contraction.

An electrophysiologic study (EPS) was subsequently performed and inducible sustained VT was shown. An ICD (Medronic Jewel 7000, Medtronic Inc.) was therefore implanted at the pectoral site with endocardial catheter, and optimal defibrillation threshold was documented. During the device implantation, a ventricular fibrillation was induced and successfully terminated by the ICD intervention. No abnormalities could be documented in the cardiomyostimulator function (figure 1). After that arthythmic episode the patient experienced no further arrhythmic episodes, and is currently in NYHA Class II.

\section{Patient 2}

A 65 year-old gentleman was referred to our Institution because of refractory heart failure secondary to idiopathic cardiomyopathy. Cardiac evaluation showed huge left ventricular dilatation (IVEDD of $95 \mathrm{~mm}$ ). LVEF of $8 \%$ by MUGA, and peak oxygen consumption of $11 \mathrm{ml} / \mathrm{kg} / \mathrm{min}$. No right ventricular failure nor pulmonary hypertension documented. Heart transplantation was 


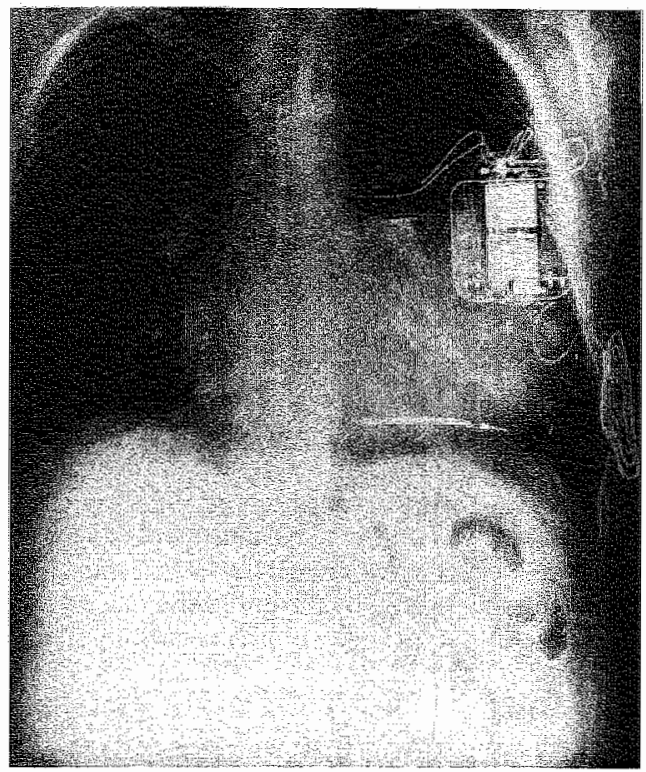

Figure 2. Postoperative chest $x$-ray is shown, ICD (above) and cardiomyostimulator (below) are visible. Subcutaneous patch was subsequently implanted at the left axilla to improve the threshold of defibrillation. Severe left ventricular dilatation is also evident (left ventricular end-diastolic diameter of $95 \mathrm{~mm}$.

not considered because of renal cancer. The patient had had an episode of ventricular tachycardia during previous hospitalization, and inducible VT was found in subsequent EPS. Because of progressive heart failure and of the presence of inducible ventricular arrhythmia, a cardiomyoplasty combined with $\llbracket C D$ implantation was proposed and performed. Cardiomyoplasty was scheduled first in order to avoid any possibility of endocardial lead dislodgement. The surgical procedure was uneventful, as well as the postoperative period. At 3 weeks from surgery the patient underwent ICD implantation.. A high defibrillation threshold ( 32 joules) was observed. Because of concomitant Amiodarone, the patient was discharged for appropriate pharmacological wash-out, and readmitted 2 months afterwards to review defibrillation parameters. Meanwhile, the patient reported an episode of syncope, and on ICD interrogation, an episode of VT was recorded. Ventricular defibrillation effectively terminated the ventricular arthythmia and caused no any impairment of the cardiomyostimulator functioning. Because of the persistence of high defibrillation threshold, a subcutaneous patch was deemed appropriated and subsequently implanted (figure 2) with substantial reduction of defibrillation threshold ( 12 joules). 


\section{Discussion}

Sudden death occurs in a significant number of patients affected by dilated cardiomyopathy (1). Ventricular arrhythmia are considered the ultimate event in the majority of these episodes. The use of ICDs has been therefore advocated to improve survival in chronic heart failure (2). Cardiomyoplasty was introduced into the clinical setting in 1985 in an attempt to provide an autologous and permanent support to chronic failing hearts. Recent analysis of postoperative outcome in cardiomyoplasty patients has clearly underlined the prevalence of sudden death $(3,4)$. As a matter of fact, initial experiences of cardiomyoplasty showed that postoperative mortality was mainly due to worsening of heart failure, but patients in NYHA Class IV were still considered eligible and included in those series. The recent change in the inclusion criteria (NYHA Class III) has also caused a modification in the outcome pattern with higher frequency of arrhythmia-related deaths. The use of ICD in high-risk patients is currently under investigation, and preliminary reports seem to confirm improvement in survival (2). The application of ICD in cardiomyoplasty has been already been advocated (4), and experimentally tested to exclude potential interference or cross-talk between the muscular pulse generator and the defibrillator (7). Indeed, the presence of impulse bursts were not recognized as VF or VT by the defibrillator in the animal study, and ventricular defibrillation was not shown to negatively affect the cardiomyostimulator device. Clinically, only one undetailed report, to our knowledge, has described the effect of concomitant implantation and function of the 2 devices (8).

Our report confirms that ventricular rhythm disturbances may be the ultimate events in cardiomyoplasty patients, and that the concomitant implantation of an ICD may be life-saving. Additionally, no damage of the cardiomyostimulator could be observed, regardless of the mode of teminating the ventricular arthythmia (external or internal defibrillation). It is worth underlining that in our patients, ventricular arrhythmia occurred in good clinical conditions, and with improved hemodynamics if compared to preoperative status. Recent reports suggest that cardiomyoplasty enhances a reverse ventricular remodeling and improved myocardial contractility $(9,10)$. The application of ICD, therefore, may provide additional rescue for cardiomyoplasty patients should malignant ventricular electrical disturbances arise.

Further evaluation of the feasibility of ICD implantalion in cardiomyoplasty is still required to eventually determine the actual effectiveness and impact on patient outcome in the long term. 


\section{References}

1. Gorgels AP, Vos MA, Smeets YLR, Wellens HJ]. Ventricular arthythmia in heart failure. Am I Cardiol $1992700.37 \mathrm{C}-43 \mathrm{C}$

2. Domanski MJ, Zipes DP, Schron E. Treatment of sudden cardiac death. Circulation $1997,95: 2694-99$.

3. Magovern GJ Sr, Simpson KA. Clinical cardiomyoplasty: review of the ten-year United States experience. Ann Thorac Surg 1996;61:413-9.

4. Bocchi EA, Moreira LFP, Vilella de Moraes A, Bacal F, Sosa F, Stoll NA, Jatene AD, Pileggi F. ArWhythia and sudden death after dynamic cardiomyoplasty. Circulation 1994;90:11107-11111.

5. Thakur RK, Chow LH, Guiraudon GM, Kostuk WJ, Brown IE, Pflugfelder PV, Guiraudon CM. Latissimus dorsi dynamic cardiomyoplasty: role of combined ICD implantation. J Card Surg $1995 ; 10: 295-297$.

6. Lorusso R, Afieri O. Pericardial "suspenders" to enhance right latissimus dorsi cardiomyoplasty. J Card Surg 1996;11:46.48.

7. Francischelli D, Peterson D, Stein PM, Gealow KK, Grandjean PA. Gardiomyoplasty and defibrillator: a combined treatment for heart failure. In, Carpentier $A$, Chachques JC, Grandiean PA (eds). Cardiac Bioassist. Futura Publishing Inc, Mount Kisko, NY, 1997, pp 417-28.

8. Guiraudon GM, Chow L., Lefebre C, Yee R, Klein J, Kostuk WI, Dobkowsky V. Combined latissimus dorsi cardiomyoplasty and jewel PCD implantation. A feasibility non-thoracotomy study in two patients. Eur T Card Pac Elect 1996:6 (Suppl 5):150 (Abstract)

9. Schreuder IJ, wan der Veen FH, van der Velde ET, Delahaye F, Alfieri $O$, Jegaden $O$, Lolusso $\mathbb{E}_{\text {, }}$ Jansen JRC, van Ormen $V_{\text {, Finet }} \mathrm{G}$, Wellens $\mathrm{HJJ}$. Beat-to-beat analysis of left ventricular pressure/volume relation and stroke wolume by conductance catheter and aortic modelflow in cardiomyoplasty patients. Circulation 1995;91:2010-201

10. Schreuder If, van der Veen FH, van der Velde ET, Delahaye F, Alfieri O, Jegaden O, Lorusso $\mathrm{R}_{\text {, }}$ Jansen JRC, Hoeksel SAAP, Finet $G$, Volterrani V, Kaulbach $\mathrm{HG}$, Baan J, Wellens HJ. Left ventricular pressure-volume relationships pre-and post-cardiomyoplasty in heart failure patients. Cinculation (in press). 


\section{CHAPTER}

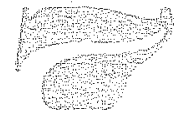

\section{Conclusions}

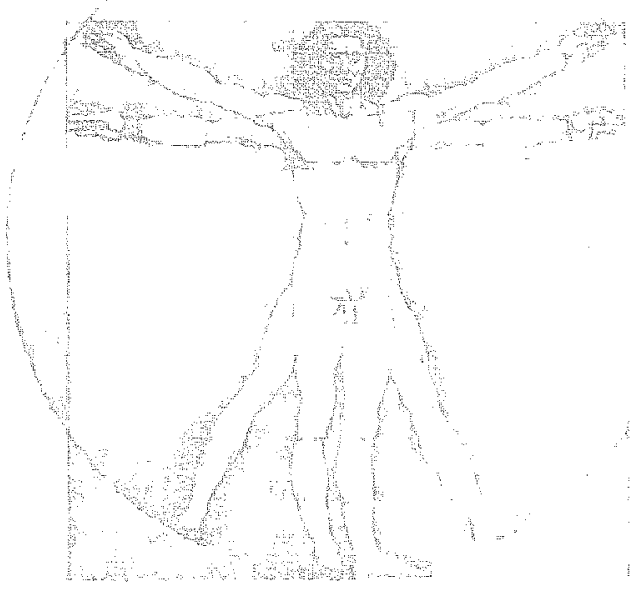


The cardiomyoplasty procedure is at present under clinical investigation. Limited or inconsistent hemodynamic improvements in some clinical series hampered the acceptance of such a procedure by the medical community and prompted researchers to better elucidate the actuall potential of this surgical technique. Most of the factors responsible for the limited efficacy of the wrapped muscle are related to skeletal muscle performance. The clescribed abnormalities of structural changes in other muscles in patients with chronic heart failure, the surgical technique itself, and the stimulation protocol after the cardiomyoplasty procedure, have all been claimed to be responsible for suboptimal muscle condition and, therefore, for a reduced contractile contribution with a negative influence on postoperative outcome. As far as the stimulation protocol is concerned, we assessed the feasibility of starting the wrapped LDM stimulation early after the cardiomyoplasty procedure, and the results described in chapter 1 confirm that early activation is not harmful to the mobilized muscle. Also, minor but significant cardiac support may be achieved despite a prudent stimulation setting. The absence of deleterious effects of early pacing has recently been confirmed by Chekanov and associates (1), who used a similar protocol. Clinically, Akhmedov described the use of LDM training without the application of the two-week recovery period with no evidence of muscle damage (2). It is, therefore, clear that further investigations are required to assess the feasibility of early activation of the LDM, provided that muscle ischemia be avoided and long-term histologic studies do not demonstrate early stimulation as being deleterious.

Cardiomyoplasty constitutes a complex dynamic situation since the presence of two different "biological pumps" may be difficult to obtain and also difficult to assess. Recent reports underlined the important influence of incorrect LDM contraction timing during ventricular systole and the clinical consequences there of (3). Our clinical observations show the importance of optimall LDM/heart interaction by echocardiography evaluation, as also demonstrated by other authors (4-6). A more detailed and sophisticated laboratory investigation has been performed in our laboratory by using pressure/volume analysis. Using that method Schreuder and associates showed the extreme variability of hemodynamic changes by varying LDM contraction timing, ranging, from a negative to significantly positive action on cardiac performance (7). Therefore. it is mandatory to attempt to define the correct cardiac/LDM interaction, and transthoracic echocardiography appears to allow this fine tuning.

Atrempts to enhance muscle contribution by preserving or improving its original characteristics have been the topic of investigation by addressing the preoperative muscular condition. Indeed, metabolic, structural, and functional impairments have been documented in patients affected by CHF, with subsequent significant abnormalities in mechanical properties of the muscle. Accordingly, the use of preoperative physical training has been introduced in 
cardiomyoplasty candidates. Our study shows that beneficial changes in terms of mechanics and histology may be induced by light exercise. This approach has already been accepted widely, and proposed to the cardiomyoplasty patient in many centres.

The long-term clinical results show that cardiomyoplasty, provided that careful and refined selection criteria are applied (table 1 and figure 1), may benefit patients with refractory chronic heart failure. Clinical stabilization with less or shorten episodes of acute heart decompensation, significant reduction of ventricular dilatation, and prevention of further cardiac enlargement (figure 2), can be achieved leading to a reduction in hospital admissions. Thorough evaluation of postoperative results seems to suggest that, with the current structural condition of the chronically stimulated muscle graft and the related generated force, active constrain of the ventricle is the most prominent effect. Systolic contribution, nonetheless, is an additional and important factor (8), but is observed in the minority of the patients.

The use of right cardiomyoplasty has been proposed clinically by Magovern and associates (9), and, in spite of promising initial results, long-term analysis of patient data seems to suggest no difference with the left cardiomyoplasty procedure (10). We used this technique in 2 patients, with a modification of the surgical procedure. Our preliminary and short-term results are encouraging. Therefore, a prospective, randomized trial of right versus left cardiomyoplasty seems appropriate to solve this dilemma.

Long-term muscle degeneration represents a major problem to obtain a more effective muscular contribution, and stimulation modes have been claimed to represent a critical factor in terms of muscle response and muscle damage (11). A modified stimulation protocol is currently under investigation in our patients, and preliminary histological findings suggesi a benefit after re-

Table 1. Contra-indications for cardiomyoplasty procedure

Absollite Contraindications

NTHA Class IV

Biventricular Failure

Reduced Lung Capacity

(FEV-FEVI $<60 \%$ )

Significant Valwular Disease

Severe Pulmonary Hypertension

Cachexia

L.DM Damage or Dysfunction
Relative Contraindications

(potentally unlaworable late outcome)

Atrial Fibrillation

Extreme Cardiac Diatation

Poor Functional Capacily

(Peak $\mathrm{Vo}_{2}<10 \mathrm{~m} / \mathrm{kg} / \mathrm{min}$

Poor EVEF $(<10-15 \%)$

High LVEDP ( $>35 \mathrm{~mm} / \mathrm{gg}$ )

Ischemic Cardiomyopethy

Malignan Ventricular Arrbythmia

(combined ACD implantation advisable) 


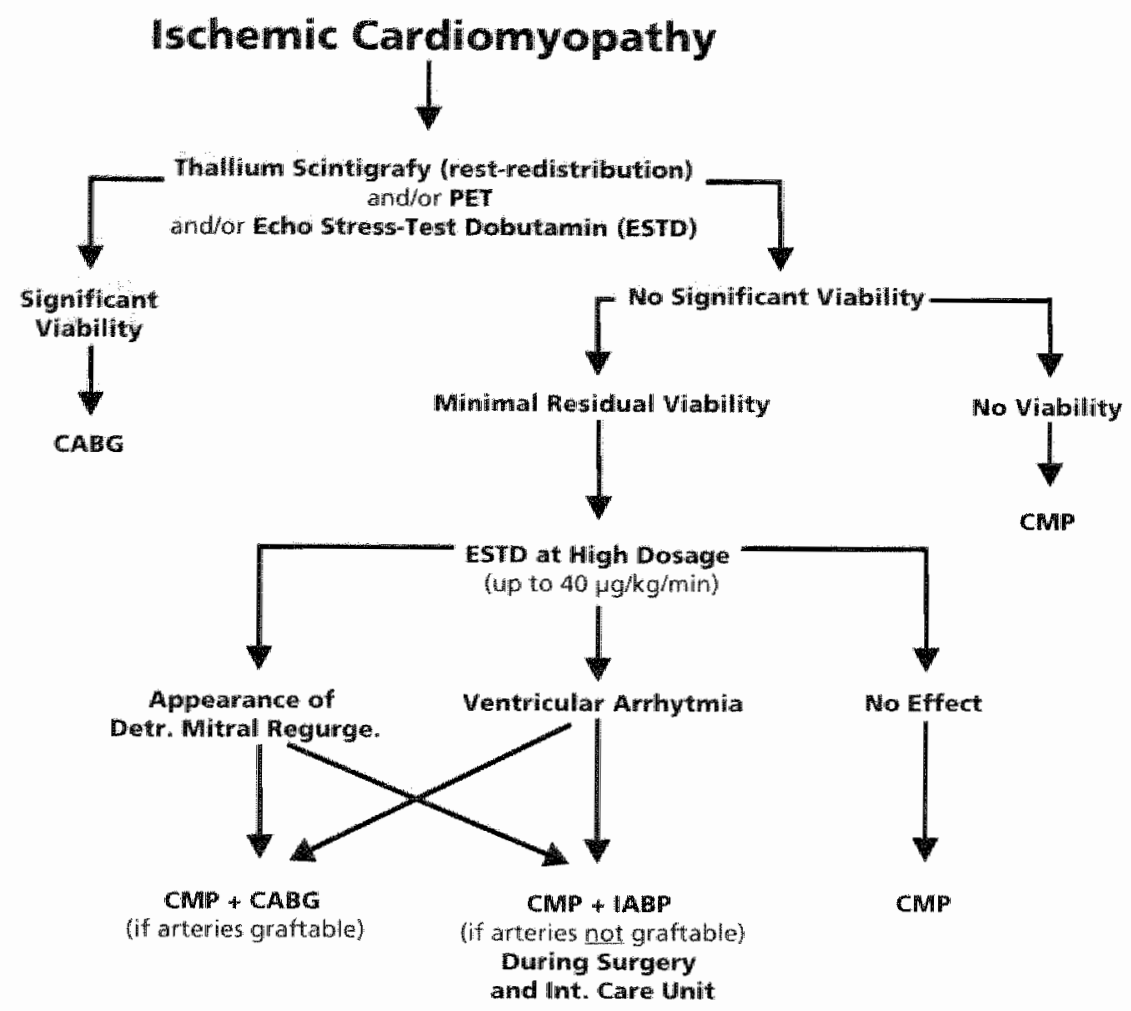

Figure I. This figure shows the patient management when chonic left ventricular dysfunction is ve lated to CAD. Search for viable myocardium is our primary goal in tems of decision-making and for therapeutic stategies. Indeed, even if CABG is not indicated, the residual amount of viable myocardiun may prompt subsequent therapeutic and management approaches.

ducing the daily muscle workload to preserve structural integrity. Maintained muscular histology appears to be intimately related to hemodynamic results, as described by Lucas and Kratz $(12,13)$, and our data confirm these experimental findings.

Sudden death proved to be a major cause of long-term mortality in recent clinical cardiomyoplasty series (14). Ventricular arrhythmias are the most likely mechanism. Prevention of sudden death by the concomitant implant of a defibrillator may be considered, as termination of a ventricular arrhythmia by endocardial shock did not show to damage the implanted cardiomyostimulator. In case of extreme cardiac dilatation, a modification of the surgical technique may be performed, together with the implantation of the AICD (figures 3 and 4). The ongoing development of a combined cardiomyostimulator/defibrillator will most likely improve long-term patient outcome.

In conclusion, for more than a decade it has been shown that skeletal muscle may be mobilized, wrapped around the heart, and synchronously stimulated. 


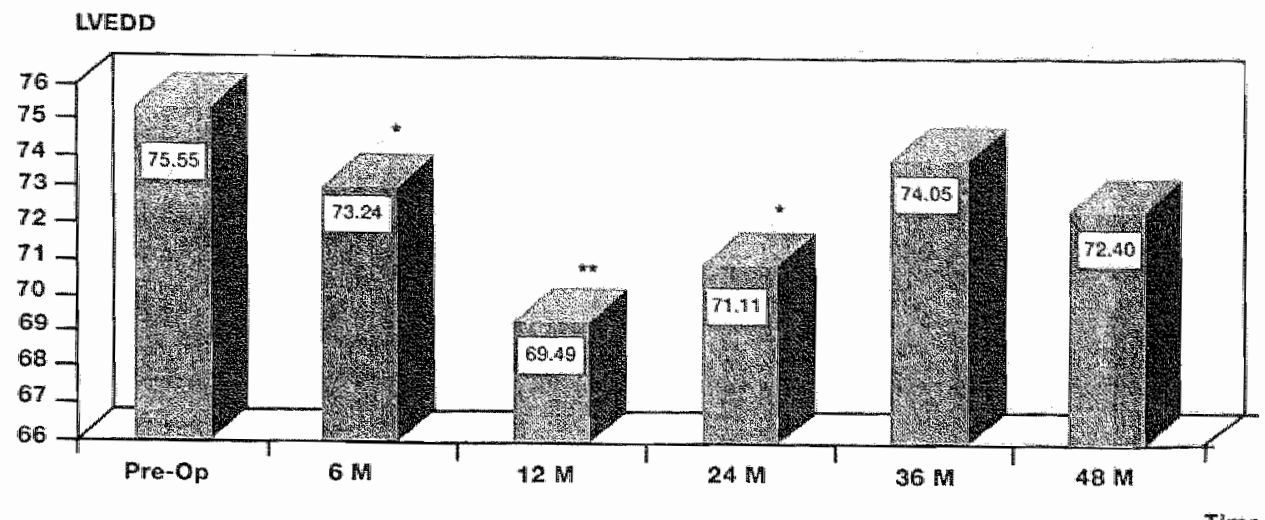

Figure 2. In this figure mean preop and postoperative values of LVDD of patients submitted to cardiomyoplasty procedure up to 4 years of follow-up are shown.

Nonetheless, the currently used methods of investigations have several limitations in documenting modest changes of hemodynamics in treated patients. Ongoing experimental and clinical research is giving new directions to give insights in basic fundamentals ultimately leading to improved muscle performance, disclosing the actual mechanisms of actions, and better patient selection. Furthermore, advances in techniques and patient management will represent additional factors to positively affect patient outcome after cardiomyoplasty.

\section{Reappraisal of CHF assessment and the role for cardiomyoplasty and other forms of permanent cardiac assistance}

It is evident that oun current knowledge on the pathophysiology of chronic heart dysfunction is incomplete $(15,16)$. Pumpfailure is the endstage of a process that interferes with normal heart function. Many different causes can be listed for such a process, like myocardial disease, valvular disease, coronary artery disease, pericardial disease and cardiac arrhythmia. Unfortunately, as shown in figure 1 , often we cannot cure or correct the initiating or basic mechanism of the process leading to pumpfailure, and we have to concentrate on therapies that interfere with adaptive mechanisms occurring during congestive heart failure. The identification of these adaptive mechanisms activated by chronic cardiac dysfunction and their long-term effects led to the development of therapies directed to these mechanisms (17). Examples are the use of ACEinhibitors and beta-blockers which have shown to positively infuence the outcome of CHF patients. Pharmacological treatments specifically directed to augment myocardial contractile function failed to modify patient survival or even 

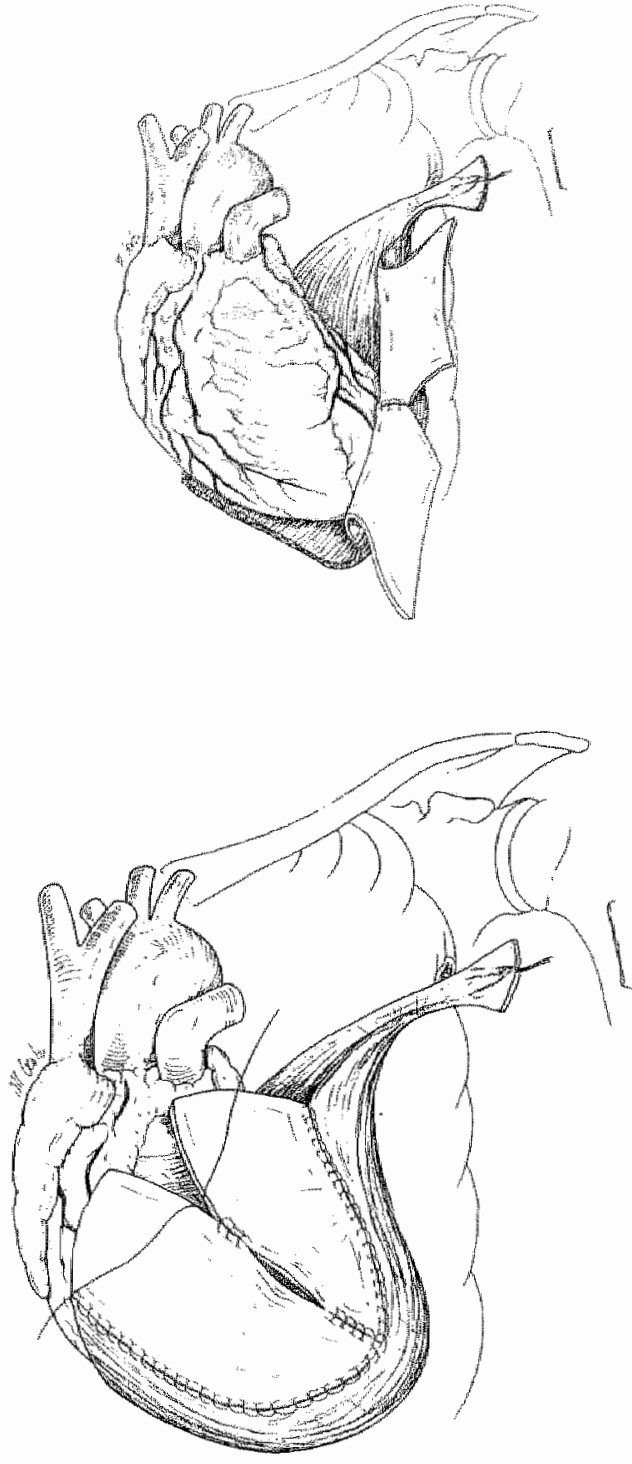

Figure 3 . The first step of a modified wrapping technique in presence of extremely dilated thearts is presented. In such cases. incomplete wrapping is likely, ofen requir" ing the use of the native pericardium to ensure the ventriculare coverture to be surured to the transposed muscle with some diffculty. The use of two wide pericardial bovine patches, sutured together and then to the anterior border of the muscle graft prior to the passage of the LDM behind the ventricles, may ease the procedure.

Figure 4. The second step of the modified wrapping technique is shown. Note the apposition of the two trimmed bovine pericardial patches anteriorly to the right ventricular outlow tract. This technique allows the LDM to wrap completely the left ventricle, while avoiding difficult suturing of the commonly used native pericardial flap to the faraway muscle graft and, therefore, potential undue tension with negative effects on right wentricular performance.

proved to be deleterious (18). This discrepancy is related to our limited knowledge regarding the details of myocyte dysfunction, to the uncertainty by which biochemical pathway function can be improved, and to which extent impaired function can be restored. In CHF many central and peripheral changes occur with adaptation to diminished function showing individual variation. It is likely that further refinements of our knowledge of CHF in terms of understanding of myocardial changes are mandatory for future progresses in surgical as well as medical treatment. Recent reports on the effects of prolonged ventricular un- 
loading due to LV assist devices have shown some signs of improvement at the structural levels $(20,21)$. True, myocardial recovery has been witnessed only in a few mechanically supported patients. While most cases of dilated cardiomyopathy are irreversible, cases of unexpected recovery of the native heart function, have been described (22). Obviously, reduction of ventricular volume is not invariably linked with restoration of hemodynamic and myocyte integrity. The problem is how to identify the patient with reversible myocardial damage, but currently diagnostic clues to predict such a recovery are few, the best example being the dilated cardiomyopathy secondary to long-lasting tachycardia (23). It is clear that, besides conventional parameters to define cardiac performance, additional tests to inform us about myocardial condition and reserve are necessary, to optimize therapy and patient management.

Bolling and associates reported a remarkable series of patients in NYHA Class IV and preoperative LVEF ranging from $8 \%$ to $34 \%$, who underwent mitral valve repair because of severe regurgitation, experiencing a $75 \%$ survival at 1 year, and impressive improvement in clinical condition. Improvement in myocardial mechanics has been postulated, but, no conclusive explanation was given to explain these results and to help patient selection (24). Recently, Batista has proposed partial LV reduction to re-establish, according to the Laplace law, a more optimal LV volume/thickness balance (25). Many patients, but not all, in the terminal phase of CHF appeared to survive the operation and to benefit from the "surgical remodeling", although long-term data are still lacking. The same situation has been encountered in the cardiomyoplasty experience, where inhomogeneous results were obtained, but improvement of subjective condition was sometimes correlated with hemodynamic amelioration and LV size reduction. Apart from the electrically or pneumatically driven mechanical left ventricular assist devices, other forms of therapy should be modified and altered in agreement with the biological properties of the chronic failing heart (figure 5), because incorrect application, even if subtle, may markedly influence the ultimate myocardial response.

In conclusion, better monitoring of the myocardial disease in CHF and the extent and reversibility of damage at the myocyte level is necessary to improve our understanding of CHF pathophysiology, and should be the basis for better management of CHF. 


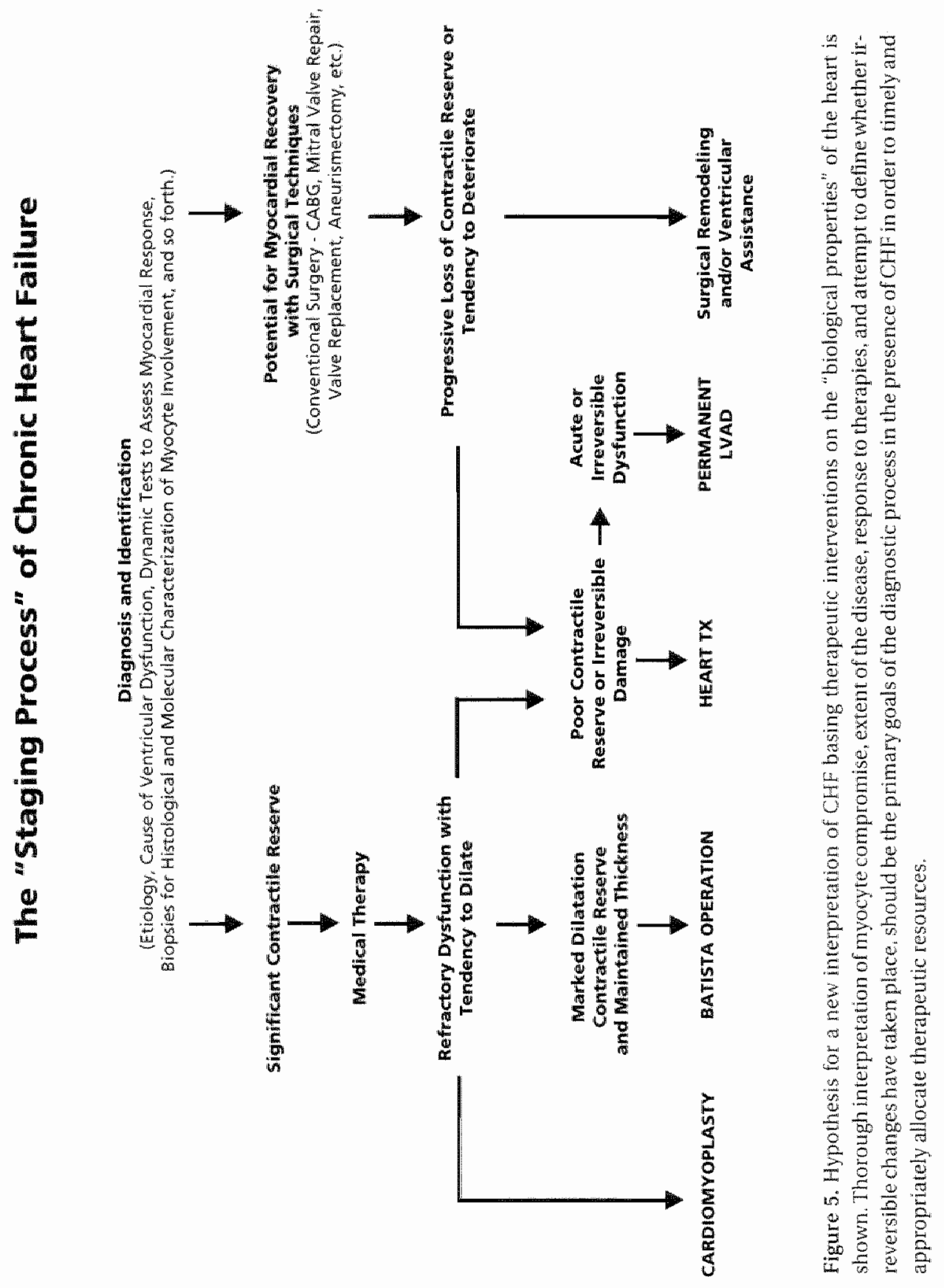




\section{References}

1. Chekanov VS. Tchekanov GV, Rieder MA, Smih LM, Jacobs GB, McConchie S, Christensen $C W$, schmidt DH. Is it possible to perform immediate cardiac ascist using untraned latis. simus dorsi muscle in a work-rest regimen?. ASA1O / 1995:41:M489-M494

2. Akhmedov SD, Kriwoschekov EV, Pekarskaya MV, Krylov AL, Vesnima ZV, Chernov V, Chem. yawsiy AM, Vechersky Y, Karpov RS, Nechaev EA, et al. Clinical results of dynamic cardiom Imyoplasty, J Card Surg 1995; 10:573-579

3. Grubb NR. Campanella C, Sutherland GR, Fox KAA. Optimizing muscle synchonization ater dynamic cardionyoplasty: two educational cases. Eur J Cardiow Thorac Surg 1995;9:45-9

4. Helou J, Misawa Y, Stewart IA, Colson M, Chiu RC-I. Optimizing "delay period" for burst stimulation in dynamic cardiomyoplasty. Ann Thorac Surg 1995;59:74-7

5. Almada H, Molteni L, Ferreira R. Ortega D, Cianciulli T, Llanos $S$, Prezioso H. The value of the echo-doppler in cardiomyoplasty procedures. J Card Surg 1991,6(Suppl):113-18

6. Molteni L, Almada HE, Ferreira RF, Ortega D. Assessment of the optimal time interwal beween QRS and single-pulse stimulation in dynamic cardiomyoplasty. In Chiu RC-). Bourgeois 1 (eds): Transformed muscle for cardiac assist of repair. Furura Publishing Company, Inc., Mount Kisko, NY, 1990, pp 189-196

7. JJ Schreuder "FH van der Veen, ET van der Velde, G Finet, F Delahaye, O Jegaden, R Lorusso, HJ) Wellens. Left ventrciular pressure/volume relationships pre and post candiomyoplasty in heart failure patients. Eur J Card Pac Elect 1996;6(Suppl 5 ):153.

8. Tasdemir O, Vural KM, Kucukaksu SD, Tarcan OK, Ozdemir M, Kutuk E. Bayazit K. Comparative study on cardiomyoplasty patients with the cardiomyostimulatol on versus off. Ann Thorac Surg 1996;62:1708-1.3

9. Magovern IA, Fumary AP, Christlieb IY, Kao RL, Magovern GI. Right latissimus dorsi cardiomyoplasty for left ventricular failure. Ann Thorac $\$$ urg $1992 ; 53: 1120-2$

10. Magovem JA, Hunter TJ, Cardone JC, Christlieb IY. Long-term results of right latissimus dorsi cardiomyoplasty. J Card Surg 1996;11:264-70

11. Lexell J, Jarvis JC, Downham DY, Salmons S. Stimulation-induced muscle damage. Bas Appl Myol 1994:4:59-66

12. Lucas CMHB, wan der Veen FH, Cheriex EC, Lorusso R, Havenith M, Penn OCKM, Wellens HIJ. Long term follow-up (12 to 35 weeks) after dynamic cardiomyoplasty, I An Coll Cardiol $1993: 22: 758-767$

13. Kratz IM, Johnson WS, Mukherjee R, HU J. Crawtord IA, Spinale fr $\mathrm{C}$. The relation between latssimus dorsi sketetal muscle structure and contractile function after cardiomyopiasty. I Thorac Cardiovasc Surg 1994:107:868-78

14. Magovem GI Sr, Simpson KA. Clinical candiomyoplasty: neview of the ten-year United States experience. Am Thorac Surg 1996;61:413-9

15. Schwinger RHG, Bohm M, Koch A, Schimdt U. Morano I, Eissner H, Uberfuhr I" Reichari B, Erdmann $E$. The failing heart is unable to use the Frank-Starling mechanism. Circulation $1994: 74: 959-69$

16. Holubarsch C, RufT, Goldstein DJ, Ashton RC. Nickl W. Pieske B, Pioch R. Ludemann I. Wiesner $\$$, Hasenfuss G. Posival H. Wust H, Burkoff D. Existence of the Frank-Starling mechanism in the faling heart. Cinculation $1996 ; 94: 683-9$

17. Eichhom EI, Bristow MR. Medicai therapy can improve the biological properties of the chronically libing heart. Circulation 1996;94:2285-96

18. Packer M, Francis GS, Abrams 1, Cobb FR, Eichhorn E1, Giles TD, Kahl FR, Tandon PK Otal milrinone increases the risk of suddery death in sewere chronic heart failure: the PROMISE Trial. Circulation 1991:84 (suppl IJ):11-30 (abstract) 
19. Pfeffer MA, Braunwald E, Moye LA, Basta L Brown EJ Ir, Cuddy TE, Davis BB, Gelman EM, Godman S. Flaker GC, Klein M, Lames GR, Packer M. Rouleau J. Roubav IL, Rutherford I. Wertheimer I. Hawkins M, on behalf of the SAVE Investigators. Effect of captopril on mortaliry and morbidity in patients with left ventricular dysfunction after myocardial infarcion: results of the surviwal and ventricular enlargement trial. N Engl I Med 1992;327:669-77

20. Levin HU, Oz MC, Chen IM, Packer M, Rose EA, Burkhoff D. Reversal of chronic ventricular dilatation in patients with end-stage cardiomyopathy by prolonged mechanical unloading. Circulation 1995-91:2717-20

21. McCarthy PM, Nakatani $\$$, Vargo $R$, Kottke-Marchant $K$, Harasaki $H$, James KB, Savage RM. Thonas ID. Structural and left ventricular histologic changes after implantable LVAD insertion Anm Thorac Surg 1995;59:609-13

22. Frazier HO. The development of an implantable, portable electrically powered left ventricuIar assist device. Sem Thorac Cardiovasc Surg 1994;6:181 -7.

23. Packer DL, Bardy GH, Worley SI, Smith MS, Cobb FR, Coleman RE, Gallagher Il, German LD. Tachycardia-induced cardiomyopathy: a reversible form of left ventricular dystunction. Am I Cardiol 1986;8:563-70

24. Bolling SF, Deeb $M$, Brunsting $L A$, Bach DS. Carly outcome of mitral valve reconstruction in pattients with end-stage cardiomyopathy. I Thorac Cardiovasc Surg 1995;109:676-83

25. Batista RVJ, Santos ILV, Takeshifa N, Bocchino L, Lima PN, Cunha MA. Partialleft ventriculectomy to improve left ventricular function in end-stage heart disease. I Card Surg 1996,11:96-7 


\section{Summary}

This aim of this thesis was to investigate how to improve the cardiomyoplasty technique, concomitantly attempting to better elucidate the clinical impact and some mechanisms of action of this surgical procedure.

In chapter 2 the currently adopted stimulation protocol was extended by applying a new pacing regimen, namely starting immediately after surgery. This concept proved to be feasible, and not harmful to muscular viability.

The importance of muscle tlap contraction timing has been underlined in chapter 3 , by using pressure/volume relations in order to detect the differences in heart/LDM interaction related to the timing of muscle support during the cardiac cycle.

Chapter 4 shows the effects of preoperative training involving the LDMs in terms of histological and mechanical properties. Light physical exercise induces marked improvement to muscle structure, partially reversing the abnormalities provoked by chronic heart failure, and with impressive advantages on mechanical responses, with potential benefits on LDM response following cardiomyoplasty procedure.

The clinical experience of cardiomyoplasty is reported in chapter 5 which represents a wide overview of the application of some new concepts in patient selection and assessment, operative technique, and provides new insights in the potential role of this surgical option in chronic heart failure treatment.

Chapter 6 is devoted to the clinical application of some experimental developments. Also, innovative techniques and management of difficult cases are described. 


\section{Samenvatting}

In dit proefschrift staan verschillende onderzoeken beschreven die als doel hadden om de wikkelhart techniek, ook wel cardiomyoplastiek genoemd, te verbeteren. Daarnaast is middels deze onderzoeken getracht om een beter beeld te krijgen van her effect van deze operatie op het functioneren van de patuent, en om er achter te komen hoe het wikkelhart dit effect veroorzaakt.

In hoofdstuk 2 is het nu in gebruik zijnde protocol om de skeletspier te stimuleren aangepas latie, en niet pas na twee weken. Dit idee bleek goed uitvoerbaar en bleek niet schadelijk voor de spier.

In hoofdstuk 3 wordt het belang beschreven om de tijdscluur tussen de hartspier samentrekking en skeletspier prikkeling goed in te stellen met behulp van de cardiomyostimulator. Hierbij is gebruik gemaakt van druk/volume relaties in de linker kamer, waarmee namelijk op een zeer nauwkeurige manier de samenwerking tussen het hart en de skeletspier kumnen worden bestudeerd bij verschillend ingestelde tijdsduren tussen de activatie van beide spieren.

Hoofdstuk 4 laat de gevolgen zien van pre-operatieve training van de Latissimus dorsi spier op de spierweefsel opbouw en op de mechanische eigenschappen. Lichte lichaamsoefeningen gaven al duidelijke verbetering van de spier weefsel structuur te zien, waarbij de afwijkingen door het chronisch hart falen gedeeltelijk worden teniet gedaan. Ook zijn duidelijke verbeteringen waargenomen van de mechanische eigenschappen, wat een potentieel voordeel geeft bij Latissimus dorsi spier stimulatie na de wikkelhart operatie.

De klinische ervaringen met het wikkelhart worden beschreven in hoofdstuk 5, waar een breed overzicht wordt gegeven van enkele nieuwe opvattingen over patiënten selectie en onderzoek, alsook over de operatie techniek, en waarin nieuwe inzichten staan beschreven over de mogelijke toepassingen van deze operatie voor de behandeling van chronisch hartalen.

Hoofdstuk 6 is gewijd aan de klinische toepassing van enkele nieuwe experimentele ontwikkelingen. Ook worden nieuwe technieken en het omgaan met complicaties die na de operatie kunnen optreden beschreven. 


\section{Riassunto}

Lo scopo della tesi è consistito nella valutazione di tecniche o metodiche approntate al fine di migliorare i risultati della cardiomioplastica, ma, allo stesso tempo "tentando di migliorare la comprensione dei meccanismi d'azione e l'impatto clinico di questa procedura chirurgica. Nel Capitolo 2 il protocollo di stimolazione postoperatoria del muscolo Grande Dorsale è stato modificato attraverso l"applicazione di un nuovo regime d'attivazione che prevede la stimolazione elettrica successivamente all'intervento chirurgico, abolendo quindi le 2 settimane di assenza di lavoro attualmente usate nel protocollo clinico. Questo nuovo concetto di attivazione muscolare anticipata si è dimostrato fattibile ed efficace sia in termini di preservata vitalità muscolare che di contributo emodinamico alla performance cardiaca. L'importanza del tempo d'attivazione del flap muscolare durante le fasi della sistole ventricolare è stato investigato in modello sperimentale acuto e descritto nel Capitolo 3 , per mezzo dell'utilizzo delle curve pressione/volume al fine di evidenziare le differenze di interazione muscolo Grande Dorsale/cuore in relazione al momento d'intervento della contrazione muscolare. Lo scompenso cardiaco cronico induce profonde alterazioni metaboliche e strutturali del muscolo scheletrico periferico. E' verosimile che l'utilizzo di tale muscolatura al fine di un supporto biomeccanico permanente possa portare a risultati subottimali in relazione alla condizione preoperatoria muscolare non adeguata. Il Capitolo 4 mostra i risultati di un protocollo di training fisico e di valutazione istologica del muscolo Grande Dorsale in pazienti candidati ad intervento di cardiomioplastica. Tale procedura si è dimostrata estremamente efficace nel migliorare la capacità funzionale del muscolo, contemporaneamente ad un mighoramento strutturale e di incremento della vascolarizzazione. L'esperienza clinica della cardiomioplastica dinamica è descritta nel Capitolo 5. Tale studio riporta l'applicazione di numerosi concetti innovativi nella selezione valutazione pre e postoperatoria dei candidati, nella tecnica chirurgica, e fornisce nuove interpretazioni nel ruolo potanziale di tale opzione chirurgica nel trattamento dello scompenso cardiaco cronico refrattario. Il Capitolo 6 è dedicato alla descrizione di varie applicazioni cliniche della cardiomioplastica in relazione a concetti sviluppati sperimentalmente, $e$, inoltre, sono descritte soluzioni innovative nel trattamento di complicanze postoperatorie e di casi complessi. 


\section{Publications}

\section{Articles}

Roberto Lorusso, Mario Zogno, Giovanni La Canna, Marco Metra, Luca Sandrelli, Valentino Borghetti, Francesco Maisano, Ottavio Alfieri. Dynamic cardiomyoplasty as an effective therapy for dilated cardiomyopathy. J Card Surg 1993;8:177-183.

Frederik van der Veen, Caroline Lucas, Roberto Lorusso, Theo van der Nagel, Olaf CKM Penn, Hein IJ Wellens. A new method to select stimulus strength after cardiomyoplasty. J Card Surg 1991;1 (suppl):259-264.

Caroline Lucas, Frederik van der Veen, Emile Cheriex, Roberto Lorusso, Michael Havenith, Olaf C Penn, Hein II Wellens. Long-term follow-up (12 to 35 weeks) after dynamic cardiomyoplasty. J Am Coll Cardiol 1993;22:1087-1095.

Schreuder J, van der Veen FH, van der Velde ET, Delahaye F, Alfieri O, Jegaden $O$, Lorusso R, Jansen JRC, van Ommen V, Finet $G$, Wellens HJ]. Beat-to-beat analysis of left ventricular pressure/volume relation and stroke volume by conductance catheter and aortic modelflow in cardiomyoplasty patients. Circulation 1995;91:2010-2017.

Lorusso R, Schreuder I, van der Veen F, Alfieri O. Optimizing cardiomyoplasty results: importance of muscle contraction timing. Ann Thorac Surg (letter) 1.995;60:1862-1863.

G Bolotin, PH van der Veen, JI Schreuder, R Lorusso, J Ben David, G Uretzky. Cardiomyoplasty: the beginning of a new era. Isr J Med Sci 1996;32:321-326.

U Carraro, S Zampieri, R Scelsi, R Lorusso, M Volterrani, O Alfieri. Fifteenmonth human dynamic cardiomyoplasty: morphometry, myosin/actin ratio, collagen, total protein, and SDS PAGE of MHC show trophic transformation of grafted latissimus dorsi. Bas Appl Myol 1996;6:337-40

Lorusso R, van der Veen FH, Schreuder IJ, Alfieri O. Recent findings on cardiomyoplasty management and mechanisms of action: implications for patient selection and postoperative care. Bas Appl Myol 1997;7:15-22 
IJ Schreuder, FH van der Veen, ET van der Velde, F Delahaye, O Alfieri, O Jegaden, R Lorusso, JRC Jansen, SAAP Hoeksel, G Finet, V Volterrani, HG Kaulbach, I Baan, HJ] Wellens. Left ventricular pressure-volume relationships before and after-cardiomyoplasty in patients with heart failure. Circulation 1997;96:2978-2986.

Roberto Lorusso, Caroline Lucas, Frederik van der Veen, Jo Habets, Theo van der Nagel, Michael Havenith, Hein I Wellens, Olaf C Penn. Early latissimus dorsi stimulation after cardiomyoplasty procedure: a preliminary study. Bas Appl Myol 1991:1:83-87.

R Lorusso, V Borghetti, M De Fabritiis, R Scelsi, U Carraro, O Alfieri. Preoperative physical training effects on latissimus dorsi muscle in patients undergoing dynamic cardiomyoplasty: a preliminary report. Bas Appl Myol 1993:3:211-218.

Lorusso R, Coletti G, Dellalvalle A, Steffenino G, Aliprandi G, Alfieri O. Right latissimus dorsi cardiomyoplasty in diaphragm eventration and cardiac malpow sition. Ann Thorac Surg 1995;60:452-454

Lorusso R, Curnis A, Struble C, Sandrelli L, Alfieri O. Bacterial infection of cardiomyostimulator abdominal pocket following cardiomyoplasty procedure : an original approach to preserve synchronous muscle stimulation. I Card Surg $1995 ; 10: 358-362$.

Roberto Lorusso, Ottavio Alfieri. Pericardial "suspenders" to enhance right latissimus dorsi cardiomyoplasty. J Card Surg 1996:11:46-48.

R Lorusso, F van der Veen, Jf Schreuder, G Bolotin, HG Kaulbach, R Frietman, J Habets, $T$ van der Nagel, HJ Wellens. Hemodynamic effects in acute cardiomyoplasty of different wrapped muscle acivation times as measured by pressure-volume relations. I Card Surg 1996;11:217-225

Roberto Lorusso, Elisa Milan, Maurizio Volterrani, Raffaele Giubbini, Frederik $H$ van der Veen, Jan J Schreuder, Alberto Picchioni, Ottavio Alfieri. Cardiomyoplasty as an isolated procedure to treat refractory heart failure. Eur J CardioThorac Surg 1997:1 1:362-72

\section{Abstracts}

E van der Velde, I Schreuder, V van Ommen, F Delahaye, G Finet, L Bonandi, $R$ Lorusso, J Baan, F van der Veen. Quantification of left ventricular function in cardiomyoplasty patients by pressur/volume analysis. I Am Coll Cardiol 1993;2(suppl A):389 A. 
Frederik van der Veen, Caroline Lucas, Kees van Leeuwen, Vincent van Ommen, Theo van der Nagel, Roberto Lorusso, Hein J Wellens. Critical importance os stimulation rate for optimal function and longevity of skeletal muscle in dynamic cardiomyoplasty. J Mol Cell Cardiol 1992;24(suppl V):S113.

Frederik van der Veen, Caroline Lucas, Roberto Lorusso, Theo van der Nagel, Olaf C Penn, Hein J Wellens. A new method to select stimulus strength after cardiomyoplasty. 4th World Symposium on "Transformed skeletal muscle for cardiac assist", Palm Springs, California, 1990 (Proceedings)

$\mathbb{R}$ Lorusso, L Sandrel]i, F Maisano, M Zogno, G La Canna, R Giubbini, M Metra, O Visioli, O Alfieri. Echo-doppler assessment to optimize wrapped skeletal muscle activation time following cardiomyoplasty procedure. Eur Heart I 1991:13(suppl):230

Frederik van der Veen, Caroline Lucas, Roberto Lorusso, Theo van der Nagel, Olaf C Penn, Hein J Wellens. Selecting stimulus strength after cardiomyoplasty. J Am Coll Cardiol 1991;17(suppl A):272 A.

R Lorusso, G La Canna, M Gargano, M Zogno, F Maisano, G Pedersini, P Marzollo, O Visioli, O Alfieri. Intraoperative transesophageal echo evaluation during cardiomyoplasty procedure: the optimal guide. 7th Annual Congress EACTA, Maastricht, 1992 (Proceedings).

R Lorusso, C Lucas, F van der Veen, T van der Nagel, y Habets, M Havenith, OC Penn. Successful anticipated latissimus dorsi muscle stimulation following cardiomyoplasty procedure. Eur Heart J 1991;12(suppl):371.

Roberto Lorusso, Caroline Lucas, Frederik van der Veen, Theo van der Nagel, fo Habets, Marie-Luise Dubelaar, Hein J Wellens, Olaf C Penn. Observations during early stimulation following dynamic cardiomyoplasty. PACE 1991;14(suppl [1] $: 669$.

R Lorusso, L Sandrelli, V Borghetti, E Tulumello, F Maisano, F De Giuli, R Confortini, R Ferrari, O Alfieri. Neuroendocrine response before and after cardiomyoplasty procedure. World Symposium on Cardiomyoplasty, Biomechanical Assist and Artificial Heart, Paris, 1993 (Proceedings).

R Lorusso, L Sandrelli, F Maisano, E Tulumello, V Borghetri, O Alfieri. Dynamic cardiomyoplasty as long-term cardiac assistance in dilated cardiomyopathy patients. XXI World Congress of The Intemational Society for Cardiovascular Surgery, Lisbon, 1993 (Proceedings). 
Kaulbach HG, van der Veen FH, Schreuder 1], Habets IW, Lorusso R, van der Nagel T, Wellens HJJ. Compensated high cardiac output in goats: a new experimental approach to study the mechanism of action of dynamic cardiomyoplasty. Eur Heart 』1995; 16(suppl):1247.

Kaulbach $\mathrm{HG}_{\mathrm{G}}$, van der Veen FH, Schreuder J, Bolotin $G_{1}$, Lorusso R, Wellens HJJ. Dynamic cardiomyoplasty in chronic cardiac overload. Circulation 1995;92(suppl):379-380.

G Bolotin, F van der Veen, If Schreuder, R Lorusso, H Kaulbach, G Uretzky. The chronic carotid-jugular AIV shunt as a model of heart failure to study cardiomyoplasty. I Heart Failure 1996;3:148.

Roberto Lorusso, Ottavio Alfieri. Cardiomyoplasty: an active and dynamic remodeling of the dilated heart. J Mol Cell Cardiol 1996;28:A11.

R Lorusso, M Volterrani, M Campana, G La Canna, E Tulumello, A Dellavalle, A Giordano, O Alfieri. Left ventricular adaptation to chronic cardiomyoplasty support. Eur ) Card Pac Elect 1996;6(Supp15):303.

JJ Schreuder, FH van der Veen, ET van der Velde, G Finet, F Delahaye, O Jegaden, $\mathbb{R}$ Lorusso, HJj Wellens. Left ventrciular pressure/volume relationships pre and post cardiomyoplasty in heart failure patients. Eur I Card Pac Elect 1996;6(Suppl 5):153.

R Lorusso, FH van der Veen, J Schreuder, G Bolotin, HG Kaulbach, I Habets, T van der Nagel. HJJ Wellens. Analysis of different wrapped muscle activation times by pressure/volume relations in acute cardiomyoplasty. Eur I Card Pac Elect 1996;6(Suppl 5):152.

Gill Bolotin, Frederik van der Veen, Jan I Schreuder, Roberto Lorusso, Hans Kaubach, Gideon Uretzky. Acute temporary decrease of end-diastolic volume and cardiac output following cardiomyoplasty. 151 J Med Science 1996:32.911.

R Lorusso, P Gerometta, F Bianchetti, A Marchini, A Arena, V Parolari, P Biglioli, O Alfieri. Long-term patient outcome following cardiomyoplasty procedure: a two-institutional report. Isr I Med Science 1996;32.911.

G Bolotin, T Wolf, R Shofi. F van der Veen, JI Schreuder, R Lorusso, Y Rubin, G Uretzky. Coronary flow diastolic augmentation following acute descending aortomyoplasty. EACTS XIth Annual Meeting, Copenhagen, Danmark 1997 , proceedings.

R. Lorusso, M: Volterrani, J Schreuder, FH van der Veen. Interpretation of cardiomyoplasty results: a controversial matter. Intemational Workshop on Cardiomyoplasty, Padua, Italy 1997. 
R Scelsi, L Scelsi,, IC Chachques, R Lorusso, U Carraro. Long-term preserved structure of myofibres and vessels of the latissimus dorsi after dynamic cardiomyoplasty. 2nd IFESS Annual Conference, Bumaby, Canada (Proceedings), pp $41-42$

\section{Chapter in books}

Lonusso R, Alfieri $O$, wan der Nagel T, Habets J, Havenith $M$, van der Veen $F$, Penn OC. Fibrin sealant application to improve cardiomyoplastu management. In: Fibrin sealing in surgical and non-surgical fields. Cardiovascular surgery Thoracic surgery. Schlag G, Woner E, Eckesberger F, eds; Vol 6:55-63. SpringerVerlag, Berlin-Heidelberg 1995.

Lorusso R, Sandrelli L, Borghetti V, Schreuder I, Alfieri O. Long-term myocardial assistance by a wrapped skeletal muscle: a clinical experience. In: Carpentier A, Chachques JC, and Grandjean PA (eds): Cardiac Bioassist. Futura Publishing, Mount Kisko, NY, 1997, pp 57-65 


\section{Curriculum Vitae}

- Born in Naples on the 26/9/1961

- Graduated at the Universiry of Milan (magna cum laude), Italy.

- Cardiac Surgery Degree at the University of Bari, Italy.

- Research Fellow (1990) at the University of Maastricht, The Netherlands.

- Clinical Fellow (1996-97) at the University Hospital, Leuven, Belgium

- Resident and, then, Staff Member Cardiac Surgery Division, Brescia, Italy

- University Diplome (1996) on "Artificial Heart and Mechanical Circulatory Support" at the University Pierre \& Marie Curie, La Pitiè Hospital, Paris, France

- Member from 1991 to 1996 of the European Concerted Action "HEART" on developments in Cardiac Support and Replacement (European Community Program BIOMED 1)

- Recipient of the "Young Investigator's Award 1995" of the European Association for Cardio-Thoracic Surgery, Paris

- Honorary Mention from the Scientific Committee of the "Mechanical Circulatory Support" World Congress, London 1993

- Chairman at Cardiostim 1994 and 1996, and Invited Speaker at many International Congresses

- Invited Lecturer at:

- the University of Munchen (Germany)

- the International Heart School, Bergamo (Italy)

- the Catholic University of Leuven (Belgium)

- European Heart House by the European Society of Cardiology 1996 (Nice, France)

- 46th American College of Cardiology 1997 (Anaheim, California)

- XnX Congress of the European Society of Cardiology. 1997 (Stockholm. Sweden)

- Congress of the Danish Society of Surgeons (Copenhagen, Danmark) 1997

- Trainer of Surgeons attending experimental and clinical procedures (in Maastricht, and Brescia) coming from many Centres (France, Germany, Israel, Jordan, Turkey, Spain, U.K., Poland, Italy, 